\title{
STRUCTURAL HEALTH MONITORING OF TWO-WAY SLABS BASED ON RANDOM DECREMENT TECHNIQUE
}

\section{By:}

\section{Azita Pourrastegar}

B.Eng, Ryerson University, Toronto, 2014

\author{
A Thesis \\ presented to Ryerson University \\ in partial fulfillment of the \\ requirements for the degree of \\ Master of Applied Science \\ in the program of \\ Civil Engineering
}

Toronto, Ontario, Canada, 2017

(C) Azita Pourrastegar 2017 


\begin{abstract}
AUTHOR'S DECLARATION
I hereby declare that I am the sole author of this thesis. This is a true copy of the thesis, including any required final revisions, as accepted by my examiners.

I authorize Ryerson University to lend this thesis to other institutions or individuals for the purpose of scholarly research.

I further authorize Ryerson University to reproduce this thesis by photocopying or by other means, in total or in part, at the request of other institutions or individuals for the purpose of scholarly research.
\end{abstract}

I understand that my thesis may be made electronically available to the public. 


\title{
STRUCTURAL HEALTH MONITORING OF TWO-WAY SLABS BASED ON RANDOM DECREMENT TECHNIQUE
}

\author{
Azita Pourrastegar, Master of Applied Science, 2017 \\ Department of Civil Engineering \\ Ryerson University, Toronto, Canada
}

\begin{abstract}
The current research attempts to explore the feasible use of a Structural Health Monitoring method for a two-way slab system through the effective vibration based damage diagnostic technique of Random Decrement (RD). Experimental investigations have been conducted on a total of four reinforced concrete two-way slab specimens. The slabs behaviour was examined under static loading. The results were presented in terms of load-deflection relationship at service and ultimate load, crack pattern and failure modes. At each stage of loading, the ambient vibration excitation test has been performed to investigate the extent of damage at the cracking, yield, and ultimate states through changes in dynamic parameters obtained from RD signatures. Additional applications of RD technique were performed on two-way slabs, first, to explore the location of damage by Multi-Channel Random Decrement using FBG sensor arrays. Secondly, RD technique was utilized to evaluate the extent of damage under successive equal dynamic impacts.
\end{abstract}




\section{ACKNOWLEDGEMENTS}

I would first like to thank and express the deepest gratitude to my benevolent supervisor, Dr. Hesham Marzouk, whose generous guidance, encouragement, and persistent help at every stage of my research work deserves sincere appreciation. Working under his supervision was a great chance for me to grow professionally and personally.

I deeply express my appreciation to former $\mathrm{PhD}$ candidate Dr. Hesham Othman for his special help in design, casting and setup of my slab specimens and moreover for his generous scheduling to give me opportunity to apply my RD test procedure on his specimens after each impact drop. In addition, I also deeply like to thank former PhD candidate Dr. Rana Morsy for her guidance in the use of RD technique and fabrication of FBG sensors.

I also would like to express my gratitude to Dr. Xijia Gu, and his Ryerson Fiber Optic Laboratory staff especially Mrs. Jane Lu for their technical cooperation in manufacturing, testing and assembling of FBG sensor arrays.

I thank Ryerson Civil Engineering Structural Laboratory staff for their kind cooperation. Special thanks to Mr. Nidal Jaalouk, the Civil Engineering lab director for assisting me in setting up, running and recording the sensors results. I also thank T. Jeddawi, A. Darab, and M. Ebadian for their assistance during the laboratory work.

In addition, I want to extend my appreciation to the examining committee members: Dr. Sennah and Dr. Kianoush for their influential insights and feedback.

Finally, I would like to heartily thank my parents for their endless love and support throughout my entire educational journey. 


\section{TABLE OF CONTENTS}

AUTHOR'S DECLARATION ..................................................... ii

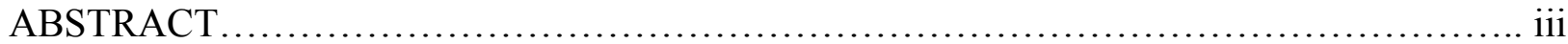

ACKNOWLEDGEMENTS.................................................... iv

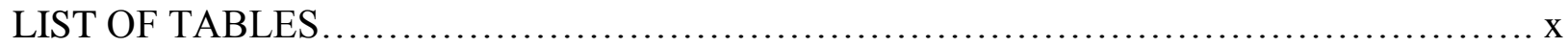

LIST OF FIGURES............................................................

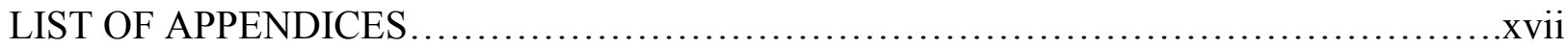

NOTATIONS AND ABBREVIATIONS............................................

\section{1) CHAPTER ONE:}

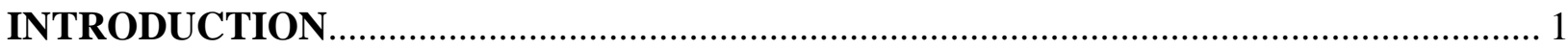

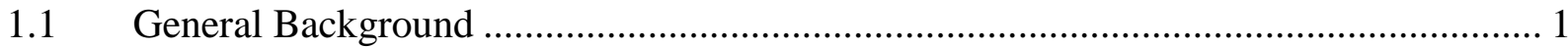

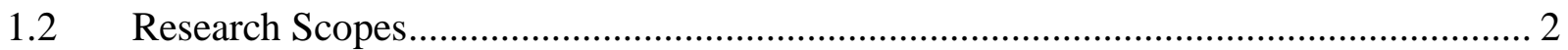

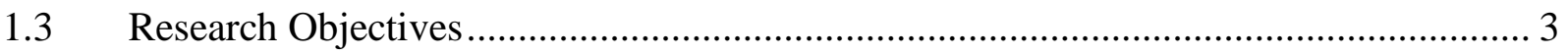

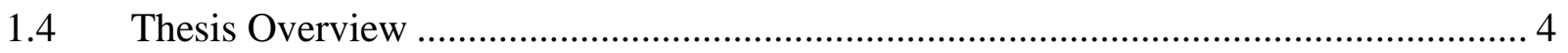

\section{2) CHAPTER TWO:}

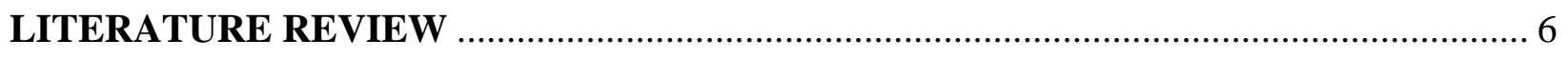

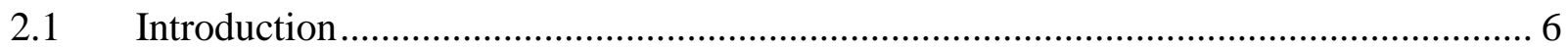

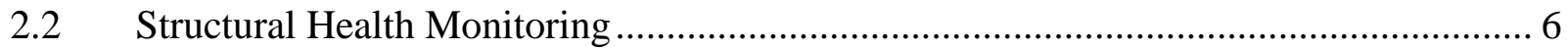

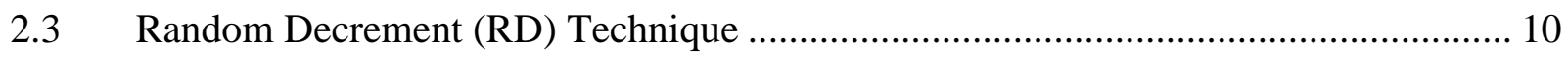

2.3.1 Historical Developments of RD Technique ............................................. 11

2.3.2 RD Technique Theoritical Approach........................................................... 13

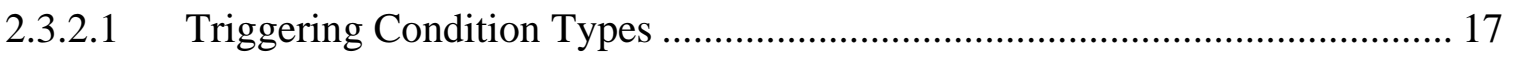

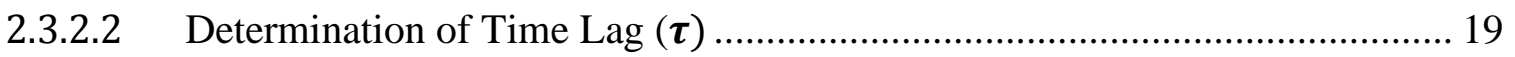

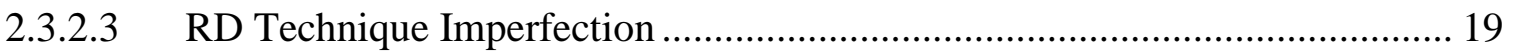

2.3.2.4 RD and Autocorrelation Functions Interrelation ..................................... 22 
2.3.2.5 Dynamic Parameter Identification from RD Signature 24

2.3.2.5.1 Logarithmic Decrement Technique................................................... 25

2.3.2.5.2 Logarithmic Decrement Damping Envelope Complementary Technique.. 26

2.4 Multi-Channel Random Decrement (MCRD) Technique....................................... 27

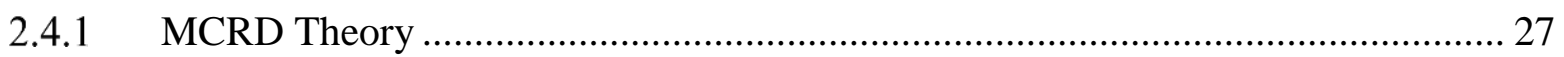

2.4.2 Mode Shape Extraction from MCRD Signatures ........................................... 29

2.4.3 Damage Localization from Mode Shape ..................................................... 31

2.4.3.1 Modified Mode Shape Difference Technique .......................................... 31

2.4.3.2 Effect of Damage on Mode Shape Extremum Location................................ 33

2.4.3.2.1 Mode Shape Extremum Damage Detection (EDD) Technique .................. 33

2.5 Introduction to Fiber Optic Technology ........................................................... 34

2.5.1 FOS Development in SHM ................................................................... 34

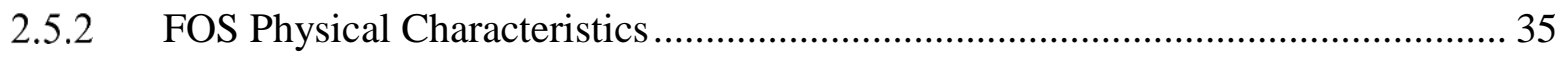

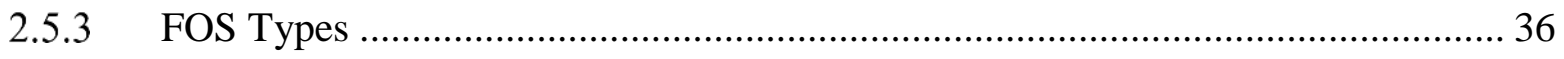

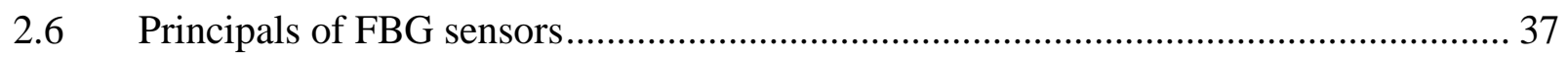

2.6.1 Strain Measurements.................................................................................... 37

\section{3) CHAPTER THREE:}

EXPERIMENTAL INVESTIGATION PROGRAM ................................................. 40

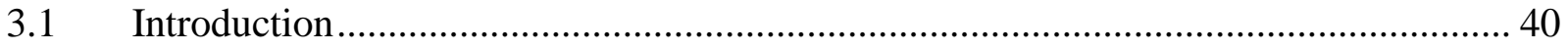

Specimen Materials ..................................................................................... 40

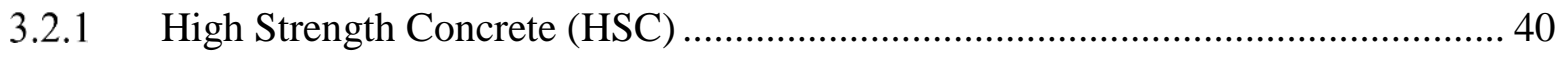

3.2.2 Ultra High Performance Fiber Reinforced Concrete (UHP-FRC)..................... 41

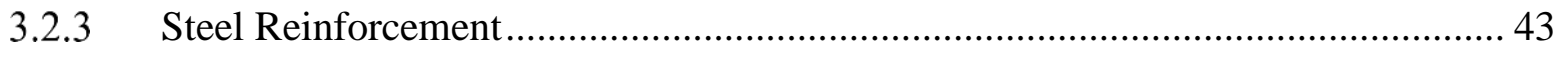

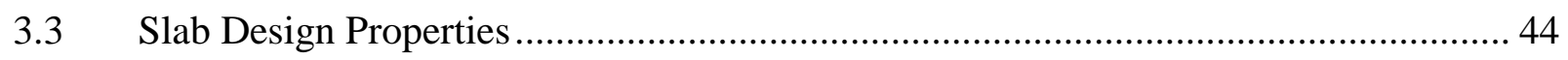

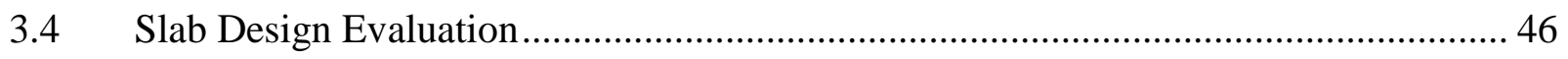


3.4.1 Ultimate Punching Shear Strength of Two-way Slab …………………................ 46

3.4.2 Ultimate Flexural Strength of Two-way Slab ...................................................... 46

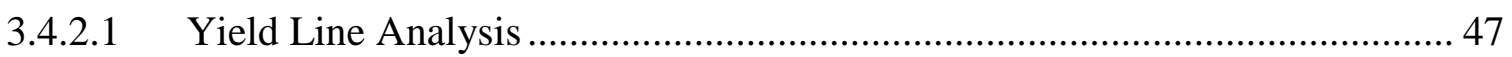

3.4.2.2 Principal of Virtual Work ....................................................................... 48

3.4.2.3 Ultimate Resistant Moment of a Flexural One-Dimensional Member

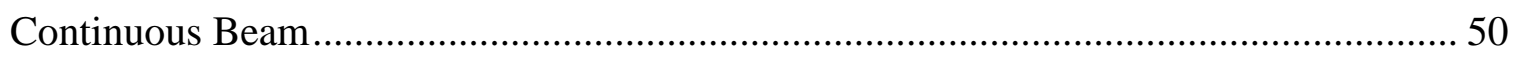

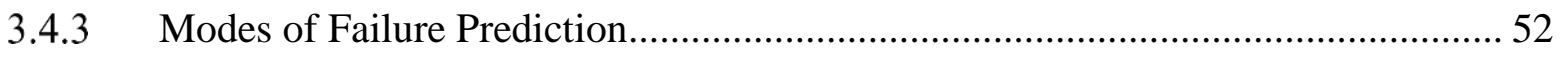

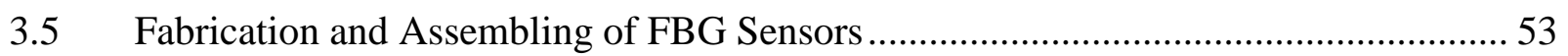

3.5.1 List of Materials Used for Manufacturing of FBG ……………………….......... 53

3.5.2 List of Equipment for FBG Preparation........................................................... 54

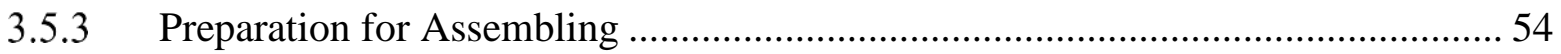

3.5.4 FBG Polymer Sensor Assembling …………..................................................... 55

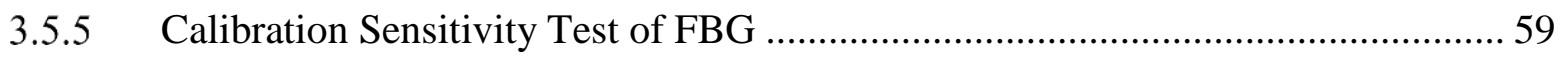

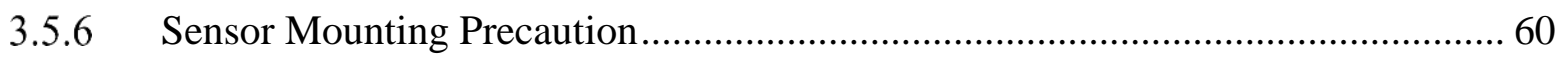

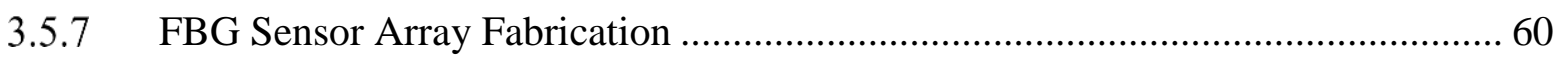

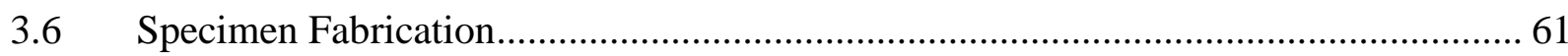

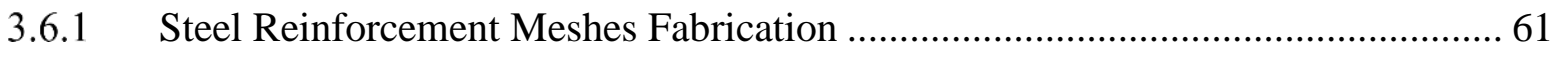

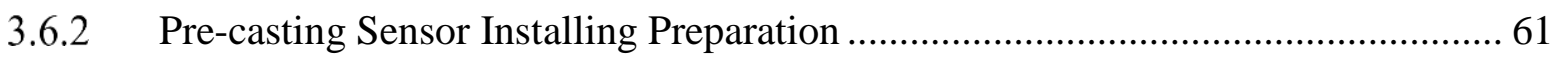

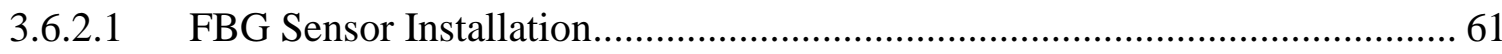

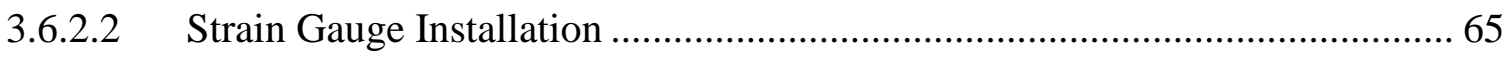

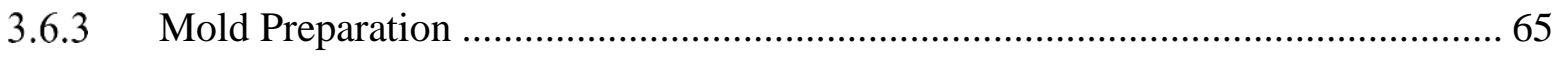

3.6.3.1 Wooden Mold Frame Preparation ……………………………........................ 65

3.6.3.2 Reinforcement Mesh Installation..................................................................... 66

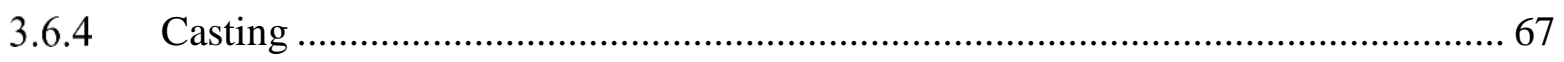

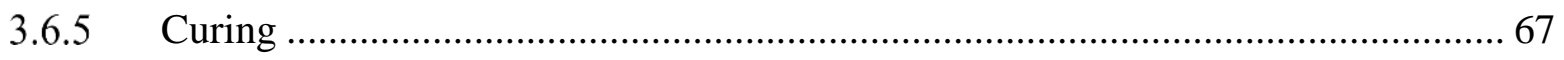


3.6.6 Sensor Patch Cord Protection after Demolding ............................................... 69

Test Set up and Instrumentation ................................................................. 70

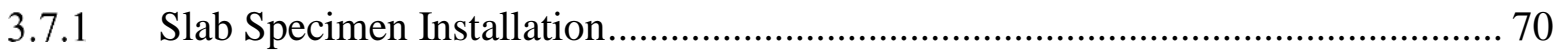

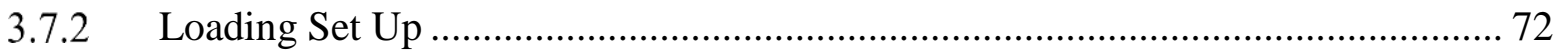

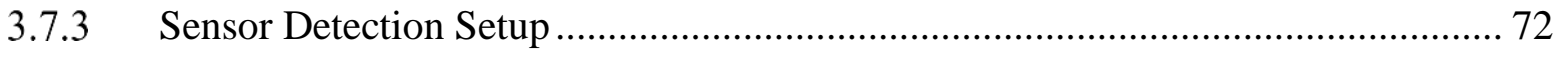

3.7.3.1 FBG Sensor Measurement System Set Up ......................................... 72

3.7.3.2 Accelerometer Sensor Measurement System Set Up ................................. 74

3.7.3.3 Strain gauge, LVDT and Load Cell Measurement System Set Up ............... 75

3.7.4 Static Load Test Procedure .......................................................................... 76

\section{4) CHAPTER FOUR:}

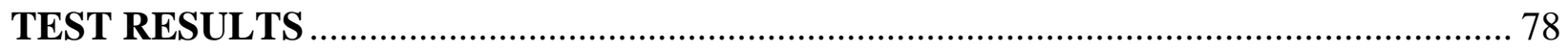

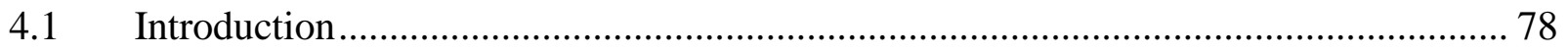

4.2 Load-Deflection Behaviour ........................................................................ 78

4.2.1 Stiffness Characteristic ........................................................................... 80

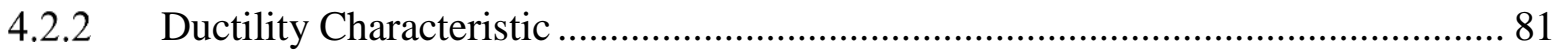

4.2.3 Energy Absorption Characteristic .......................................................... 81

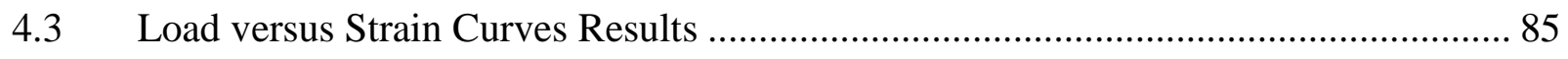

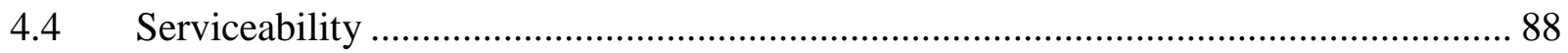

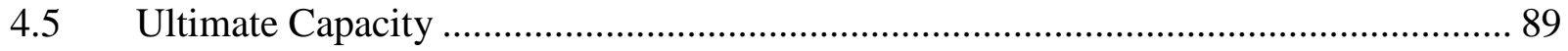

4.6 Crack Pattern Failure Mode Results .................................................................. 89

4.7 Ambient Vibration Excitation Test Results .................................................. 95

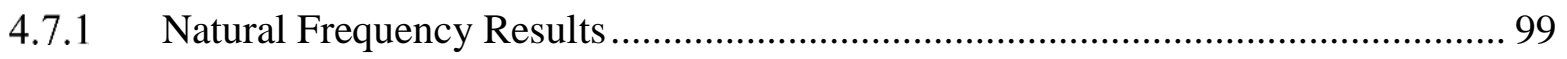

4.7.2 Damping Ratio Results ............................................................................ 100

\section{CHAPTER FIVE:}

APPLICATIONS ON THE USE OF RD METHOD FOR DAMAGE DETECTION OF

SLABS. 
5.A Applying MCRD Technique for Damage Allocation ............................................ 103

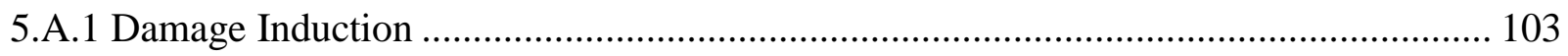

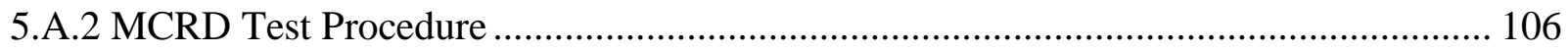

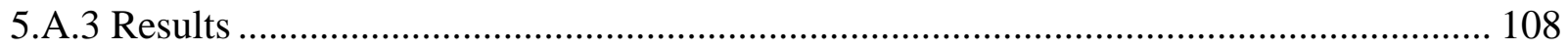

5.B Applying RD Technique to Evaluate Damage under Dynamic Impact ....................... 116

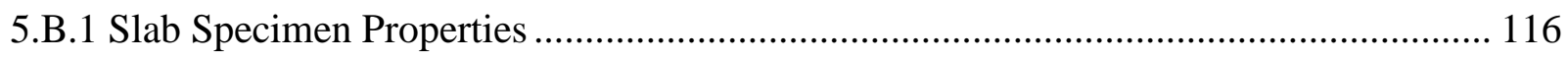

5.B.2 Test Procedure ......................................................................................... 117

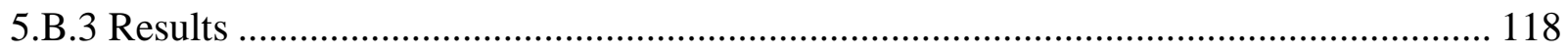

\section{6) CHAPTER SIX:}

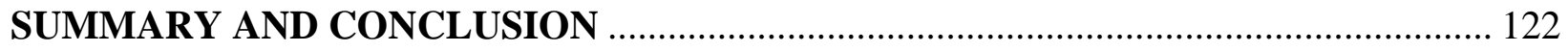

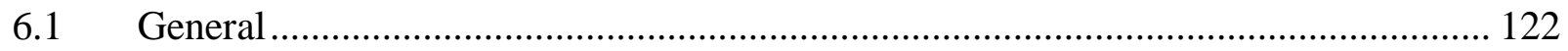

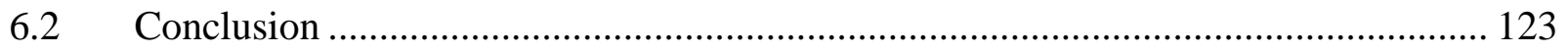

6.3 Recommendation for Future Research.................................................... 125

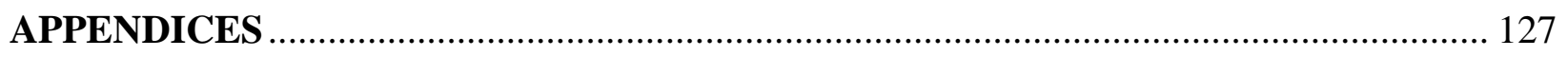

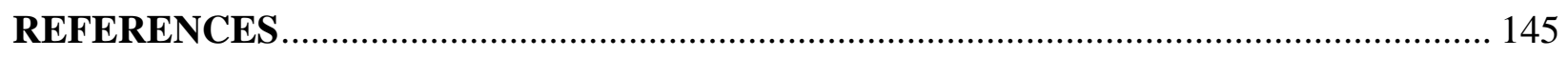




\section{LIST OF TABLES}

Table 3.1 Properties of HSC and UHP-FRC Materials.................................................. 43

Table 3.2 Reinforcement Properties of all Tested Specimens ............................................ 44

Table 3.3 Reinforcement Properties of all Tested Specimens (cont.) ..................................... 44

Table 3.4 The Predicted Results for Ultimate Moment and Ultimate Load of Slab Specimens.. 51

Table 3.5 Failure Modes Prediction for All Slab Specimens ........................................... 52

Table 3.6 The Wavelengths of FBG Sensors at all Various Stages ....................................... 64

Table 4.1 Observed Load, Deflection, Strain, and Failure Mode of Slab Specimens................. 79

Table 4.2 Observed Ductility, Stiffness, and Energy Absorption ......................................... 82

Table 4.3 Mode 1, Natural Frequency of H.S 0.5, H.S 1, H.S 2, and UHP-FRC 1 Slabs at Intact,

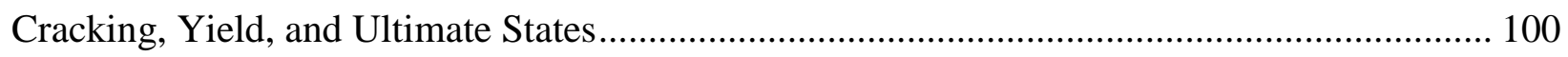

Table 4.4 Mode 1, Damping Ratios of H.S 0.5, H.S 1, H.S 2, and UHP-FRC 1 Slabs at Intact,

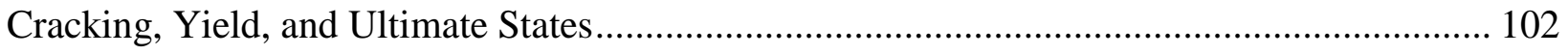

Table 5.1 Details of UHP-FRC Slab Specimens ........................................................... 116

Table 5.2 Properties of UHP-FRC Materials .............................................................. 116

Table 5.3 Mode 1, Damping Ratio for Four Slabs at Four Points (2, 3, 6 and 7) .................. 119

Table 5.4 Mode 1, Natural Frequency for Four Slabs at Four Points (2, 3, 6 and 7).............. 119 


\section{LIST OF FIGURES}

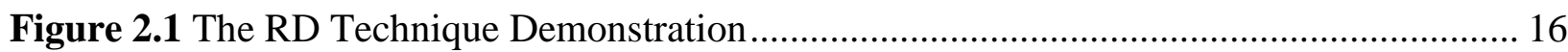

Figure 2.2 Fitting Damping Envelope to RD Signature Peaks in order to Find Equivalent

Viscous Damping Ratio 27

Figure 2.3 Triggering Condition for Simultaneous Multi-Channel Signals from Dynamically

Coupled Locations 28

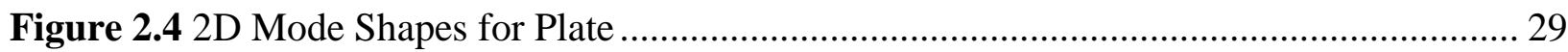

Figure 2.5 Frequency Spectrum Extracted by FFT …………………………….................. 29

Figure 2.6 Four Simultaneous RD Signatures (RD1, RD2, RD3 and RD4) Obtained by MCRD

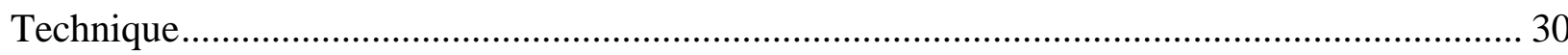

Figure 2.7 Phase Mask Method (Nieuwland et al., 2016)........................................................ 37

Figure 2.8 FBG Strain Measuring System (Kin-tak et al., 2001) ……………………………... 38

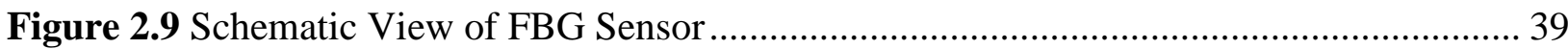

Figure 3.1 Slump Test Views for High Strength SCC Concrete ................................................. 41

Figure 3.2 Compressive Strength Test of Cylindrical Concrete Specimens ................................ 42

Figure 3.3 Splitting Tensile Strength Test of Cylindrical Concrete Specimens .......................... 42

Figure 3.4 Flexural Strength Test of Concrete (Using Simple Beam with Third-Point Loading)43

Figure 3.5 Cross Section View of Reinforced Specimens: a) H.S 0.5, b) H.S 1, c) H.S 2 and

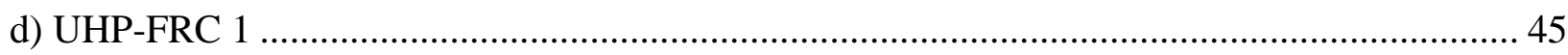

Figure 3.6 Yield line Pattern for Corner Edge Simply Supported Slab Specimens...................... 47

Figure 3.7 Schematic Diagram of Load and Deflection for Slab Specimens .............................. 49

Figure 3.8 Whitney Stress Block Representation …….......................................................... 50

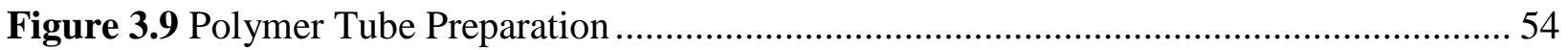


Figure 3.10 FBG and Epoxy Bonding Location at the Polymer Tube..... 55

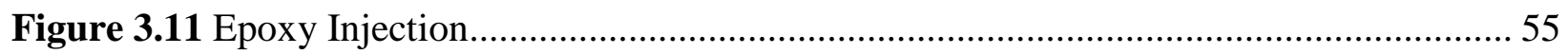

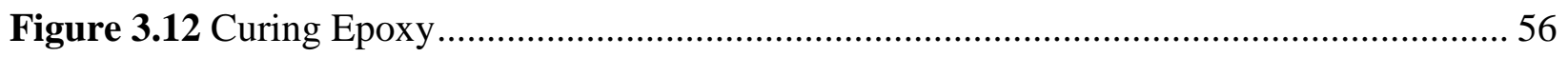

Figure 3.13 Bonded Stainless Steel Tubing with Polymer Tube $(\mathrm{Pu}, 2010)$........................... 56

Figure 3.14 Cleaver the Precision Cutting Machine for Fibers .......................................... 57

Figure 3.15 Splicing Machine and Splice Loss Control Monitoring Views ............................ 57

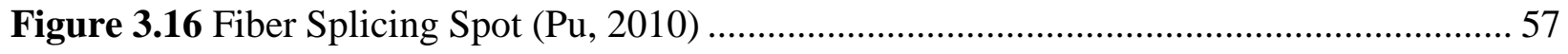

Figure 3.17 View of FBG Strain Sensors after Initial Packaging ....................................... 58

Figure 3.18 FBG Sensor Load vs. Wavelength Calibration Apparatus ................................... 58

Figure 3.19 View of an OSA Device for Measurement of Wavelength ................................. 58

Figure 3.20 Peak Calibration Sensitivity Result for Different FBG Sensors............................ 59

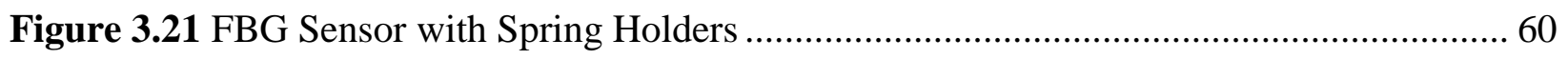

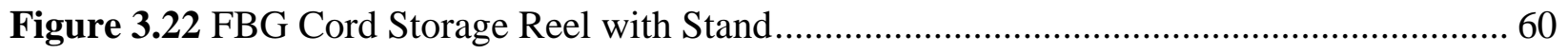

Figure 3.23 The Reinforcement Assembling Apparatus .................................................... 61

Figure 3.24 Location of FBG Sensors Relative to Reinforcement (Dimensions Are in

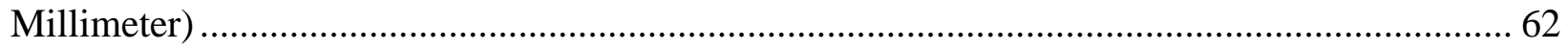

Figure 3.25 Top View of the FBG Sensors Located on the Top Reinforcement...................... 62

Figure 3.26 Steel Wire Bonded to the Reinforcement with Epoxy to Make the Hooks for FBG Installation.

Figure 3.27 Concrete FBG Sensor Installed via Springs to the Steel Wire Custom Made Hooks

Figure 3.28 The Detail Involved to Prepare H.S 0.5 Slab ............................................... 64

Figure 3.29 Strain Gauge Installed on Grinded Surface of Reinforcement ............................ 65 


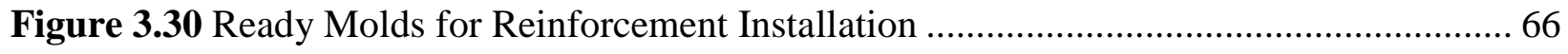

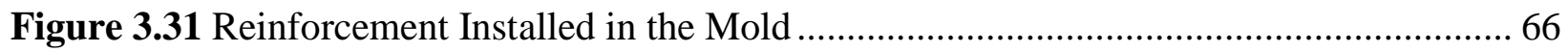

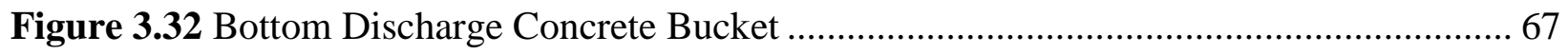

Figure 3.33 Slabs Pre-cured with Spray Water and Plastic Sheeting .................................... 68

Figure 3.34 The Pre-cured Cylinders and Prisms ........................................................... 68

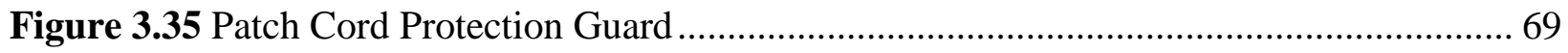

Figure 3.36 Patch Cord Protection Guard Viewed from Inside ........................................... 69

Figure 3.37 Loading Apparatus Arrangement ................................................................. 70

Figure 3.38 Installed Slab on Loading Apparatus........................................................ 70

Figure 3.39 Top View Schematic Diagram of Test Set Up ............................................ 71

Figure 3.40 Side View Schematic Diagram of Test Set Up (Sec A-A) ................................. 71

Figure 3.41 Wavelength Monitoring System Elements .................................................. 72

Figure 3.42 Wavelength Monitoring System Schematic Diagram .................................... 73

Figure 3.43 Lab View Software Detecting Four Sensors in Array X ..................................... 73

Figure 3.44 Random Decrement Test with Accelerometer Equipment ................................ 74

Figure 3.45 Fixture Designed for Holding the Accelerometer Safely .................................. 74

Figure 3.46 Different Sizes of Kistler Hammers (Large, Medium and Small)........................ 75

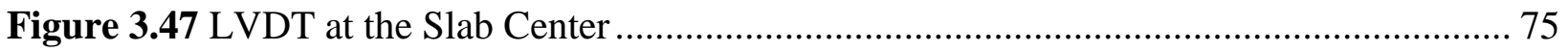

Figure 3.48 Static Load Test Apparatus (UHP-FRC Slab) ............................................... 76

Figure 4.1 Load vs. Deflection Curve H.S 0.5 Slab......................................................... 82

Figure 4.2 Load vs. Deflection Curve H.S 1 Slab............................................................ 83

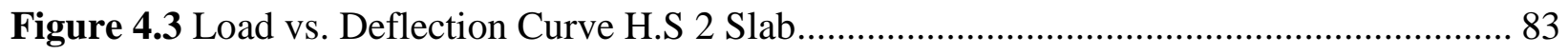

Figure 4.4 Load vs. Deflection Curve UHP-FRC 1 Slab..................................................... 84 


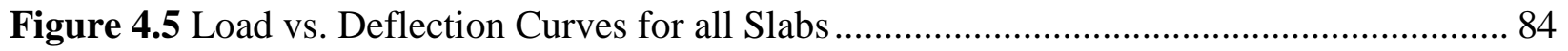

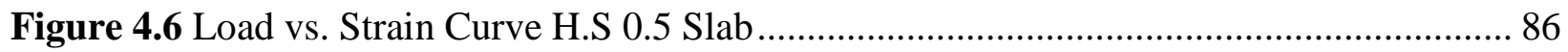

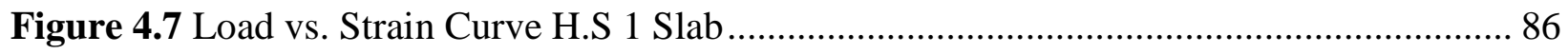

Figure 4.8 Load vs. Strain Curve H.S 2 Slab ................................................................ 87

Figure 4.9 Load vs. Strain Curve UHP-FRC 1 Slab ...................................................... 87

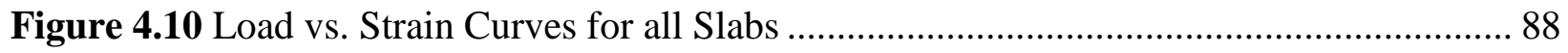

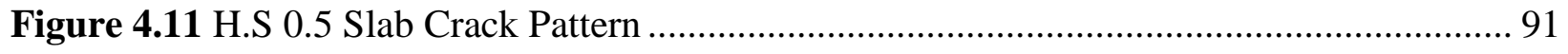

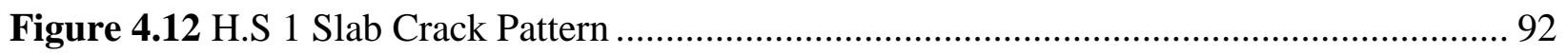

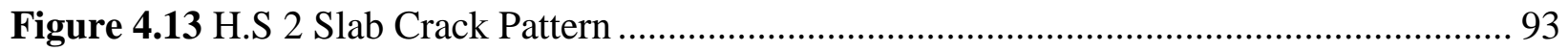

Figure 4.14 UHP-FRC 1 Slab Crack Pattern ............................................................... 94

Figure 4.15 Time Acceleration Reading Plot for H.S 1 Slab at Yield State............................ 96

Figure 4.16 Enlarged Time Acceleration Reading Plot for H.S 1 Slab at Yield State .............. 96

Figure 4.17 Mode 1, Random Decrement Signatures at Intact, Cracking, Yield and Ultimate

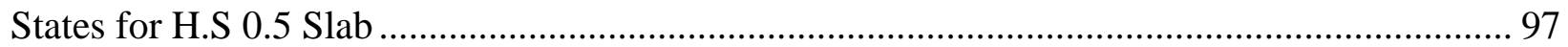

Figure 4.18 Mode 1, Random Decrement Signatures at Intact, Cracking, Yield and Ultimate

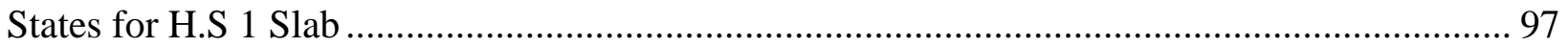

Figure 4.19 Mode 1, Random Decrement Signatures at Intact, Cracking, Yield and Ultimate

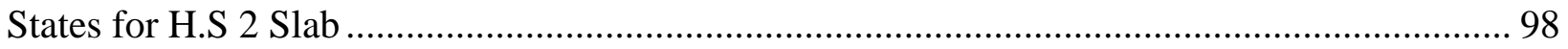

Figure 4.20 Mode 1, Random Decrement Signatures at Intact, Cracking, Yield and Ultimate

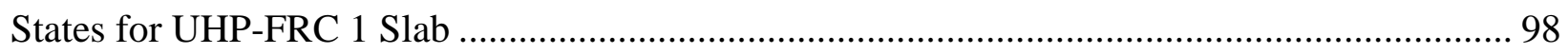

Figure 4.21 Mode 1, Natural Frequency of H.S 0.5, H.S 1, H.S 2, and UHP-FRC 1 Slabs at Intact, Cracking, Yield, and Ultimate States............................................................... 100 
Figure 4.22 Mode 1, Damping Ratios of H.S 0.5, H.S 1, H.S 2, and UHP-FRC 1 Slabs at Intact,

Cracking, Yield, and Ultimate States............................................................................ 102

Figure 5.1 Sono-tubes Bolted Down in the H.S 0.5 Slab Mold for Damage Induction............. 104

Figure 5.2 The Location of Sono-tubes and FBG Sensors .................................................. 104

Figure 5.3 Three Double Layer Sono-tubes to be Casted with the Same Concrete Material for

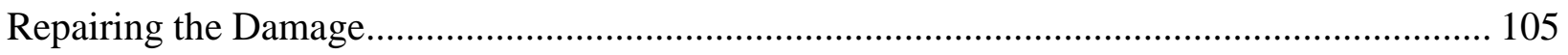

Figure 5.4 The Detail Involved to Prepare H.S 0.5 Slab .................................................. 105

Figure 5.5 MCRD Test Apparatus …..................................................................... 106

Figure 5.6 Damage Eliminating Concrete Cylinders ..................................................... 107

Figure 5.7 Slab Conditions for MCRD Test Procedure .................................................. 107

Figure 5.8 Damage Stages (N Indicates Node) .............................................................. 109

Figure 5.9 Rough Shape of Mode 1 in Array X as Extracted by MCRD .............................. 110

Figure 5.10 Rough Shape of Mode 1 in Array Y as Extracted by MCRD ........................... 110

Figure 5.11 Normalized Mode Shape Difference for Mode 1 in Array X............................. 111

Figure 5.12 Normalized Mode Shape Difference for Mode 1 in Array Y ............................. 112

Figure 5.13 Smoothed Mode 1 Shape Constructed By Best Fit Curve through the MCRD Output

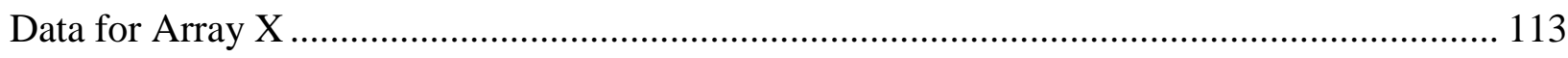

Figure 5.14 Smoothed Mode 1 Shape Constructed By Best Fit Curve through the MCRD Output

Data for Array Y 113

Figure 5.15 Magnified Normalized Mode 1 Shapes around Extremum Location for Array X. 114

Figure 5.16 Magnified Normalized Mode 1 Shapes around Extremum Location for Array Y . 115

Figure 5.17 Details of Drop-Weight Impact Test Setup (Dimensions in mm) (Othman and

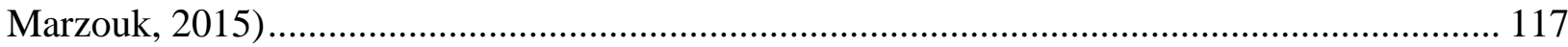


Figure 5.18 Test Site a) Impact Load View b) Locations of Accelerometer......

Figure 5.19 Mode 1, Normalized Random Decrement Signatures for Slab 3 Point 3 with

Different Impact Loading (Intact, First and Second Drop)............................................. 119

Figure 5.20 Mode 1, Damping Ratio for Four Slabs at Four Points (2, 3, 6 and 7)............... 120

Figure 5.21 Mode 1, Natural Frequency for Four Slabs at Four Points (2, 3, 6 and 7) ........... 120 


\section{LIST OF APPENDICES}

APPENDIX A: ULTIMATE STATIC CAPACITIES OF SLABS ..................................... 127

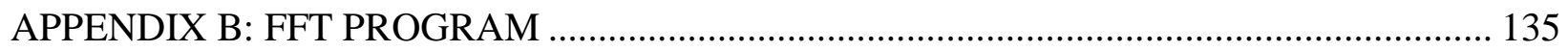

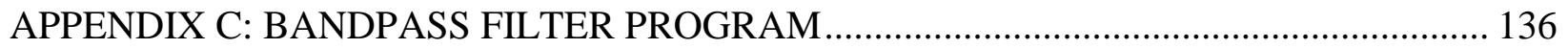

APPENDIX D: RD TECHNIQUE PROGRAM.............................................................. 137

APPENDIX E: LOGARITHMIC DECREMENT PROGRAM .......................................... 138

APPENDIX F: DAMPING ENVELOPE PROGRAM .................................................... 139

APPENDIX G: MCRD PROGRAM ........................................................................ 140

APPENDIX H: RD SIGNATURES WITH BEST FITTED DAMPING ENVELOPES .......... 142 


\section{NOTATIONS AND ABBREVIATIONS}

a

$\mathrm{A}_{\mathrm{s}}$

$\mathrm{A}_{\mathrm{i}}$

$\mathrm{A}_{\mathrm{i}+\mathrm{n}}$

b

$b_{o}$

$b_{c}$

C

[C]

d

$d_{b}$

$\mathrm{d}_{\mathrm{f}}$

$\mathrm{d}_{\mathrm{g}}$

$\mathrm{D}_{\mathrm{xx}}(\tau)$

$\mathrm{E}$

$\mathrm{E}_{\mathrm{X}}$

$\mathrm{E}[\mathrm{X}(\mathrm{t}) \mid \mathrm{a}, \mathrm{b}]$ and $b$

$\mathrm{f}_{\mathrm{c}}^{\prime} \quad$ Specified compressive strength of concrete

$\mathrm{f}_{c f}^{\prime} \quad$ Compressive strength of fibrous concrete

$f_{n}$

Area of tension steel

Amplitude of cycle i of the RD curve

Amplitude of cycle $i+n$ of the RD curve

Width of the beam

Perimeter of the shear critical section

Depth of neutral axis

Damping matrix reinforcement

Bar diameter

Diameter of steel fibre

Diameter of biggest aggregate

Auto RD function

Expectation operator

Energy of the signal $x(t)$

Natural frequency
Depth of equivalent rectangular stress block

Cross-section dimension of a square column (or) Clear cover depth

Distance from extreme compression fiber to the centroid of the flexural

Expected value on the response $\mathrm{X}(\mathrm{t})$ with initial condition (triggering condition) a 


\begin{tabular}{|c|c|}
\hline$f_{U t}$ & Post-cracking tensile strength determined by uniaxial test \\
\hline $\mathrm{f}_{\mathrm{y}}$ & Specified yield strength of steel reinforcement \\
\hline $\mathrm{F}_{\mathrm{b}}$ & Bond efficiency factor for steel fibre \\
\hline $\mathrm{F}(\mathrm{t})$ & Excitation force \\
\hline h & Slab thickness \\
\hline$h(t-\tau)$ & Impulse response function for the system \\
\hline$[\mathrm{K}]$ & Stiffness matrix \\
\hline$l_{\mathrm{f}}$ & Length of steel fibre \\
\hline $1_{\mathrm{s}}$ & Length of yield line \\
\hline $\mathrm{m}_{\text {un }}$ & Ultimate flexural moment of resistance per unit length at a yield line \\
\hline [M] & Mass matrix \\
\hline $\mathrm{M}_{\mathrm{r}}$ & Moment of resistance \\
\hline $\mathrm{n}$ & Average effective index of refraction of the grating \\
\hline $\mathrm{N}$ & Number of triggering points \\
\hline $\mathrm{P}$ & Probability density function (or) Total load on a segment of the yield line \\
\hline $\mathrm{P}_{\mathrm{u}}$ & Ultimate flexural load \\
\hline $\mathrm{P}\left(\mathrm{Y}, \mathrm{t} \mid \mathrm{Y}_{0}\right)$ & Conditional probability density function of the motion $Y(t)=\left\{\begin{array}{l}y_{1} \\
y_{2}\end{array}\right\}$ \\
\hline$r_{b}$ & Radius of slab \\
\hline $\mathrm{RD}_{\mathrm{Xx}}$ & Auto RD \\
\hline $\mathrm{RD}_{\mathrm{YX}}$ & Cross RD \\
\hline $\mathrm{R}_{\mathrm{X}}\left(\mathrm{t}_{1}, \mathrm{t}_{2}\right)$ & Autocorrelation function \\
\hline $\mathrm{R}_{\mathrm{XF}}\left(\mathrm{t}_{1}, \mathrm{t}_{2}\right)$ & Cross correlation function \\
\hline
\end{tabular}




\begin{tabular}{|c|c|}
\hline $\mathrm{R}_{\mathrm{X}}(\tau)$ & Autocorrelation function for $\mathrm{X}(\mathrm{t})$ at $\tau$ \\
\hline ti & Time past the triggering time of the response \\
\hline $\mathrm{T}_{\mathrm{f}}$ & Tension force due to fibre \\
\hline $\mathrm{T}_{\mathrm{n}}$ & Natural period \\
\hline $\mathrm{T}_{\mathrm{s}}$ & Tension force in steel \\
\hline $\mathrm{Tx}(\mathrm{ti})$ & Triggering condition applied to time history $\mathrm{x}(\mathrm{t})$ \\
\hline$v_{c}$ & Shear resistance \\
\hline$V_{f}$ & Volume fraction of steel fibre \\
\hline $\mathrm{V}_{\mathrm{u}}$ & Ultimate punching capacity \\
\hline$V_{R, c}$ & Punching shear resistance of matrix \\
\hline$V_{R, f}$ & Punching shear resistance due to fiber \\
\hline $\mathrm{w}_{\mathrm{u}}$ & Distributed ultimate load per unit area \\
\hline$x(t)$ & Displacement function \\
\hline$X_{R}(\tau)$ & RD function \\
\hline$\alpha_{1}$ & $\begin{array}{l}\text { Ratio of average stress in rectangular compression block to the specified concrete } \\
\text { strength }\end{array}$ \\
\hline$\alpha$ s and $\alpha 0$ & Thermal expansion coefficients of the substrate and sensor respectively \\
\hline$\alpha_{\mathrm{s}}$ & Factor that adjust $\mathrm{v}_{\mathrm{c}}$ for support dimension \\
\hline$\beta$ & Apparent thermal strain over the temperature change factor \\
\hline$\beta_{0}$ & Thermo-optic response of the FBG at fabrication \\
\hline$\beta_{1}$ & Ratio of depth of rectangular compression block to depth of neutral axis \\
\hline$\beta_{c}$ & Ratio of long side to short side of concentrated load or reaction area \\
\hline$\delta$ & $\begin{array}{l}\text { Dirac delta function (or) Logarithmic decrement } \\
\qquad \mathrm{XX}\end{array}$ \\
\hline
\end{tabular}




\begin{tabular}{|c|c|}
\hline$\delta_{\operatorname{Pmax}}$ & Displacement at maximl force \\
\hline$\delta(\mathrm{x}, \mathrm{y})$ & Displacement function corresponding to the dimension of slab \\
\hline$\Delta \mathrm{T}$ & Temperature change relative to the temperature at installation \\
\hline$\varepsilon$ & Strain \\
\hline$\varepsilon_{\mathrm{y}}$ & Steel yield strain \\
\hline$\theta_{\mathrm{n}}$ & Relative rotation of yield line \\
\hline$\lambda$ & $\begin{array}{l}\text { Bragg wavelength (or) Factor to account for low-density concrete (or) UHP-FRC } \\
\text { stress block parameter }\end{array}$ \\
\hline$\lambda_{\mathrm{i}}$ & ith mode shape \\
\hline$\Lambda$ & Pitch spacing \\
\hline$\mu_{1}$ & Displacement mean \\
\hline$\mu_{2}$ & Velocity mean \\
\hline$\xi$ & Damping ratio of the system \\
\hline$\rho$ & Reinforcement ratio \\
\hline$\rho_{\mathrm{X}}(\tau)$ & Normalized autocorrelation function \\
\hline$\sigma_{t}$ & Post cracking tensile strength \\
\hline$\sigma_{\mathrm{x}}$ & Standard deviation of the time response \\
\hline$\tau$ & Length of each segment or time lag \\
\hline$\varphi_{0}$ & Ratio of ultimate punching strength to ultimate flexural strength \\
\hline$\varphi_{\mathrm{c}}$ & Resistance factor for concrete \\
\hline$\phi_{\mathrm{i}}$ & Phase angle \\
\hline$\Psi$ & Slab rotation \\
\hline
\end{tabular}




$\begin{array}{ll}\Psi_{0} & \text { Variance of the excitation } \\ \omega_{0} & \text { Undamped natural frequency } \\ \omega_{1} & \text { Damped natural circular frequency } \\ \omega_{\mathrm{u}} & \text { Ultimate crack opening }\end{array}$

ACI American Concrete Institute

ASTM American Society for Testing and Materials

CSA Canadian Standard Association

DAQ Data Acquisition

FBG Fiber Bragg Grating

FE Finite Element

FFT Fast Fourier Transform

FOS Fiber Optic Sensor

FOG Fiber Optic Gyro

GF FBG gage factor

HSC High Strength Concrete

ICOLD International Commission on Large Dams

ISIS Intelligent Sensing for Innovative Structure

ITZ Interfacial Transition Zone

LVDT Linear Variable Displacement Transformer

MCRD Multi-Channel Random Decrement

NI National Instrument 


$\begin{array}{ll}\text { NDT } & \text { Non-Destructive Testing } \\ \text { OSA } & \text { Optical Spectrum Analyzers } \\ \text { RD } & \text { Random Decrement } \\ \text { RC } & \text { Reinforced Concrete } \\ \text { SCC } & \text { Self-Consolidating Concrete } \\ \text { SHM } & \text { Structural Health Monitoring } \\ \text { UHP-FRC } & \text { Ultra High Performance Fiber Reinforced Concrete } \\ \text { UV } & \text { Ultra-violet } \\ \text { VBDIT } & \text { Vibrations Based Damage Identification Techniques }\end{array}$

*(or) means only one of the notations is applicable depending on subject criteria 


\section{CHAPTER ONE INTRODUCTION}

\subsection{General Background}

Structural Health Monitoring (SHM) as a modern engineering discipline has attracted worldwide attention during the last few decades within various fields of mechanical and aerospace engineering, and more recently in civil engineering applications. All types of structures degrade during their service life. Degradation is simply denoted as damage defined by changes introduced to a system that adversely affects its current or future performance and usually may occur in form of cracking, delamination, or fastener loosening. In general, SHM is a process for early damage detection of infrastructure over designated period of time, evaluates its performance and aids to plan proper maintenance activities.

Economic and/or social safety motivations justify the implementation of SHM. Early detection of damage can prevent failure of a critical component of a structure. The failure may be a fracture in tension or an instability under compression leading to collapse of whole structure which is very costly in terms of human life and property loss. Hence, ensuring integrity and safety of structure always is the most important factor under consideration and has to be managed carefully. Undoubtedly, prompt identification of structural damage is crucial and saves lives, time and money. Recently, the development of important and vital megastructures such as large dams, railroads, highway bridges, and offshore platforms for oil and gas industry sets the standards for safety and extended lifespans which require the highest level of SHM. Nowadays, efficient application techniques of early damage detection are developed for advanced SHM to enhance functionality and serviceability based on reliable and durable sensors. 


\subsection{Research Scopes}

For superb aging of infrastructure, SHM with Non-Destructive Testing (NDT) procedures for damage detection is the best alternative which experiences also reveal a considerable reduction of maintenance cost. Existing NDT procedures are radar wave penetration analysis, acoustic emission, shear wave tomography, piezoelectric ceramic sensing, remote sensing technologies, detection of delamination of concrete and rust of reinforcement, ultrasonic wave analysis, concrete crack microscopy, impact-echo test and vibration based damage identification techniques (VBDIT). Among NDT procedures, VBDIT provides a substantial amount of information about the structure status in form of changes in global dynamic properties such as natural frequency, damping ratio, and mode shape. The powerful and practical VBDIT is Random Decrement (RD) technique which is a time domain procedure with the aim of obtaining free decay structure response best known as RD signature from stationary response measurement data. The signature is unique at each structural state and unique global dynamic parameters natural frequency and damping ratio can be extracted from in order to track the structural health condition. The main advantage of RD technique is its independency to input excitation and only output response has to be measured which makes it easier to apply since evaluating input excitation force is overly difficult. Furthermore, the RD approach is extended to Multi-Channel Random Decrement (MCRD) technique in order to locate damage by extracting mode shape through applying RD at multiple points of structure simultaneously under certain triggering time vector segments.

The scope of current thesis is to explore theoretically and verify experimentally of Random Decrement (RD) technique as an effective VBDIT for reinforced concrete (RC) two-way slab system. The RD technique has been proven successful to determine the strength and degradation of RC beam as an anisotropic structural element. However, two-way slab system which is widely used in building, bridge, dam, offshore, etc. has different nature compared to a beam system. Twoway slab is a thin and flat rectangular plate structural element. Development of two-dimensional plate theory employs the in-plane coordinates. Solution to reduced approximation of partial differential equations according to classical elastic theory for two-way slab (plate) structure are direct stresses and bending stresses. Bending stresses vary linearly through the thickness and are proportional to the moment resultants Mx, My and the twisting moment Mxy. Plate encompasses more boundary conditions and the twisting moment which are not manifest in beam theory 
contributing to different behaviour of plate compared to beam. The effects of these differences over feasibility of RD technique on two-way slab has not already been investigated profoundly. In this research, RD technique is applied on simply supported two-way slab to detect extent and location of different damage conditions. Fiber Optic Sensor (FOS) has been proven to be a very effective method to track damage and the Fiber Bragg Grating (FBG) has been recommended for civil engineering applications as a cutting edge sensing technology with an advantage of multiplexing functionality is selected to be used in arrays. The Multi-Channel Random Decrement (MCRD) technique is used to observe the structure multi-responses simultaneously and to identify extent and location of the induced damage.

With regard to increasing demand of SHM for modern infrastructures constructed with modern materials like High Strength Concrete (HSC) and Ultra High Performance Fiber Reinforced Concrete (UHP-FRC), these particular materials are selected for this research in order to build experimental samples.

\subsection{Research Objectives}

The objectives of this research are aimed to express theoretically and verify experimentally the practical and reliable SHM method for two-way reinforced concrete slabs focused on assessment of the damage, utilizing effective vibration based damage diagnostic technique of Random Decrement (RD);

(1) to investigate the extent of damage induced by progressive static loading at cracking, yield, and ultimate states through changes in dynamic parameters natural frequency and damping ratio obtained from RD signatures of three reinforced High Strength Concrete (HSC) two-way slabs with different reinforcement ratios and one Ultra High Performance Fiber Reinforced Concrete (UHP-FRC) two-way slab with the same reinforcement ratio as one of the HSC two-way slabs;

(2) to present the behaviour of two-way slabs stated in objective one under progressive static loading in terms of load-deflection relationship at service and ultimate load, crack pattern and failure modes; 
(3) to identify the location of induced incremental damages at three levels of severity on HSC two-way slab by Multi-Channel Random Decrement (MCRD) technique using in-house fabricated Fiber Bragg Grating (FBG) sensor arrays at Ryerson University and finally;

(4) to evaluate the extent of damage under successive equal dynamic impacts through changes in dynamic parameters using RD technique of four UHP-FRC two-way slabs with different reinforcement ratios and fiber contents.

\subsection{Thesis Overview}

Chapter 1 presents the introduction including general background, research scopes, objectives, and overview of the thesis.

Chapter 2 describes the literature review of the research work regarding the definition, development and advantage of SHM. Furthermore, the RD damage diagnostic technique historical development and theoretical approach are explained in detail. Moreover, the damage localization techniques based on mode shape extraction by MCRD technique is investigated and explored by presenting Modified Mode Shape Difference and Mode Shape Extremum Damage Detection (EDD) techniques. Finally, the successful instrumentations for SHM based on cutting edge Fiber Optic sensing technology are demonstrated by physical characteristics and types with special focus on FBG sensor strain measurement characteristic.

Chapter 3 demonstrates the experimental investigation carried out to validate vibration-based damage identification of RD technique as a practical SHM methodology for concrete plates. The experimental program consists of the evaluation, casting, and testing of four two-way slabs: three High Strength Concrete (HSC) and one Ultra High Performance Fiber Reinforced concrete (UHP-FRC) slabs under ambient vibration and static load testing procedures. Furthermore, the fabrication, assembling and installation of FBG sensor array are described. 
Chapter 4 reveals the results and observations obtained from the experimental program explained in Chapter 3. Static behaviour are considered in terms of load-deflection relationship at service and ultimate load, stiffness, ductility, energy absorption, crack pattern and failure modes. The extent of damage induced by progressive static loading at cracking, yield, and ultimate states are examined through changes in dynamic parameters natural frequency and damping ratio obtained from RD signatures.

Chapter 5 expresses and verifies two additional conducted applications of RD technique. First, MCRD technique is implemented to extract the mode shapes and subsequently Modified Mode Shape Difference technique and Mode Shape Extremum Damage Detection (EDD) technique are utilized in order to investigate the damage location in reinforced HSC two-way slabs under induced incremental damages at three levels of severity. Secondly, RD technique is employed on four UHP-FRC two-way slabs to evaluate the extent of damage under successive equal dynamic impacts by changes in dynamic parameters natural frequency and damping ratio.

Chapter 6 presents the summary, conclusions and recommendations of the research. 


\section{CHAPTER TWO \\ LITERATURE REVIEW}

\subsection{Introduction}

The aim of the present chapter is to provide a conceptual background and to discuss related theoretical and empirical studies for Structural Health Monitoring (SHM) of two-ways slab based on Random Decrement (RD) technique. Primarily, definition, development and advantage of SHM are described. Furthermore, damage diagnostic technique and instrumentation used in this research are explained in detail. Particularly, an ambient vibration based damage detection RD technique with great potential to detect damage through changes in dynamic parameters has been focused. Damage localization techniques based on mode shape extraction by Multi-Channel Random Decrement (MCRD) technique is investigated and explored by presenting Modified Mode Shape Difference technique and Mode Shape Extremum Damage Detection (EDD) technique. The successful instrumentations for SHM data collection to obtain output information about health or damage status of the structure are summarized. Fiber Bragg Grating (FBG) optical sensor as a cutting edge technology is selected for this research experiment and investigated in detail.

\subsection{Structural Health Monitoring}

From the second half of the 20th century, Structural Health Monitoring (SHM) has been offered as a smart system which integrates communication and control sensing technologies to guarantee infrastructure integrity, sustainability and safety.

Non-destructive on-site structural evaluation methods are commonly used in SHM. Although SHM was associated with problematic aspects at the beginning, the recent advances in electronic sensing technology made it more convenient to implement. Advanced SHM technology consists of advanced sensor technology, data processing including data acquisition, transmission and storage, and health evaluation system including damage analysis and condition assessment techniques. In order to obtain output information about health or damage status of the structure, several types of sensors are used. The sensors could be attached on or embedded in structure with the merits of durability, cost effectiveness, the convenience of installation and maintenance, high sensitivity, and so on. 
SHM as an intelligent system implements strategies for early damage detection that can save lives and money. Generally, monitoring is performed at two levels: local material or global structural level. Monitoring at material level provides information related to material behaviour locally and the probability of detecting the damage in this level is low, but on the other hand, the probability of detecting the damage in global level is very high because monitoring at this level provides information about the structure as a whole. Monitoring at the structural level also has an advantage of providing information about material performance indirectly through changes in structural behaviour.

SHM process like any other monitoring processes can be performed continuously or periodically to record representative parameters over a short or long period of times. The timing and duration of SHM process depend on the type of structure, its location, particular conditions, and budget feasibility. Generally, short term monitoring can be done during construction phase of any structure to detect defects that arise during the construction and also to validate whether required values are achieved. For SHM of any system, a common method is using designated particular sensors to observe some essential existing structure performance parameters and compare them with normal or previous structure performance parameters. The essential parameters can be mechanical, physical and/or even chemical. The goal is to identify the damage via changes in these essential parameters between two initial and damaged states. Identifying the presence of the damage is the first step to take preventive actions and start analyzing the root cause of the problem. As a broadly accepted assumption, researchers identified four levels for damage identification: detection, localization, quantification of damage, and decision making about type and severity of damage.

Implementation of well-designed SHM system encompasses several advantages. It detects the onset of the damage, assures structural strength and serviceability, reduces downtime for upgrade and repair activities, helps to develop better management and maintenance strategies for allocation of budget and scarce resources, and last but not the least enables usage of innovative materials by providing opportunities for performance verification.

To date, the successful applications of SHM technology have been for aerospace, mechanical and some sectors of civil engineering. Major drivers in civil engineering applications are agencies of 
large dams, railroads, highway bridges, and offshore platforms for oil and gas industry whose implementations of SHM have received significant attention and research efforts.

Historically dams are the first class structure that is mandated for SHM. In 1864, failure of $30 \mathrm{~m}$ dam caused the death of 254 people near Sheffield, UK. As a matter of fact from dam engineering point of view, SHM of the dam is equivalent to surveillance. Since then, many organizations have been established to promote dam safety and maintenance around the world. The International Commission on Large Dams (ICOLD, 2000) is a good example for formalized dam monitoring organization.

In the last two decades, bridge SHM systems have been evolved by permanent monitoring programs which implemented in major bridge superstructure projects. Global SHM procedures with a minimum of optimally located sensors could detect defects such as foundation settlement, rupture of deck element, bearing failure, and loss of main cable tension. The first modern major superstructure considered to be extensively monitored is Confederation Bridge. The bridge links provinces of Prince Edward Island and New Brunswick and was opened to the public in 1997. Several innovative technologies have been implemented to create this bridge with a 100 year design life (twice as long as a typical highway bridge). Engineers evaluate the short and long term performance of the bridge by using Fiber Optic Sensors (FOSs) and several other conventional sensors with respect to ice loads, deformations, traffic loads, vibration, corrosion and thermal effects (Cheung, 1997). The primary role in the FOSs technology used in this structure is undertaken by Intelligent Sensing for Innovative Structure (ISIS) Canada.

Another major on-going bridge monitoring project is implemented in Millau Viaduct Bridge. This multi-span cable-stayed bridge is crossing the turn in Southern France and is considered the tallest bridge in the world with $343 \mathrm{~m}$ height at the top of the pylons (Virlogeux et al., 2005). The pylons, deck, masts and stays are equipped with a multitude of sensors. Twelve fibre optic extensometers were installed in the base of tallest pylon as it is under the most intense stress. These sensors detect movements on the order of a micrometer.

Continuous SHM plays an important role in early damage detection of offshore structure. Offshore structures are subjected to extreme environmental loads which mandatory inspection is required to monitor its safety. Due to expense and danger of undersea diver inspection, vibration based 
damage detection for an offshore structure is preferred. The range of system identification techniques for ambient response is developed with considering the fact that offshore structure is a non-stationary system with frequent changes of mass through structural modifications, fluid flows, loading and unloading of stores, and drilling operations. After the discovery of large oil reserves in Atlantic Canada, several offshore projects have been taken place. Hibernia is ongoing project, producing oil since 1997, highly committed for health monitoring and continually improving its performance in order to assure the structure strength and serviceability. Hebron project is another gravity based concrete offshore structure under development which is committed to use cutting edge health monitoring technology such as Fiber Optic Sensing technology. Among enormous health monitoring advantages, minimizing economic loss and reducing environmental pollution arising from accidental oil spills have more important roles in offshore oil and gas industry.

Among three basic components of structure beam, column and slab, the slab is an irreplaceable efficient structural component. Irreplaceable by means of that it cannot be replaced by any other components. Compared to one way slab system, two-way slab system is more cost effective because of its larger area coverage characteristic. Two-way slab system is used in various structural applications for instance roofs and floors of building, walls of tank and dam, offshore platform, nuclear containment, and decks of the bridge. Major concerns associated with economic applications of the two-way slab system are slab column connection failure and impact force failure. This current research focuses on detecting presence and extent of damage mostly in forms of critical cracks at the cracking, yield, and ultimate states and location of damage in two-way slab system. Random Decrement (RD) technique is applied for monitoring dynamic parameters of slabs under designated dynamic impact and static loading using accelerometer and smart network of Fiber Bragg Grating (FBG) sensors in forms of an array. 


\subsection{Random Decrement (RD) Technique}

In SHM, non-destructive testing (NDT) techniques are very common for detecting damage without interrupting the infrastructure integrity. In the last few decades, several vibrations based damage identification techniques (VBDIT) have been implemented due to a development of intelligent diagnostic techniques for reducing overall cost. These methods detect damage through changes in dynamic parameters of the structure. Damage effects by changing the local properties where the damage occurs such as mass and stiffness. For monitoring purpose accessibility to these properties are not always easy. In other hand, global properties have this advantage that is usually more accessible for monitoring and enhance convenience and simplicity. The main goal of using VBDIT methods is to observe changes in local dynamic properties by monitoring changes in global dynamic properties in order to interpret the damage. Theoretically, Eigenvalue (natural frequency), Eigenvector (mode shape), and damping ratio are global dynamic properties under consideration.

Eigenvalue also denoted as natural frequency is the frequency that system have highest level of response to harmonic forces with that frequency. At respective Eigen frequency, the Eigenvector or mode shape reveals relative displacement of the system at certain concerning points or in other word nodes. For each Eigen frequency there is also associated dimensionless measure known as damping ratio which describes how fast vibration in a system dissipates after disturbance. System might vibrate after disturbed from its position of static equilibrium. If damping ratio is less than unity $(\xi<1)$, the system vibrates and is considered as an underdamped condition. If it is greater than unity $(\xi>1)$, the system is considered as an overdamped condition and it will not vibrate but damping ratio still reveals how fast disturbance decays to an equilibrium position. All structures without special damping accessories are underdamped and have damping ratio less than 0.2.

As an example, one of the VBDIT methods is mode shape analysis which detects damage through changes in mode shape derivatives (Ismail et al., 2006). Eigen frequency evaluation is another example (Ndambi et al., 2002). For both of these techniques both input and output individual measurements are necessary. In fact, this is a challenging task among most of VBDIT methods. There are different types of excitation input motions: harmonic excitation, random excitation, impulse excitation, step excitation, white noise excitation (a type of random excitation), and ambient excitation. Due to the fact that most of the time the excitation input motions caused by 
input forces such as wind load, truck load passing by, or pedestrian walking are not easy to measure individually, techniques which are only based on output measurements are more convenient. RD technique is a time domain NDT procedure based on output measurement without any knowledge of the excitation force as a requirement.

\subsubsection{Historical Developments of RD Technique}

In the late 1960s, a damage detection technique using RD was originally deployed for aerospace industry by H. A. Cole at Ames Research Center. The aim of the project was to detect damage in aerospace wing structure surface. The main goal was to determine the dynamic response of space shuttle structure exposed to ambient loads and vibrations. Cole was seeking an easy direct method to translate the aberrant time history obtained by a transducer into a normal clear result. He tried FFT algorithm to find damping ratio using half power bandwidth spectral density but the technique had large variance among the results. Cole found out that this problem arose from the unmeasurable ambient loads which have non-linearity and random nature. Instead, he used the concept of the autocorrelation functions for sample estimation. In the early days, it was recognized that the envelope of autocorrelation functions can be used to define the main dynamic properties of a structure such as natural frequency and damping ratio.

Damping ratio and natural frequency are changed by both load variations and damage. In order to detect damage, there was a need to eliminate the response to load variations. This led to the introduction of RD technique to transform a random time series response of the structure into a free decay response. Free decay purely contains information of the structure itself and not the random loads. In fact, the dynamic parameters the natural frequency and damping ratio which are extracted from the free decay (decrement) signature are promising tools to detect damage.

Cole used the following explanation for the validity of the RD technique. The response of a system to random input loads is, at each time instant $t$, composed by three parts: the response to an initial displacement; the response to an initial velocity; and the response to the random input loads between the initial state and the time instant $t$. Through averaging, a large number of time segments

of the response with the same initial condition (triggering condition), the random part of the response fade out from the average, and free decay response (response to initial displacement) will be obtained. 
After Cole, other researchers improved the RD technique. (Chang, 1975) worked on significance of the RD function length and number of triggering points. He also explored level crossing triggering condition and zero crossing with a positive slope triggering condition. (Houbolt and Brincker et al., 1975) adopted different approaches to triggering conditions in order to obtain better results. Up to this point, all of the researchers were involved for single channel RD technique. Furthermore, the concept was extended to cross RD signatures by (Ibrahim, 1977) for multichannel measurements. Ibrahim efforts resulted to the possibility of obtaining the mode shape from the cross RD signatures.

Due to the existence of random input excitations through the wind, current, waves, seismic, traffic load, and crane and elevator activities in civil infrastructures, application of RD technique has become a desired converging method for extracting meaningful information from random data. In 1984, Yang et al. applied RD technique on an offshore platforms subjected to random input excitations to detect damage in forms of cracks by using mean square deviation of the RD signatures. In 1985, Tsai et al. induced saw cut damages in a model of offshore structure and the extent of damage was detected using RD signatures obtained from accelerometer responses. A curve fitting autoregressive models to the RD signatures were used for monitoring damages through the changes in natural frequency and damping ratio. In 2004, Li et al. investigated damage in a form of localized delamination of a fiber reinforced composite beam using RD technique. It was found that as delamination length is increased, the natural frequency of fundamental mode is decreased and corresponding damping ratio is increased. (Asayesh et al., 2008) proposed a method to extend the application of RD technique on a system that is subjected to both random and periodic excitation. In 2009, Elshafey et al., used RD technique to predict damping and natural frequency and subsequently obtain the reaction forces and moment at the foundation of fixed offshore platform subjected to wind-generated random waves using its stationary response. (Shiryayev and Slater, 2010) successfully used RD technique to detect fatigue cracks in a cantilevered aluminum beam. (Morsy et al., 2016) assessed RD as a suitable method for monitoring of reinforced concrete (RC) beams; and also compared the indication of damage using a randomic signature for RC and steel beam. It was concluded that the change in damping ratio for $\mathrm{RC}$ beam is a better indicator for the extent of the damage. 


\subsubsection{RD Technique Theoritical Approach}

$\mathrm{RD}$ technique is a time domain NDT procedure, with the aim of obtaining free decay response under any service load conditions. RD signature is equivalent to free decay response which its changes is widely used to indicate the damage. The concept of ensemble averages is used to define the equivalent $\mathrm{RD}$ signature. The assumption of ergodic behaviour of the time history data under RD procedure is presumed for the results validity. This assumption means that averages obtained from any single time history are equivalent to averages obtained across the ensemble of all potential time histories of the process. There is another definition for RD signature which describes this theory more concisely: RD signature is the conditional expected value of the random process. For the ergodic random process, the average and the conditional expected value are equivalents (Equations 2.1 and 2.2).

$$
E[f(x)]=\int_{-\infty}^{\infty} f(x) \cdot p(x) d x=\mu
$$

Where $\mathrm{E}$ is the expectation linear operator, $\mathrm{x}$ is a random variable, $\mathrm{p}(\mathrm{x})$ is the probability of random variable, $\mathrm{f}(\mathrm{x})$ is the continuous function of random variable, and $\mu$ is the mean vector.

$$
E[X]=\int_{-\infty}^{\infty} X \cdot p(x) d x=\mu
$$

Where $\mathrm{E}$ is the expectation linear operator, $\mathrm{x}$ is a random variable, $\mathrm{p}(\mathrm{x})$ is the probability of random variable, $\mathrm{X}$ is the discrete function of random variable, and $\mu$ is the mean vector.

In RD theory, conditioning is defined for computing the probability which is called triggering condition. Through conditioning for the expected value computation, members of ensemble are omitted unless they possess the specified value for initial conditions which are essential for extracting the signature.

$\mathrm{RD}$ technique is based on output measurements identification. Although this technique is applicable for multi degree of freedom complex systems, the theory would be more comprehensive with considering a single degree of freedom mechanical oscillator excited by zero mean, stationary, Gaussian random force. 
The general equation of motion of the system is given by Equation 2.3:

$$
[\mathrm{M}]\{\ddot{\mathrm{X}}(\mathrm{t})\}+[\mathrm{C}]\{\dot{\mathrm{X}}(\mathrm{t})\}+[\mathrm{K}]\{\mathrm{X}(\mathrm{t})\}=\{\mathrm{F}(\mathrm{t})\}
$$

Where $[\mathrm{M}]$ is the mass matrix, $[\mathrm{C}]$ is the damping matrix, $[\mathrm{K}]$ is the stiffness matrix, and $\mathrm{F}(\mathrm{t})$ is the excitation force.

Normalized equation of the motion for single degree relative to the mass, Equation 2.4 is:

$$
\ddot{x}(t)+2 \omega_{0} \zeta \dot{x}(t)+\omega_{0}^{2} x(t)=f(t)
$$

Where $\mathrm{x}(\mathrm{t})$ is the displacement, $\omega_{\mathrm{o}}$ is the natural frequency and $\xi$ is the damping ratio of the system. The random excitation force $\mathrm{f}(\mathrm{t})$ is assumed to be Gaussian, zero mean and stationary process which meets the following requirements (Equations 2.5 and 2.6):

$$
\begin{aligned}
& E[f(t)]=0 \\
& E[f(t-\tau) f(t)]=\psi_{0} \delta(\tau)
\end{aligned}
$$

Where $\delta$ is the Dirac delta function and $\psi_{0}$ is the variance of the excitation.

The following variables (Equation 2.7) are exchanged for better representation of following partial differential Equation 2.9:

$$
\begin{aligned}
& \mathrm{y}_{1}=\mathrm{x} \\
& \mathrm{y}_{2}=\dot{\mathrm{x}} \\
& \dot{\mathrm{y}}_{1}=\mathrm{y}_{2}
\end{aligned}
$$

By considering the above changes to the Equation 2.4, the Equation 2.8 is obtained as (Elshafey et al., 2009):

$$
\dot{\mathrm{y}}_{2}=-2 \omega_{\mathrm{o}} \xi \mathrm{y}_{2}-\omega_{\mathrm{o}} \mathrm{y}_{1}+\mathrm{f}(\mathrm{t})
$$


For the single mass system (particle) under influence of both drag forces and random forces, a partial differential equation is represented by Fokker-Plank equation. This partial equation can be the time evolution of conditional probability density function $\mathrm{P}\left(\mathrm{Y}, \mathrm{t} \mid \mathrm{Y}_{0}\right)$ of the motion $Y(t)=\left\{\begin{array}{l}y_{1} \\ y_{2}\end{array}\right\}$ (Haddara, 2006). The partial equation can be written as Equation 2.9:

$$
\frac{\partial \mathrm{P}}{\partial \mathrm{t}}=\frac{\partial}{\partial \mathrm{y}_{1}}\left(\mathrm{y}_{2} \mathrm{P}\right)+\frac{\partial}{\partial \mathrm{y}_{2}}\left(-2 \omega_{\mathrm{o}} \xi \mathrm{y}_{2}-\omega_{\mathrm{o}}^{2} \mathrm{y}_{1}\right) \mathrm{P}+\frac{\psi_{\mathrm{o}}}{2} \frac{\partial^{2} \mathrm{P}}{\partial \mathrm{y}_{2}^{2}}
$$

Where symbol $\mathrm{P}$ denotes $\mathrm{P}\left(\mathrm{Y}, \mathrm{t} \mid \mathrm{Y}_{0}\right)$.

Equation 2.9 can be rewritten as Equation 2.10:

$$
\begin{aligned}
P\left(Y, t+d t \mid Y_{0}\right) & -P \\
& =\left(\frac{\partial}{\partial y_{1}}\left(y_{2} P\right)+\frac{\partial}{\partial y_{2}}\left(-2 \omega_{0} \xi_{2}-\omega_{0}^{2} y_{1}\right) P+\frac{\psi_{o}}{2} \frac{\partial^{2} P}{\partial y_{2}^{2}}\right) d t
\end{aligned}
$$

The displacement and velocity mean are $\mu_{1}$ and $\mu_{2}$, Equations 2.11 and 2.12:

$$
\begin{aligned}
& \mu_{1}=E\left[\mathrm{y}_{1}\right]=\int_{-\infty}^{\infty} \mathrm{y}_{1} \mathrm{P} d \mathrm{y}_{1} \\
& \mu_{2}=\mathrm{E}\left[\mathrm{y}_{2}\right]=\int_{-\infty}^{\infty} \mathrm{y}_{2} \mathrm{P} d \mathrm{~d}_{2}
\end{aligned}
$$

By integrating the Equation 2.10 with respect to $y_{1}$ and $y_{2}, \mu_{1}$ and $\mu_{2}$ displacement and velocity mean are obtained as Equation 2.13 (Elshafey et al., 2009):

$$
\ddot{\mu}_{1}=\dot{\mu}_{2}=-\left\langle 2 \omega_{0} \xi y_{2}+\omega_{o}^{2} y_{1}\right\rangle
$$

Ultimately, the equivalent free decay response can be derived from the stationary random response by Equation 2.14 as: 


$$
\ddot{\mu}+2 \xi \omega_{0} \dot{\mu}+\omega_{0}{ }^{2} \mu=0
$$

Where $\mu$ is the mean value of the displacement $\left(\mu=\mu_{1}\right)$ which also can be shown by vector $\bar{x}$.

Equation 2.15 is the solution for the $\mu$ which is called RD function $X_{R}(\tau)$.

$$
X_{R}(\tau)=\frac{1}{N} \sum_{i=1}^{N} x(t i+\tau)
$$

Where the RD function $X_{R}(\tau)$ is obtained from an averaging process of time history segments $\mathrm{x}(\mathrm{ti}+\tau)$ of random vibration responses that contain certain triggering condition (Figure 2.1$)$. The triggering condition must be selected in such a way that maintains correlation among segments. The triggering points (xi, ti) are determined by triggering condition which will be described further in detail later. $\mathrm{N}$ is the number of triggering points which also depend on the triggering condition. As it can be recognized $\mathrm{N}$ is also the number of the segments. $\boldsymbol{\tau}$ is the length of each segment. (Chang, 1975) introduced the significance of the length of RD function, $\boldsymbol{\tau}$, and the number of triggering point or ensemble averages, $\mathrm{N}$, in a simulation study. For extracting accurate natural frequency and damping ratio from RD signature, he recommended at least 2000 ensemble averages.
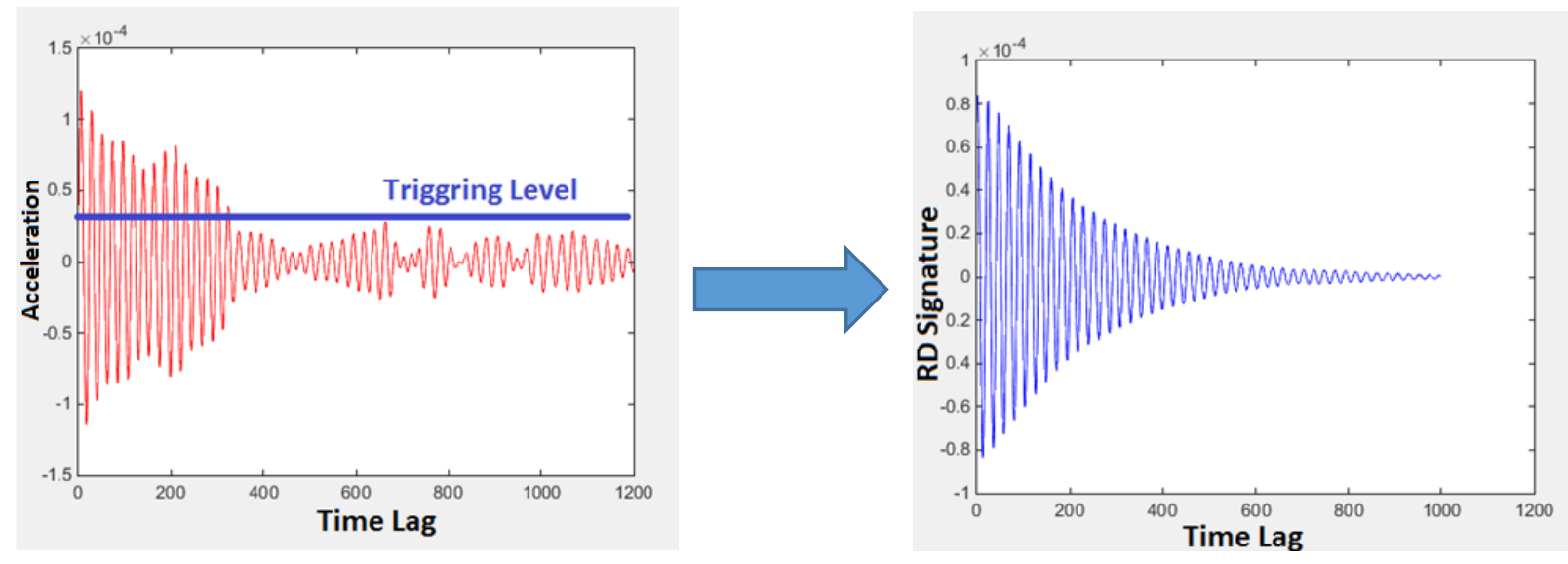

Figure 2.1 The RD Technique Demonstration 


\subsubsection{Triggering Condition Types}

The challenging part in using RD theory is how to define triggering condition which basically depends on a type of experimental procedure, nature of load and motion, and capability and speed of deployed computer. Stochastically, using more triggering points reduces variance of the RD signature contributing to reduction of noise. In the past, speed of the deployed computers forced users to minimize the number of triggering points. Today, this obstacle is overcome by using high speed computers. The only limitation still remained for the triggering condition is to provide correlation among segments. The Equation 2.15 for RD function can be rewritten as Equation 2.16:

$$
\mathrm{D}_{\mathrm{xx}}(\tau)=\frac{1}{\mathrm{~N}} \sum_{\mathrm{i}=1}^{\mathrm{N}} \mathrm{x}(\mathrm{ti}+\tau) \mid \mathrm{Tx}(\mathrm{ti})
$$

Where $\mathrm{D}_{\mathrm{xx}}(\tau)$ is auto RD function meaning that the triggering condition and the time segments to be averaged are defined in the same response signal, and $\mathrm{Tx}(\mathrm{ti})$ is the triggering condition applied to time history $\mathrm{x}(\mathrm{t})$.

In terms of expectation linear operation the RD technique can be also formulated as Equation 2.17:

$$
\mathrm{D}_{\mathrm{xx}}(\tau)=\mathrm{E}\left[\mathrm{X}(\mathrm{t}+\tau) \mid \mathrm{T}_{\mathrm{X}(\mathrm{t})}\right]
$$

There are several triggering conditions that can be applied to RD technique. These triggering conditions can also be used in combination. In below, the most common types of triggering condition are listed in Equations 2.18 to 2.21 (Asmussen, 1997):

a) positive points

$$
\mathrm{Tx}\left(\mathrm{t}_{\mathrm{i}}\right)=\left\{\mathrm{a} \leq \mathrm{x}\left(\mathrm{t}_{\mathrm{i}}\right)<\mathrm{b}\right\}
$$


b) level crossing

$$
\operatorname{Tx}\left(t_{i}\right)=\left\{x\left(t_{i}\right)=a\right\}
$$

c) zero crossing with positive slope

$$
\operatorname{Tx}\left(t_{i}\right)=\left\{x\left(t_{i}\right)=0, \dot{x}\left(t_{i}\right)>0\right\}
$$

d) local extremum

$$
\operatorname{Tx}\left(t_{i}\right)=\left\{a \leq x\left(t_{i}\right)<b, \dot{x}\left(t_{i}\right)=0\right\}
$$

The triggering boundaries $\mathrm{a}$ and $\mathrm{b}$ can be applied in the positive part of the time history response. In order to increase the number of triggering points to achieve the minimum recommended amount for example 2000 as (Chang, 1975) stated, one may apply the same triggering condition in negative part of the response signal and average the two responses by changing the sign of one of them to avoid the responses cancelling out each other. This procedure is applicable for most of the triggering conditions and approximately doubles the triggering point amounts. From the above statements, an idea of counter correlation scenario is exposed. The reversely correlated segments with different signs cancel out each other. If they would be identifiable, the sign of one of them can be changed and they can be used as correlated data but otherwise, the counter correlated data will cancel out each other and the desirable correlation will be lost. Using lower triggering level, increases the probability of counter correlation which causes decrease in the probability of correlation among segments which is not appropriate for extracting free decay signature. (Brincker and Rodrigues, 2005) has mentioned this scenario as a noise contamination. In general, optimization between a high triggering level and a large number of triggering points is essential. The efforts have been done to define different triggering conditions were all considering this optimization.

The simplest triggering condition is positive points triggering condition (Equation 2.18). Challenge for this condition is assumption of triggering level boundaries a and b. (Sim et al., 2011) recommended the triggering level interval to be within standard deviation of the response positive 
points and 2.5 times the standard deviation. Recently due to implementation of high speed computer technology, the mostly used assumption is to consider $a=\sigma_{x}$ and $b=\infty$, where $\sigma_{x}$ is the standard deviation of the response time history. In this case, half of the data could be triggering points. There is another suggestion by Asmussen (1997) in the case of the level crossing triggering condition. This optimum triggering level has to be $a=\sqrt{2} \sigma_{x}$ in order to minimize the variance of the obtained RD function. In this research paper by considering the fact that positive points triggering condition is a generalization of level crossing triggering condition, the positive points triggering condition with $a=\sqrt{2} \sigma_{x}$ and $b=\infty$ is employed successfully.

\subsubsection{Determination of Time $\operatorname{Lag}(\tau)$}

In the averaging process of time history segments of RD technique, the length of each segment $\boldsymbol{\tau}$ (time lag) must be specified. Since RD technique is a time domain procedure, obtaining dynamic modal parameters natural frequency and damping ratio procedure are not sensitive to time lag value. In RD frequency domain applications, estimation of the spectral densities using the Fourier Transform of the RD functions is dependent to time lag (Brincker and Rodrigues, 2005). Having complete decay within the length of RD signature prevents leakage or aliases. Leakage inevitably creates false frequency. In fact, accurate time lag acts as a window function without the disadvantage of leakage for finite Fourier Transform of RD functions. Although in this research time domain RD technique procedure is applied and there is no necessity for accurate time lag values, efforts have been made toward implementing accurate time lag for better illustration and analyzing of RD graphs purposes. For instance, the damping ratios are graphically confirmed by RD signatures.

\subsubsection{RD Technique Imperfection}

By applying RD technique to the random process, the RD signature is obtained. Through following example it will be observed that the RD signature is not always equivalent to free decay response.

Consider a single degree of freedom mechanical oscillator excited by a zero mean, stationary, Gaussian random force, for which the equation of motion is given in Equation 2.3. Assume the response $\mathrm{X}(\mathrm{t})$ is also zero mean, stationary, Gaussian process. At first glance, the solution for 
$\mathrm{X}(\mathrm{t})$ if the excitation force is removed at time $\mathrm{t}=0$ seems to be the transient decay response which classically is obtained as Equation 2.22:

$$
\begin{aligned}
& X(t)=a e^{-\xi \omega_{0} t}\left[\cos \omega_{1} t+\frac{\omega_{0}}{\omega_{1}} \sin \omega_{1} t\right]+\frac{b}{\omega_{1}} e^{-\xi \omega_{0} t} \sin \omega_{1} t \\
& \omega_{0}=\sqrt{\frac{K}{M}}, \omega_{1}=\omega_{0} \sqrt{1-\xi^{2}}
\end{aligned}
$$

Where $\mathrm{a}$ and $\mathrm{b}$ are initial values $\mathrm{a}=\mathrm{X}(0)$ initial amplitude and $\mathrm{b}=\dot{\mathrm{X}}(0)$ initial slope, $\omega_{0}$ is undamped natural circular frequency, $\omega_{1}$ is damped natural circular frequency, $\xi$ is the damping ratio, $\mathrm{M}$ is the mass, and $\mathrm{K}$ is the stiffness.

But in reality, the force cannot be removed at a time interval equal to zero and this should be considered concisely. A powerful technique of convolution integral is used here to calculate the response of the system to a zero input initial condition (zero state response). The convolution integral of the impulse response function for the system $h(t-\tau)$ and the excitation $F(\tau)$ should be added to transient decay response in order to have an overall system response as in Equation 2.24 (Vandiver et al., 1982):

$$
\begin{aligned}
X(t)=a e^{-\xi \omega_{0} t} & {\left[\cos \omega_{1} t+\frac{\omega_{0}}{\omega_{1}} \sin \omega_{1} t\right]+\frac{b}{\omega_{1}} e^{-\xi \omega_{0} t} \sin \omega_{1} t } \\
& +\int_{0}^{t} h(t-\tau) F(\tau) d \tau
\end{aligned}
$$

The RD technique can be applied to response $\mathrm{X}(\mathrm{t})$ for extracting RD signature as Equation 2.25: 


$$
\begin{aligned}
E[X(t) \mid a, b] & =a e^{-\xi \omega_{0} t}\left[\cos \omega_{1} t+\frac{\omega_{0}}{\omega_{1}} \sin \omega_{1} t\right]+\frac{b}{\omega_{1}} e^{-\xi \omega_{0} t} \sin \omega_{1} t \\
& +\int_{0}^{t} h(t-\tau) E[F(\tau) \mid a, b] d \tau
\end{aligned}
$$

Where $\mathrm{E}[\mathrm{X}(\mathrm{t}) \mid \mathrm{a}, \mathrm{b}]$ is the expected value on the response $\mathrm{X}(\mathrm{t})$ with initial condition (triggering condition) $\mathrm{a}$ and $\mathrm{b}$.

In 1961, Caughey believed that since the input is zero mean, stationary, random process, then the expected value of the force function in convolution integral is equal to zero. He concluded that in this case, the RD signature is simply the transient decay (free decay) response. (Vandiver et al., 1982) mathematically proved that the Caughey's conclusion is not generally true. He used correlation theory for the proof (Equation 2.26).

$$
R_{X F}\left(t_{1}, t_{2}\right)=\int_{X_{1}} \int_{F_{2}} X_{1} F_{2} P\left(X_{1}, F_{2}\right) d X_{1} d F_{2}
$$

Where $R_{X F}\left(t_{1}, t_{2}\right)$ is cross correlation function, $t_{2}$ is time vector related to input, $t_{1}$ is time vector related to output, $X_{1}$ is output response vector $X\left(t_{1}\right), F_{2}$ is input force vector $F\left(t_{2}\right)$, and $P$ demonstrates joint probability density function.

The joint probability distribution function can be expressed in terms of a first order probability distribution function and conditional probability distribution function as Equation 2.27:

$$
P\left(X_{1}, F_{2}\right)=P\left(X_{1}\right) P\left(F_{2} \mid X_{1}\right)
$$

By incorporating Equation 2.27, the cross correlation function Equation 2.26 can be rewritten as Equation 2.28:

$$
\mathrm{R}_{\mathrm{XF}}\left(\mathrm{t}_{1}, \mathrm{t}_{2}\right)=\int_{\mathrm{X}_{1}} \mathrm{X}_{1} \mathrm{P}\left(\mathrm{X}_{1}\right) \int_{\mathrm{F}_{2}} \mathrm{~F}_{2} \mathrm{P}\left(\mathrm{F}_{2} \mid \mathrm{X}_{1}\right) \mathrm{dF}_{2} \mathrm{dX} \mathrm{X}_{1}
$$


In order to accept Caughey's argument which states that the expected value of the force function in convolution integral is equal to zero, $\mathrm{P}\left(\mathrm{F}_{2} \mid \mathrm{X}_{1}\right)$ must also be zero and consequently cross correlation $R_{X F}\left(t_{1}, t_{2}\right)$ must always be zero which is not always true. Here it should be noticed that what happens in a mechanical oscillating system if cross correlation between input force and output response exists? The answer is that resonance will happen. From engineering point of view, it is concluded that RD technique result is not valid for resonance condition. By taking this conclusion into account, for SHM of resonance susceptible building system, it is more conservative to have also another parallel resonance detection monitoring system.

\subsubsection{RD and Autocorrelation Functions Interrelation}

In 1982, Vandiver et al. established a stronger mathematical basis for RD technique. He stated that RD technique acts as a particular case of autocorrelation function over a random process.

RD formula can be rewritten as Equation 2.29:

$$
\mathrm{D}_{\mathrm{X}_{0}}\left(\mathrm{t}_{1}, \mathrm{t}_{2}\right) \equiv \mathrm{E}\left[\mathrm{X}\left(\mathrm{t}_{2}\right) \mid \mathrm{X}\left(\mathrm{t}_{1}\right)=\mathrm{X}_{0}\right]
$$

Where $t_{1}$ is triggering points time vector, $t_{2}$ is end points of segments time vector which is also equal to $t_{2}=t_{1}+\tau, X\left(t_{1}\right)$ is the triggering points amplitude vector which all its elements are constant equal to the triggering level $\mathrm{X}_{0}, \mathrm{X}\left(\mathrm{t}_{2}\right)$ is the end points of the segments amplitude vector , and $\mathrm{E}$ is expectation operator.

Crandall and Mark (1963) have done studies on autocorrelation of random process $\mathrm{X}(\mathrm{t})$. Autocorrelation is usually function of $\mathrm{t}_{1}$ and $\mathrm{t}_{2}$, in the case of this research it is function of $\tau=\mathrm{t}_{2}-$ $t_{1}$ for stationary random process. Because $X_{1} X_{2}$ denotes product of random variable values in a same sample at two time instances $t_{1}$ and $t_{2}$, the prefix auto is rightfully granted to the name autocorrelation. The autocorrelation function of random process $\mathrm{X}(\mathrm{t})$ is given as Equations 2.30 and 2.31: 


$$
\begin{aligned}
& \mathrm{R}_{\mathrm{X}}\left(\mathrm{t}_{1}, \mathrm{t}_{2}\right)=\mathrm{E}\left[\mathrm{X}\left(\mathrm{t}_{1}\right) \mathrm{X}\left(\mathrm{t}_{2}\right)\right] \\
& \mathrm{R}_{\mathrm{X}}\left(\mathrm{t}_{1}, \mathrm{t}_{2}\right)=\int_{\mathrm{X}_{1}} \int_{\mathrm{X}_{2}} \mathrm{X}_{1} \mathrm{X}_{2} \mathrm{p}\left(\mathrm{X}_{1}, \mathrm{X}_{2}\right) \mathrm{d} \mathrm{X}_{1} \mathrm{dX} \mathrm{X}_{2}
\end{aligned}
$$

Where $X\left(t_{1}\right)=X_{1}, X\left(t_{2}\right)=X_{2}$ and $p\left(X_{1}, X_{2}\right)$ is the joint probability distribution function of $\mathrm{X}_{1}, \mathrm{X}_{2}$ simultaneously.

By using probability chain rule theory, mathematical analysis rule of constant factor integration, and the RD signature formula (Equation 2.29) the general autocorrelation function can be written as Equation 2.32:

$$
R_{X}\left(t_{1}, t_{2}\right)=\int_{X_{1}} X_{1} p\left(X_{1}\right) D_{X_{1}}\left(t_{1}, t_{2}\right) d X_{1}
$$

Vandiver mathematically traced the above formula for a linear, time-invariant system. He assumed that the excitation and the response are a zero mean, stationary and Gaussian random processes. By relating the probability distribution function to the autocorrelation function and using inverse probability chain rule, mathematical analysis and the definition of RD signature, proportionality of RD signature $D_{X_{0}}(\tau)$ to normalized autocorrelation function $\rho_{X}(\tau)$ and the triggering level $X_{0}$ are developed as follows:

$$
D_{X_{0}}(\tau)=\frac{R_{X}(\tau)}{R_{X}(0)} X_{0}=\rho_{X}(\tau) X_{0}
$$

Where $\tau$ is arbitrary lag for stationary random process $\left(\tau=t_{2}-t_{1}\right), R_{X}(\tau)$ is autocorrelation function for $X(t)$ at $\tau$, and $R_{X}(0)$ is autocorrelation function at $\tau=0$.

So far up to this point, the product of the autocorrelation function and the triggering level represent the transient decay only when the excitation force is white noise. However, in practice the excitation force might not be exclusively white noise. Experiences reveal that for sharply tuned systems, a band limited spectrum of the response provides the response which is equivalent to the 
response of white noise. Furthermore, the random process response also can be filtered by a band pass filter for extracting transient decay response which is widely used in practice. The quality of filter effect on the accuracy of the result.

\subsubsection{Dynamic Parameter Identification from RD Signature}

For single degree of freedom system, dynamic parameters can be identified from the transient free decay curve. In order to convert multi degree of freedom system with multiple natural frequencies into a single degree of freedom system, a band pass filter is used to isolate the random response for each modal natural frequency. For each isolated random response, RD technique should be applied to extract the corresponding RD signature. If $\mathrm{RD}$ technique is processed appropriately by assuming time lag and triggering condition concisely, then the RD signature would be precisely equivalent to free decay curve. The desired dynamic parameters for SHM are mostly natural frequency, damping ratio and mode shape. According to ensemble averaging concept of RD technique, the dynamic parameters can be extracted directly from the RD signature and there is no need for re-averaging process for obtaining better results.

The natural frequency is simply obtained from the RD signature (free decay curve). The most common technique used to identify the damping ratio from the RD signature is Logarithmic Decrement (Morsy et al., 2016).

The natural frequency $f_{n}$ is calculated as an inverse of its period $T_{n}$ (Equation 2.35). The period can be computed by averaging from length of several consecutive cycles $\left(T_{c}\right)$ on the RD curve, Equation 2.34:

$$
\begin{aligned}
& \mathrm{T}_{\mathrm{n}}=\frac{1}{\mathrm{~m}} \sum_{1}^{\mathrm{m}} \mathrm{T}_{\mathrm{c}} \quad \text { Sec } \\
& \mathrm{f}_{\mathrm{n}}=\frac{1}{\mathrm{~T}_{\mathrm{n}}} \mathrm{Hz}
\end{aligned}
$$

Where $\boldsymbol{\omega}_{\mathrm{n}}$ is natural angular frequency. 


$$
\omega_{\mathrm{n}}=\frac{2 \pi}{\mathrm{T}_{\mathrm{n}}} \quad \mathrm{Rad} / \mathrm{Sec}
$$

Because in most of the practical cases it is almost impossible to determine the amount of damping of structure analytically, the experimental data must be encountered for identification of damping. There are several ways to compute damping ratio from experimental time history results such as half power bandwidth in the frequency domain and Logarithmic Decrement technique in time domain. According to research conducted by (Chun Pong Sing, 2014), for reinforced concrete structure, the results of damping using half power bandwidth were unexpected and Logarithmic Decrement technique was recommended. For identifying damping, the Logarithmic Decrement is the most common method which also is the simplest one. To apply this technique to a system, the system damping must decay linearly or in other word it must be viscous in nature. This is a valid assumption for structure made of homogenous material like steel. Bearing in mind that concrete is non homogenous. For reinforced concrete structure, the results of this technique directly may not be accurate. Thus, other complementary techniques might be used to achieve accuracy for damping determination based on Logarithmic Decrement technique. Attributed to the fact that the structural members are combination of steel and reinforced concrete, determination of same damping parameter (damping ratio) for both steel and reinforced concrete is convenient for comparison. Primarily, the Logarithmic Decrement technique is postulated in detail.

\subsection{Logarithmic Decrement Technique}

In order to find damping ratio of an underdamped $(\xi<1)$ linear oscillating system in a time domain, the rate of decay of free oscillation must be figured out. First, the Logarithmic Decrement $\delta$ is found as the natural logarithm of any two successive peak amplitudes $\mathrm{A}_{1}$ and $\mathrm{A}_{2}$ ratio (Equation 2.37):

$$
\delta=\ln \frac{\mathrm{A}_{1}}{\mathrm{~A}_{2}}
$$

In most practical situations the assumption of linearity is approximately true. In such cases it is better to use non-consecutive peak amplitudes $A_{i}$ and $A_{i+n}$ which carry the concept of averaging (Equation 2.38). 


$$
\delta=\frac{1}{n} \ln \left|\frac{\mathrm{A}_{\mathrm{i}}}{\mathrm{A}_{\mathrm{i}+\mathrm{n}}}\right|
$$

Where $A_{i}$ is the amplitude of cycle $i$ and $A_{i+1}$ is the amplitude of cycle $i+n$ of the RD curve.

Secondly, the modal damping ratio $\xi$ is obtained as Equation 2.39:

$$
\zeta=\sqrt{\frac{\delta^{2}}{4 \pi^{2}+\delta^{2}}}
$$

\subsection{Logarithmic Decrement Damping Envelope Complementary Technique}

This complementary technique is developed based on hysteresis damping or structural damping non-linear characteristic. In hysteresis damping same as Logarithmic Damping, under vibration energy is dissipated within the material mainly because of internal friction due to slippage and sliding of particles through cyclic deformation. Hysteresis damping can be defined as an equivalent viscous damping in such a way that energy loss per damping cycle for both be equal. In signal processing theory energy of a signal is defined as Equation 2.40. The power of two in the Equation 2.40 is because a signal can have both positive and negative values. In order for the two values not to cancel each other out, the power of two is established. By accepting this theory, it is transpired that the area underneath the damping signal $\mathrm{X}(\mathrm{t})$ (RD signature) is a good indicator for energy loss per damping cycle.

$$
E_{x}=\int_{-\infty}^{\infty}|x(t)|^{2} d t
$$

Where $E_{X}$ is the energy of the signal $x(t)$.

For obtaining the damping ratio by the complementary technique, first, two peaks of RD signature of the time history response data are selected to obtain the initial trial value of damping ratio using Logarithmic Decrement technique. Second, the damping ratio obtained and the corresponding natural frequency are used to draw the Damping Envelope. It is evident that if the RD signature would be linear, the Damping Envelope curve must fit the RD signature. But this does not happen for reinforced concrete structures. In this case, few trials for damping ratio are required to achieve the best-fit Damping Envelope. The logarithmic transient decay corresponding to this best-fitted 
envelope has the closest energy dissipation to the RD signature and its damping ratio can be assumed as an equivalent viscous damping ratio for the RD signature (Figure 2.2).

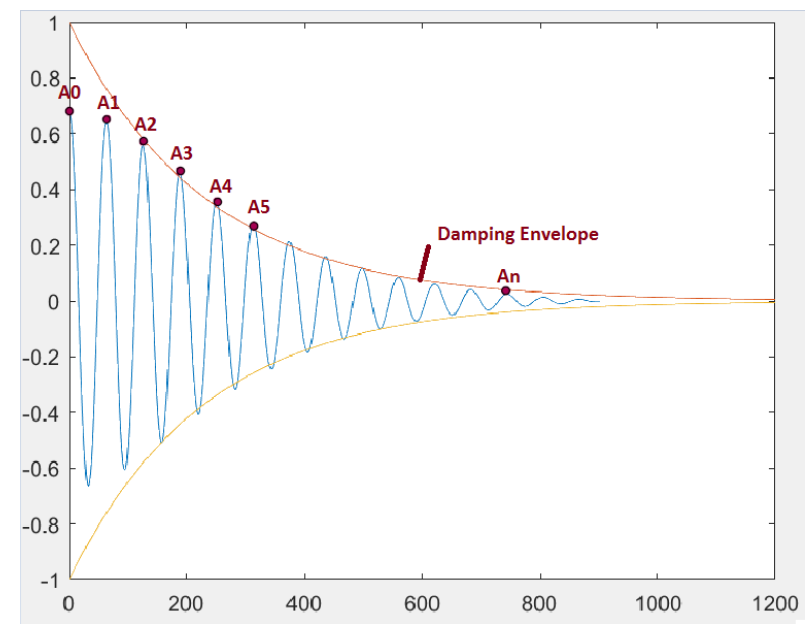

Figure 2.2 Fitting Damping Envelope to RD Signature Peaks in order to Find Equivalent Viscous Damping Ratio

\subsection{Multi-Channel Random Decrement (MCRD) Technique}

Prior to 1977, application of RD signature technique was successful for single station, single mode response cases to obtain dynamic parameters natural frequency, damping ratio and subsequently determination of failure existence and intensity. At that time, Ibrahim proposed for using this technique on multiple signals in order to obtain mode shape and failure location. In this technique, time correlation among individual signals is an asset. To keep time correlation among signals using RD techniques, he developed an algorithm and successfully tested it on the response of two models: "generalized payload" and "space shuttle" models. His algorithm is based on the underlying assumption that the structure non-linearity is small.

\subsubsection{MCRD Theory}

This theory explains how to use measured responses coming from channels at different designated locations (nodes) in order to extract the mode shape. These locations must be dynamically coupled and the responses must be captured simultaneously. They should be 
dynamically coupled in order to preserve correlation, and their responses should be captured simultaneously to reserve the phase shift between separate RD signatures of channels. At this state, the time corresponding to triggering condition for any one of the channels can be assigned for rest of the channels and is considered as the base leading channel for triggering condition (Figure 2.3).

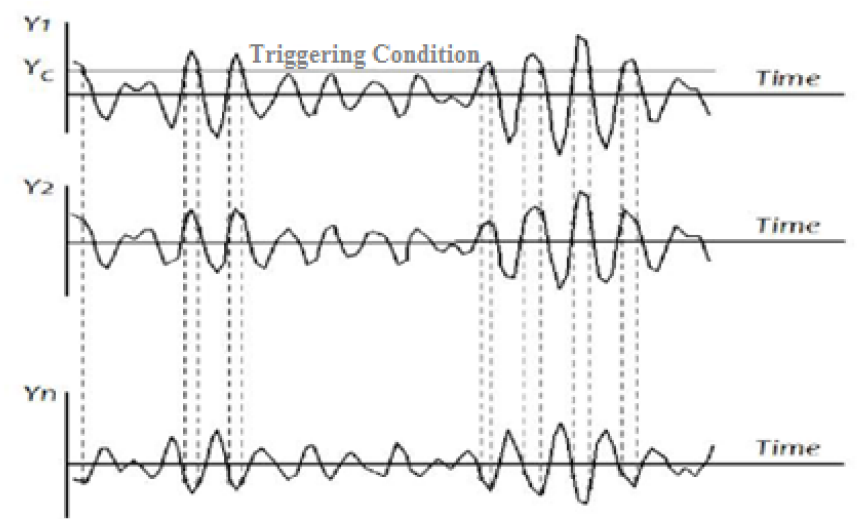

Figure 2.3 Triggering Condition for Simultaneous Multi-Channel Signals from Dynamically Coupled Locations

Then the RD signatures of experimental response data for all the channels are extracted numerically by using Equations 2.41 and 2.42 (Elshafey et al., 2009).

If the triggering condition is from same response function, it is called Auto RD:

$$
\mathrm{RD}_{\mathrm{XX}}=\left(\frac{1}{\mathrm{~N}}\right) \sum_{\mathrm{n}=1}^{\mathrm{N}}\left\{\mathrm{X}\left(\mathrm{t}_{\mathrm{i}}+\tau\right) \mid \mathrm{T}(\mathrm{X})\right\}
$$

On the other hand, if the triggering condition is from different response function, it is called Cross RD:

$$
\mathrm{RD}_{\mathrm{YX}}=\left(\frac{1}{\mathrm{~N}}\right) \sum_{\mathrm{n}=1}^{\mathrm{N}}\left\{\mathrm{Y}\left(\mathrm{t}_{\mathrm{i}}+\tau\right) \mid \mathrm{T}(\mathrm{X})\right\}
$$

Where $R D_{Y X}$ is Cross $R D, R D_{X X}$ is Auto $R D, N$ is a number of summations, $\boldsymbol{\tau}$ is time lag in $R D$ function, and $\mathrm{T}(\mathrm{X})$ is triggering for $\mathrm{X}$. 


\subsubsection{Mode Shape Extraction from MCRD Signatures}

In this research paper, dynamic parameter identifications including mode shapes (Figure 2.4) are considered for plate type reinforced concrete structure. The plate is a $2 \mathrm{D}$ element which its harmonic mode shapes can be identified as two 1D elements in two orthogonal directions. In each direction, an algorithm of the MCRD mode shape extraction can be followed as a beam like structure.

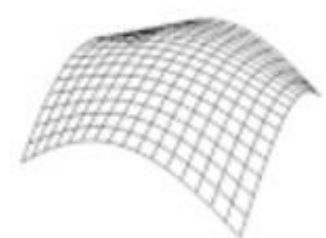

Mode 1

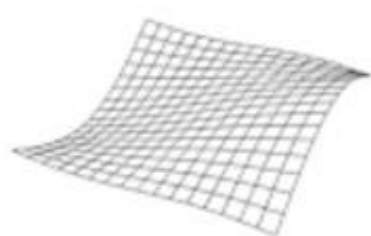

Mode 2

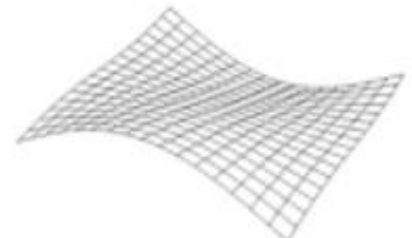

Mode 3

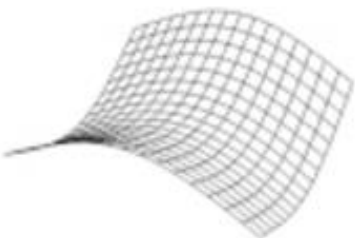

Mode 4

Figure 2.4 2D Mode Shapes for Plate (Li et al., 2015)

The algorithm steps to extract mode shapes for a beam like structure using MCRD is as follow (Elshafey et al., 2011):

1- Identifying a number of modes using Fast Fourier Transform (FFT) as shown in Figure 2.5. The Matlab program for FFT analysis is provided in Appendix B.

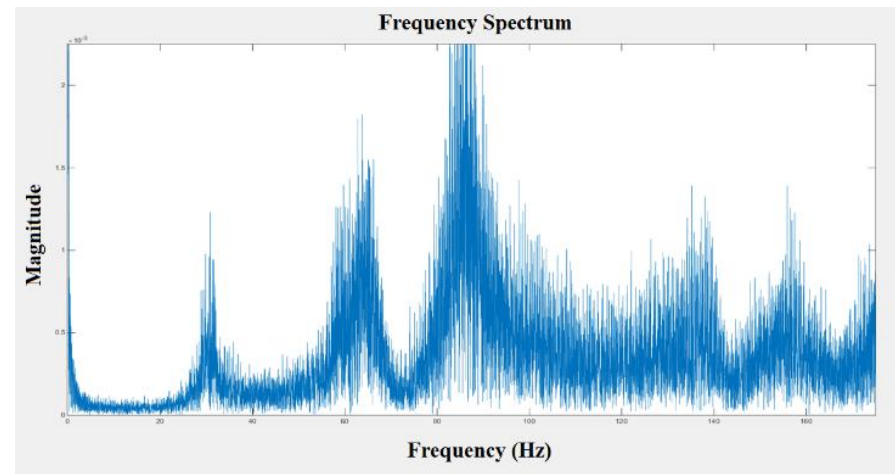

Figure 2.5 Frequency Spectrum Extracted by FFT

Each mode has its own single mode shape and can be found by MCRD. 
2- Using Band pass filter to extract response signals corresponding to each mode.

3- Selecting the leader channel for obtaining the RD signatures. To maximize accuracy, it is better that the leading channel is selected at the point of maximum deflection in the mode shape. This point can be found by trial and error procedure.

4- By using the same triggering time vector segments of the leading channel for all of the channels experimental responses, the simultaneous mechanically coupled non normalized RD signatures for all the channels are numerically obtained. Figure 2.6 shows the RD signatures for four channels of the array $\mathrm{X}$ which are obtained from real experimental responses conducted for this research.
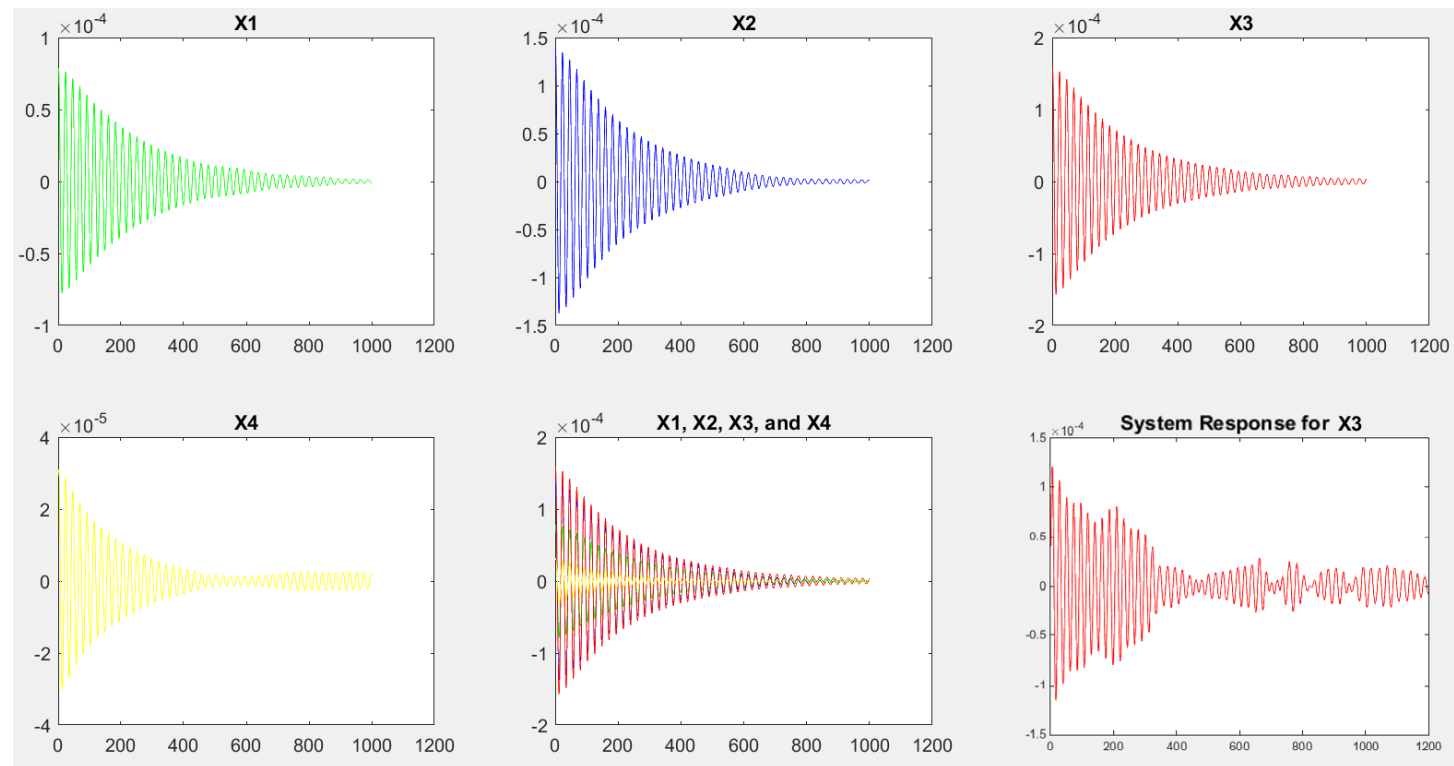

Figure 2.6 Four Simultaneous RD Signatures (RD1, RD2, RD3 and RD4) Obtained by MCRD Technique

5- Taking certain readings from RD signatures of all the channels at same time lag usually time 0 , if chosen other than 0 , it is better to be at local extremum (peak) of the leading channel.

6- Using the maximum reading, normalize the values to unity.

7- At the end, the normalized mode shape is obtained by drawing the normalized values at each node. 


\subsubsection{Damage Localization from Mode Shape}

The accurately extracted mode shape from stationary vibratory responses is an effective tool for damage detection and localization in the structure. In civil engineering, researchers implemented various aspects of mode shape for damage analysis. Methods utilizing modal flexibility changes is found efficient for damage monitoring in offshore platform structure due to insensitivity to mass change (Rubin and Coppolino, 1983). Another method utilizing mode shape curvature changes was proposed by (Pandey et al., 1991) for analyzing a beam. In this method, the magnitude of changes in curvature of the mode shapes would indicate the amount of damage in the structure. (Yam et al., 1996) have found that strain mode shape compared to displacement mode shape is more sensitive to structural local parameter changes. In 1997, Petro.et al. suggested the modal strain energy damage index for damage localization which is the rate of change in strain energy between intact and damaged states of a structure. In 2001, Abdo and Hory investigated numerically the effect in rotation of mode shape for damage localization on a simply supported cantilever steel plates and found it very sensitive indicator of damage. (Elshafey et al., 2013) applied the modified mode shape difference method to explore the influence of significant damage and its location on the flexural mode of vibration in simply supported steel beam. (Morsy et al., 2016) explored the suitability of modified mode shape difference method in detecting and localizing damage in reinforced concrete beam structure.

\subsubsection{Modified Mode Shape Difference Technique}

In this research paper, the method of Modified Mode Shape Difference is applied to reinforced concrete plate structure after obtaining the mode shapes by MCRD technique (Equations 2.43 and 2.44). Since the plate is a 2D element, harmonic mode shapes can be identified as two 1D elements in any two orthogonal directions on the plate. The Modified Mode Shape Difference method is applied to each of two selected orthogonal directions mode shapes in order to locate the induced local damages.

In this method, normalized difference between the modes shapes of damaged and intact state is considered as a virtual displacement at every node. In order to locate damage one has to obtain coordinate of virtually deformed shape (displacements). Virtual deformed shape is configured by 
submitting the virtual displacement for each node to its coordinates at un-deformed structure normal to the beam or plate.

There are other methods which locate damage by mode shape difference based on an absolute difference of mode shapes, squares of absolute difference, a summation of absolute difference, or derivatives. The method using absolute differences are valid under this assumption that zero amplitude points on the mode shape are fixed but due to damage they do not remain fixed and give false peak. To overcome this problem, in the proposed Modified Mode Shape Difference method, mode shapes are normalized to unity for intact and damaged states. After that, their difference is computed and normalized with respect to maximum value (Equations 2.43 to 2.45) (Elshafey et al., 2011). The obtained normalized difference is considered as virtually deformed shape which its irregularity locations address damage.

$$
x_{i}(t)=A_{i} e^{-2 \omega \zeta t} \cos \left(\omega_{i} t-\phi_{i}\right), \quad i=1,2,3 \ldots, N
$$

Where $x_{i}(t)$ is the RD at specific node via its corresponding channel, $A_{i}$ is the amplitude at time $\mathrm{t}=0, \omega_{\mathrm{i}}$ is the natural frequency, $\phi_{\mathrm{i}}$ is the phase angle, and $\zeta$ is the damping ratio.

$$
\lambda_{\mathrm{i}}=\left\{\mathrm{A}_{1}, \mathrm{~A}_{2}, \ldots, \mathrm{A}_{\mathrm{m}}\right\}^{\mathrm{T}}
$$

Where $\lambda_{\mathrm{i}}$ is the ith mode shape.

$$
\Delta \lambda_{\mathrm{i}}=\left\{\mathrm{A}_{1}{ }^{\mathrm{n}}-\mathrm{A}_{1}{ }^{* \mathrm{n}}, \mathrm{A}_{2}{ }^{\mathrm{n}}-\mathrm{A}_{2}{ }^{* \mathrm{n}}, \ldots, \mathrm{A}_{\mathrm{m}}{ }^{\mathrm{n}}-\mathrm{A}_{\mathrm{m}}{ }^{* \mathrm{n}}\right\}
$$

Where $\Delta \lambda_{\mathrm{i}}$ is the normalized modal vector difference for ith mode, $\mathrm{n}$ represents normalized intact state, and $*$ n represents normalized damage state. 


\subsubsection{Effect of Damage on Mode Shape Extremum Location}

According to the uniqueness of the mode shape, the extremum (maximum or minimum) locations are also unique. Due to damage, reduction in stiffness occurs totally at the centroid of damage and the extremum of mode shape shifts toward the damage centroid. Bearing in mind that this conclusion is not always valid. There is a damage which does not cause the shift in extremum of mode shape while the centroid of damage is located at the location of extremum.

\subsection{Mode Shape Extremum Damage Detection (EDD) Technique}

Due to limited numbers of sensors, the plots of obtained mode shapes from MCRD technique at the damage and intact states are not smooth curves. The mode shape plot can be smoothed by drawing best fit curve and the accurate location of the extremum can be extracted from the curve. In this research paper, the EDD technique is performed to justify the location of damage by monitoring the damage is occurred in which quadrant. The EDD technique is cost effective in terms of reducing the number of sensors required for data collection and also reducing the cost of other subsequent appropriate damage detection methods such as radiography, ultrasonic, acoustic emission, etc. 


\subsection{Introduction to Fiber Optic Technology}

In the past few decades, Fiber Optic Sensor (FOS) technology has grown rapidly worldwide. They are emerging for most of infrastructure applications rapidly. FOSs are considered as the primary candidate due to their numerous advantages over other electrical sensors. These types of sensors start playing the main role for research and development scenarios.

\subsubsection{FOS Development in SHM}

Sensor is device which play a role as key element for understanding the structural state and their appropriate and robust selection are essential for the effectiveness of any SHM system. In civil engineering applications, sensors measure the desired parameter which mostly are strain, deflection, and acceleration to provide information required for monitoring and analysis of the damage. In order to select the sensors, depending upon the type of project being monitored, variety of criteria should be considered which include accuracy, sensitivity, reliability, durability, multiplexibility, ease of installation, signal transmission limitation, power resource, safety and cost.

The common conventional sensors technologies for health monitoring in civil engineering applications are: semiconductor strain gauge so called piezo resistor, nanoparticle-based strain gauge, mercury-in-rubber strain gauge, vibrating wire strain gauge, and accelerometer. These conventional sensors are electrical power based and are not immune to electromagnetic fields and require two wire serving as input and output ports. On the other hand, recently advanced Fiber Optic Sensor (FOS) technology available are immune to electromagnetic field and can have several sensors multiplexed at same optical fiber. The size of FOS is smaller compared to other conventional sensor which allows it to be mounted on structure without interfering with physical (mechanical, magnetic, electrical) properties of the structure. The last but not the least advantage is its durability which makes it convenient for long term monitoring (Kin-tak et al., 2001).

The invention of FOS goes back to 1978 when the technical researchers of Delta Rocket project were looking for a replacement instead of mechanical spinning gyros which were used in navigation systems. The replacement required to be more compact, lighter and more sensitive. 
Their research involved the use of equipment available at that time: the very first single-mode fiber, 3-dB coupler which is an optical component, fusion splicer, and multimode optical connector. Their research ended to the invention of Fiber Optical Gyro (the "FOG"). Since 1960 to 1978 , all activities focused on fibre optic were for communication purposes with the goal of smooth and reliable signal transmission. The goal that was difficult to achieve due to environmental perturbations mainly temperature, pressure, strain, and rotation. Due to various environmental perturbations, optical fibres experienced geometrical (size and shape) and optical (refractive index and mode conversion) changes. This became a great hint for researchers. They discovered that such optical changes can be used to measure the environmental parameters such as temperature. As a matter of fact, application of fiber optic as sensors was born.

Further investigations revealed that perturbations by other means physical quantities like temperature, pressure, strain, acceleration and rotation can be converted or encoded into transmitted light optical properties such as amplitude (intensity), phase, frequency, wavelength and polarization. Subsequently, these light properties can be detected by well-designed demodulation or interrogation systems. By technological achievements in mass production of fiber optic cable due to growing demand of implementation of fibre optics in communication systems, fibre optic price significantly decreased (Hong-Nan et al., 2004). Eventually by decrease in price, fiber optic based measurement systems switched from laboratory research to practical engineering applications which effectively encompass following eras: aerospace, composites, chemical products, medicine, concrete and steel structures, and electrical power industry.

\subsubsection{FOS Physical Characteristics}

Optical fibres are identified as dielectric devices in order to confine and guide light. Fiber optic wire has three layers: fiber core, cladding and jacket. Fibre cores and claddings are made up of silica glass. Fiber core has higher refractive index in compared to cladding. The ratio of these two indexes is designed according to Snell's law in order to guarantee the total internal reflection by means of confining light to propagate only along the fibre core and hence minimizing the energy loss of light. The outer layer of fibre optic wire is the plastic jacket. The jacket provides mechanical strength and protects it from damage and/or moisture absorption (Grassino, 2000). As the fibers are relatively fragile materials, special mechanical reinforcing covers are used to protect them from 
harsh environment such as concrete during casting. Unlike metallic wire, FOS is susceptible toward bending, hence extra care should be taken during its handling. The specific FOS fabrication process is provided in detail in Section 3.5.

\subsubsection{FOS Types}

After decades of research, currently, four general types of FOS are developed which due to their advantages over each other can be selected for Non-Destructive Testing (NDT) applications. The first type is Long Gauge FOS which directly measures displacement generally in form of elongation or contraction of an object. As it is bonded to the object in any desired direction, it can measure the change in the path distance between two optical fibre's mirrors placed at the ends. Its size limitation is between $5 \mathrm{~cm}$ to $100 \mathrm{~m}$. It is specific for static monitoring even on non-straight paths. The second type is Fabry-Perot FOS which measures the change in the length of the gap that is exerted by precision cutting at the certain location of the optical fiber length. Same as third type sensor, the Fabry-Perot FOS measures the local point strain of an object but cannot be used in an array. It is specific for dynamic and static local monitoring and can be welded, bonded, or imbedded. The third type is Fiber Bragg Grating (FBG) FOS which has more advantages compared to others. The FBG sensor have been developed to measure strain and/or acceleration locally with high resolution by detecting the longitudinal deflection of the grating (written mirrors). The most beneficial advantage of FBG is multiplexing functionality which several of them can be used in a reliable array for multi-sensor analysis. Multi-sensor analysis is vital to allocate damage. FBG sensor is the most popular type of FOS with high accuracy used in structural applications and successfully used in this experimental research. The fourth type is Brillouin Scattering FOS which is still in the developing stage. This sensor aim to measure static strain profiles along the whole length of the single optical fibre. The gauge length limitation of this sensor is estimated to be from $15 \mathrm{~cm}$ to more than $1000 \mathrm{~m}$. The unique advantage of Brillouin Scattering FOS is that it can provide data from which temperature and mechanical strains can be separated. 


\subsection{Principals of FBG sensors}

\subsubsection{Strain Measurements}

FBG technology has been invented by Hill et al in 1987. A simple FBG system consists of optical fiber with prewritten grating sensors, broadband source (light emission device), coupler and optical spectrum analyzers (OSA). In order to obtain strain measurement from any structure, FBG should bond properly to the structure by means of any of welding, gluing, or embedding methods. Once the load is applied, it causes longitudinal deflection of the grating which also indicates the local strain of the structure at the direction of the sensor. The grating can be written to the fiber by different techniques: holographic interface method and phase mask method (Zhi and Jinping, 2005). The provided gratings for this research experiment are written by phase mask method in Electrical Lab of Ryerson University. In phase mask method, a short segment of fibre is exposed to a pair of intense Ultra-Violet (UV) interference laser beam signals. This procedure converts the short segment of optical fibre core to what is called Bragg grating. The Bragg grating performs fundamentally as a set of wavelength selective mirrors. Phase mask method is shown in Figure 2.7 which shows how to write (make) the grating in the optical fiber for strain and temperature measurements.

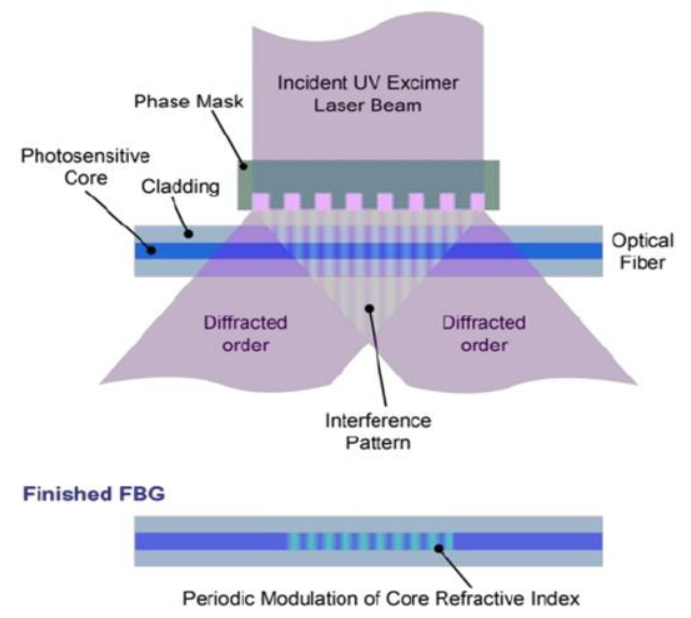

Figure 2.7 Phase Mask Method (Nieuwland et al., 2016) 


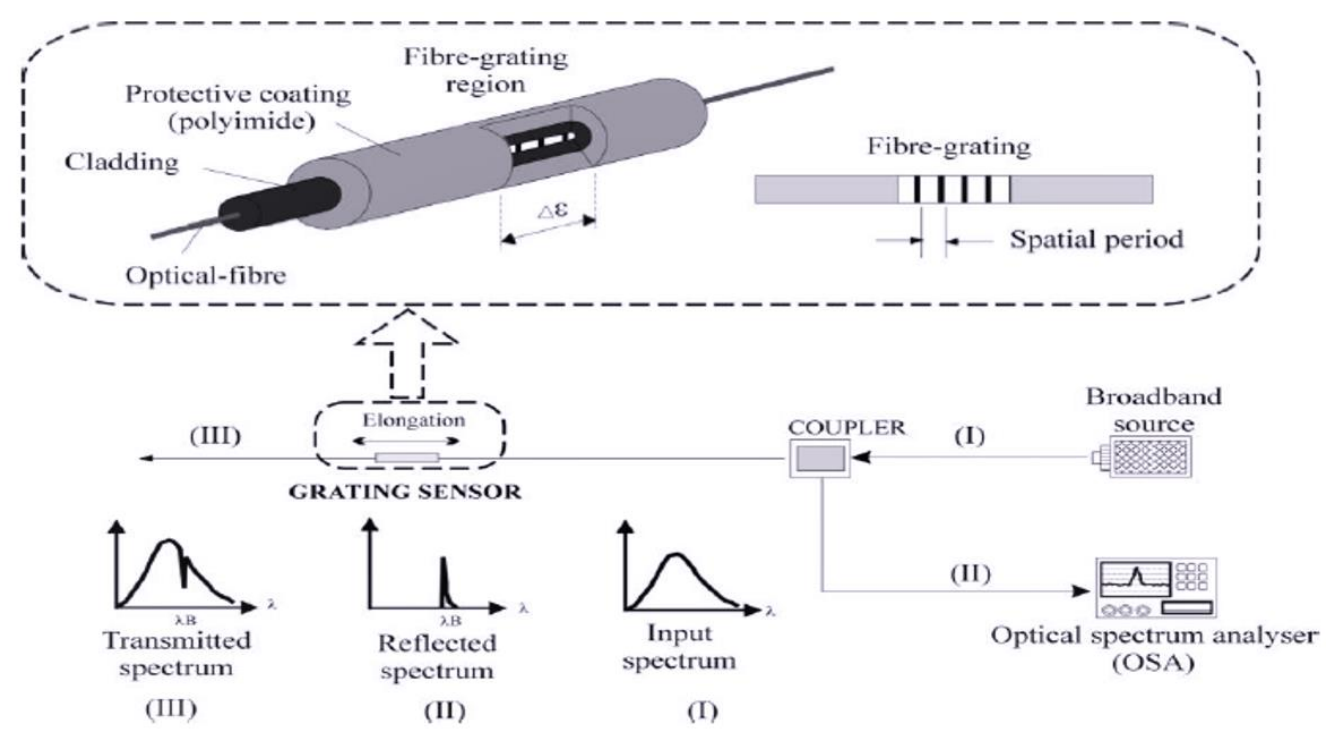

Figure 2.8 FBG Strain Measuring System (Kin-tak et al., 2001)

FBG strain measurement system is illustrated in schematic diagrams (Figure 2.8). In this system, a broad band light source emits light ray that passes the coupler via the fiber optic and reaches to the grating. A part of the ray reflects back from the grating to the coupler and the corresponding wavelength is detected by OSA. The grating length (sensing region) ranges from 5-20 mm. To obtain the mechanical properties of the structure such as strain, the reflected wavelength alteration would be measured from the system. Thus, the FBG acts as a point sensor similar to electrical strain gauges (Allan C.L et al., 2006). Each grating is corresponded by a modulated index of refraction deeply dependent to the precise spacing of the Bragg grating which is so called the pitch. Load and temperature effect on the pitch and the wavelength of the reflected light ray from the grating would be changed. The wavelength of the reflected light signal from the Bragg grating is given in the Equation 2.46.

$$
\lambda=2 \mathrm{n}(\Lambda)
$$

Where $\lambda$ is the Bragg wavelength, $\mathrm{n}$ is the average effective index of refraction of the grating, and $\Lambda$ is the pitch spacing, as shown in Figure 2.9. 


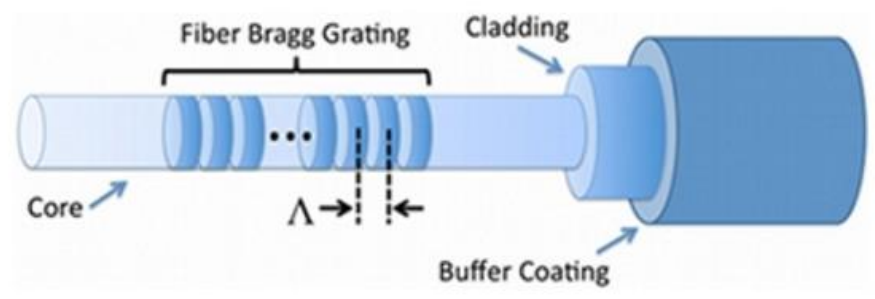

Figure 2.9 Schematic View of FBG Sensor

The shift in wavelength of the reflected light ray can be used to obtain the strain variation of grating location in fiber taking into account the temperature effects, Equation 2.47.

$$
\frac{\Delta \lambda}{\lambda_{\text {in }}}=(\mathrm{GF}) \varepsilon+\beta \Delta \mathrm{T}
$$

Where $\Delta \lambda=\lambda-\lambda_{\text {in }}, \lambda_{\text {in }}$ is the initial Bragg wavelength, GF is the FBG gage factor typically about $0.75-0.82, \varepsilon$ is the strain, $\beta$ is the apparent thermal strain over the temperature change factor, and $\Delta \mathrm{T}$ is the temperature change relative to the temperature at installation. Factor $\beta$ can be calculated from Equation 2.48:

$$
\beta=\beta_{0}+\operatorname{GF}\left(\alpha_{s}-\alpha_{0}\right)
$$

Where $\beta_{0}$ is the thermo-optic response of the FBG at fabrication (typically $1-25 \mu \varepsilon$ per degree Celsius), $\alpha_{\mathrm{s}}$ and $\alpha_{0}$ are the thermal expansion coefficients of the substrate and sensor respectively. By neglecting the effect of deboning and slippages between concrete as host environment and the optical fiber, the strain and temperature of the concrete and the grating can be assumed equivalent. Therefore FBG system can be used appropriately to detect the temperature and strain changes of the concrete structure at the grating location.

In this research study, embedded FBG sensors in arrays have been successfully utilized for vibration based damage detection and localization of reinforced concrete two-way slab. 


\section{CHAPTER THREE \\ EXPERIMENTAL INVESTIGATION PROGRAM}

\subsection{Introduction}

This chapter presents in detail the experimental investigation carried out at the Structural Laboratory of Ryerson University to study the Structural Health Monitoring (SHM) of the concrete plate system. The experimental program consists of the evaluation, casting, and testing of four two-way slab specimens: three High Strength Concrete (HSC) specimens and one Ultra High Performance Fiber Reinforced Concrete (UHP-FRC) specimen.

The main objective of this investigation is to validate Random Decrement (RD) technique as a practical SHM methodology for concrete plates. A better understanding of changes in mechanical properties of concrete plates subjected to ambient vibration and static loading are developed. In the design of the specimens, two variables are considered: namely the steel reinforcement ratio; and the concrete compressive strength.

\subsection{Specimen Materials}

\subsubsection{High Strength Concrete (HSC)}

The ready mixed HSC used for three experimental slabs H.S 0.5, H.S 1, and H.S 2 is Agilia $^{\mathrm{TM}}$ self-consolidating concrete (SCC) innovated and marketed by Innocon under licence from Lafarge SA (Innocon, 2013). The slump test is performed according to ASTM C1611 and the value of slump obtained is $625 \mathrm{~mm}$ in 38 seconds (Figure 3.1). The cylinders and prisms control specimens are tested for compression, splitting tensile, and flexure elastic modulus according to ASTM C39, ASTM C496 and ASTM C78, respectively (Figures 3.2 to 3.4). The results are shown in Table 3.1. The type of fracture tests are type 3, columnar vertical cracking through both ends with no well-formed cones. The failure face of splitting tensile test specimens are both aggregate and cement. 


\subsubsection{Ultra High Performance Fiber Reinforced Concrete (UHP-FRC)}

The UHP-FRC mix used for specimen 4 of UHP-FRC and reinforcement ratio of $1 \%$ is Ductal® innovated and marketed by Lafarge Canada and commercially available in North America (Lafarge, 2015). The mix has target 28-day cylinder compressive strength of $150 \mathrm{MPa}$. The steel fiber volume ratio used is $2 \%$. Identical short steel fibers with the length of $13 \mathrm{~mm}$ and a nominal

diameter of $0.2 \mathrm{~mm}$ are used. The minimum tensile strength and elastic modulus of 2,600 MPa and $205 \mathrm{GPa}$ are specified by the manufacturer of fiber. The cylinders and prisms control specimens are tested for compression, splitting tensile, and flexure elastic modulus according to ASTM C39, ASTM C496 and ASTM C78, respectively. The results are shown in Table 3.1.
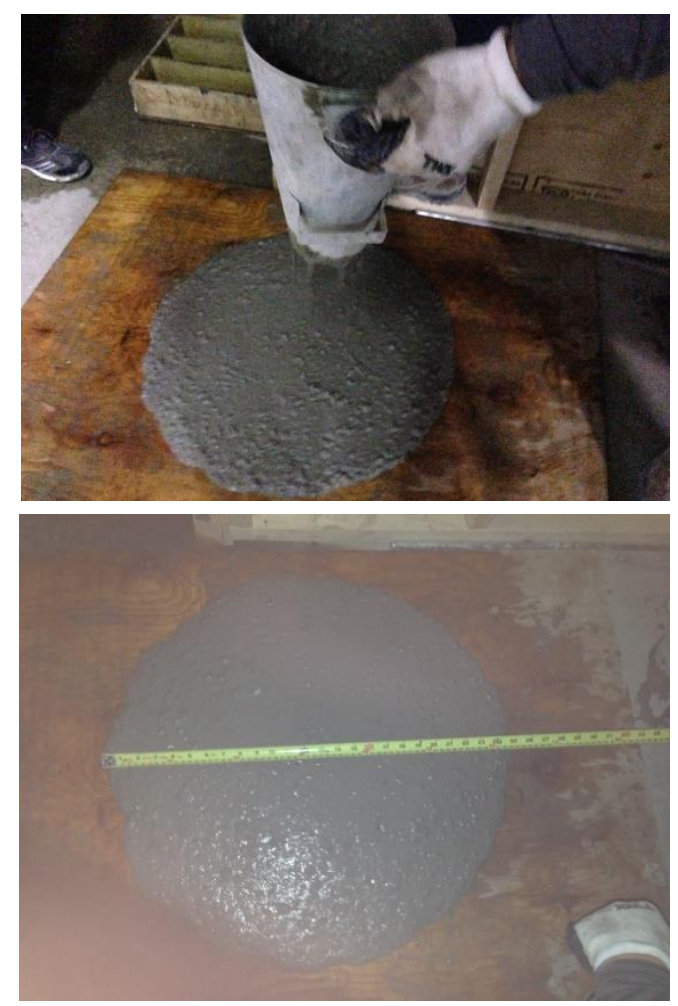

Figure 3.1 Slump Test Views for High Strength SCC Concrete 


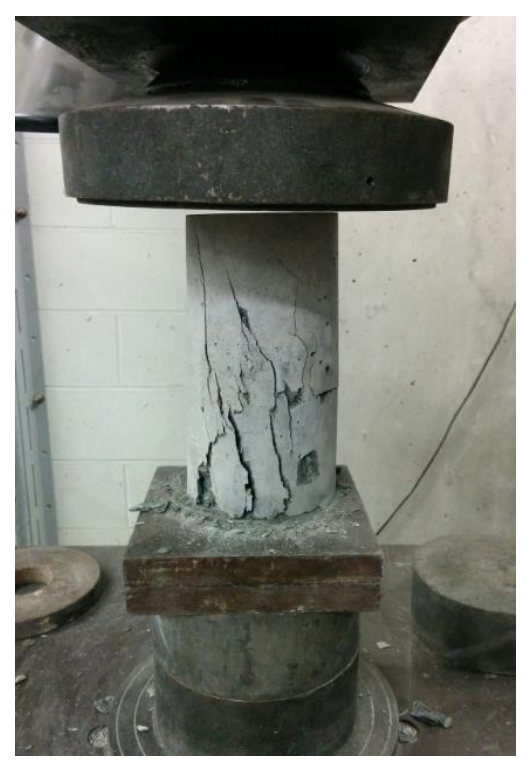

Figure 3.2 Compressive Strength Test of Cylindrical Concrete Specimens

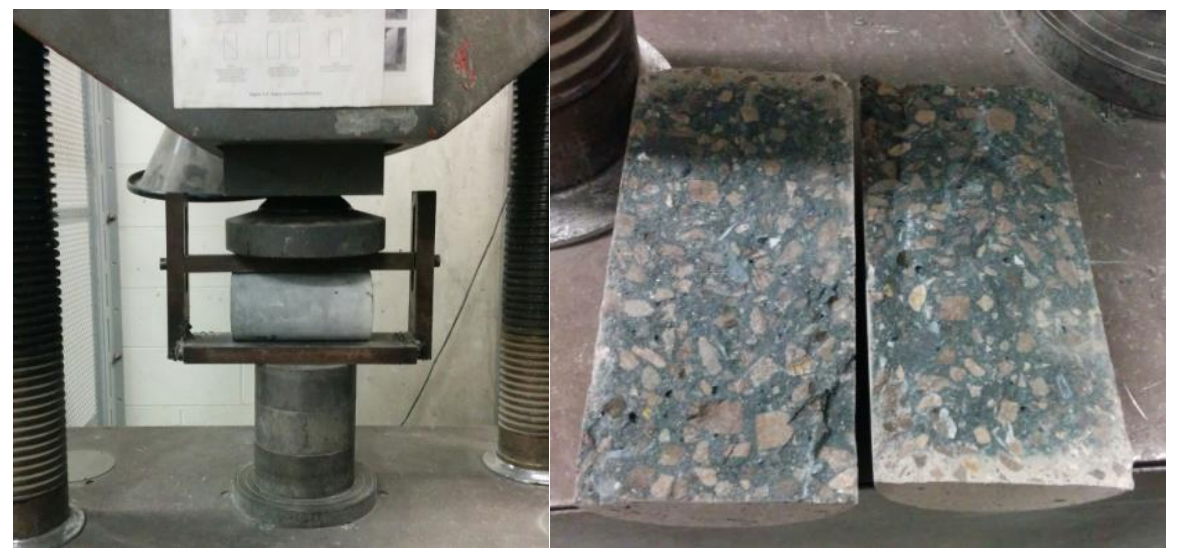

Figure 3.3 Splitting Tensile Strength Test of Cylindrical Concrete Specimens 


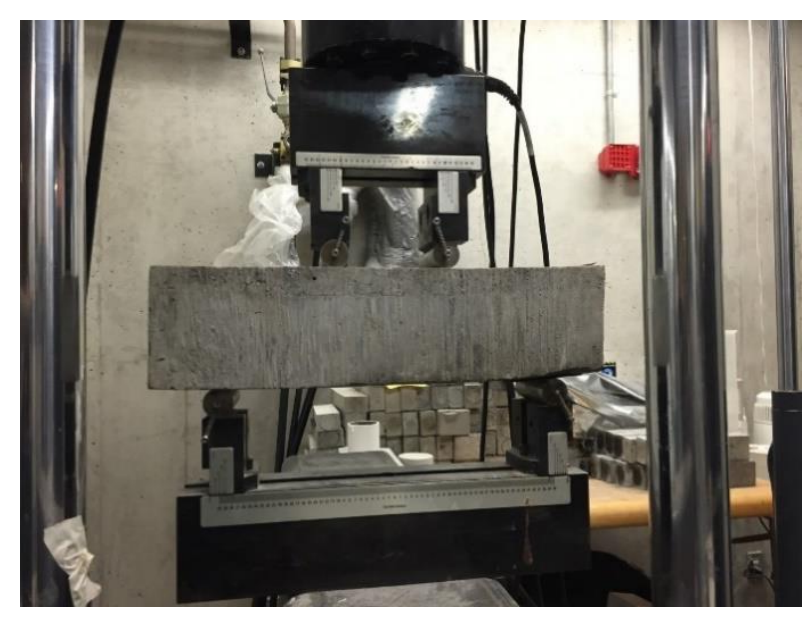

Figure 3.4 Flexural Strength Test of Concrete (Using Simple Beam with Third-Point Loading)

Table 3.1 Properties of HSC and UHP-FRC Materials

\begin{tabular}{|l|l|l|l|l|}
\hline Series No. & Specimen & $\begin{array}{l}\text { Compressive } \\
\text { strength }\left(\mathrm{f}^{\prime}{ }_{\mathrm{c}}\right) \\
\mathrm{MPa}\end{array}$ & $\begin{array}{l}\text { Splitting tensile } \\
\text { strength }\left(\mathrm{f}_{\mathrm{tsp}}\right)\end{array}$ & $\begin{array}{l}\text { Elastic modulus } \\
\left(\mathrm{E}_{0}\right)\end{array}$ \\
\hline 1 & H.S 0.5 & 68.0 & 4.50 & $\mathrm{MPa}$ \\
\hline 2 & H.S 1 & 71.0 & 4.73 & 29.06 \\
\hline 3 & H.S 2 & 78.5 & 5.03 & 30.26 \\
\hline 4 & UHP-FRC 1 & 162.4 & 11.10 & 45.80 \\
\hline
\end{tabular}

\subsubsection{Steel Reinforcement}

The reinforcing bars are consist of Grade 400 steel conforming to CSA standard with an actual tested yield strength of $490 \mathrm{MPa}$. 


\subsection{Slab Design Properties}

A total of four slab specimen with identical dimensions of $1950 \times 1950 \times 100 \mathrm{~mm}$ are constructed. All the slabs are reinforced with conventional steel rebar. Two parameters are considered: namely the steel reinforcement ratio; and the concrete compressive strength. The dimension and reinforcement details of specimens H.S 0.5, H.S 1, H.S 2 and UHP-FRC 1 are shown in Figure 3.5, Tables 3.2 and 3.3.

Table 3.2 Reinforcement Properties of all Tested Specimens

\begin{tabular}{|l|l|l|l|l|l|l|l|}
\hline Series No. & Specimen & $\begin{array}{l}\text { Steel } \\
\text { Rebar } \\
\text { Ratio } \\
(\boldsymbol{\rho})\end{array}$ & $\begin{array}{l}\text { Steel } \\
\text { Fiber } \\
\text { Content }\end{array}$ & $\begin{array}{l}\text { Bar } \\
\text { Size } \\
(\text { Top) }\end{array}$ & $\begin{array}{l}\text { Bar } \\
\text { Size } \\
\text { (Bottom) }\end{array}$ & $\begin{array}{l}\text { Top } \\
\text { Reinforcement } \\
\text { Spacing } \\
\mathrm{mm}\end{array}$ & $\begin{array}{l}\text { Bottom } \\
\text { Reinforcement } \\
\text { Spacing }\end{array}$ \\
\hline 1 & H.S 0.5 & 0.5 & 0 & $10 \mathrm{M}$ & $10 \mathrm{M}$ & 210 & $\mathrm{~mm}$ \\
\hline 2 & H.S 1 & 1 & 0 & $10 \mathrm{M}$ & $10 \mathrm{M}$ & 210 & 100 \\
\hline 3 & H.S 2 & 2 & 0 & $10 \mathrm{M}$ & $15 \mathrm{M}$ & 210 & 100 \\
\hline 4 & UHP-FRC 1 & 1 & 2 & $10 \mathrm{M}$ & $10 \mathrm{M}$ & 100 & 100 \\
\hline
\end{tabular}

Table 3.3 Reinforcement Properties of all Tested Specimens (cont.)

\begin{tabular}{|c|c|c|c|c|}
\hline Series No. & Specimen & $\begin{array}{l}\text { Effective } \\
\text { Top Reinforcement } \\
\text { Area } \\
\qquad \mathrm{mm}^{2}\end{array}$ & $\begin{array}{l}\text { Effective } \\
\text { Bottom } \\
\text { Reinforcement } \\
\text { Area } \quad \mathrm{mm}^{2}\end{array}$ & $\begin{array}{l}\text { Reinforcement } \\
\text { Effective } \\
\text { Depth } \\
\\
\quad \mathrm{mm}\end{array}$ \\
\hline 1 & H.S 0.5 & 1000 & 1000 & 74.5 \\
\hline 2 & H.S 1 & 1000 & 2000 & 74.5 \\
\hline 3 & H.S 2 & 1000 & 4000 & 72 \\
\hline 4 & UHP-FRC 1 & 2000 & 2000 & 74.5 \\
\hline
\end{tabular}




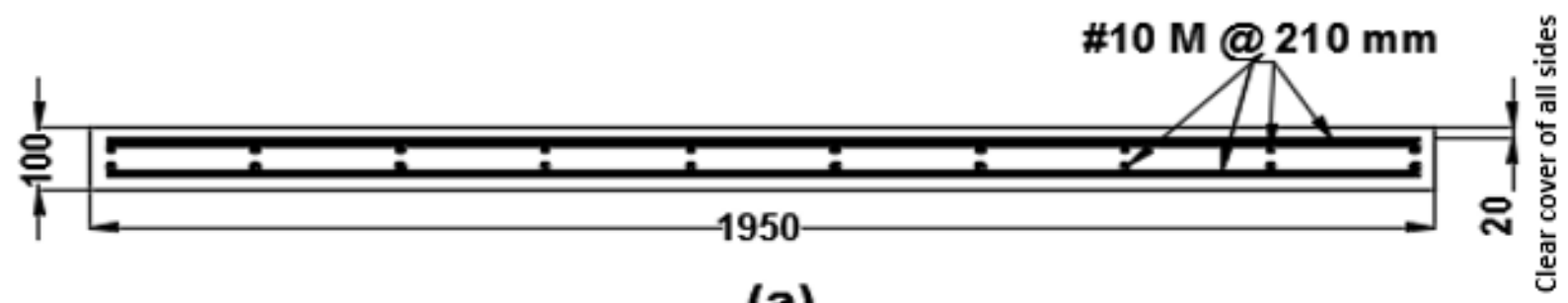

(a)

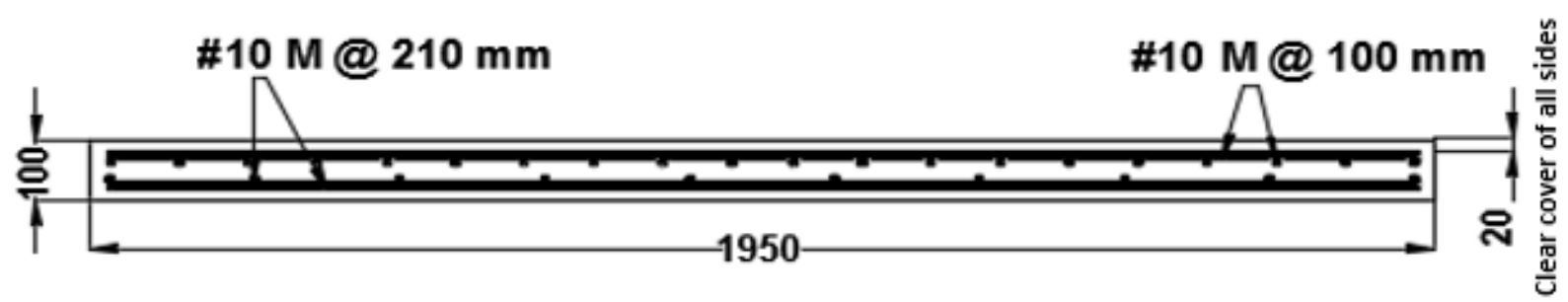

(b)

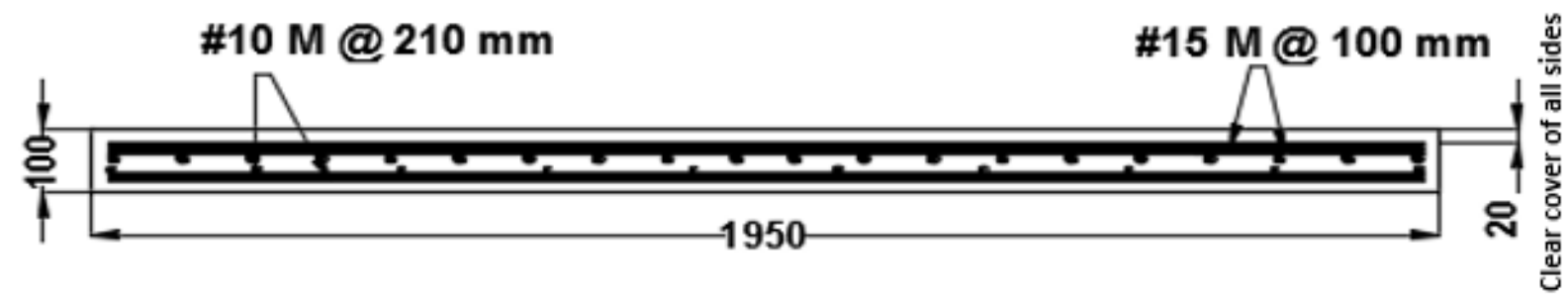

(c)

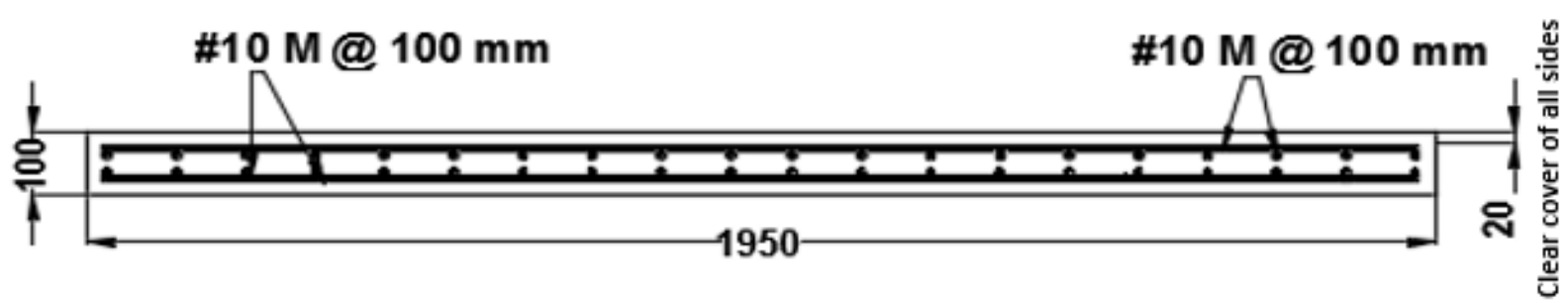

(d)

Figure 3.5 Cross Section View of Reinforced Specimens: a) H.S 0.5, b) H.S 1, c) H.S 2 and d) UHP-FRC 1 


\subsection{Slab Design Evaluation}

\subsubsection{Ultimate Punching Shear Strength of Two-way Slab}

For evaluating the failure modes of the slabs, the ultimate punching shear strength has to be estimated. In American ACI 318-14 and Canadian CSA A23.3-14, the square root of concrete compressive strength is used to estimate punching failure resistance of concretes of relatively low compressive strength, varying from 14 to $40 \mathrm{MPa}$. The effect of reinforcement ratio is also neglected. As stated in research conducted by (Marzouk and Hussein, 1991) on the reinforced HSC two-way slabs, using the square root of concrete compressive strength appears to overestimate the punching failure resistance. Using cubic root of concrete compressive strength was recommended for estimating the punching resistance of HSC. Due to the above compelling remarks the new CSA A23.3-14 put the limit that the square root of concrete compressive strength shall not exceed 8 MPa for evaluating punching resistance of HSC. Furthermore, for estimating punching failure resistance of UHP-FRC, the contribution of fiber should be considered. The punching shear failure model for UHP-FRC was adopted by (Moreillon et al., 2013) based on critical shear crack theory developed by (Muttoni, 2008). The ultimate punching shear resistance of slab specimens are computed in Appendix A.1.2 for HSC and A.2.2 for UHP-FRC 1 and tabulated in Table 3.5.

\subsubsection{Ultimate Flexural Strength of Two-way Slab}

For evaluating the modes of failure of the slabs, the ultimate flexural strength of two-way slab has to be estimated. The slab ultimate flexural resistance is determined using the principal of virtual work method. In virtual work method, a yield line pattern has to be postulated for the slab in order to find the ultimate flexural resistance. The slab ultimate flexural resistance is computed in term of ultimate moment of resistance per unit length at a yield line. The ultimate moment of resistance is obtained by considering the slab a one-dimensional flexural member (continuous beam) at the yield line. 


\subsubsection{Yield Line Analysis}

For evaluating the ultimate flexural resistance of slabs, the yield line theorem is used. Twoway slab systems are statically indeterminate, to achieve reasonable results, inelastic analysis (yield line analysis) is conducted. The advantage of 'Yield line analysis' is that instead of conducting a two-dimensional flexural member (plate or slab) analysis, a one-dimensional flexural member (continuous beam) analysis is performed. To assume possible yield line pattern, deformation compatibility of adjacent segments must be considered. The following are the guidelines for assuming possible yield lines pattern (Gopal, 2012):

i) Yield lines are generally straight lines forming the axes of rotation due to yield deformation of the segment.

ii) In general, the axes of rotation lie along the lines of support (the support line may be a real hinge, or a plastic hinge).

iii) A Yield line passes through the intersection of the axes of the rotation of adjacent slab segment.

Figure 3.6 illustrates the yield line pattern for the corner edge simply supported slab specimens.

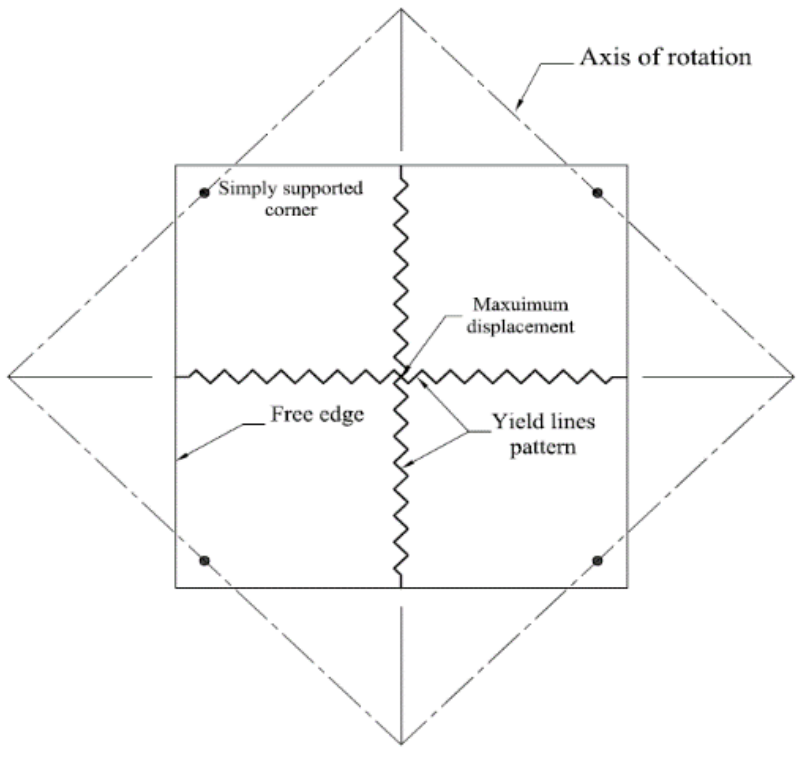

Figure 3.6 Yield line Pattern for Corner Edge Simply Supported Slab Specimens (Othman, 2016) 


\subsubsection{Principal of Virtual Work}

In order to find the slab ultimate flexural resistance load, a yield line pattern is postulated for the slab which is substantial for using the virtual work method. The principal of the virtual work is stated as: "if a rigid body that is in equilibrium statically under a system of forces is given a virtual displacement, the sum of the virtual work done by the forces is zero" (Park and Gamble, 2000). The precision of this method is highly dependent on the magnitude of arbitrary virtual displacement which should be small. The yield line segments are assumed as rigid body where the deflection occurs. For ease of calculation, a point on the slab is selected and given a small displacement $\delta$ in the direction of the load.

Then the displacement function corresponding to the dimension of slab is obtained as $\delta(\mathrm{x}, \mathrm{y})$. The external work done by a uniformly distributed ultimate load per unit area $\mathrm{w}_{\mathrm{u}}$ along the yield lines, Equation 3.1 is (Brzev and Pao, 2013):

$$
\text { External Work }=\iint \mathrm{w}_{\mathrm{u}} \delta(\mathrm{x}, \mathrm{y}) \mathrm{dx} \mathrm{dy}=\sum \mathrm{P} . \delta
$$

Where $\mathrm{P}$ is the total load on a segment of the yield line and $\delta$ is the displacement of its centroid in the direction of load.

Due to the fact that the actions on each side of yield line are equal and opposite, the works which are done by torsional moments and shear forces are zero. Only the ultimate bending moment contributes to internal work. The internal work is done by the ultimate flexural moment of resistance on the yield line segment, Equation 3.2 (Brzev and Pao, 2013):

$$
\text { Internal Work }=-\int m_{u n} \theta_{n} l_{s} d \theta=-\sum m_{u n} \theta_{n} l_{s}
$$

Where $m_{u n}$ is the ultimate flexural moment of resistance per unit length at a yield line, $1_{s}$ is the length, and $\theta_{\mathrm{n}}$ is the relative rotation of yield line.

Therefore, the general simple form of virtual work equation will retrieve as, Equation 3.3: 


$$
0=\sum \text { P. } \delta-\sum \mathrm{m}_{\mathrm{un}} \theta_{\mathrm{n}} \mathrm{l}_{\mathrm{s}}
$$

For the experimental slab specimens simply supported at corners (Figure 3.7), the principal of virtual work is as follows (Equations 3.4 to 3.8 ):
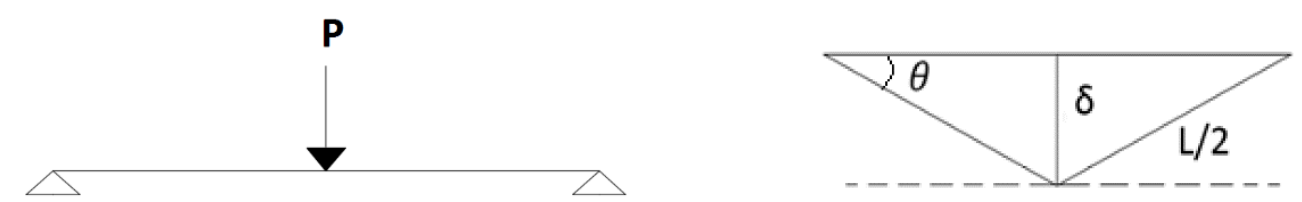

Figure 3.7 Schematic Diagram of Load and Deflection for Slab Specimens

$$
\text { External Work }=\mathrm{P} * \delta
$$

Where $\mathrm{P}$ is the total load on a segment of the yield line and $\delta$ is the displacement of its centroid in the direction of load:

$$
\text { Internal Work }=\sum \mathrm{m}_{\mathrm{un}} \theta_{\mathrm{n}} \mathrm{l}_{\mathrm{s}}
$$

Where $m_{u n}$ is the ultimate flexural moment of resistance per unit length at a yield line, $1_{\mathrm{s}}$ is the length, and $\theta_{\mathrm{n}}$ is the relative rotation of yield line.

$$
\theta=\frac{\delta}{\mathrm{L} / 2}
$$

Because $\delta$ is relatively small $\tan \theta=\theta$

$$
\sum \mathrm{m}_{\mathrm{un}} \theta_{\mathrm{n}} \mathrm{l}_{\mathrm{s}}=4 * \mathrm{M}_{\mathrm{u}} * \frac{\delta}{\frac{\mathrm{L}}{2}} * \frac{\mathrm{L}}{2}
$$




$$
\begin{aligned}
& \mathrm{P}_{\mathrm{u}} * \delta=4 * \mathrm{M}_{\mathrm{u}} * \delta \\
& \mathrm{P}_{\mathrm{u}}=4 \mathrm{M}_{\mathrm{u}}
\end{aligned}
$$

The slab ultimate flexural resistance load is computed in terms of the ultimate flexural moment of resistance (Equation 3.9). The ultimate flexural moment of resistance is obtained by considering the two-way slab a one-dimensional member continuous beam at the yield line.

\subsubsection{Ultimate Resistant Moment of a Flexural One-Dimensional Member Continuous Beam}

As per American code ACI 318-14 and Canadian code CSA A23.3-14, the ultimate state for flexural member occurs after cracking and yielding states of reinforced concrete. The stress in tension steel remains constant after its yielding, while strain continuous to increase until the compressive stress at the extreme fiber reaches the maximum value. The reinforced concrete demonstrates nonlinear behaviour at high compressive strains. The Whitney stress block (the most widely used model in American code) is used to approximate compressive stress distribution as a rectangular distribution for concrete beam cross section (Figure 3.8).

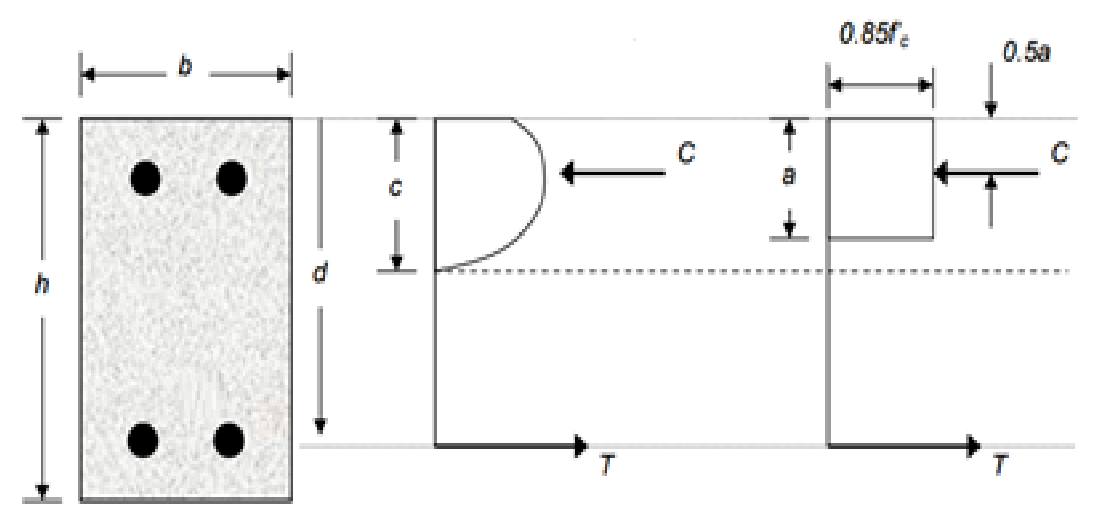

Figure 3.8 Whitney Stress Block Representation 
The ultimate moment resistance of the slab specimens at yield line as a continuous beam are calculated as in Appendix A.1.1 for HSC specimens and A.2.1 for UHP-FRC 1 specimen. Bearing in mind the large ductility and compressive strength of UHP-FRC due to steel fiber content and dense packing Nano technology for matrix, the equivalent compressive and tensile stress blocks values can be specified. Then for flexural analysis, the principles of force equilibrium and strain compatibility is used. As research conducted by (Wasan and Tayfur, 2013), the method similar to ACI ultimate strength design method is implemented in which the tensile strength computed for the fibrous concrete is added to that contributed by the reinforcing bars to obtain the ultimate moment resistance of UHP-FRC beam. The yield line analysis and the principal of virtual work are then used to determine the ultimate flexural load of each slab specimen from the ultimate moment of resistance as a continuous beam. The predicted results for the ultimate moment and the ultimate load of the slab specimens are depicted in Table 3.4.

Table 3.4 The Predicted Results for Ultimate Moment and Ultimate Load of Slab Specimens

\begin{tabular}{|l|l|l|l|}
\hline Series No. & Specimen & $\begin{array}{l}\text { Ultimate Moment of } \\
\text { Resistance per Unit } \\
\text { Length of Yield Line } \\
\mathrm{kN} \cdot \mathrm{m} / \mathrm{m}\end{array}$ & \\
\hline 1 & H.S 0.5 & 29.00 & $\mathrm{kN}$ \\
\hline 2 & H.S 1 & 56.50 & 226.00 \\
\hline 3 & H.S 2 & 103.78 & 415.12 \\
\hline 4 & UHP-FRC 1 & 81.82 & 327.00 \\
\hline
\end{tabular}




\subsubsection{Modes of Failure Prediction}

There is a strong correlation between the shear and flexural behaviors of the slab-column connection region. The correlation is defined in terms of $\varphi_{0}$, which is the ratio of ultimate punching strength $\left(\mathrm{V}_{\mathrm{u}}\right)$ to ultimate flexural strength $\left(\mathrm{P}_{\mathrm{u}}\right)$. It identifies the failure mode into the punching failure for $\varphi_{0} \leq 1$, and flexure failure for $\varphi_{0}>1$ (Marzouk and Hussein, 1991). Primarily before starting the experimental phase, all the two-way slabs ultimate punching shear strength and ultimate flexural strength are computed. The modes of failure for all the slabs except H.S 2 are predicted as the flexure failure and the records are given in Table 3.5.

Table 3.5 Failure Modes Prediction for All Slab Specimens

\begin{tabular}{|c|c|c|c|c|c|}
\hline Series No. & Specimen & $\begin{array}{l}\text { Reinforcement } \\
\text { Ratio } \\
\end{array}$ & k & $\begin{array}{l}\text { V ultimate } \\
(400 \times 400 \\
\text { mm column }) \\
\text { kN }\end{array}$ & $\begin{array}{l}\varphi_{0}\left(\mathrm{~V}_{\mathrm{u}} / \mathrm{P}_{\mathrm{u}}\right) \\
(400 \times 400 \\
\mathrm{mm} \text { Column })\end{array}$ \\
\hline 1 & H.S 0.5 & 0.5 & 116.00 & 348.20 & $\begin{array}{l}3.00>1 \\
\text { Flexure } \\
\text { failure }\end{array}$ \\
\hline 2 & H.S 1 & 1 & 226.00 & 348.20 & $\begin{array}{l}1.54>1 \\
\text { Flexure } \\
\text { failure }\end{array}$ \\
\hline 3 & H.S 2 & 2 & 415.12 & 311.62 & $\begin{array}{l}0.75<1 \\
\text { Punching } \\
\text { shear failure }\end{array}$ \\
\hline 4 & UHP-FRC 1 & 1 & 327.00 & 397.43 & $\begin{array}{l}1.22>1 \\
\text { Flexure } \\
\text { failure }\end{array}$ \\
\hline
\end{tabular}




\subsection{Fabrication and Assembling of FBG Sensors}

One of the common Fiber Optic Sensors used in Structural Health Monitoring applications is Fiber Bragg Grating (FBG) sensor. The length and wavelength of gratings vary for different applications. For sensing mechanical properties of concrete structures, it is recommended that the gauge length of the FBG sensors to be at least two to three times longer than the size of the coarse aggregate in the concrete mixture and the sensor wavelength to be in the range of 1520-1550 nm. There is a restriction in the wavelength design of the sensors using in one array. The wavelengths must vary within certain limit amount in order to sort out by the wavelength detection system.

For the production purpose of the FBG sensors to be implemented in the experimental program, the gratings of eight FBG sensors are fabricated at Ryerson University Electrical Lab. The phase mask method using the Ultra-Violet (UV) interference laser beam is implemented to write the gratings. Because the bare fabricated FBGs are very fragile, they are not suitable to use directly in an aggressive environment like concrete. The certain procedure is followed for the assembling of eight FBG sensors. The sensors are assembled in two arrays of four sensors each in the Electrical department of Ryerson University under the supervision of technical staffs.

\subsubsection{List of Materials Used for Manufacturing of FBG}

- Polymer tubing: polymer circular tubing sleeve with $254 \mu \mathrm{m}(0.1$ ') $) \mathrm{ID} \times 1.5875 \mathrm{~mm}(0.6$ ' ') OD

- Stainless steel tubing type A: 304 Hypodermic circular 14.5 Gauge tubing with $1.6002 \mathrm{~mm}$ ( .063 ') $\mathrm{ID} \times 1.9812 \mathrm{~mm}\left(.078^{\prime \prime}\right) \mathrm{OD} \times .1905 \mathrm{~mm}(.0075$ '’) Wall thickness

- Stainless steel tubing type B: 316 Hypodermic thin wall tubing 10 Gauge with $2.8956 \mathrm{~mm}$ (.114' ') ID $\times 3.4036 \mathrm{~mm}\left(.134{ }^{\prime \prime}\right) \mathrm{OD} \times .254 \mathrm{~mm}\left(.01{ }^{\prime \prime}\right)$ Wall thickness

- Epoxy: 353ND thermosetting polymer with Part A, epoxy resin and Part B, polyamine hardener

- Quick setting steel reinforced Metal/Plastic epoxy

- Steel springs: Material size $0.4 \mathrm{~mm}$, Free length of $30 \mathrm{~mm}$, Coil diameter of $4 \mathrm{~mm}$, and Pitch of $2 \mathrm{~mm}$

- Cord storage reel with stand:150 ft. 16/3 cord capacity

- FBG Fiber Bragg Grating: Electrical technician prepared all grating prior to the packaging process. 


\subsubsection{List of Equipment for FBG Preparation}

- OSA - optical spectrum analyzer

- Fusing splicing machine

- Thermal heater

- Light Source

- Circulator

\subsubsection{Preparation for Assembling}

1. The polymer tubes are cut in $110 \mathrm{~mm}$ sized lengths with a sharp knife to obtain the gauge length of $100 \mathrm{~mm}$ appropriate for the concrete strain measurement. Two bore holes are drilled with a diameter of $0.018 "(0.457 \mathrm{~mm})$ at a distance $5 \mathrm{~mm}$ from the end of each polymer tube, as shown in Figure 3.9. The polymer tubes are honed by sliding a steel string with the same size as the fiber diameter to guarantee that $250 \mu \mathrm{m}$ fiber would slide through safely.

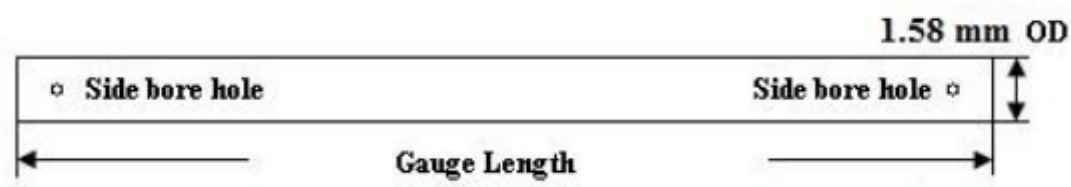

Figure 3.9 Polymer Tube Preparation

2. For each sensor a couple of type A stainless steel tubes are cut into $30 \mathrm{~mm}$ pieces and one stainless steel tube of type B is cut into $70 \mathrm{~mm}$ piece. One extra of type B stainless steel tube is cut into $70 \mathrm{~mm}$ piece for each array of the sensors. Both ends of the steel tubes are grounded smoothly and deburred in the mechanical lab to guarantee the polymer tube or yellow jacket sliding through smoothly.

3. For calibration purpose, a hole is drilled through one side of the stainless steel tube type A with $0.99 \mathrm{~mm}$ steel drill bit. The tubes are fixed on the table to avoid movement. 
4. Part $\mathrm{A}$ and part $\mathrm{B}$ epoxies are mixed by the ratio of $9: 1$ and stored it in the fridge to delay the hardening time and avoid it to be spoiled. It spoils within 2 hours if kept out of the freezer. The mixing procedure is done with proper equipment in Ryerson Chemical lab.

5. The thermal heater plate is set to $40^{\circ} \mathrm{C}$ and a thermocouple was fixed on it using the heat resistant tape to monitor the proper temperature.

\subsubsection{FBG Polymer Sensor Assembling}

1. The fiber coating is stripped out at both end sides for $4 \mathrm{~mm}$, aiming at two polymer tube side bore holes. The FBG pigtail is inserted gently through the polymer tube; the FBG is located at the polymer tube center; as shown in Figure 3.10.

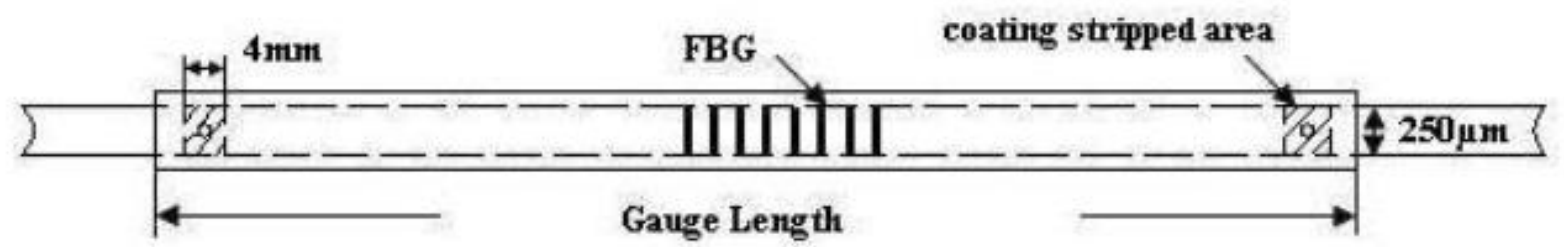

Figure 3.10 FBG and Epoxy Bonding Location at the Polymer Tube

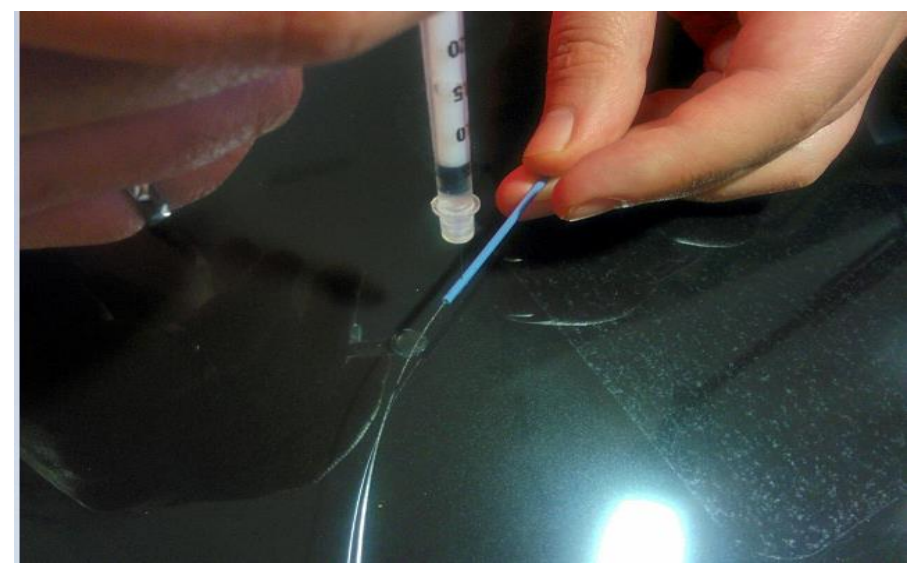

Figure 3.11 Epoxy Injection

2. A syringe is filled with epoxy mixture. The epoxy drops are injected gently into the polymer tube side bore holes by using a syringe or plunging device (Figure 3.11), and then placed on the heater for 2 hours in $80^{\circ} \mathrm{C}$ for curing (Figure 3.12) . 


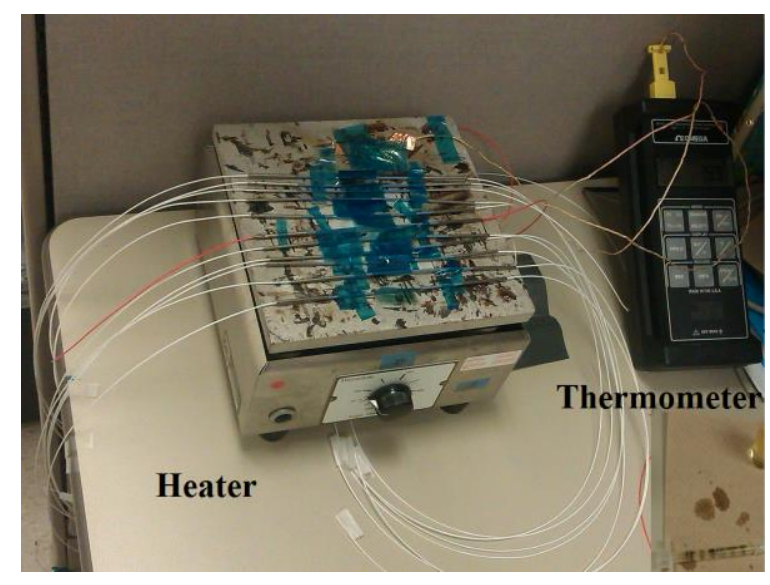

Figure 3.12 Curing Epoxy

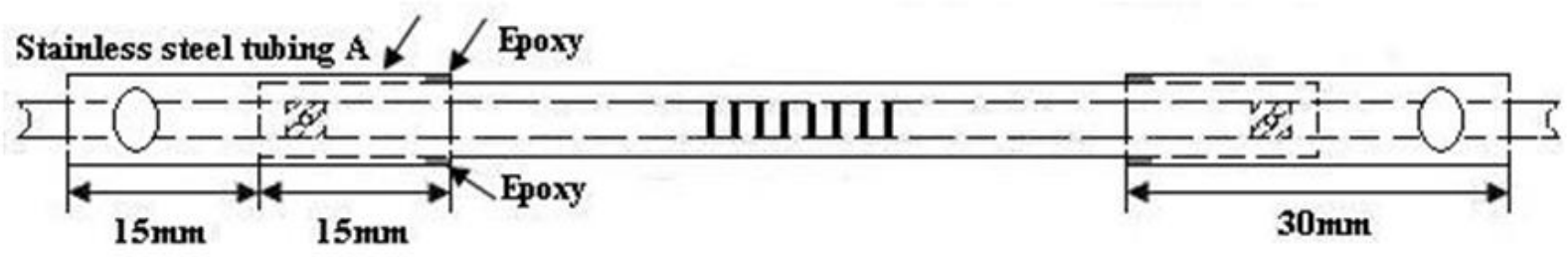

Figure 3.13 Bonded Stainless Steel Tubing with Polymer Tube (Pu, 2010)

3. The stainless steel tube type $\mathrm{A}$ is bonded to the polymer tube by epoxy; the fiber pigtail is covered with $900 \mu \mathrm{m}$ white jacket and bonded to the end of stainless steel tube type A by injecting epoxy through the tube hole, and the bonds are cured by the heater for 2 hours at $80^{\circ} \mathrm{C}$, as shown in Figure 3.13.

4. The Fiber pigtail is worn first with the bullet proof vest Teflon material (aramid fiber) and then with $3 \mathrm{~mm}$ patchcord yellow jacket.

5. The length of $40 \mathrm{~mm}$ yellow jacket is slid over the polymer tube, the space created is taken with a splicing protection sleeve. The stainless steel tube type B (Figure 3.17) is pulled over the $3 \mathrm{~mm}$ yellow jacket buffer. $45 \mathrm{~mm}$ fiber splicing space is vacant for the fusing splicing machine operation. A new fiber optic patchcord is prepared by the stripper to fit the cleaver and splicing machine. The fiber ends are uncoated by acid and cleaved precisely as shown in Figure 3.14. The fiber ends are spliced with control loss less than .04 decibels (dB) (Figure 3.15). The protection sleeve is pulled gently over the spliced portion and thermally shrunk by the heating device on the splicing machine. Protection sleeve protects the fiber joint from the moisture or other 
environmental hazards (the joints are not as flexible as fiber are). $40 \mathrm{~mm}$ of the yellow jacket is removed back to cover the bare white jacket. The stainless steel tube type B is moved to cover the protection sleeve area symmetrically. The shrinkage rubber tubes are applied to cover all the connections as in Figure 3.16. The view of the FBG strain sensors after initial packaging is shown in Figure 3.17.
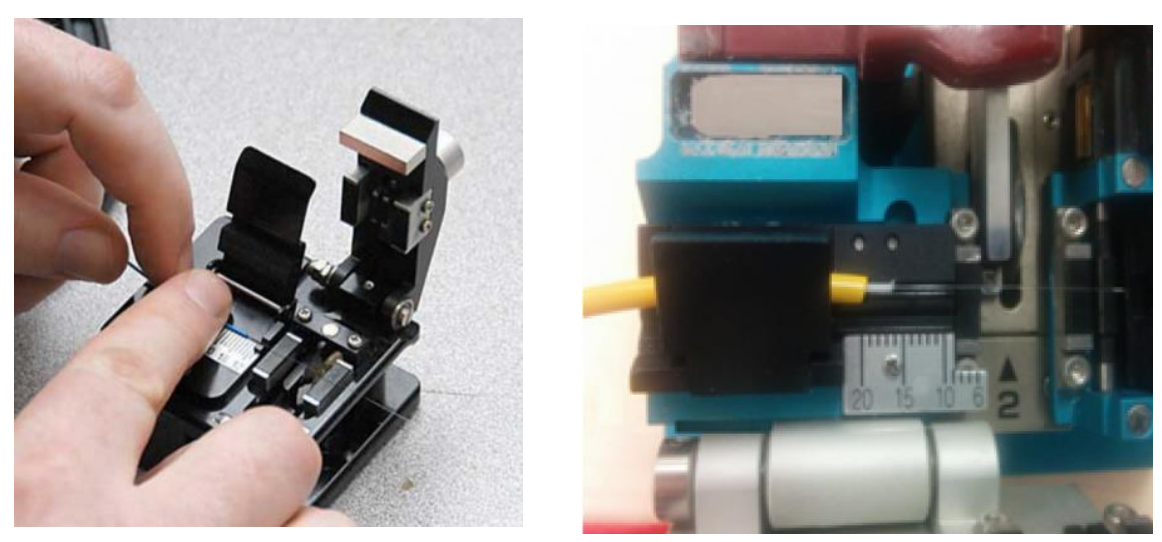

Figure 3.14 Cleaver the Precision Cutting Machine for Fibers
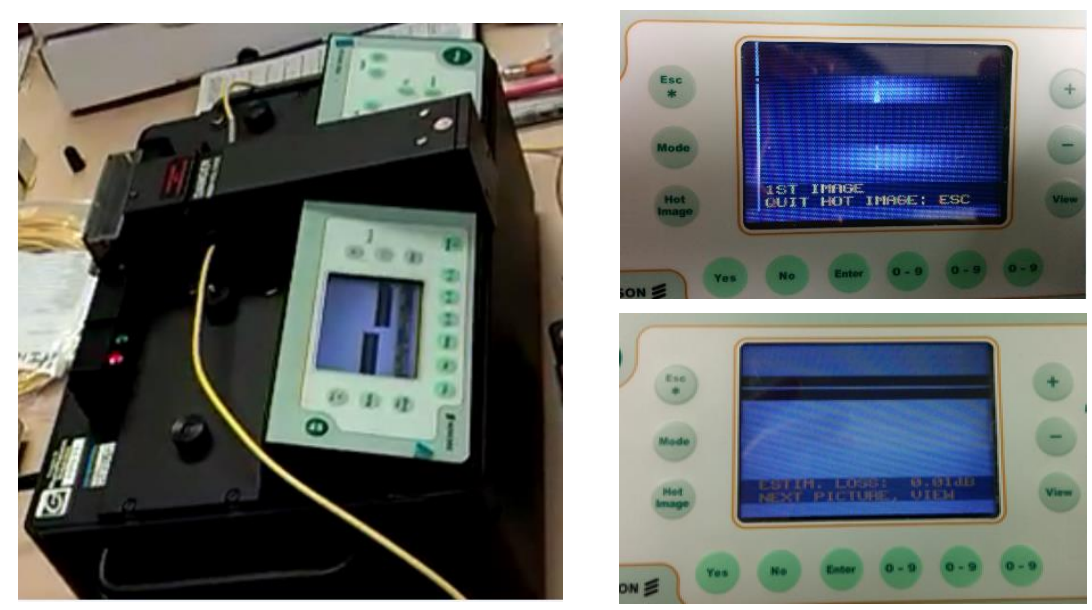

Figure 3.15 Splicing Machine and Splice Loss Control Monitoring Views

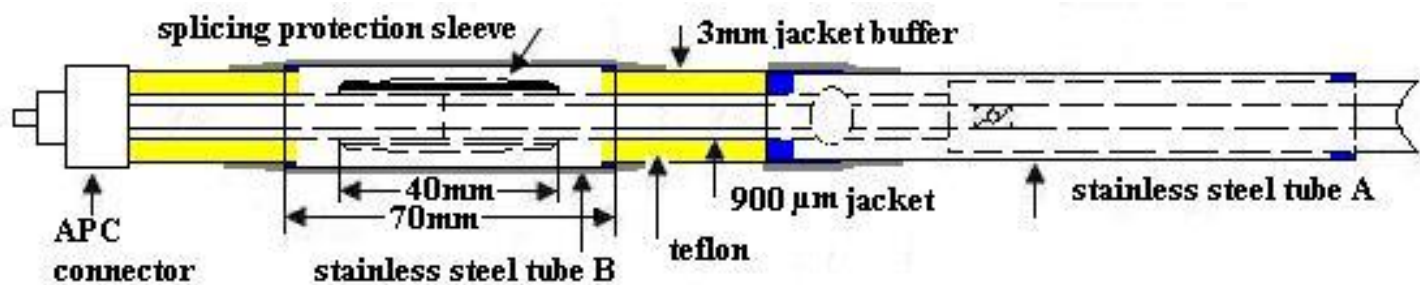

Wr shrinkage rubber tube a epoxy bonding

Figure 3.16 Fiber Splicing Spot (Pu, 2010) 


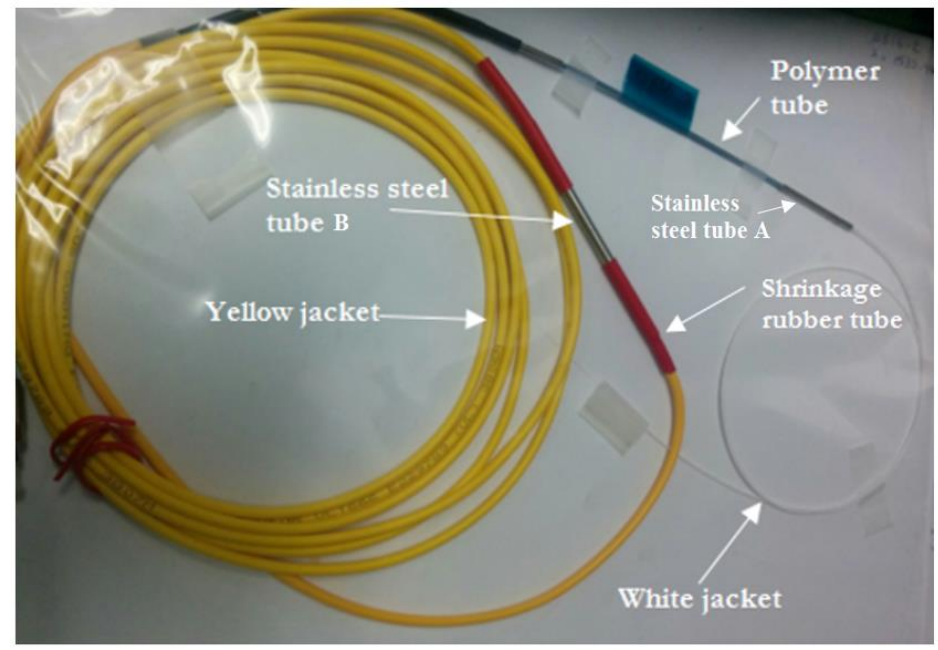

Figure 3.17 View of FBG Strain Sensors after Initial Packaging

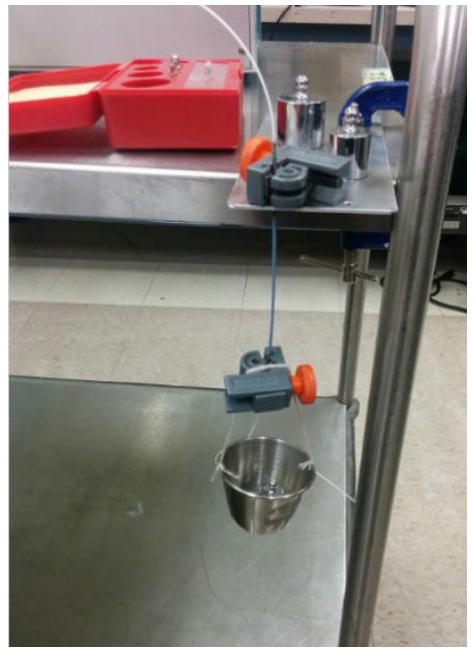

Figure 3.18 FBG Sensor Load vs. Wavelength Calibration Apparatus

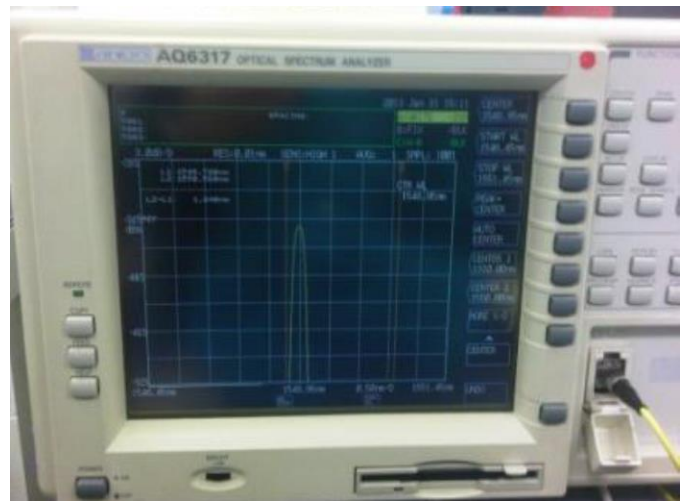

Figure 3.19 View of an OSA Device for Measurement of Wavelength 


\subsubsection{Calibration Sensitivity Test of FBG}

The sensors are tested through the load versus wavelength calibration procedure to make sure that the packaging did not contribute to the sensitivity and wavelength movement. The sensor is suspended vertically and five different small loads (20, 50, 80,100, 200 grams) are applied by adding weights to its end and the corresponding wavelength are recorded by the OSA peak detection device. The view of the measured wavelength by the OSA peak detection device is shown in Figure 3.19. The apparatus for the calibration is shown in Figure 3.18. All results (Figure 3.20) reveal linear relationship between the wavelength and load, and clearly depict that the sensors sensitivity are not affected by the packaging.
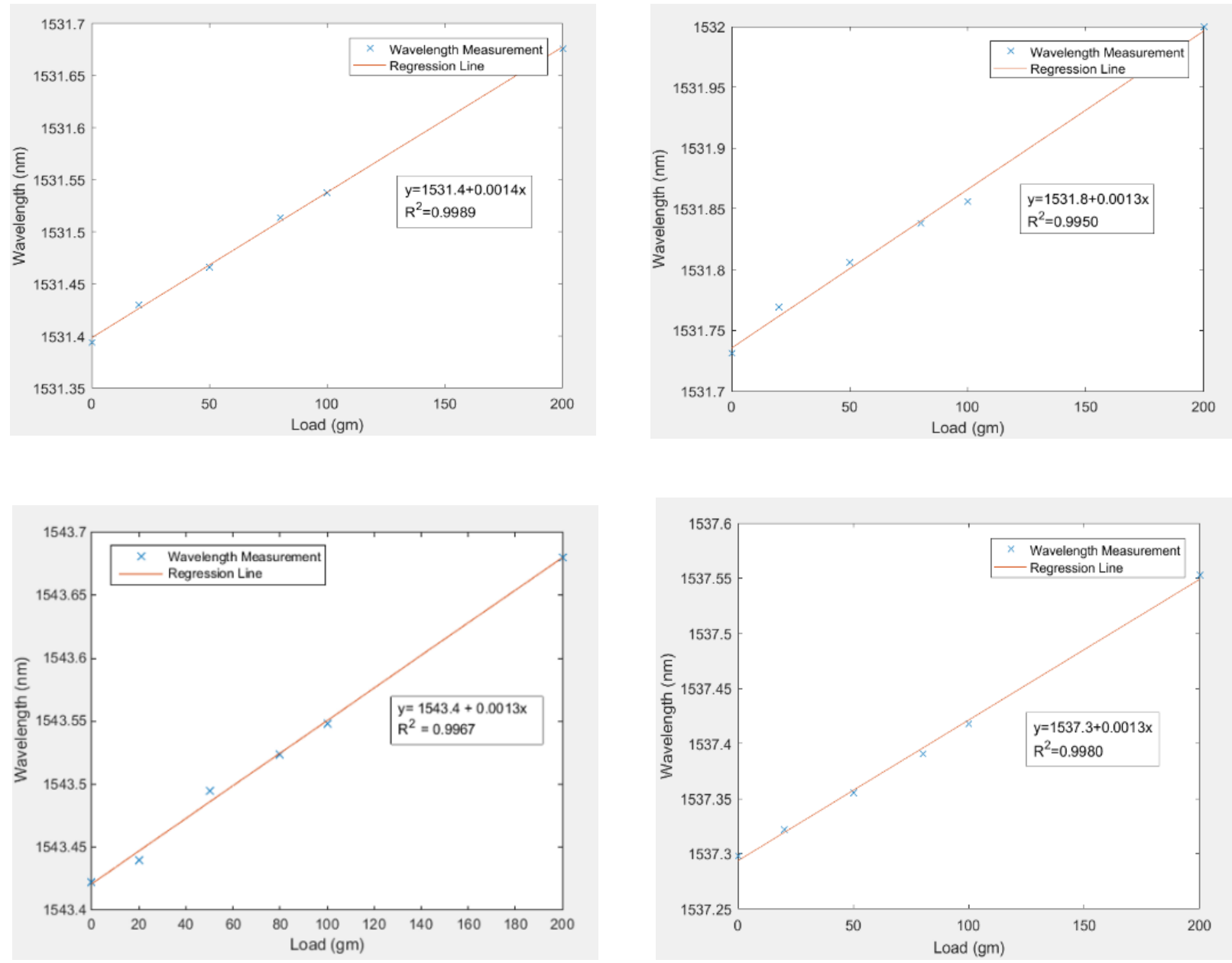

Figure 3.20 Peak Calibration Sensitivity Results for Different FBG Sensors 


\subsubsection{Sensor Mounting Precaution}

In order the FBG sensor delivers a proper response, it has to be straight and also in a same direction with the other sensors in the array. This is done by adding two springs at each end of the sensor peak tube as Figure 3.21. The springs are bonded to the peak tube using quick setting steel reinforced Metal/Plastic epoxy. The end of the springs is formed as a loop in order to fix it to the custom made hooks bonded on the steel reinforcement. By pre tensioning the springs first, then the springs allow the sensor to be initially stretched when they are mounted in the slab before the casting. The stretching guarantees considerably the straightness of the FBG during the casting and prevents the loss of data. As an additional advantage, the epoxy and spring act as extra bond between the sensor and concrete after casting which makes the result more reliable.

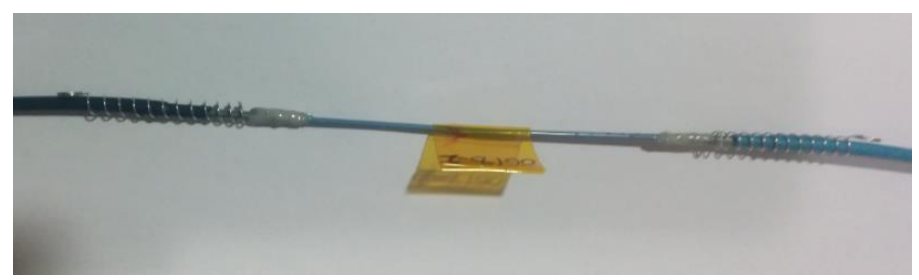

Figure 3.21 FBG Sensor with Spring Holders

\subsubsection{FBG Sensor Array Fabrication}

Eight FBG sensors are fabricated in two arrays with four sensors in each array. As explained in the FBG polymer sensor assembling step 5 in Section 3.5.4, all four sensors are spliced to each other in an array following the same splicing procedure. The two ends of the FBG array are spliced with a FBG patch cord. The signal response of the sensors in array is checked using the OSA device. For ease of handling the FBG sensors, they are rolled around a cord storage reel with stand as shown in Figure 3.22.

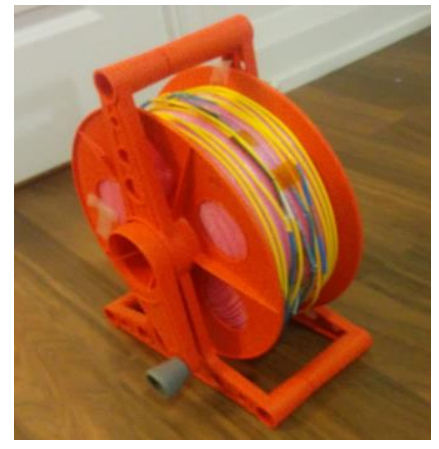

Figure 3.22 FBG Cord Storage Reel with Stand 


\subsection{Specimen Fabrication}

\subsubsection{Steel Reinforcement Meshes Fabrication}

All four specimens are reinforced with CSA standard steel bars of Grade 400 as longitudinal reinforcement. The reinforcement in compression side is $10 \mathrm{M}$ at $210 \mathrm{~mm}$ for all three HSC slabs and 10M at $100 \mathrm{~mm}$ for an UHP-FRC slab. Whereas the reinforcement in the tension side is $10 \mathrm{M}$ at $210 \mathrm{~mm}, 10 \mathrm{M}$ at $100 \mathrm{~mm}$, and $15 \mathrm{M}$ at $100 \mathrm{~mm}$ for HSC slabs and $10 \mathrm{M}$ at $100 \mathrm{~mm}$ for UHP-FRC slab. The length of the reinforcements are $1900 \mathrm{~mm}$ and tied orthogonally using steel wire and a twister as shown in Figure 3.23.

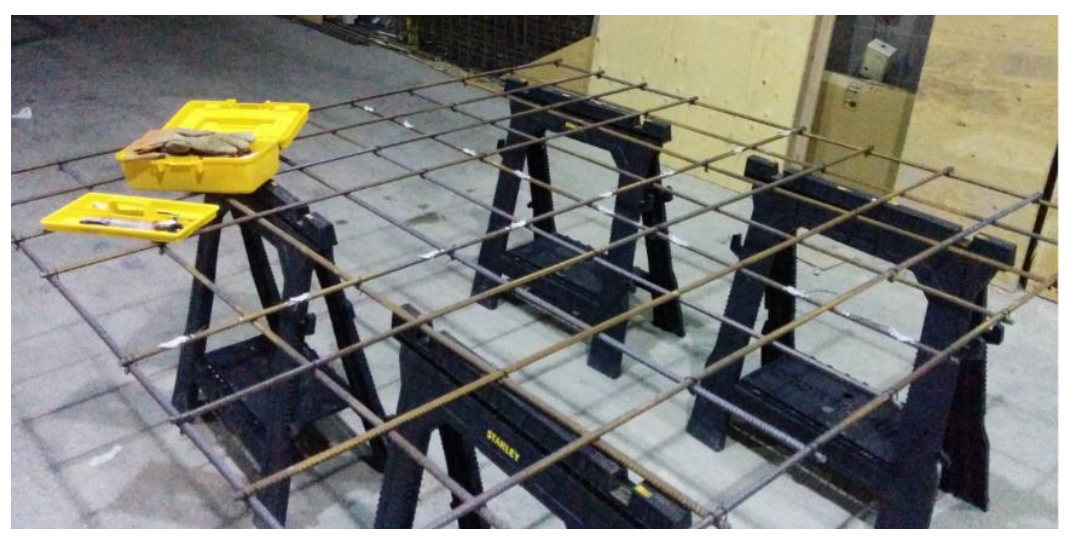

Figure 3.23 The Reinforcement Assembling Apparatus

\subsubsection{Pre-casting Sensor Installing Preparation}

There are two types of sensors installed before casting: the FBG sensor and electrical strain gauge.

\subsubsection{FBG Sensor Installation}

On the H.S 0.5 slab top layer reinforcement mesh, two orthogonal reinforcement bars in the middle are selected for two arrays of the FBG sensor to be mounted on. The location of the FBG sensors relative to reinforcement for the array $\mathrm{X}$ and array $\mathrm{Y}$ are the same. For each FBG sensors, two hooks are custom made from steel wire which primarily are bonded with epoxy glue to the reinforcement at designated locations as shown in Figures 3.24 to 3.26. The hooks are made 
in a way that all the sensors be in the same level in the concrete which is mandatory for the mode shape extraction.

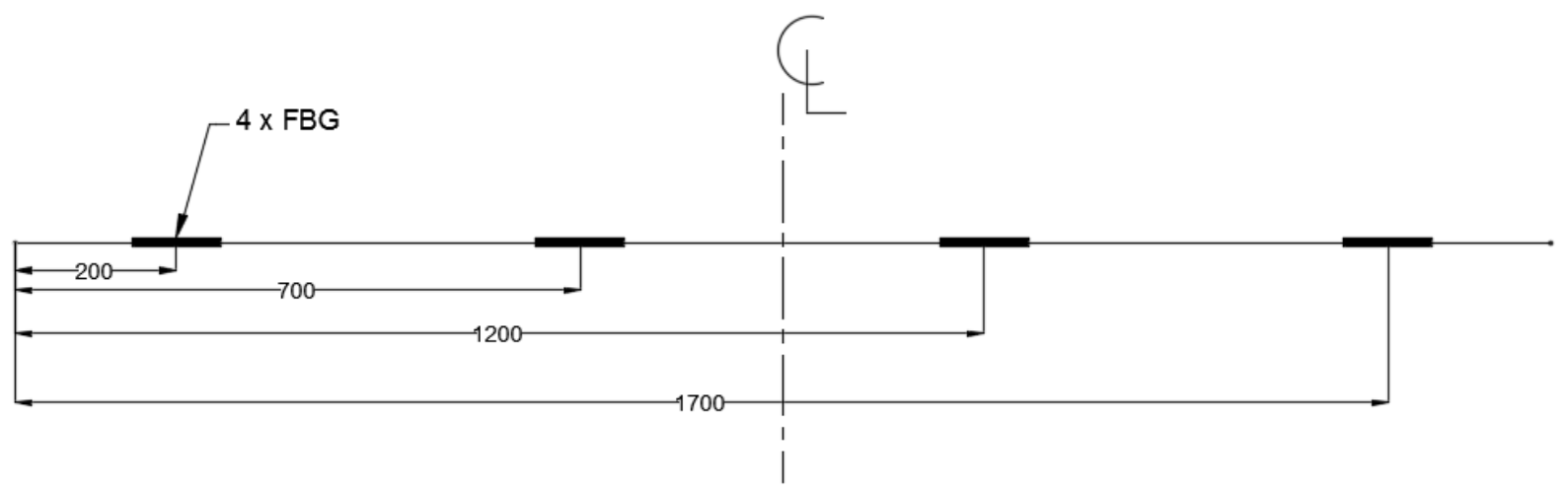

Figure 3.24 Location of FBG Sensors Relative to Reinforcement (Dimensions Are in Millimeter)

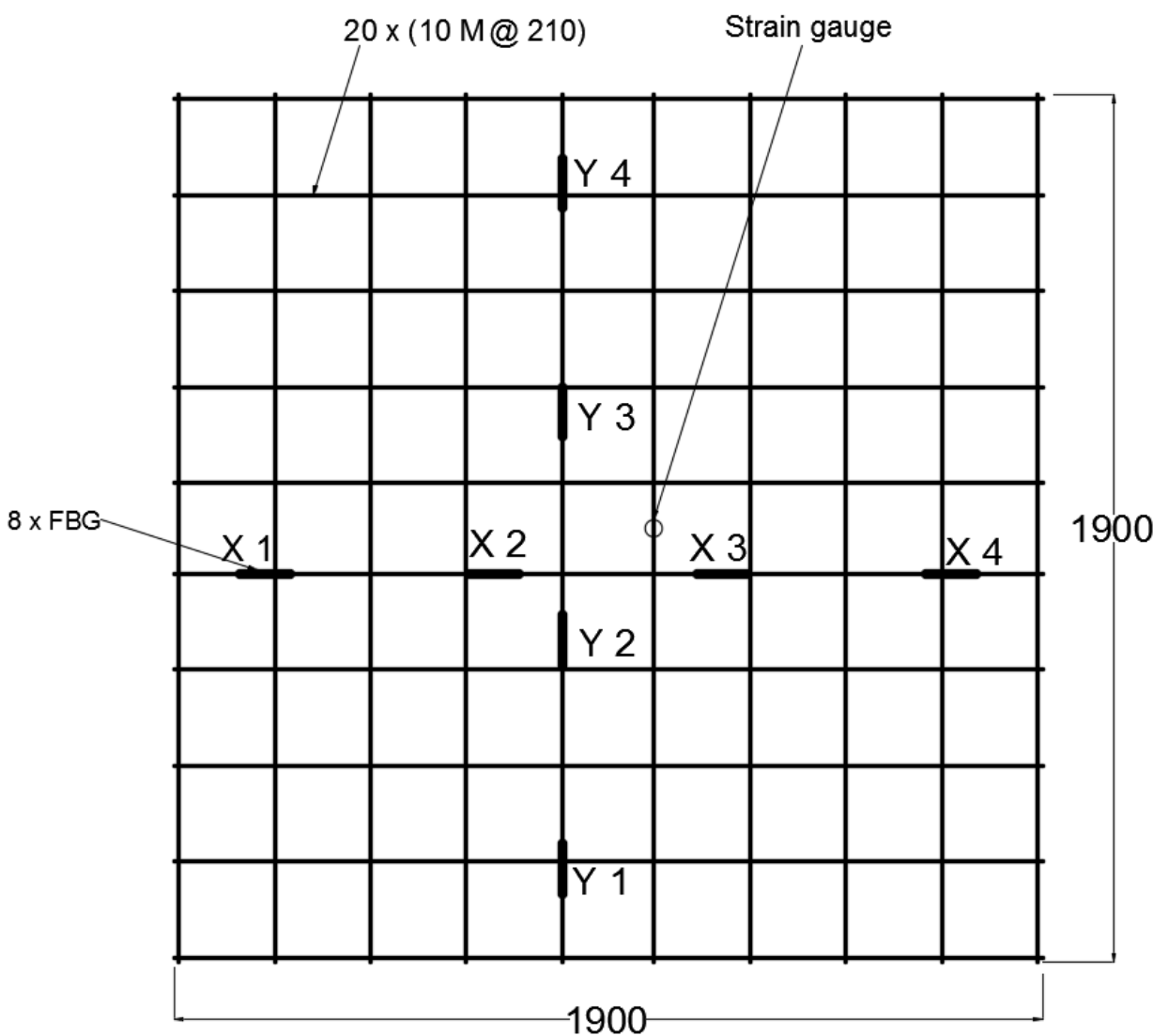

Figure 3.25 Top View of the FBG Sensors Located on the Top Reinforcement 


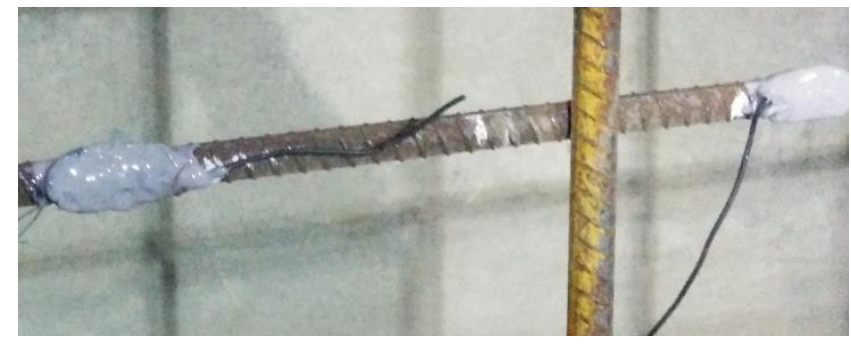

Figure 3.26 Steel Wire Bonded to the Reinforcement with Epoxy to Make the Hooks for FBG Installation

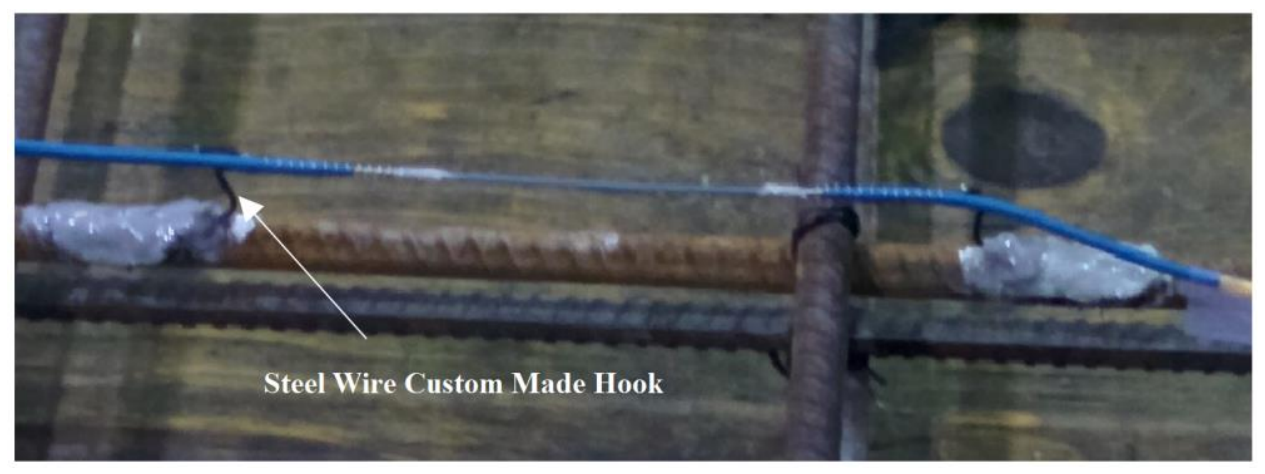

Figure 3.27 Concrete FBG Sensor Installed via Springs to the Steel Wire Custom Made Hooks

At the next step after the molds are ready, the sensors are installed in two arrays in $\mathrm{X}$ and $\mathrm{Y}$ direction as shown in Figures 3.25 and 3.28. The sensors are stretched via the spring and hooked to the reinforcement (Figure 3.27) and the stretch amount is predesigned to achieve the certain amount of the wavelength. The sensor Y2 and Y4 had overlap in the wavelength after packaging and splicing. To overcome this problem, double spring is used for sensor Y2 in order to pre-strain the sensor more sufficiently. The wavelengths of the FBG sensors are recorded using the OSA and the DAQ system at all the different stages (Table 3.6). The extra FOS wire lengths between adjacent sensors are looped carefully. The four end of sensor arrays are also looped and stocked in foam rap shields at the four sides of the mold in order not to be damaged during the casting procedures. 


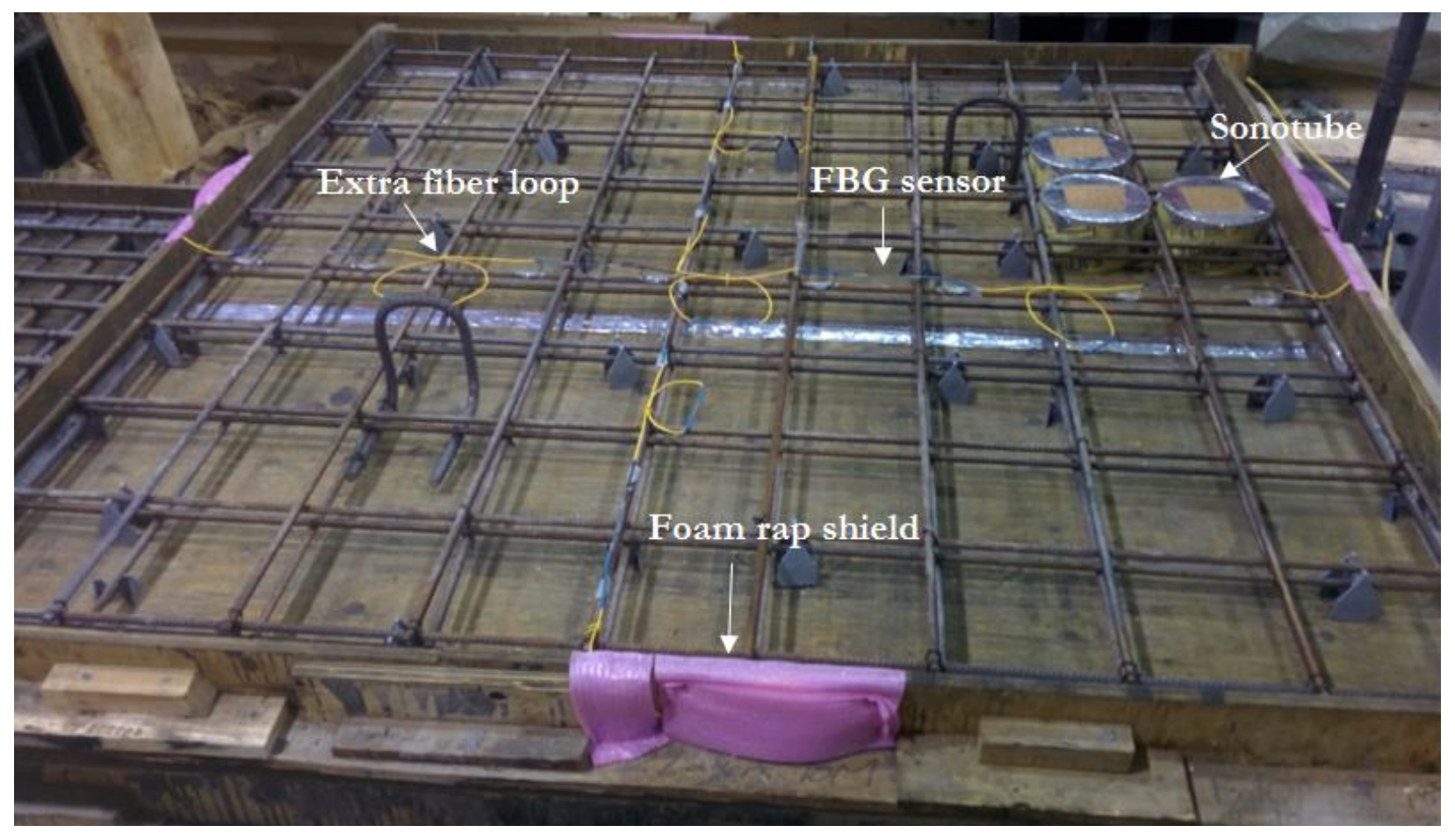

Figure 3.28 The Detail Involved to Prepare H.S 0.5 Slab

Table 3.6 The Wavelengths of FBG Sensors at all Various Stages

\begin{tabular}{|l|l|l|l|l|l|}
\hline Array & $\begin{array}{l}\text { Sensors } \\
\text { No. }\end{array}$ & $\begin{array}{l}\text { Wavelength } \\
(\eta \mathrm{m})\end{array}$ & $\begin{array}{l}\text { Wavelength } \\
\text { After } \\
\text { packaging }\end{array}$ & $\begin{array}{l}\text { Wavelength } \\
\text { After splicing }\end{array}$ & $\begin{array}{l}\text { Wavelength } \\
\text { After casting }\end{array}$ \\
\hline \multirow{3}{*}{ A X } & X 1 & 1545.40 & 1543.428 & 1543.576 & 1543.398 \\
& X 2 & 1539.44 & 1537.800 & 1537.687 & 1537.185 \\
& X 3 & 1532.98 & 1531.744 & 1531.873 & 1531.547 \\
\hline \multirow{3}{*}{ A Y } & X 4 & 1550.86 & 1549.16 & 1549.699 & 1549.218 \\
& Y 2 & 1538.97 & 1537.298 & 1536.800 & 1536.419 \\
& Y 3 & 1544.86 & 1543.562 & 1543.424 & 1543.123 \\
& Y 4 & 1543.04 & 1431.950 & 1531.885 & 1531.478 \\
\hline
\end{tabular}




\subsubsection{Strain Gauge Installation}

One electrical resistance strain gauge is used for each specimen to measure the instantaneous amounts of strain on the tension side of the reinforced concrete slabs. The strain gauges have the resistance of $120 \pm 0.6 \%$. The locations of strain gauges are the same for all the slab specimens and revealed in Figure 3.25. The surfaces of the reinforcements are grinded properly at the designated area in order to attach the strain gauge. The strain gauges are glued and sealed through recommended procedure at Ryerson University Civil Engineering Structural Laboratory (Figure 3.29).

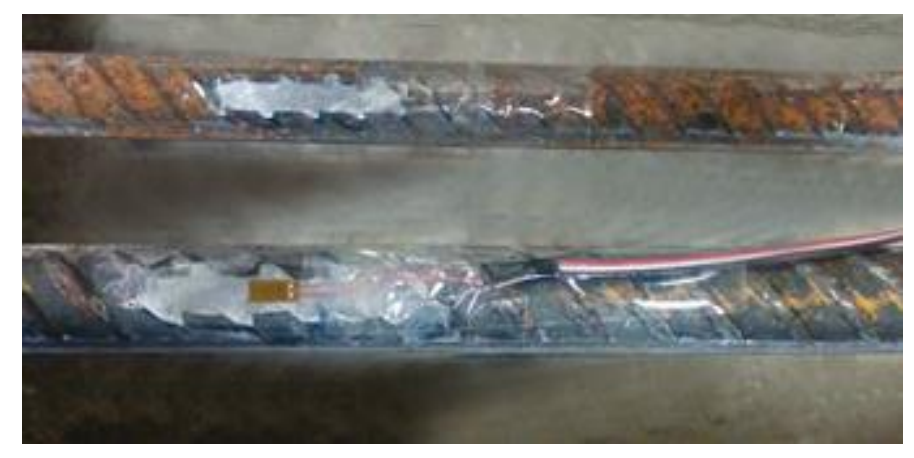

Figure 3.29 Strain Gauge Installed on Grinded Surface of Reinforcement

\subsubsection{Mold Preparation}

\subsubsection{Wooden Mold Frame Preparation}

Four wooden mold frames with the dimension of $1950 \times 1950 \times 100 \mathrm{~mm}$ are previously fabricated and used by $\mathrm{PhD}$ student Mr. Hesham Othman at Ryerson University lab. The preparation of the molds are included as: Allocating, cleaning, repairing, levelling, sealing with aluminum tape, and coating with oil based release agent as shown in Figure 3.30. 


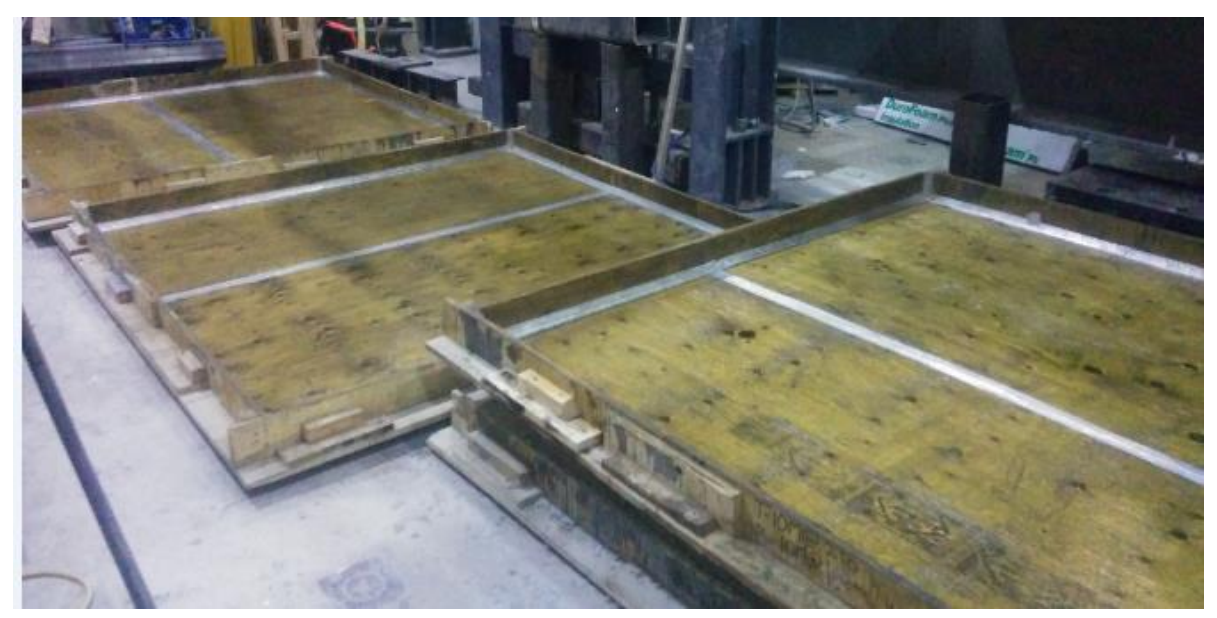

Figure 3.30 Ready Molds for Reinforcement Installation

\subsubsection{Reinforcement Mesh Installation}

The plastic rebar chairs are used in order to hold the reinforcement mesh inside the mold. In order to achieve $20 \mathrm{~mm}$ concrete cover, some of the chairs are modified in size manually. An overhead crane is used to install the mesh reinforcements inside the mold as shown in Figure 3.31.

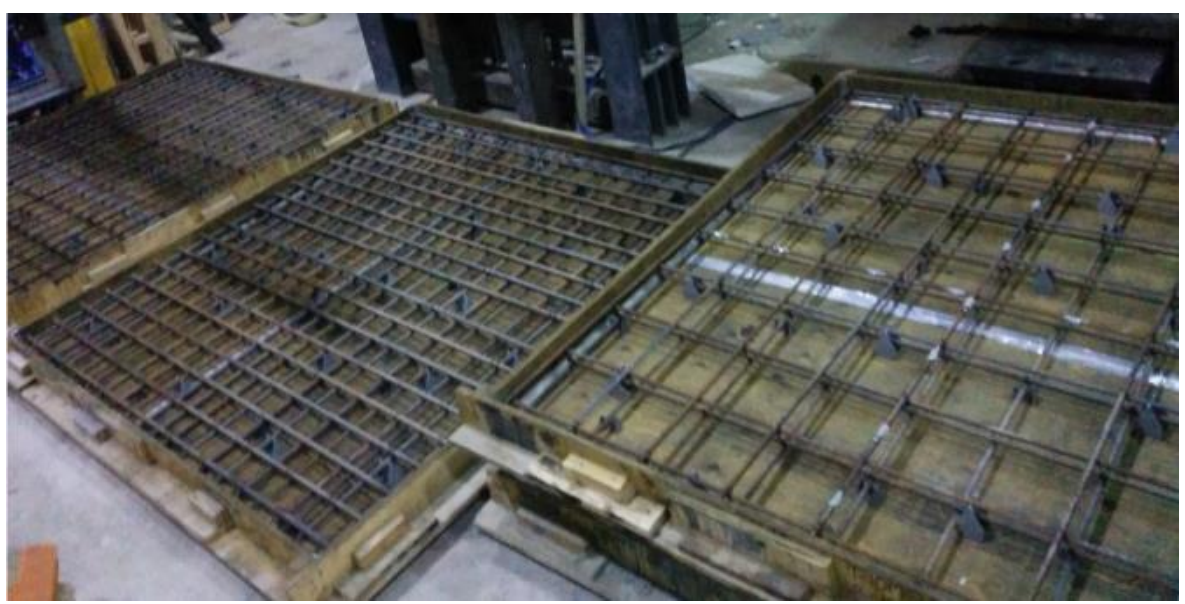

Figure 3.31 Reinforcement Installed in the Mold 


\subsubsection{Casting}

All four slab specimens are casted with the material composition explained in Section 3.2. Three HSC specimens are ready mixed and one UHP-FRC slab is mixed at Ryerson University Structural Laboratory following Ductal ${ }^{\circledR}$ mixing procedure. The bottom Discharge Concrete Bucket (Figure 3.32) and overhead crane are assisted to transfer concrete into the specimen molds. The cylinders for tension and compression test, prisms for flexural tests, and sono-tubes are manually casted using the plastic pail and scoop.

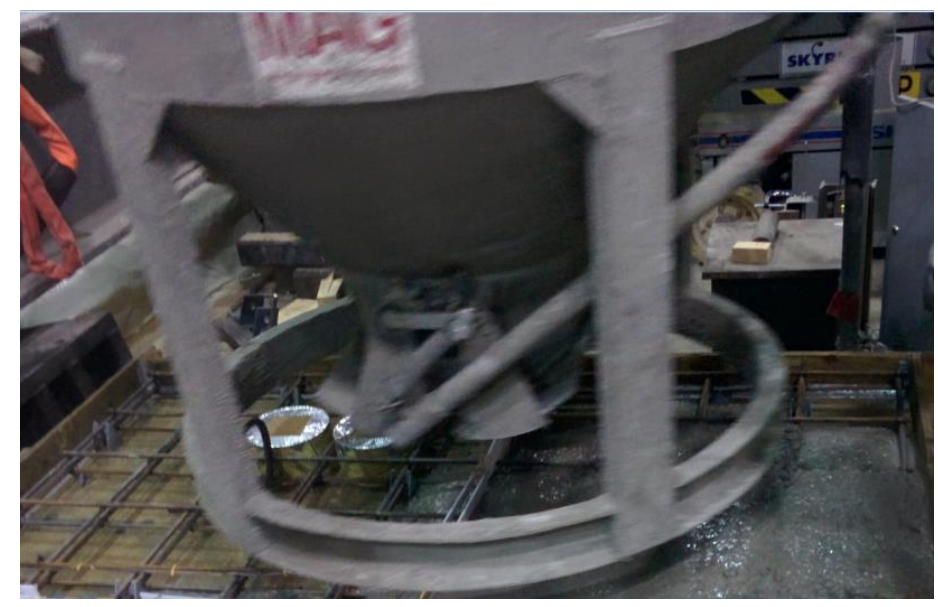

Figure 3.32 Bottom Discharge Concrete Bucket

\subsubsection{Curing}

All the specimens are pre-cured for one week using the spray water and sealed with plastic sheeting (Figure 3.33). Furthermore, the specimens are post-cured for at least 28 days in laboratory conditions with a relative humidity and temperature of $50 \% \pm 2.5 \%$ and $24 \pm 2{ }^{\circ} \mathrm{C}$, respectively. The same conditions are applied to the cylinders, prisms, and sono-tubes specimens (Figure 3.34). 


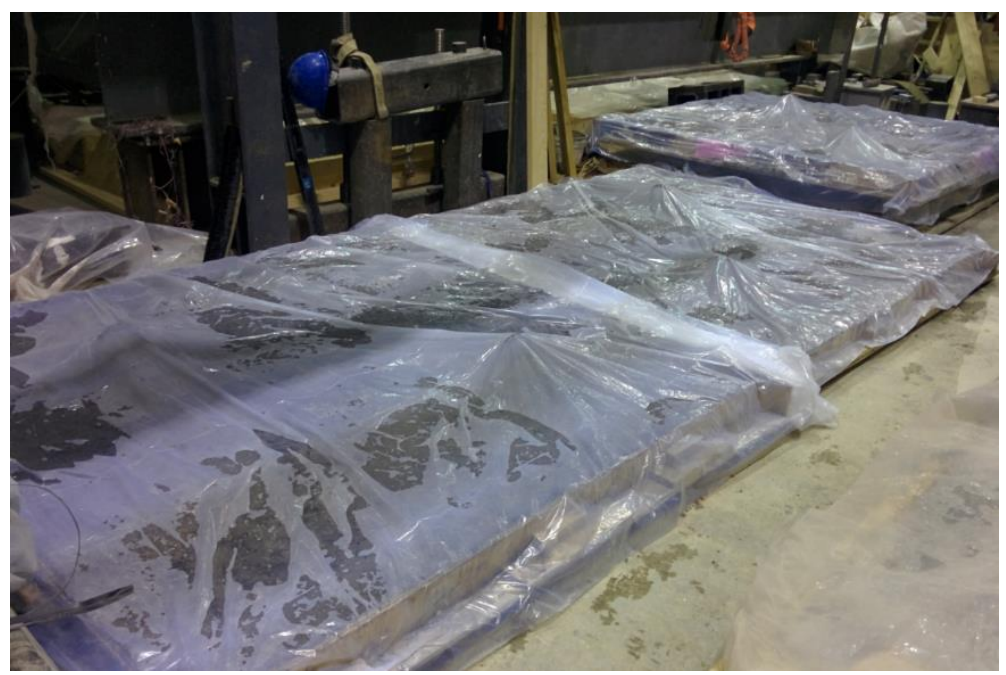

Figure 3.33 Slabs Pre-cured with Spray Water and Plastic Sheeting

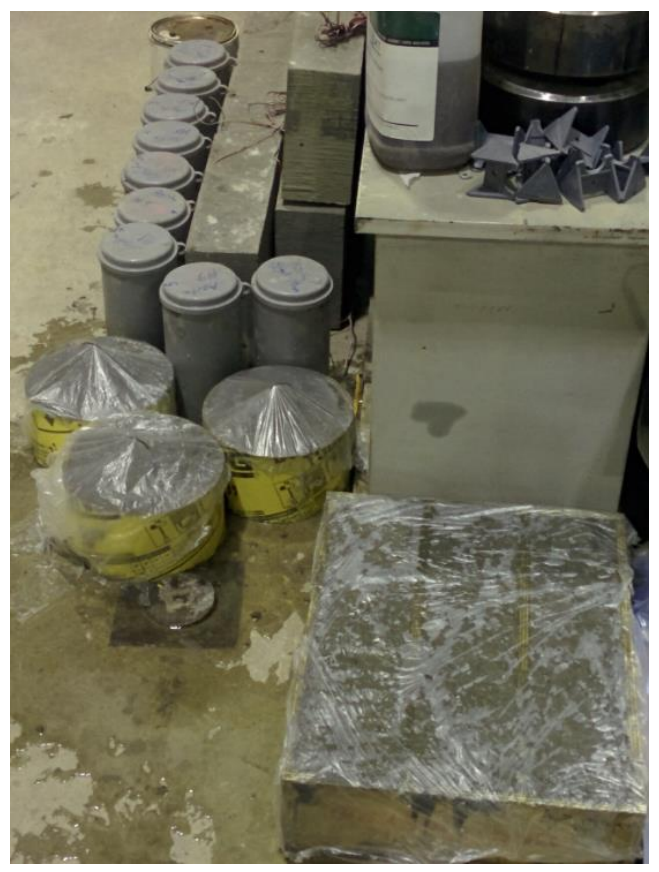

Figure 3.34 The Pre-cured Cylinders and Prisms 


\subsubsection{Sensor Patch Cord Protection after Demolding}

For the specimen H.S 0.5 embedded with the FBG sensors, in order the sensor patch cord ends not to be damaged during the storage time between demolding and testing, four wooden shields protector are used. The shields are bolted as a guard to the four sides of slab as shown in Figure 3.35. The extended patch cord are rolled inside the shield and packed with foam sheet (Figure 3.36).

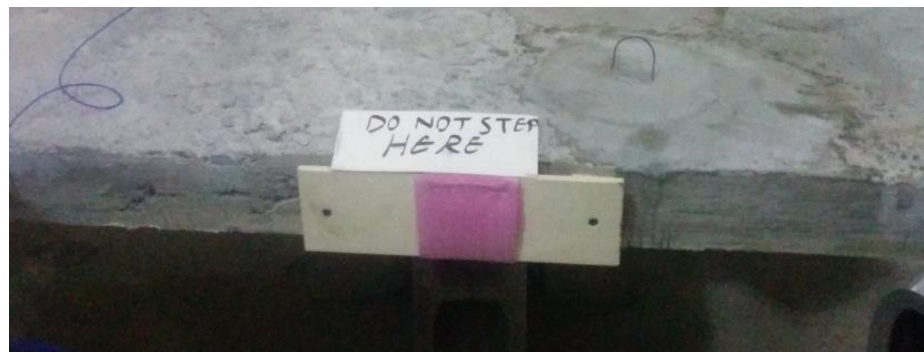

Figure 3.35 Patch Cord Protection Guard

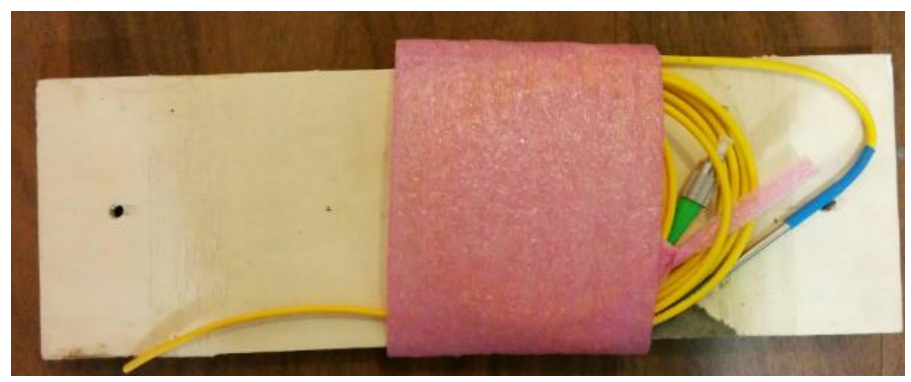

Figure 3.36 Patch Cord Protection Guard Viewed from Inside 


\subsection{Test Set up and Instrumentation}

\subsubsection{Slab Specimen Installation}

By using steel and concrete blocks available at Ryerson University Laboratory, a test setup is arranged as shown in Figures 3.37 to 3.40. The load cells at the four corners of apparatus are used only as spacers. The only load cell which is used is placed at the center on the top of hydraulic jack under the $400 \times 400 \mathrm{~mm}$ steel loading block. The 20 -ton over head crane is used to place the slab specimens on the loading apparatus. The goal is to create corner edge simply supported slab simulation boundary condition. To achieve this, four bracing beams (HSS $152 \times 152 \times 12.7 \mathrm{~mm}$ ) are employed. The load is transferred through eight steel threaded rods and nuts to the ground floor of laboratory which is designed for this purpose (Figures 3.37, 3.38 and 3.40). At the supporting points between the slab specimen and HSS bracing beams, rubber packing sheets $(200 \times 150 \times 10$ $\mathrm{mm})$ are installed.

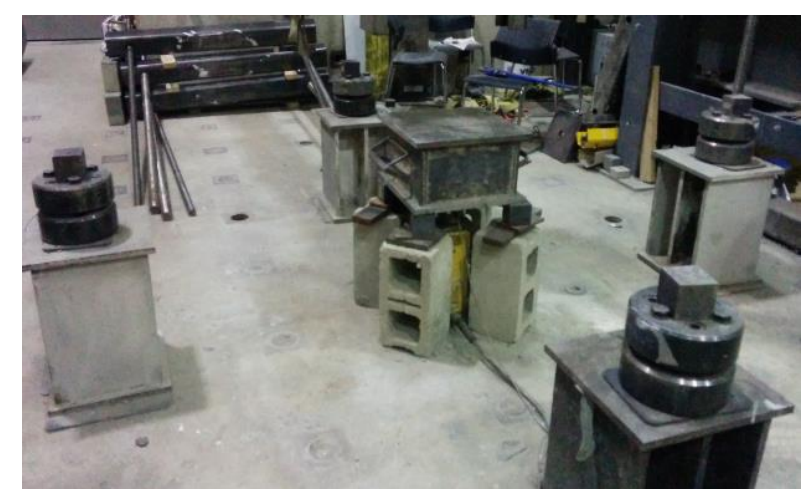

Figure 3.37 Loading Apparatus Arrangement

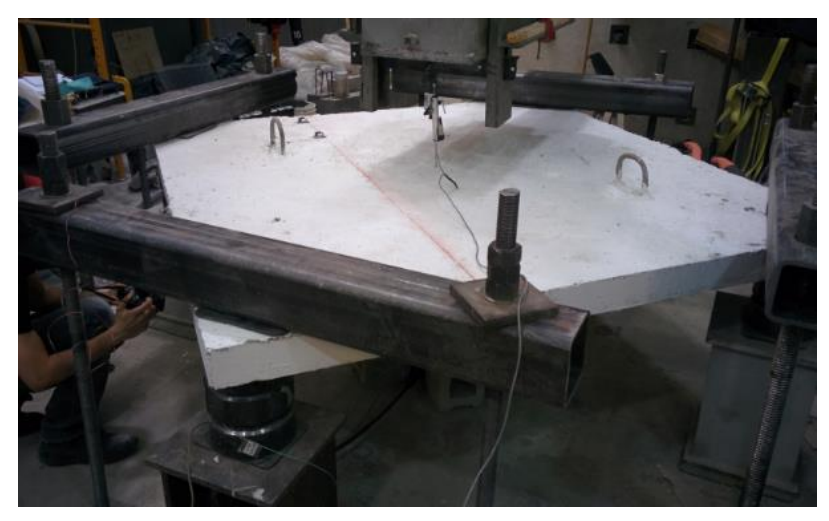

Figure 3.38 Installed Slab on Loading Apparatus 


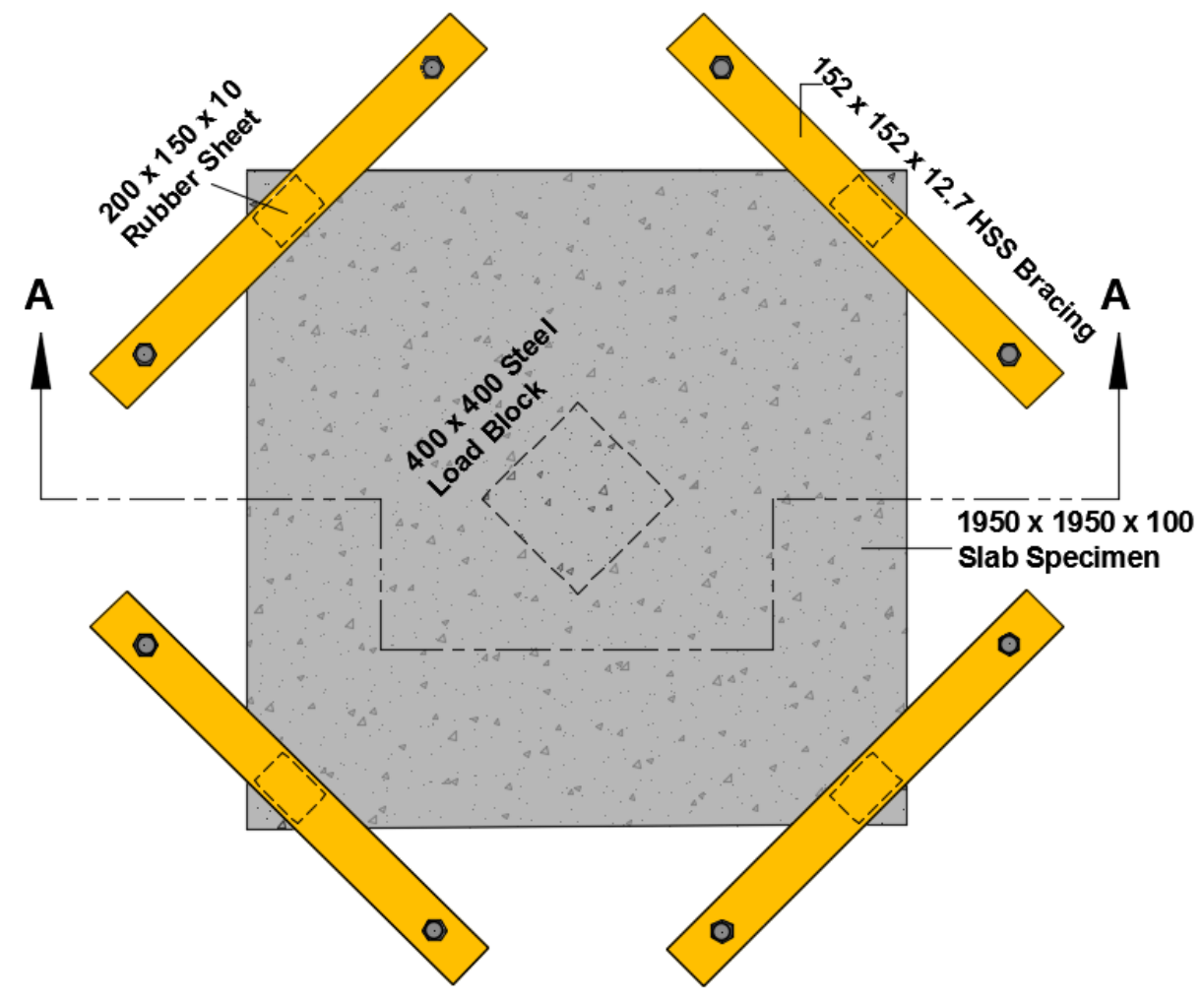

Figure 3.39 Top View Schematic Diagram of Test Set Up

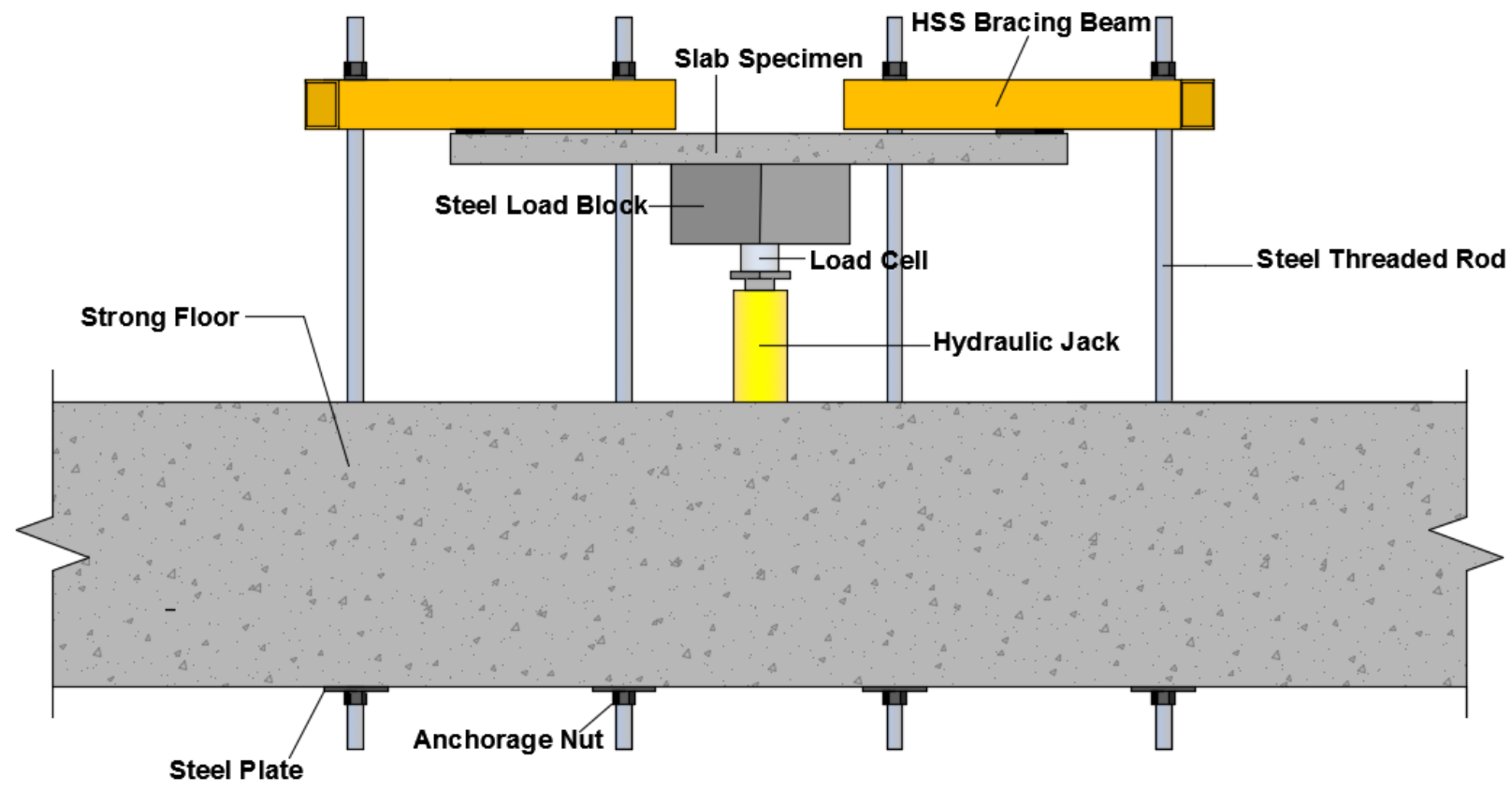

Figure 3.40 Side View Schematic Diagram of Test Set Up (Sec A-A) 


\subsubsection{Loading Set Up}

A central manual hydraulic jack commercially known as ENERPAC is used to apply load in all four slabs. The capacity of the hydraulic jack that was used to carry the experimental program is 100 tons (200 kips), $0.153 \mathrm{~m}$ (6 inches) stroke and a maximum operating pressure of $69 \mathrm{MPa}$ (10000 psi), Figure 3.40.

\subsubsection{Sensor Detection Setup}

\subsubsection{FBG Sensor Measurement System Set Up}

For monitoring the damage location for the specimen H.S 0.5 using the FBG sensors, the data acquisition system are used (Figure 3.41). The system main devices are an optic electronic demodulation unit (circulator) manufactured by Micron-Optics Incorporation, a PC laptop and a digital interface card (DAQ - data acquisition). The data acquisition communicates between the circulator and PC. The optical circulator interrogates the wavelength of the reflected light from the FBG sensors and sends the data to the PC. The PC is facilitated with a custom software application. The optical circulator is profoundly a fiber-FP tunable filter which is able to observe wavelength with pm resolution.

The data transmitted from the sensors require being obtained and saved. For this reason, a custom software application (I-MON E-USB 2.0) has been developed. This software application runs under Lab-View (National Instruments) programming environment on the PC laptop and also controls demodulation system (circulator).

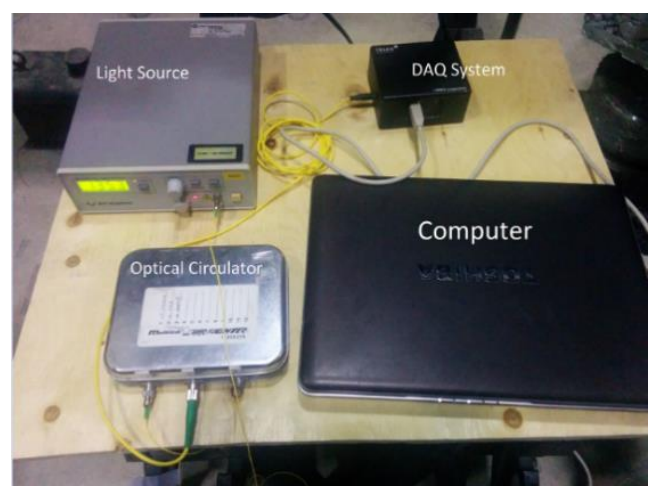

Figure 3.41 Wavelength Monitoring System Elements 
A schematic illustration of the wavelength monitoring system is shown in Figure 3.42 .

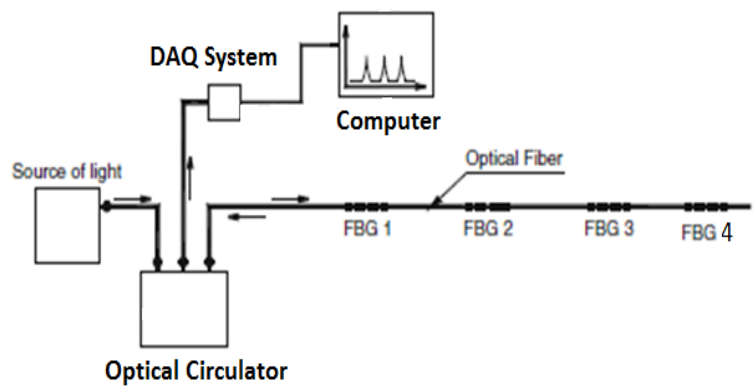

Figure 3.42 Wavelength Monitoring System Schematic Diagram

The Lab-View software detecting four sensors in array $\mathrm{X}$ is shown in the Figure 3.43.

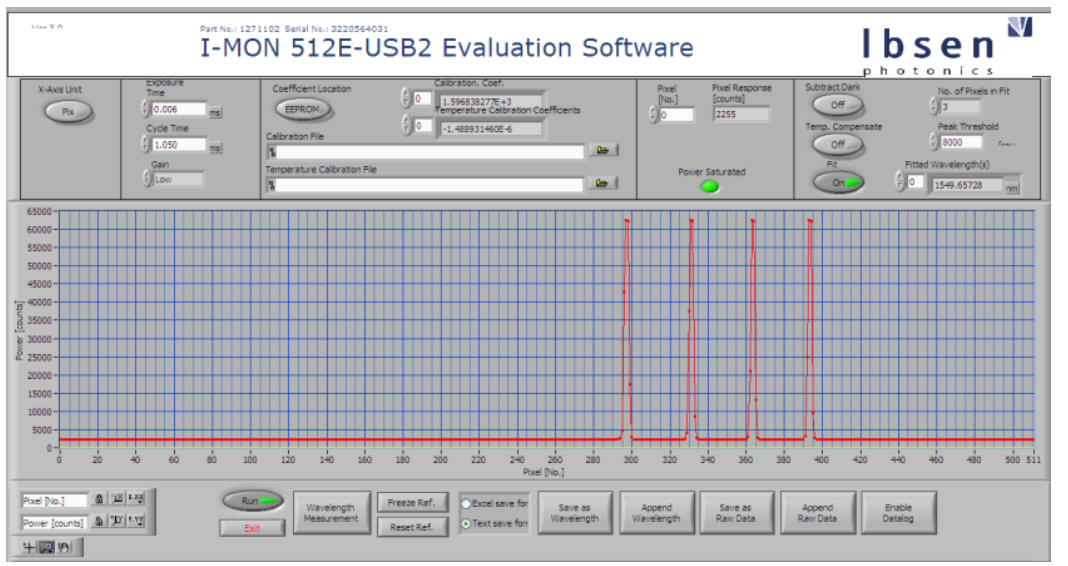

Figure 3.43 Lab View Software Detecting Four Sensors in Array X

The I-MON 256/512 USB interrogation monitors enable the data administrator to review the overall processes and functions performed on the data in real time, or as it happen. For monitoring of the FBG sensors, it offers a spectrum up to $6 \mathrm{kHz}$ whereas sub-pico meter spectral fit resolution wavelength measurements are maintained. The high spectrum resolution combined with broad wavelength range allows measurement of a large number of FBG sensors up to 70. There are other features associated with the software such as: high measurement frequency, large dynamic range and compact size. The common applications of the software include: temperature measurements, pressure monitoring, strain measurements and vibration analysis. In this research 
the vibration analysis application of the software is used. The sampling frequency used to acquire FBG data was $952 \mathrm{~Hz}$ for all the measurements.

\subsubsection{Accelerometer Sensor Measurement System Set Up}

For monitoring the intensity of damage in all the slabs, the accelerometer, impact hammer and respective data acquisition are used (Figure $3.44 \mathrm{~b}$ ).

a)

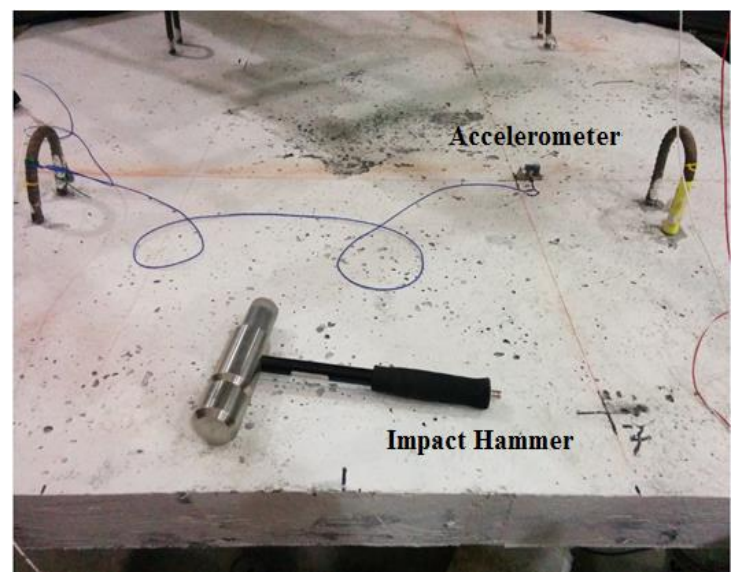

b)

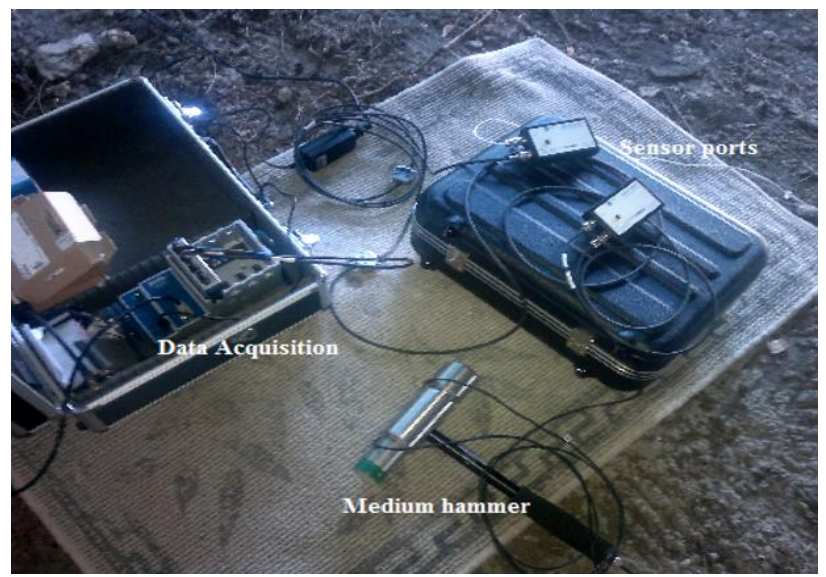

Figure 3.44 Random Decrement Test with Accelerometer Equipment

For all the slab specimens the acceleration responses are captured using same set up. $50 \mathrm{~g}$ accelerometer type Kistler 8640 A50 with the sensitivity of $102.5 \mathrm{mV} / \mathrm{g}$ are installed to the slab at typical location (Figure 3.44 a). For fixing the accelerometer on the slab, a special fixture is designed in such a way that any relative movement cannot occur between the accelerometer and slab. The fixture is mounted to the slab using super glue (Figure 3.45). For better glue functioning, the surface underneath the fixture is smoothed using a grinder. The accelerometer is placed in the fixture carefully with minimum shock possible and the fixture bolt is gently tightened.

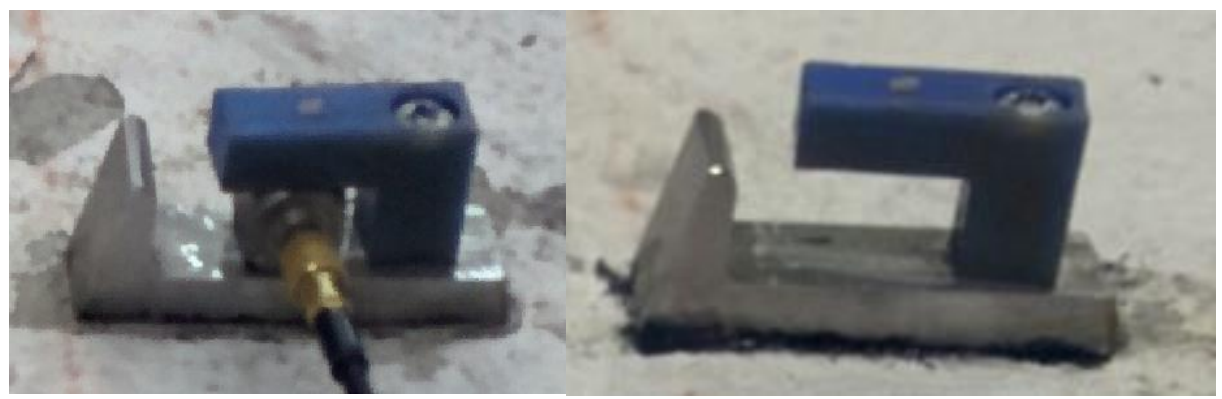

Figure 3.45 Fixture Designed for Holding the Accelerometer Safely 
The random excitations are applied on the slabs using a $0.5 \mathrm{~kg}$ impact hammer type Kistler 9728A with the sensitivity of $1.05 \mathrm{mV} / \mathrm{LbF}$ (Figure 3.46). The respective data acquisition system used is compact DAQ-NI-9184 with four channels. A single Lab-View program is prepared to capture data from NI 9184 data acquisition. The input sampling rate set up in the program for the accelerometer is $2500 \mathrm{~Hz}$.

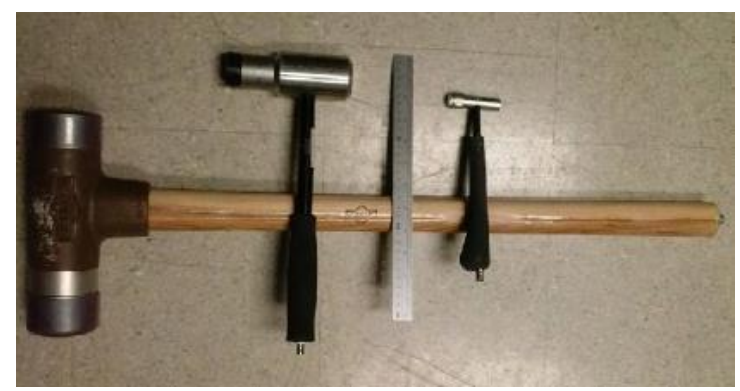

Figure 3.46 Different Sizes of Kistler Hammers (Large, Medium and Small)

\subsubsection{Strain gauge, LVDT and Load Cell Measurement System Set Up}

The strain gauges installation is explained in detail in Section 3.6.2.2. The deflection at all the slabs centers are recorded by the linear variable differential transformer (LVDT) (Figure 3.47). The load cell with the capacity of $10000 \mathrm{kN}$ is located at the center of the slab on top of the hydraulic jack (Figure 3.40).

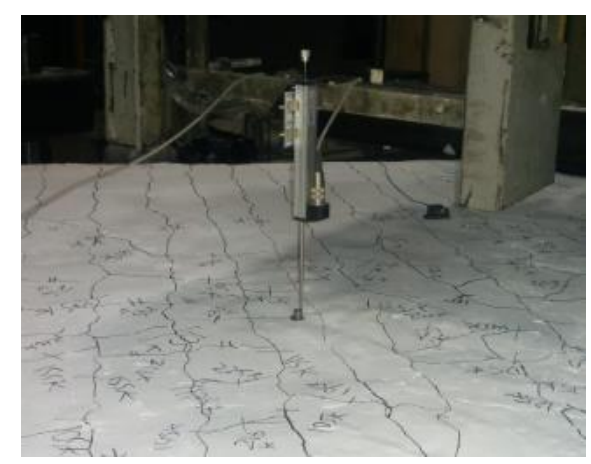

Figure 3.47 LVDT at the Slab Center 
The electronic strain gauges, LVDT and load cell reading are connected to a computerized data acquisition system (VISHAY system 5000). The measurements are recorded using the Strain Smart software with scanning rate equal to $10 \mathrm{~Hz}$.

\subsubsection{Static Load Test Procedure}

This test is conducted for all the slabs specimens. Each specimen is placed on the testing apparatus as described in Section 3.7.1. The measuring equipment is mounted as explained in Sections 3.7.3.2 and 3.7.3.3 (Figure 3.48).

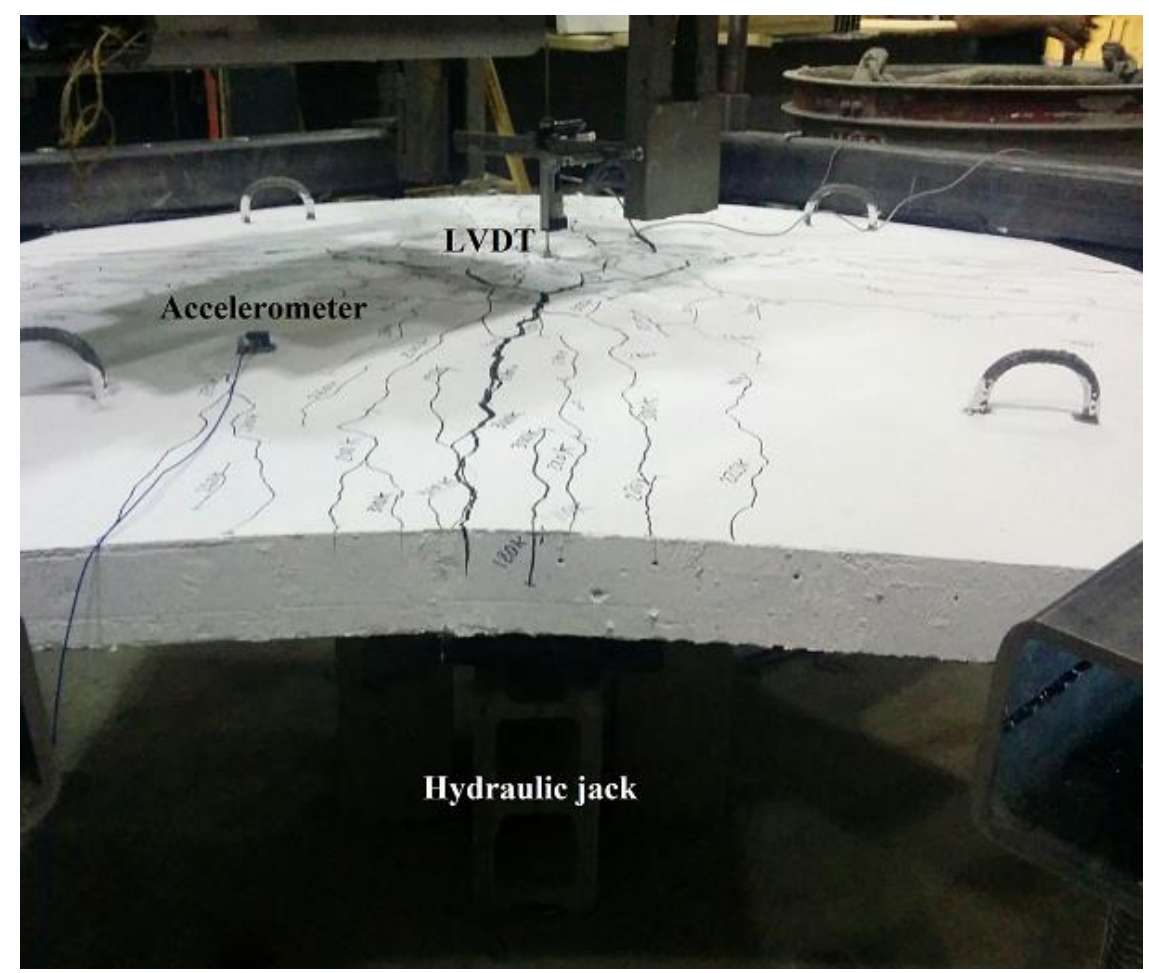

Figure 3.48 Static Load Test Apparatus (UHP-FRC Slab)

The random excitations are applied on the slab using a medium impact hammer 20 to 30 times. The response is captured two times from $50 \mathrm{~g}$ accelerometer for intact state of slab. The static load is applied gradually by manual hydraulic jack up to the observation of initial cracks (cracking load). All the data are recorded from the LVDT, strain gauge and load cell in real time. At this 
stage the load is released to eliminate its effect as an extra support in the middle for the ambient vibration based analysis using the accelerometer and hammer. Again, random excitations are applied on slab using a medium impact hammer 20 to 30 times and the response is captured two times from $50 \mathrm{~g}$ accelerometer for cracking state of slab. Another time, the static load is applied gradually by manual hydraulic jack and stopped at $5 \mathrm{kN}$ increments to mark the cracks for mapping the crack pattern.

This task is repeated until the strain reading of reinforcement reached 2000 micro strain which approximately depicts the yield state of the slab. Meanwhile, all the data are recorded from the LVDT, strain gauge and load cell in real time. At this stage, the load is released and the ambient vibration test (excitation test) using medium hammer and accelerometer is repeated for gathering data at the yield state. One more time, the static load is incrementally increased and the crack pattern is marked until the slab could not be tolerating any more load which depicts the failure stage. At this stage, the load is released and the excitation test is repeated for ultimate state. The captured acceleration data at intact, cracking, yield, and ultimate states are subsequently employed for the RD signature analysis technique. 


\section{CHAPTER FOUR \\ TEST RESULTS}

\subsection{Introduction}

This chapter presents the results and observations obtained from the experimental program explained in Chapter 3. The experimental program test results include the static load test results obtained from the load cell, LVDT, strain gauge, and accelerometer. The results are obtained from a total of four reinforced concrete slab specimens, three HSC with different reinforcement ratios H.S 0.5, H.S 1, and H.S 2 and one UHP-FRC 1. The behaviour of the specimens are examined under the static loading and ambient vibration excitation. The static behaviour is presented in terms of the load-deflection relationship at service load, yield load, and ultimate load. The reinforcement strain, crack pattern, and failure modes are examined at each load. The extent of the damage induced by the progressive static loading at cracking, yield, and ultimate states are investigated through the changes in the dynamic parameters natural frequency and damping ratio obtained from the RD signatures.

\subsection{Load-Deflection Behaviour}

The load-deflection relationship at the center of the slab specimens is measured from the LVDT and load cell (Figures 3.40 and 3.47). The load-deflection curves for four specimens H.S 0.5, H.S 1, H.S 2 and UHP-FRC 1 are shown in Figures 4.1 to 4.4.

The load-deflection curves are not smooth due to multi pause operation which was necessary to map the cracks as well as gathering data from the accelerometer at the different stages of cracking, yield and ultimate. However, the load-deflection curves are considered smooth by neglecting the local relaxation curves for the energy absorption determination. The effect of these relaxations on the total slabs capacities is negligible. The points for the cracking, yield, and the ultimate states are marked on each graph and tabulated in Table 4.1. 
Table 4.1 Observed Load, Deflection, Strain, and Failure Mode of Slab Specimens

\begin{tabular}{|c|c|c|c|c|c|}
\hline $\begin{array}{l}\text { Slab } \\
\text { Specimen } \\
\text { Name }\end{array}$ & & $\begin{array}{r}\text { Load } \\
\text { kN }\end{array}$ & $\begin{array}{r}\text { Deflection } \\
\mathrm{mm}\end{array}$ & Micro Strain & Failure Mode \\
\hline \multirow[t]{4}{*}{ H.S 0.5} & Cracking & 35 & 2.85 & 172 & \multirow{4}{*}{ Flexure Failure } \\
\hline & Estimated Yield & 76 & 18.63 & 2000 & \\
\hline & Yield & 100 & 27.48 & 3147 & \\
\hline & Ultimate & 156 & 69.97 & NA, MF > 12000 & \\
\hline \multirow[t]{4}{*}{ H.S 1} & Cracking & 45 & 4.05 & 197 & \multirow{4}{*}{ Flexure Failure } \\
\hline & Estimated Yield & 125 & 26.02 & 2000 & \\
\hline & Yield & 180 & 41.5 & 3671 & \\
\hline & Ultimate & 209 & 70.02 & $\mathrm{NA}, \mathrm{MF}>14500$ & \\
\hline \multirow[t]{4}{*}{ H.S 2} & Cracking & 22 & 0.94 & 58 & \multirow{4}{*}{$\begin{array}{l}\text { Compression }+ \\
\text { One-way Shea } \\
\text { Failure at One } \\
\text { Support }\end{array}$} \\
\hline & Estimated Yield & 216 & 32.54 & 2000 & \\
\hline & Yield & NA & NA & NA & \\
\hline & Ultimate & 275 & 42.75 & 2402 & \\
\hline \multirow[t]{4}{*}{ UHP-FRC 1} & Cracking & 70 & 2.89 & 270 & \multirow{4}{*}{ Flexure Failure } \\
\hline & Estimated Yield & 190 & 19.96 & 2000 & \\
\hline & Yield & 260 & 31.18 & 3068 & \\
\hline & Ultimate & 370 & 97.5 & NA, MF > 15000 & \\
\hline
\end{tabular}

"MF: Malfunction of strain gauge 


\subsubsection{Stiffness Characteristic}

The slope of the load-deflection curve determines the stiffness which represent the amount of load need to produce a unit displacement at the center of the slab. Prior to the formation of the first crack, the curve is linear and the slope is very steep more than five times steeper than after the crack slopes. The amounts are tabulated in Table 4.2.

By increasing the applied load, the cracks start to form. The stiffness amounts gradually decrease; this is called the transition stage. According to experimental results graphs, the deflection for the transition stage is around two millimetres for reinforced HSC specimens and three to four millimetres for UHP-FRC specimen. After transition stage, the specimens experience the dramatic decrease of the stiffness compared to that of un-cracked stage. For all the HSC specimens, tension stiffening is observed at about 12 to $18 \mathrm{~mm}$ after the end of the transition stage deflection. After this point, the stiffness increases about $25 \%$ due to the tension stiffening characteristic of reinforced HSC. For the UHP-FRC specimen, this increasing amount is about zero. After the yield point for the H.S 0.5 and H.S 1 specimens, the average stiffness reduction is about $75 \%$ as compared to the previous stage. At ultimate, H.S 0.5, H.S 1 and UHP-FRC 1 stiffness become zero.

According to (Marzouk and Hussein, 1991), the failure modes of the slabs can be indicated by the load-deflection curve. The load-deflection curves of H.S 0.5 and H.S 1 and UHP-FRC 1 are typical examples of flexural failure (Figures 4.1 to 4.4). For H.S 2, the stiffness at failure is not zero as the load-deflection curve shows a positive slope of the tension stiffening stage for the stiffness. The failure at this point happens suddenly before the yield of tension reinforcement. This is a typical example of the compression failure due to being over reinforced which leads to sudden one-way shear failure.

For all reinforced HSC specimens there is a trend, as the reinforcement ratio is increased, the stiffness is also increased. In Figure 4.5, the load-deflection curves of all four specimens are plotted on top of each other. There is another remark for the H.S 2 specimen with $2 \%$ reinforcement ratio which starts to crack earlier than other specimens. The reason is attributed to the less strength of concrete for the H.S 2 specimen compared to the other HSC specimens. In fact, the H.S 2 diameter size of the reinforcement is double compare to the other specimens. Thus, less amount of the 
concrete contributes to the strength and stiffness that is why it cracks earlier than the other specimens. As the compressive strength is higher for the UHP-FRC 1 specimen compared to the H.S 1 specimen with the same reinforcement ratio, the stiffness is also higher (Table 4.2).

\subsubsection{Ductility Characteristic}

The slab static ductility is defined as the ratio of the ultimate deflection to the deflection at first yield (Marzouk and Hussein, 1991). In another words, the ductility also refers to the structure deformation ability from the service limit state to the ultimate limit state. The graphically computed ductility are tabulated in Table 4.2. The HSC specimen with the lower reinforcement ratio deflects more presenting more ductility. The ductility of the H.S 0.5 specimen is about two times greater than the H.S 2 specimen and one and half times greater than the H.S 1 specimen that reveals the ductility is inversely proportional to the square root of the reinforcement ratios. The UHP-FRC 1 specimen is about $85 \%$ more ductile than the H.S 1 specimen with the same reinforcement ratio. This is because the presence of the steel fiber in the concrete mixture used for UHP-FRC 1.

\subsubsection{Energy Absorption Characteristic}

The static fracture energy absorption capacity is defined as the area under the loaddeflection curve. The graphically computed values of the energy absorption are tabulated in Table 4.2. For the slabs with same failure mode, as the reinforcement ratio is increased, the energy absorption capacity is increased. The energy absorption capacity is increased by $42 \%$ as the reinforcement ratio doubled in the H.S 1 and H.S 0.5 specimens. The static energy absorption capacity for UHP-FRC 1 is $160 \%$ more than H.S 1 with the same reinforcement ratio. This is due to the greater amounts of both the compressive strength and ductility associated with the UHP-FRC 1 specimen mainly in respect to the steel fiber contribution in its strain hardening. From Figure 4.5 , it is visually observed that for the serviceability deflection of $11 \mathrm{~mm}$, the energy absorption for the HSC specimens slightly increases by increase in the reinforcement ratio, however, for UHP-FRC 1 this amount is more than twice of the HSC specimens' amount. 
Table 4.2 Observed Ductility, Stiffness, and Energy Absorption

\begin{tabular}{|l|l|l|l|l|l|l|}
\hline $\begin{array}{l}\text { Slab } \\
\text { Specimen } \\
\text { Name }\end{array}$ & $\begin{array}{l}\text { Concrete } \\
\text { Strength } \\
\mathrm{f}^{\prime}{ }^{\prime} \quad\end{array}$ & $\begin{array}{l}\text { Steel } \\
\text { Rebar } \\
\text { Ratio } \rho\end{array}$ & Ductility & $\begin{array}{l}\text { Uncracked } \\
\text { Stiffness } \\
\mathrm{kN} / \mathrm{mm}\end{array}$ & $\begin{array}{l}\text { Cracked } \\
\text { Stiffness } \\
\mathrm{kN} / \mathrm{mm}\end{array}$ & $\begin{array}{l}\text { Energy } \\
\text { Absorption } \\
\text { Capacity } \\
\mathrm{kN} . \mathrm{m}\end{array}$ \\
\hline H.S 0.5 & 68.0 & 0.5 & 2.55 & 25 & 3.0 & 7.06 \\
\hline H.S 1 & 71.0 & 1.0 & 1.69 & 26 & 3.3 & 10.03 \\
\hline H.S 2 & 78.5 & 2.0 & 1.31 & 28 & 5.3 & 6.62 \\
\hline UHP-FRC 1 & 162.4 & 1.0 & 3.13 & 50 & 6.6 & 26.80 \\
\hline
\end{tabular}

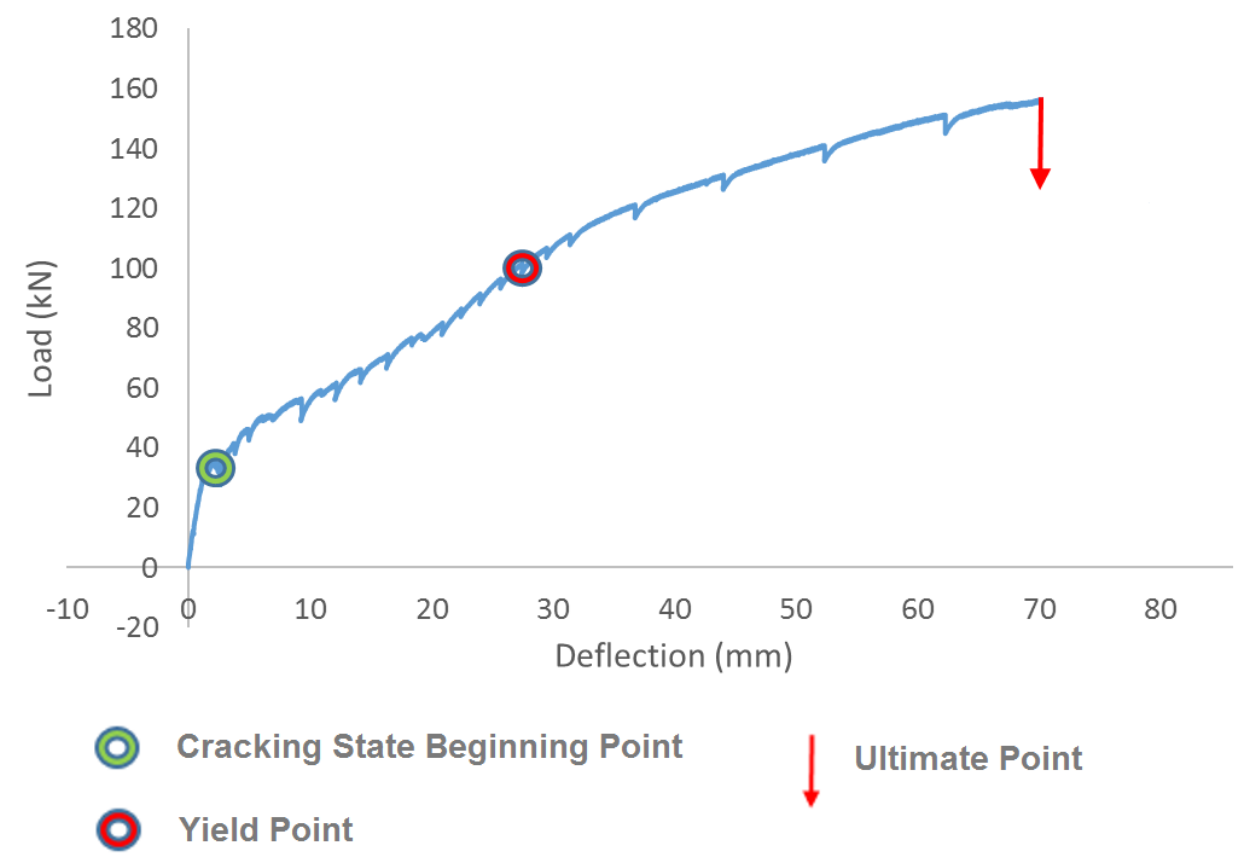

Figure 4.1 Load vs. Deflection Curve H.S 0.5 Slab 


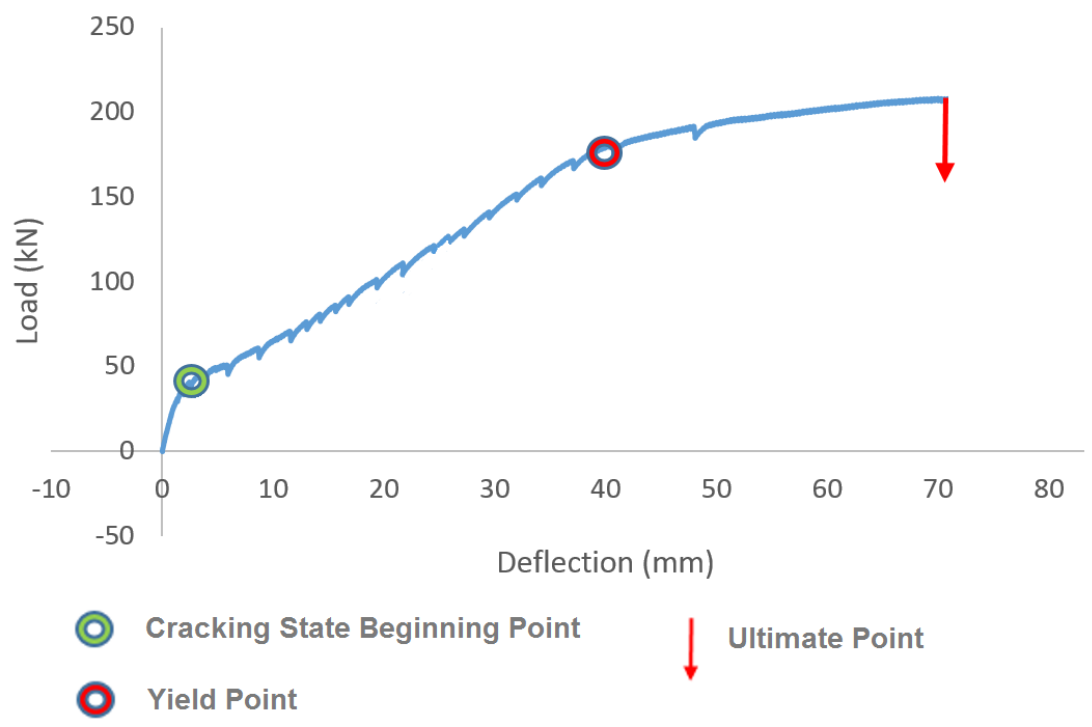

Figure 4.2 Load vs. Deflection Curve H.S 1 Slab

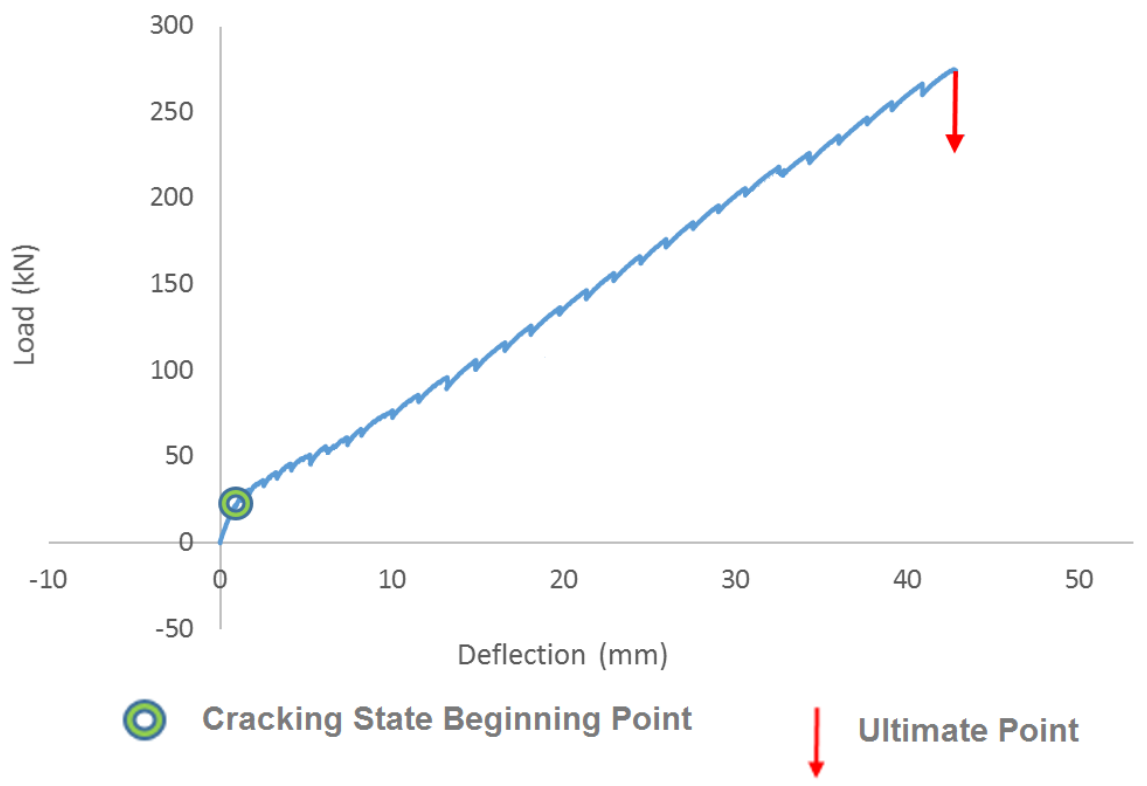

Figure 4.3 Load vs. Deflection Curve H.S 2 Slab 


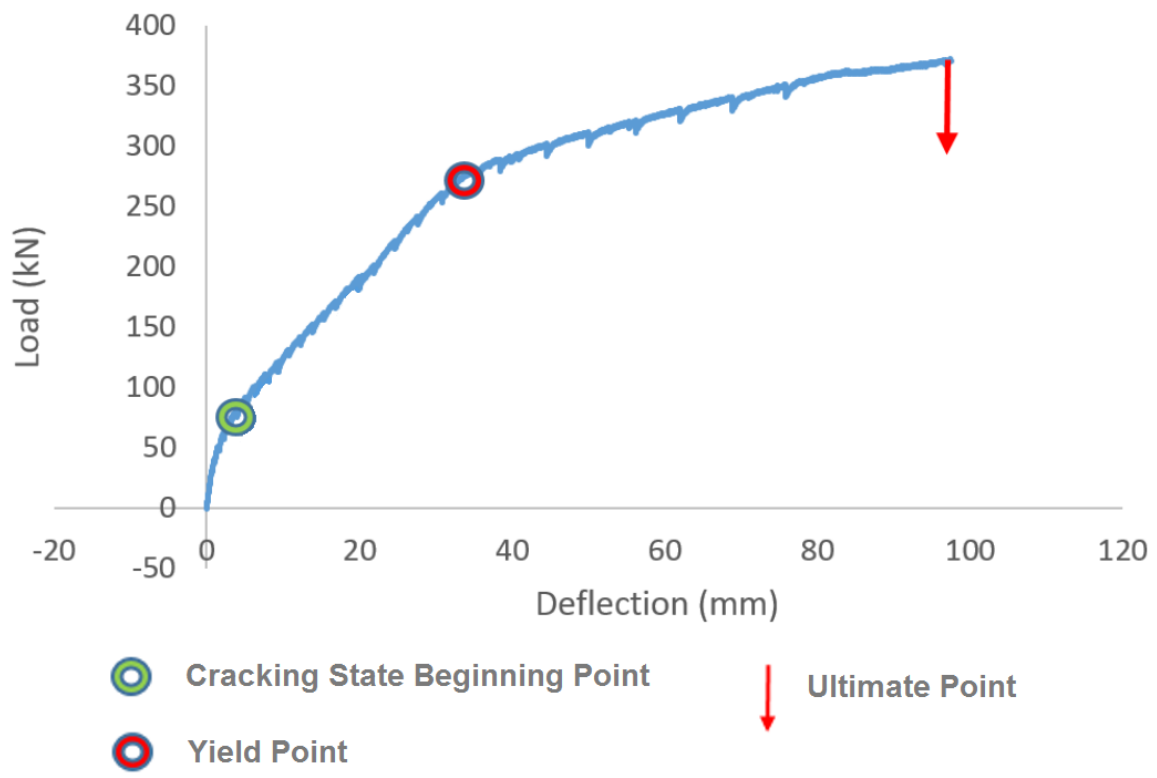

Figure 4.4 Load vs. Deflection Curve UHP-FRC 1 Slab

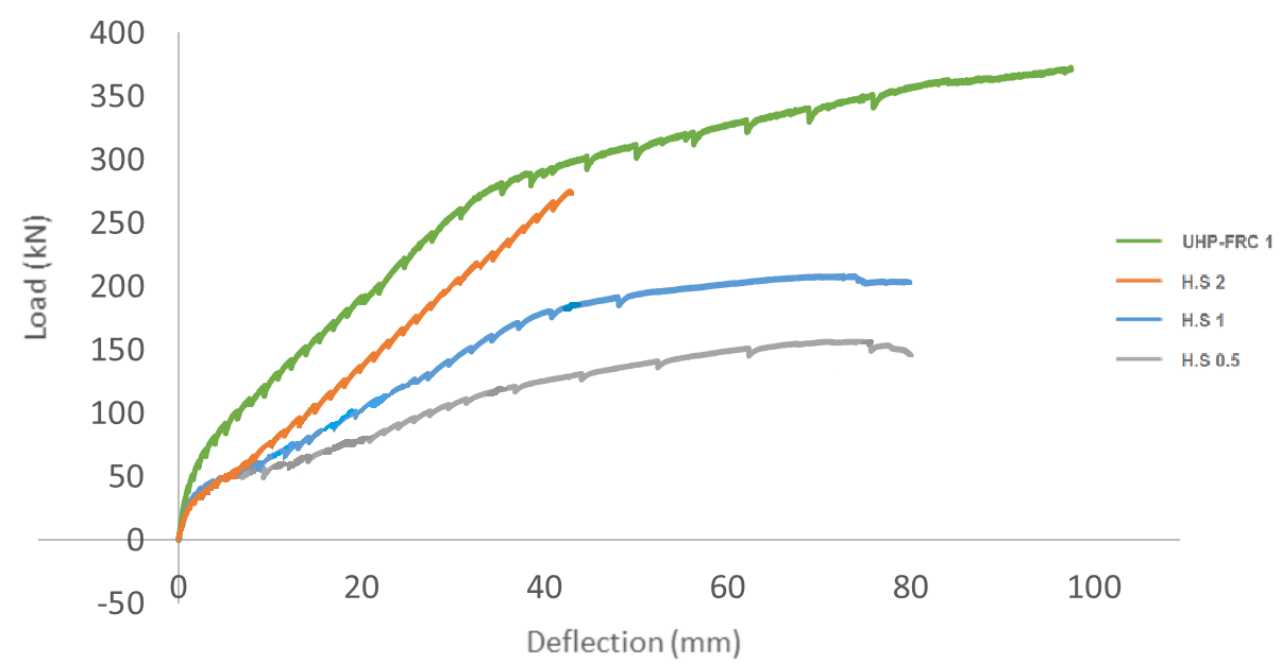

Figure 4.5 Load vs. Deflection Curves for all Slabs 


\subsection{Load versus Strain Curves Results}

The strain on the tension steel reinforcements located at the middle of the slabs are measured where the amount of strain is about maximum (Figure 3.25). The load strain curves for all the specimens are shown in Figures 4.6 to 4.9. The points for the cracking and yield states are marked on each graph and tabulated in Table 4.1. The ultimate state points are not revealed because of the malfunction of the strain gauge for the H.S 0.5, H.S 1, and UHP-FRC 1 specimens. The reason for these malfunctions is attributed to either surpassing capacity or loss of bond for the strain gauge. For the specimen H.S 2, the one-way shear failure at the support has happened before the strain gauge becoming malfunctioned. Also, the one-way shear failure at the support happens before reaching the yield point.

As it can be seen from Figure 4.10, the higher reinforcement ratio leads to steeper slope of the load reinforcement strain curve between the cracking and yield states for all the specimens. As it is also observable from the load-deflection curve results, the cracking point load is increased by increase in the reinforcement ratio using the same reinforcement diameter of 10M for H.S 0.5 and H.S 1. This amount is decreased for H.S 2 with the reinforcement diameter of $15 \mathrm{M}$ due to the less contribution of concrete in the total slab stiffness.

The concave shape of the load strain curves of the HSC specimens H.S 0.5, H.S 1, and H.S 2 between the cracking and the yield points are due to the tension stiffening effects of the cracked concrete on the specimen reinforcement. At the cracks, the reinforcements carry all the tensile force; but on the un-cracked regions, the concrete would continue to carry the growing tensile load through the bond between the reinforcement and the concrete; this phenomena is defined as the tension stiffening. The explanation can be stated due to locally demobilization and partially remobilization of reinforcement and concrete at the un-cracked region of the specimen. The results for the HSC specimens H.S 0.5, H.S 1, and H.S 2 curves, Figure 4.10, reveal that the tension stiffening regions are about $1000 \mu \varepsilon, 500 \mu \varepsilon$, and $250 \mu \varepsilon$ respectively.

The assumption that the reinforcement will carry all the load at the cracking does not manifest itself in UHP-FRC 1 due to contribution of the fibers and formation of multiple cracking which is leading to the strain hardening behaviour. 


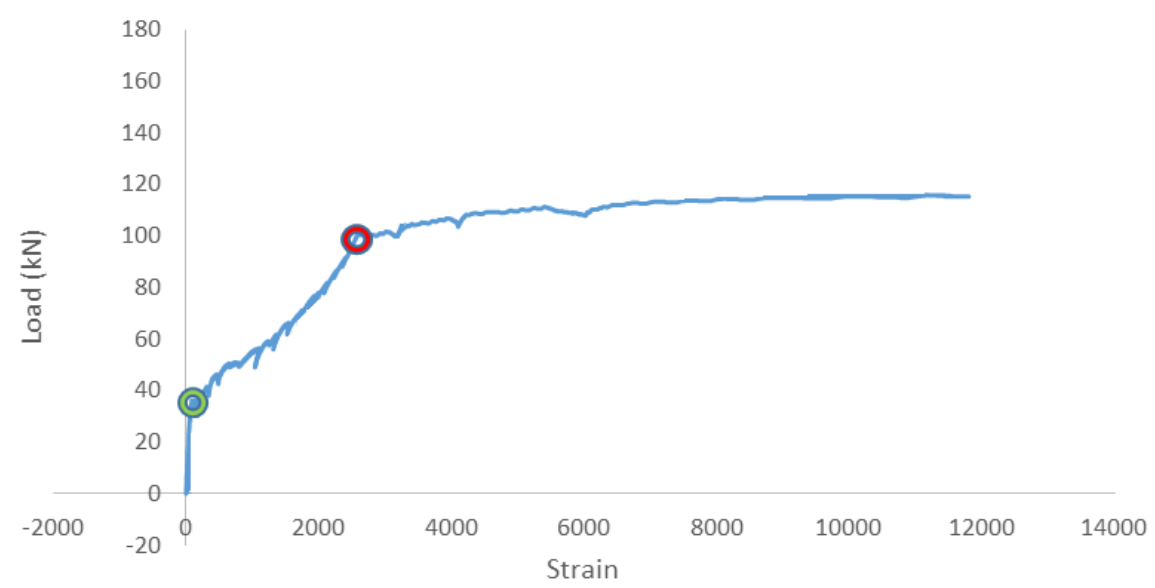

(2) Cracking State Beginning Point
(- Yield Point

Figure 4.6 Load vs. Strain Curve H.S 0.5 Slab

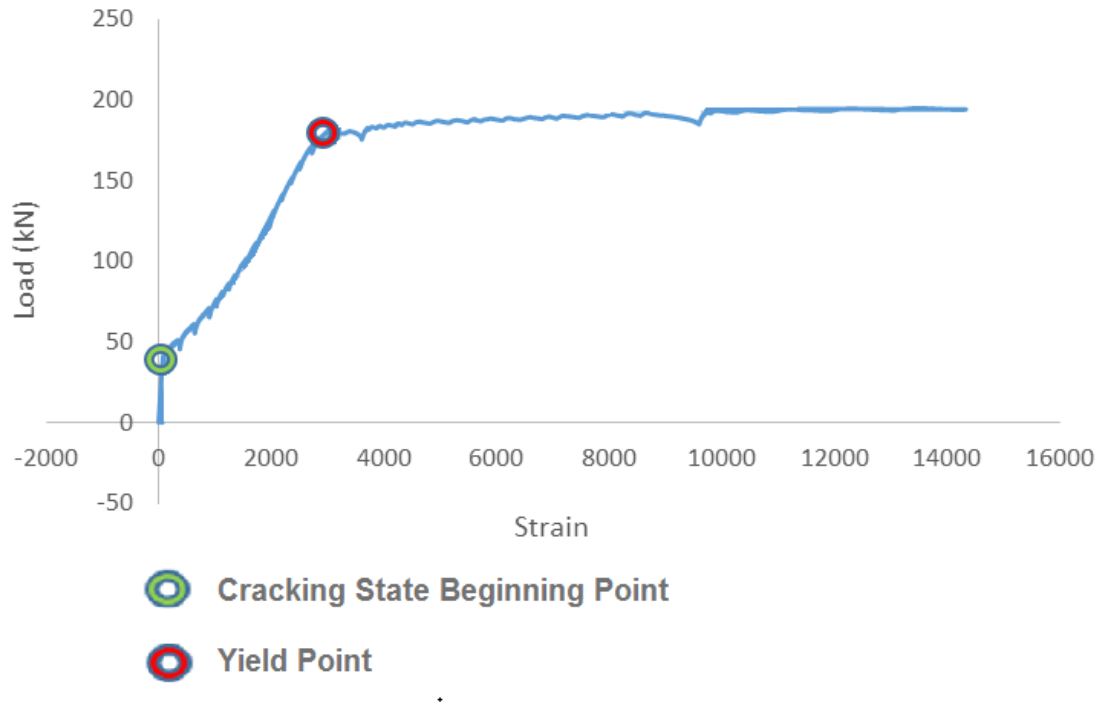

Figure 4.7 Load vs. Strain Curve H.S 1 Slab 


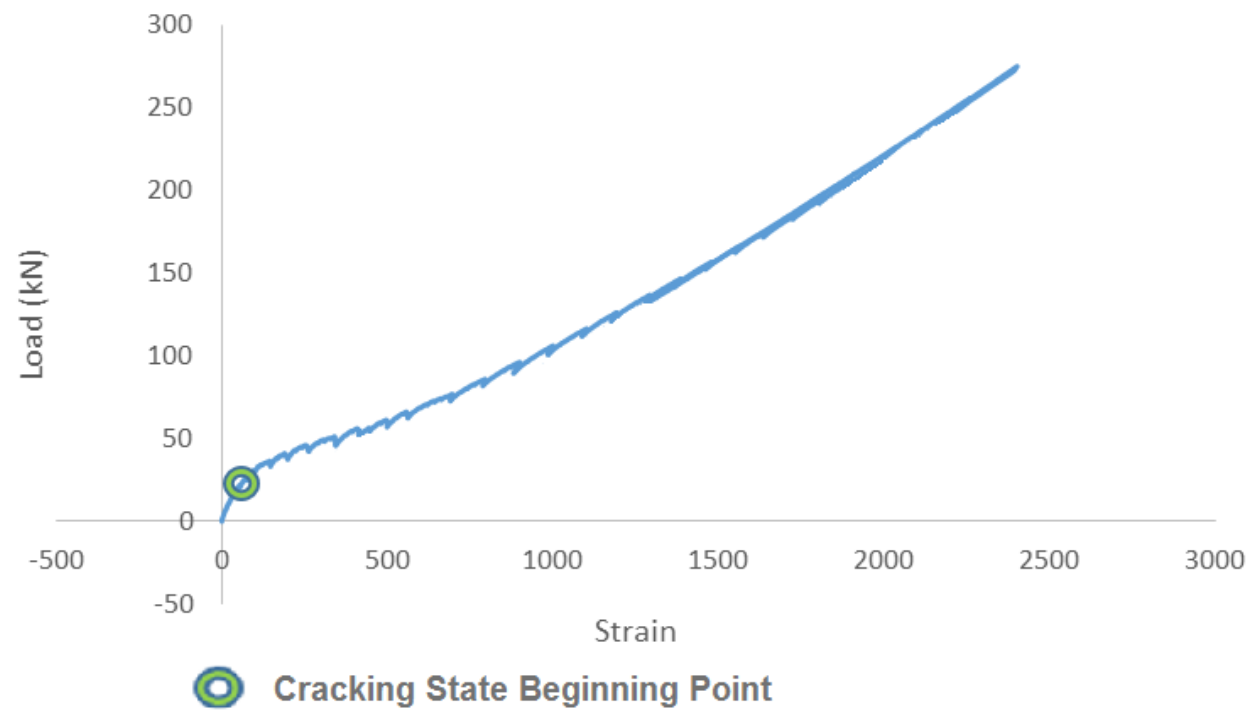

Figure 4.8 Load vs. Strain Curve H.S 2 Slab

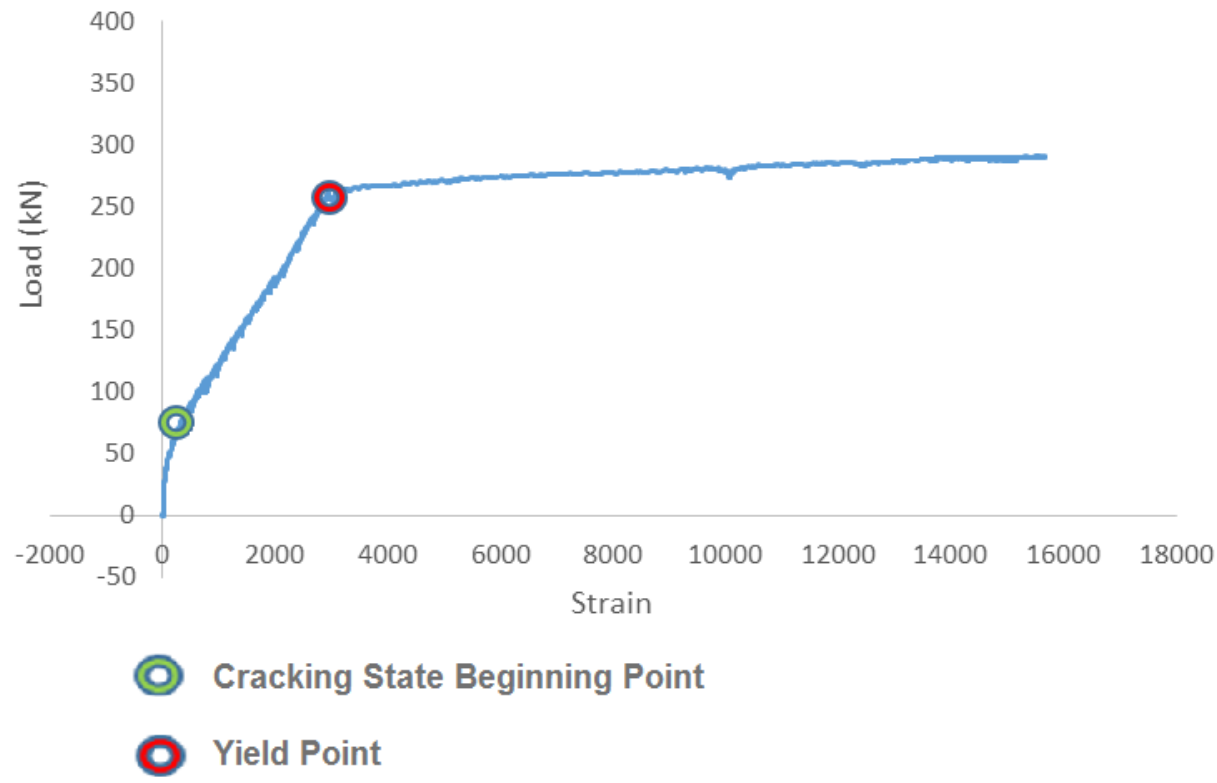

Figure 4.9 Load vs. Strain Curve UHP-FRC 1 Slab 


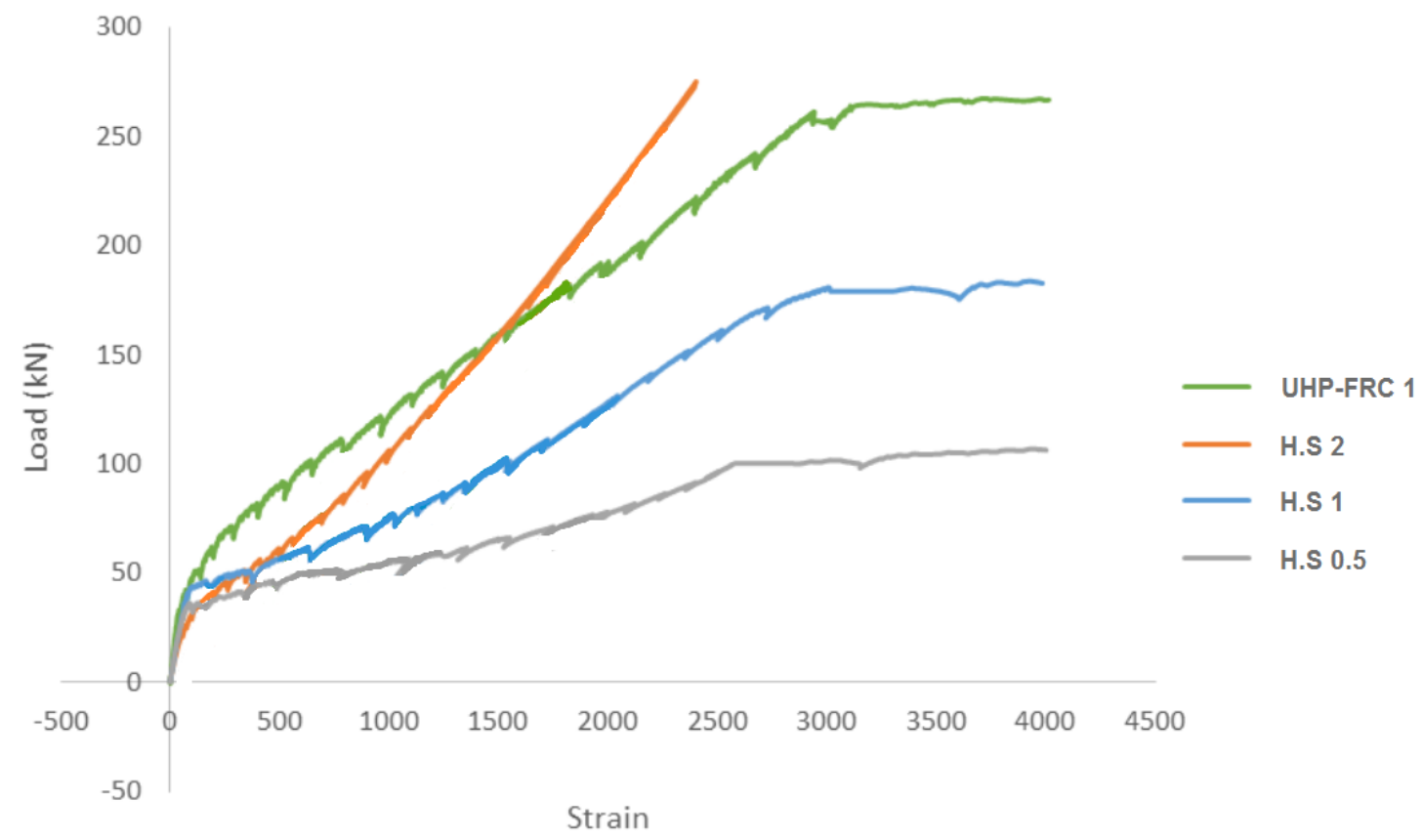

Figure 4.10 Load vs. Strain Curves for all Slabs

\subsection{Serviceability}

According to ACI 318-14, the serviceability criteria for the steel reinforced specimen in terms of the deflection and strain are as follows:

1. Deflection limit $1 / 180$ for the serviceability, where 1 is the member span.

2. In general, acceptable stresses in the steel reinforcement should be around $0.6 \mathrm{f}_{\mathrm{y}}$ at the service loads, which correspond to a strain approximately 1200 micro-strains for grade 400 steel.

By comparing the deflection and strain curves with the serviceability criteria, all the slab specimens show acceptable serviceability deflection within the limit. H.S 2 and UHP-FRC 1 deflections are about twice beyond the serviceability limit. It means that they could be designed with the smaller thickness or lower reinforcement ratio in actual practice. The range of service load of the slab specimens is $60 \mathrm{kN}$ to $120 \mathrm{kN}$ corresponding to 1200 micro strains. The observed values of the service loads are at the range of $27 \%$ to $38 \%$ of the ultimate strain. 


\subsection{Ultimate Capacity}

The ultimate load capacity and the corresponding ultimate deflection are observed from the load-deflection curves and tabulated in Table 4.1. For the H.S 0.5 and H.S 1 specimens which both are failed in the flexural mode, the ultimate capacity is increased by $33 \%$ as the reinforcement ratio is doubled. Also for UHP-FRC 1 and H.S 1 with the same reinforcement ratio and same flexural failure mode, the ultimate capacity is increased by $77 \%$ as the compressive strength is increased by $128 \%$. The flexural ultimate deflections are between $69.7 \mathrm{~mm}$ to $97.5 \mathrm{~mm}$.

\subsection{Crack Pattern Failure Mode Results}

For all four specimens H.S 0.5, H.S 1, H.S 2, and UHP-FRC 1, the crack pattern are mapped on the tension side surface at $5 \mathrm{kN}$ increments of the gradual static loading applied by manual hydraulic jack, as are pictured in Figures 4.11 to 4.14. The first crack at the initial cracking load is observed at the yield line close to the edge of the slab parallel to the transverse reinforcement direction ( $\mathrm{x}$ or $\mathrm{y}$ ) followed by the formation of similar cracks in the orthogonal horizontal direction ( $\mathrm{y}$ or $\mathrm{x}$ ). By increasing the load, more parallel cracks are developed toward the column circumference. All the previous cracks become widened. The spacing between the parallel cracks matches to the spacing of the reinforcements which are $100 \mathrm{~mm}$ for H.S 1, H.S 2, and UHP-FRC 1 and $200 \mathrm{~mm}$ for H.S 0.5. The formation of the new cracks slowdown as the load approaches to the failure load. Near the ultimate load, some audible sound is heard due to the separation of the reinforcements from the concrete as well as the noise corresponding to the spalling.

According to (Marzouk and Hussein, 1991), two main modes of failure are associated with the reinforced two-way slab, the flexure and shear modes of failure. The flexure mode is characterized by the yield of steel or bond slip failure which leads in the exhaustion of the flexural capacity of the slab at failure. The shear failure mode is divided into two types, pure punching failure and ductile punching failure. The pure punching failure happens before the yielding of the steel that is associated with the localized crack patterns and a sudden failure. The ductile punching failure happens after the yielding of the steel and it resembles the flexural behaviour with the gradual load-deflection development. 
The modes of failure for all the slab specimens except H.S 2 are predicted as the flexure failure and the records are given in Table 3.5. The experimental results confirm the predicted failure modes. The pure punching failure for slab H.S 2 is not occurred in the middle at the vicinity of the loading plate, it is occurred as one-way shear failure at one support. The diagonal one-way shear failure at the support is not considered in the prediction calculation. The calculation are just for the punching at the middle of the slab. As shown in Figure 4.3, this failure is happened in positive slope before the actual yield point of the steel, this means that the actual yield strength of steel is higher than 2400 micro strain. Hence the H.S 2 slab is over reinforced it fails as compression failure at one support. Immediately after the compression failure at the bottom surface, one-way shear failure happens at the vicinity of support tangent to the HSS support beam edge (Figures 3.39 and 4.13). 


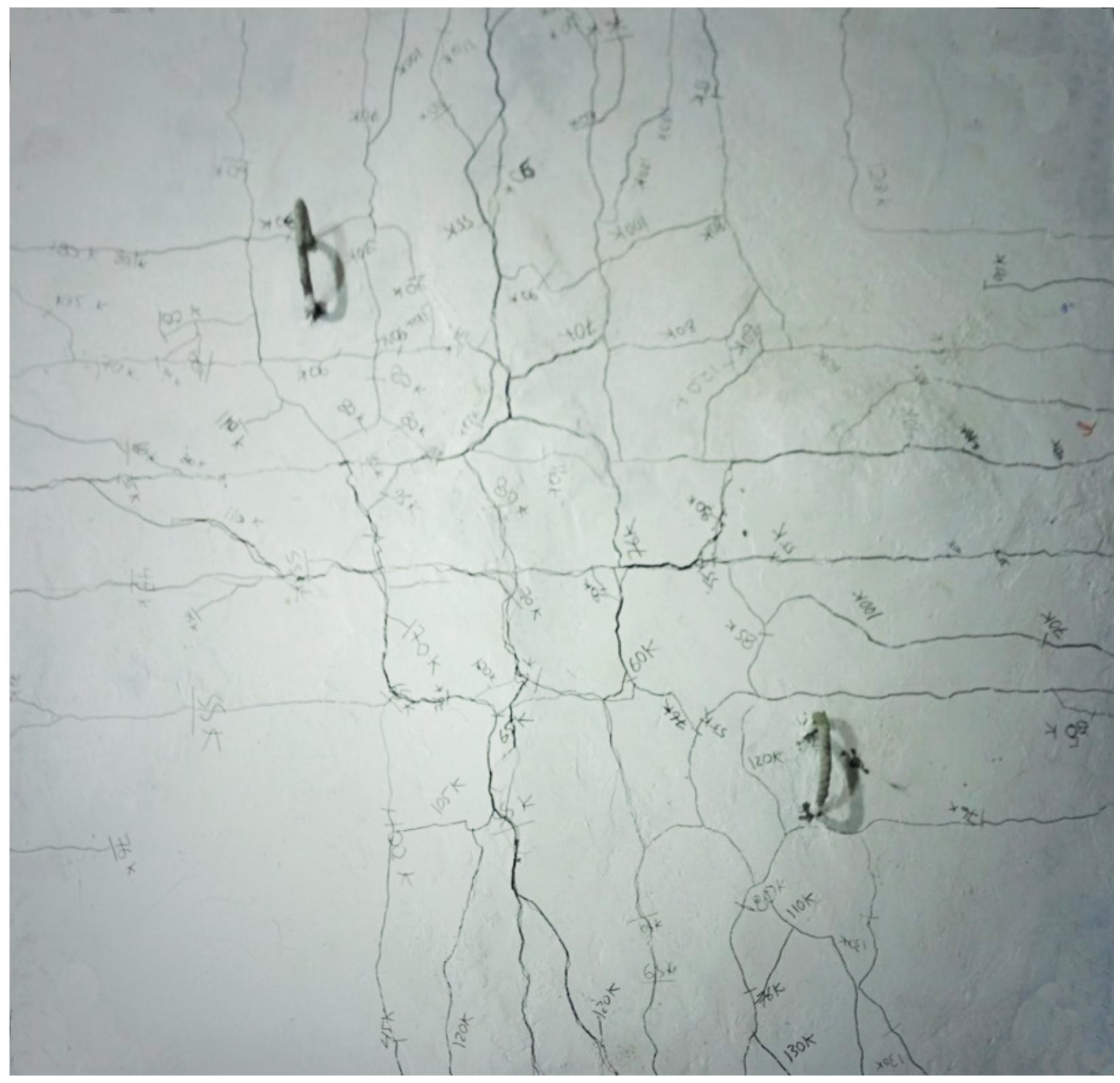

Figure 4.11 H.S 0.5 Slab Crack Pattern 


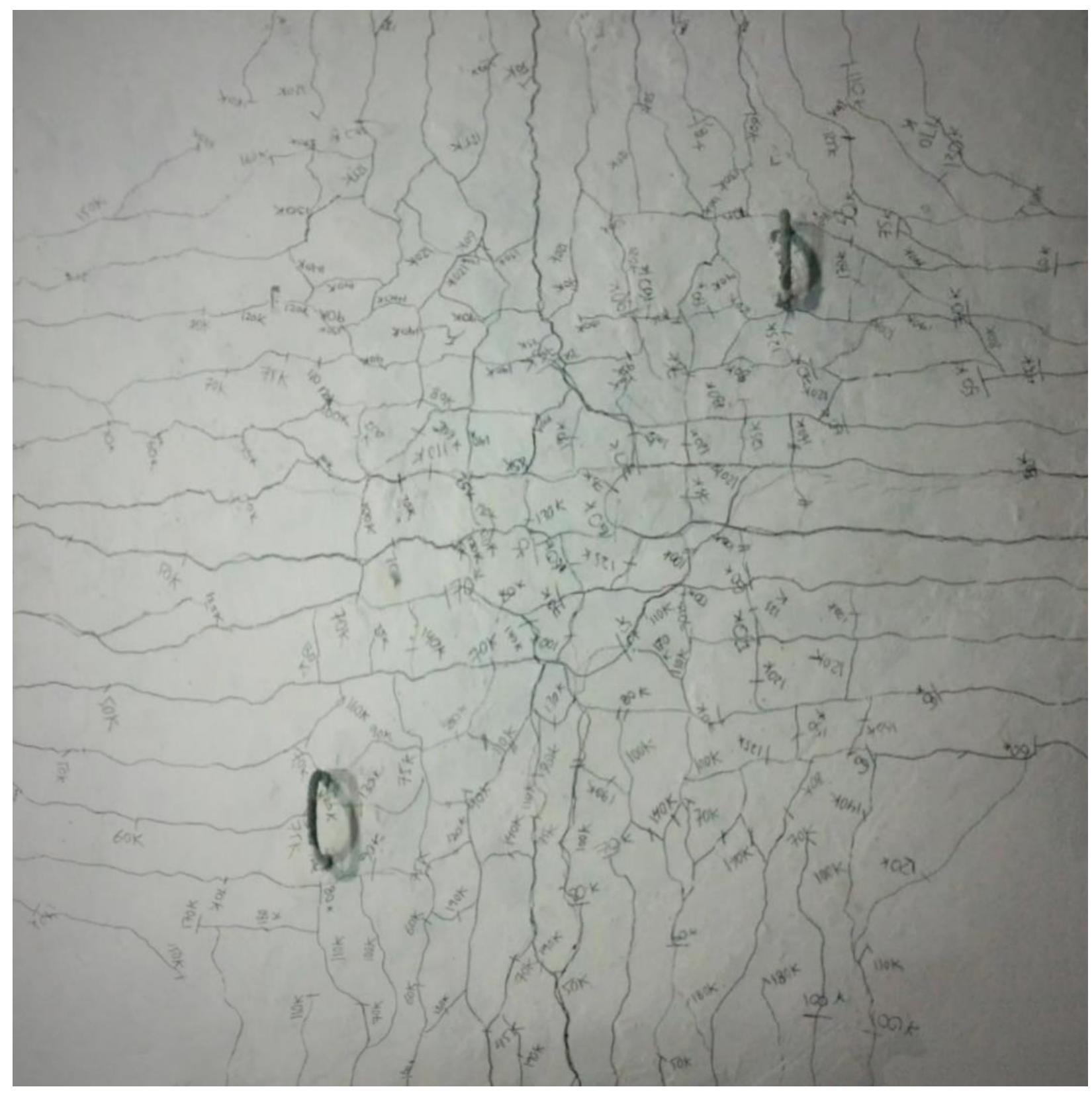

Figure 4.12 H.S 1 Slab Crack Pattern 


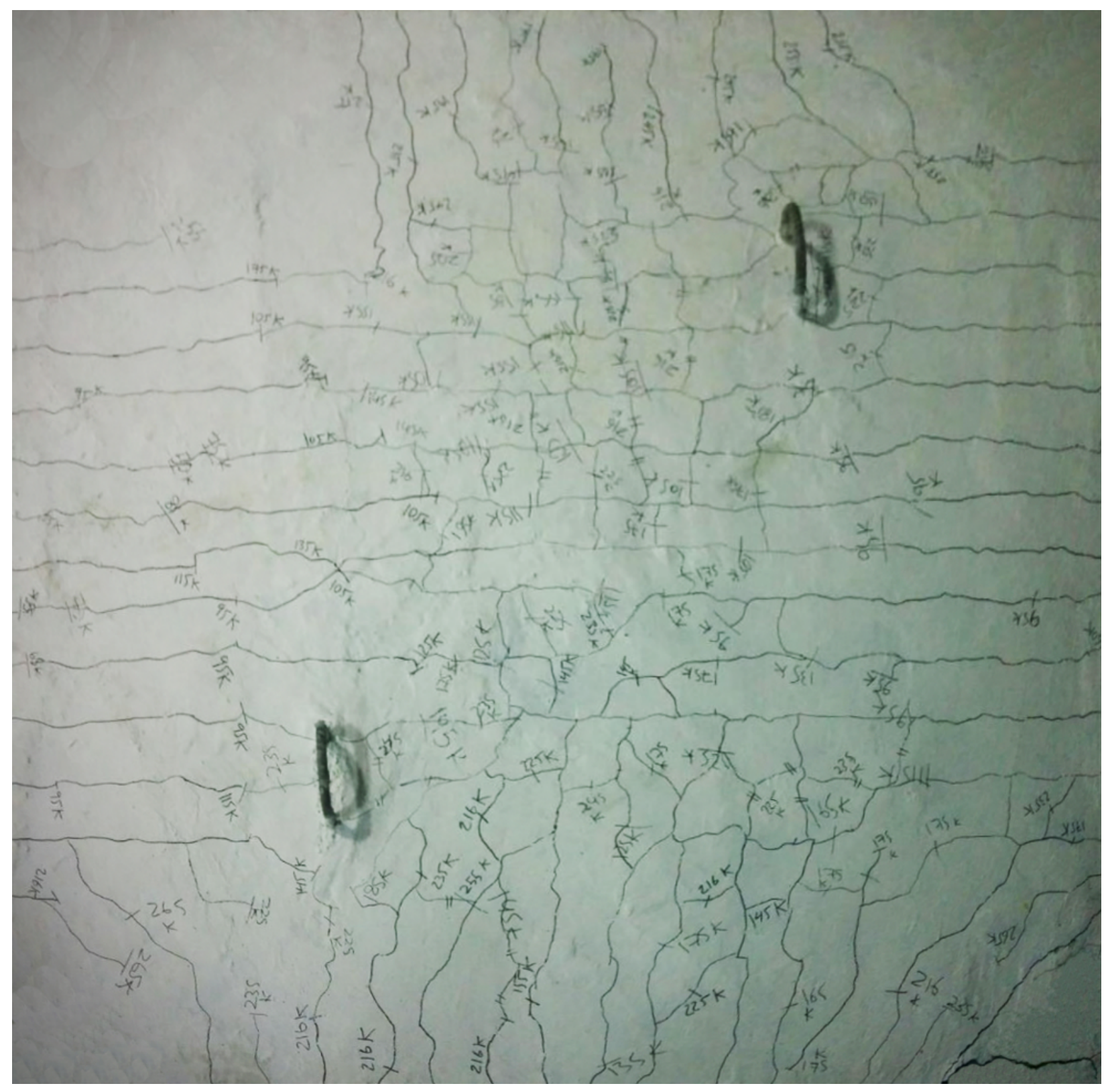

Figure 4.13 H.S 2 Slab Crack Pattern 


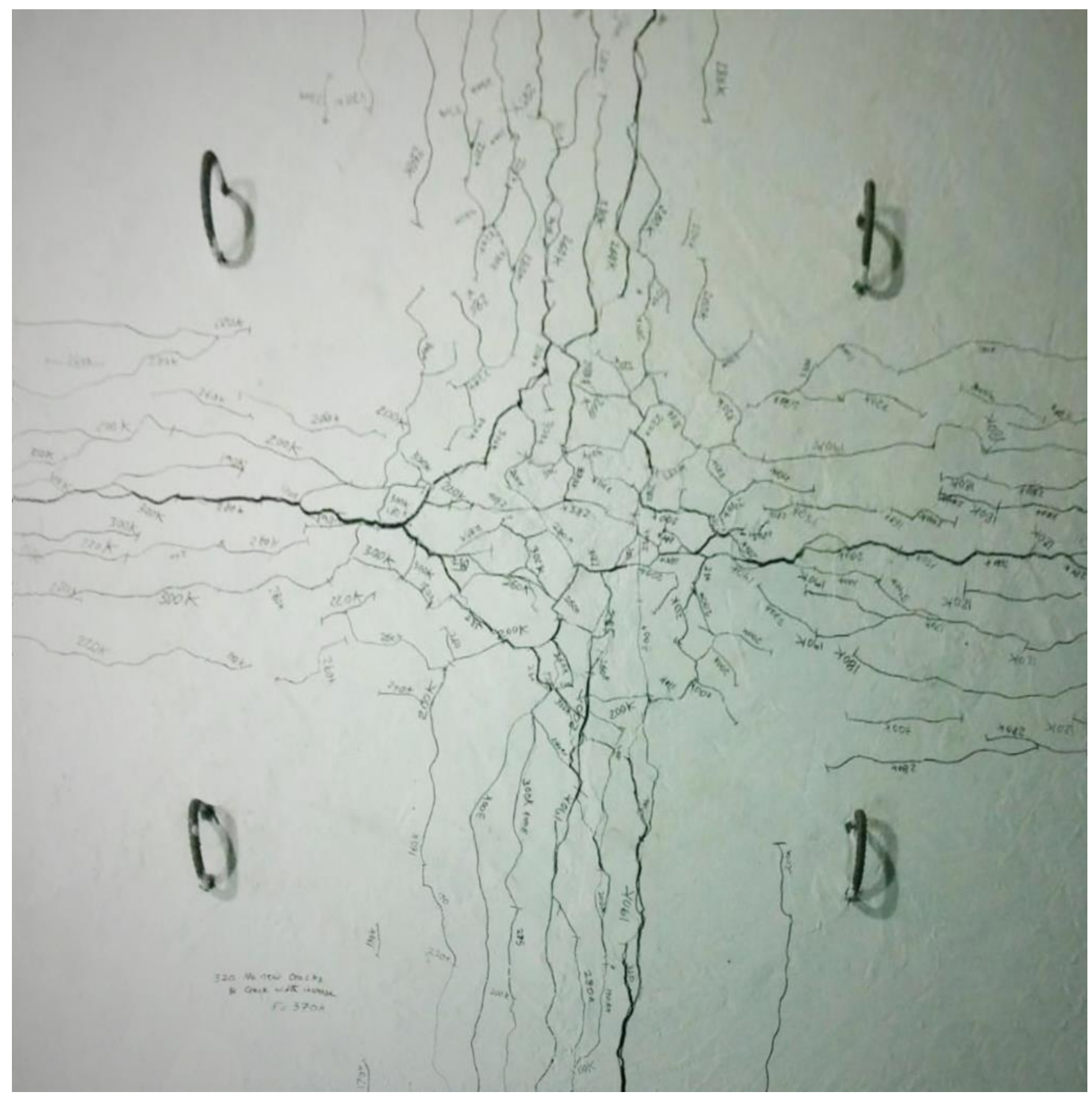

Figure 4.14 UHP-FRC 1 Slab Crack Pattern 


\subsection{Ambient Vibration Excitation Test Results}

The RD technique is applied to detect the presence and extent of the damage at the cracking, yield, and ultimate states. In order to exert the damage, the static loading in the middle of the slab is applied using the hydraulic jack. The slab is excited randomly using a $0.5 \mathrm{~kg}$ impact hammer type Kistler 9728A with the sensitivity of $1.05 \mathrm{mV} / \mathrm{LbF}$. The vertical acceleration response (Figures 4.15 and 4.16 ) is captured from the $50 \mathrm{~g}$ accelerometer type Kistler 8640A50 with the sensitivity of $102.5 \mathrm{mV} / \mathrm{g}$. The vertical acceleration is measured using $2500 \mathrm{~Hz}$ sampling rate which according to Nyquist-Shannon Sampling theorem it will cover up to $1250 \mathrm{~Hz}$ possible natural frequencies. FFT analyses is used to determine the frequency spectrum of data and a bandpass Butterworth filter is used to filter the first mode of the acceleration response data around the first natural frequency. A Matlab code written for Butterworth filtering is presented in Appendix C. In order to extract the RD signature from the filtered acceleration response, the triggering level of 1.4 times of the standard deviation of the response is used. Appendix D presents a Matlab program written to obtain the normalized RD signature from the response data. The extracted RD signatures for the H.S 0.5, H.S 1, H.S 2, and UHP-FRC 1 specimens at the intact, cracking, yield, and ultimate damage condition are shown in Figures 4.17 to 4.20. The integration is conducted using a time increment of $0.0004 \mathrm{sec}$ and the number of segments used to construct the $\mathrm{RD}$ is equal to the half of the triggered data number approximately 3000 to 4000 . Respectively, the total length of time series generated to extract each RD signature is approximately 1200 to $1600 \mathrm{sec}$. This equals to 3 to 4 million sampling points.

The dynamic parameters the natural frequency and damping ratio are obtained from the RD signatures and are pictured and tabulated in Figures 4.21 and 4.22, and Tables 4.3 and 4.4. 


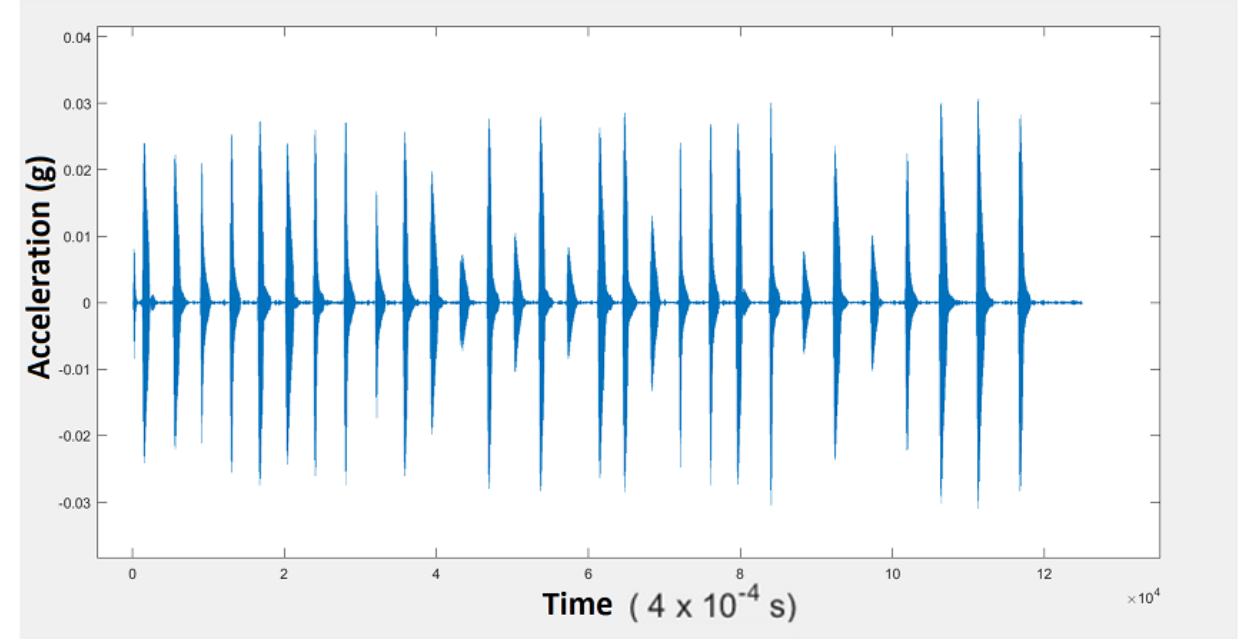

Figure 4.15 Time Acceleration Reading Plot for H.S 1 Slab at Yield State

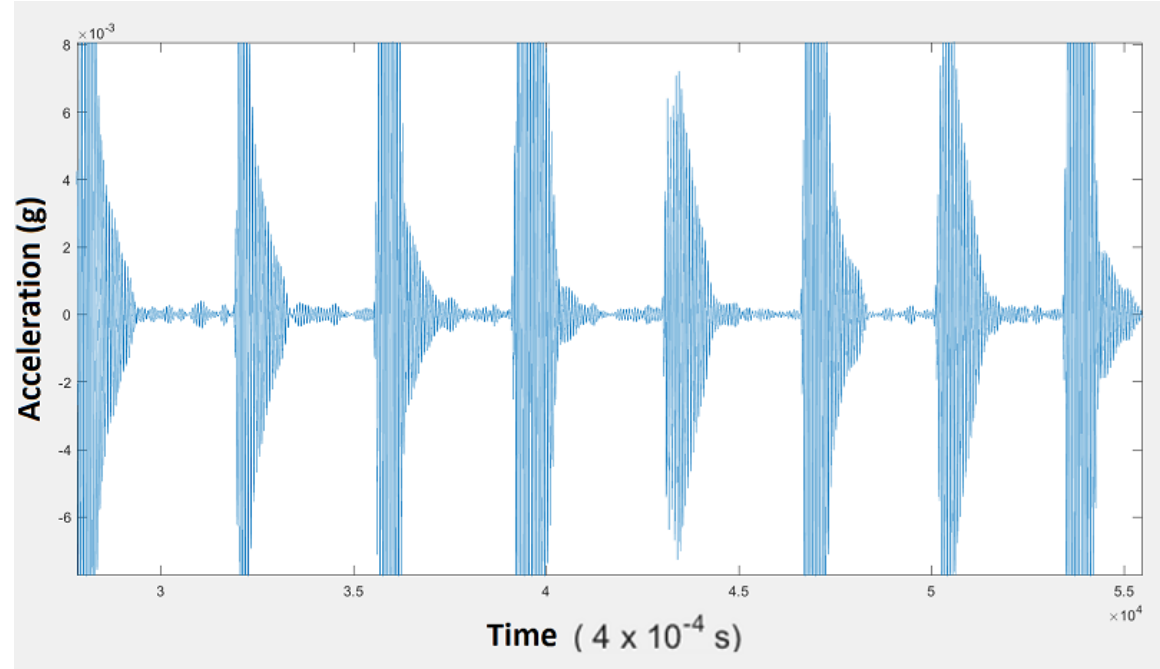

Figure 4.16 Enlarged Time Acceleration Reading Plot for H.S 1 Slab at Yield State 

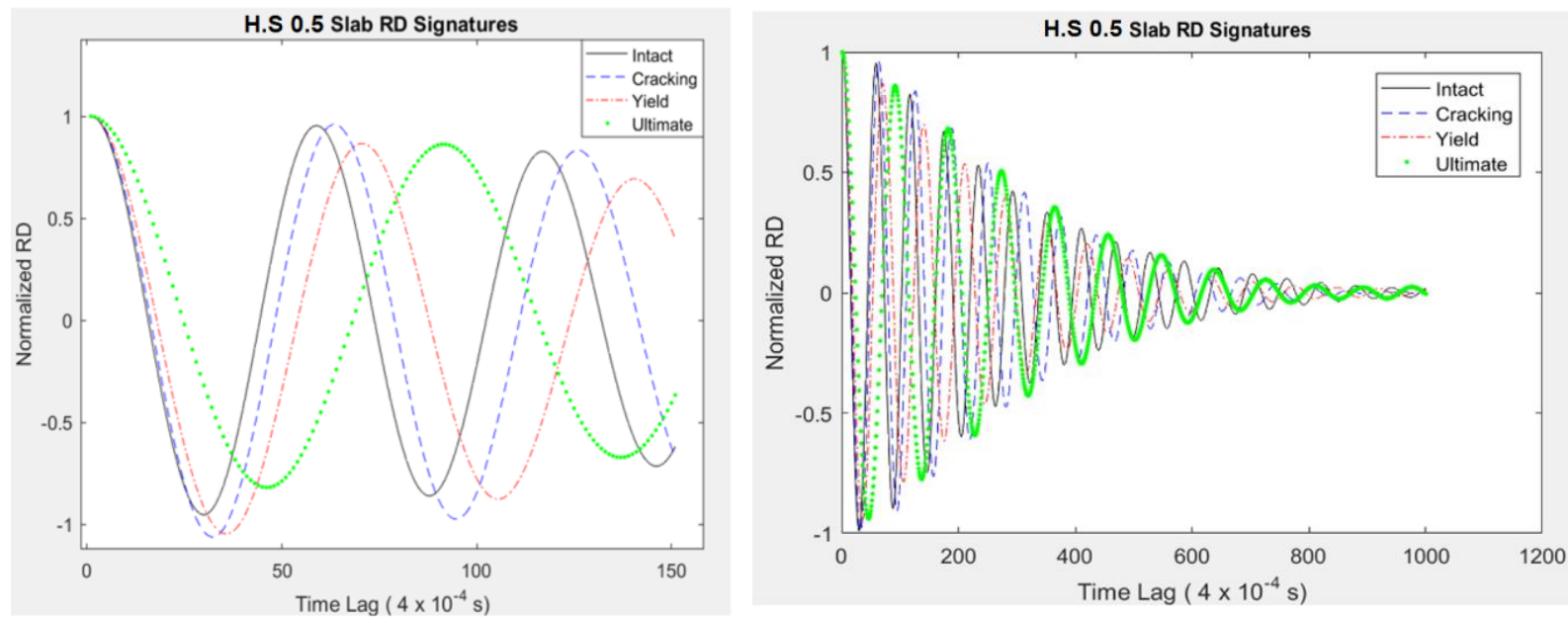

Figure 4.17 Mode 1, Random Decrement Signatures at Intact, Cracking, Yield and Ultimate States for H.S 0.5 Slab
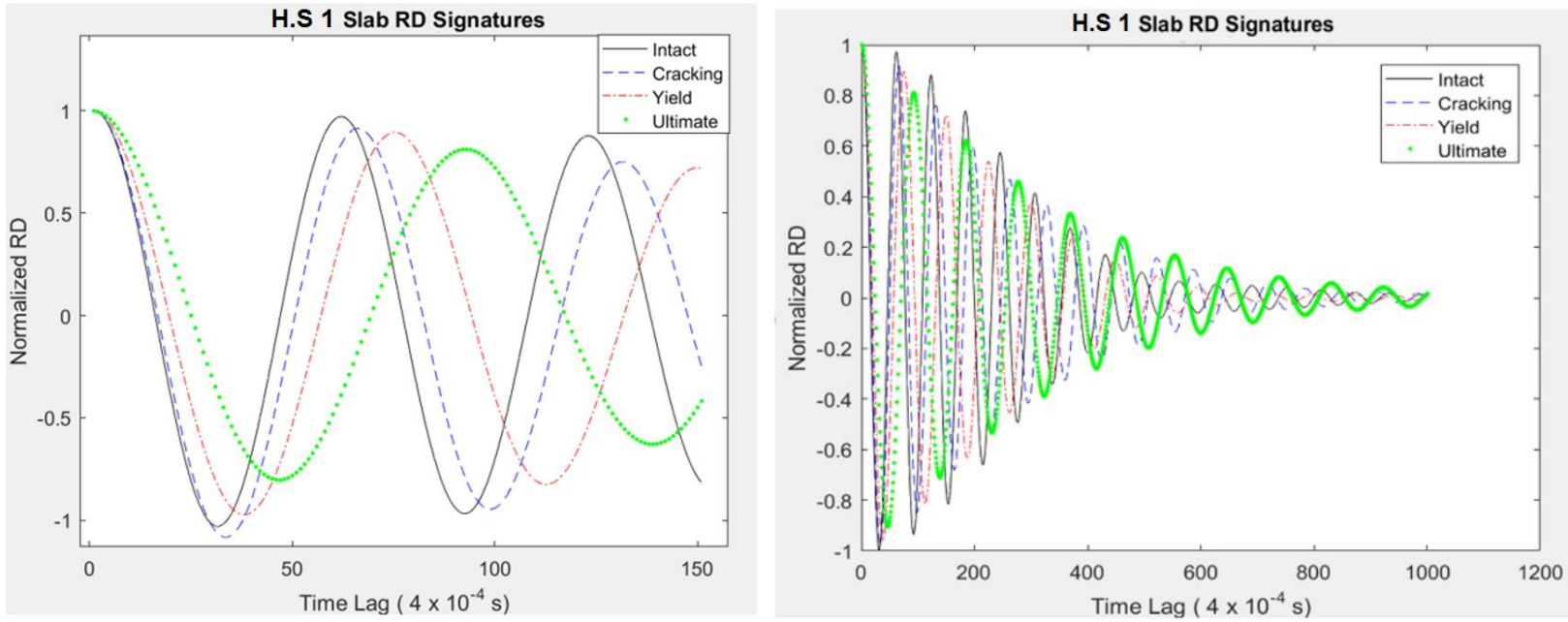

Figure 4.18 Mode 1, Random Decrement Signatures at Intact, Cracking, Yield and Ultimate States for H.S 1 Slab 

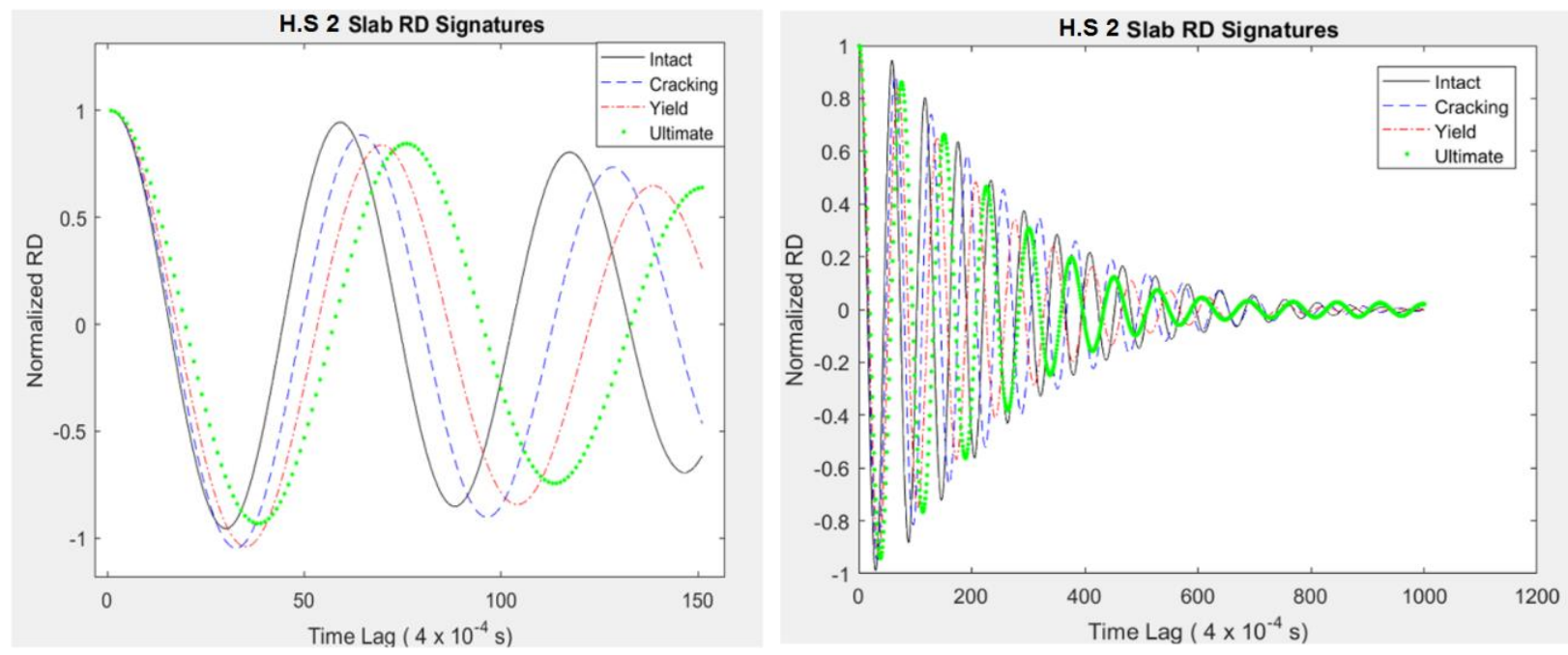

Figure 4.19 Mode 1, Random Decrement Signatures at Intact, Cracking, Yield and Ultimate States for H.S 2 Slab
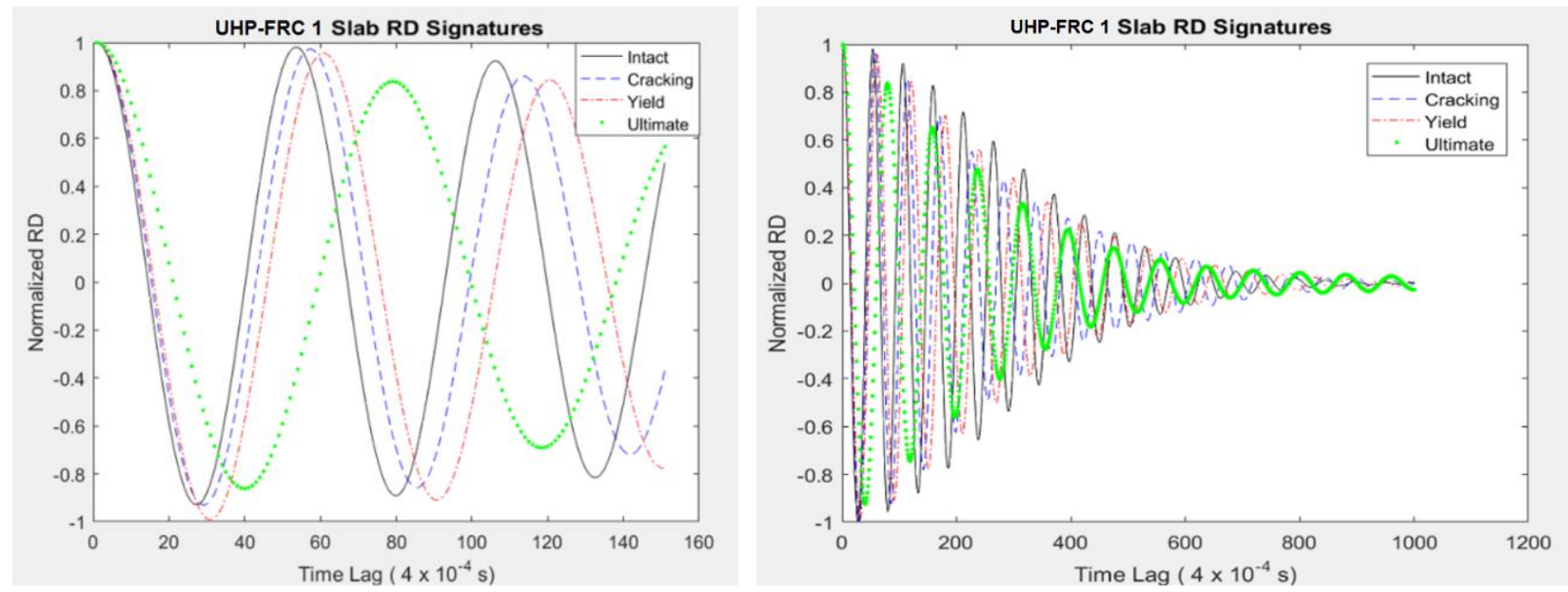

Figure 4.20 Mode 1, Random Decrement Signatures at Intact, Cracking, Yield and Ultimate States for UHP-FRC 1 Slab 


\subsubsection{Natural Frequency Results}

For all the specimens H.S 0.5, H.S 1, H.S 2, and UHP-FRC 1, the natural frequency is dropped at each damage states cracking, yield and ultimate. It is dropped from the intact to cracking $7 \%$ to $8 \%$, from intact to yield $16 \%$ to $26 \%$ and from intact to ultimate $24 \%$ to $34 \%$. The natural frequency for H.S $1(\boldsymbol{\rho}=1 \%)$ is $3.7 \%$ less than H.S $0.5(\boldsymbol{\rho}=0.5 \%)$. Bearing in mind that the natural

frequency is proportional to the squarer root of stiffness over mass $\left(\omega=\sqrt{\frac{k}{m}}\right)$. For these two specimens H.S 0.5 and H.S 1, the reinforcement mass is increased about four times and the stiffness is increased about two times, thus the effect of these changes would be the reduction in $\boldsymbol{\omega}$ natural frequency of H.S 1.

On the other hand, from the specimen H.S $1(\boldsymbol{\rho}=1 \%)$ to the specimen H.S $2(\boldsymbol{\rho}=2 \%)$, the frequency is increased about 3\%. By the same approximation analysis, the reinforcement mass is increased about two times but the stiffness is increased more than two times due to the larger reinforcement diameter. Thus, the effect of these changes would be an increase in $\boldsymbol{\omega}$ natural frequency of the H.S 2 specimen.

The highest natural frequency among four specimens is observed in UHP-FRC 1 because of its high stiffness mostly due to the presence of the steel fibers in the concrete mix.

The natural frequency in the H.S 2 specimen dropped 12.2\% from the yield to ultimate state, while this reduction is more in the H.S 0.5, H.S 1, and UHP-FRC 1 specimens which are 19.7\%, 16.5\%, and $25.23 \%$ respectively. The lower reduction in the frequency of H.S 2 is attributed to its different failure mode type which is one-way shear failure at one support, while the other slab specimens are failed in the flexure. 


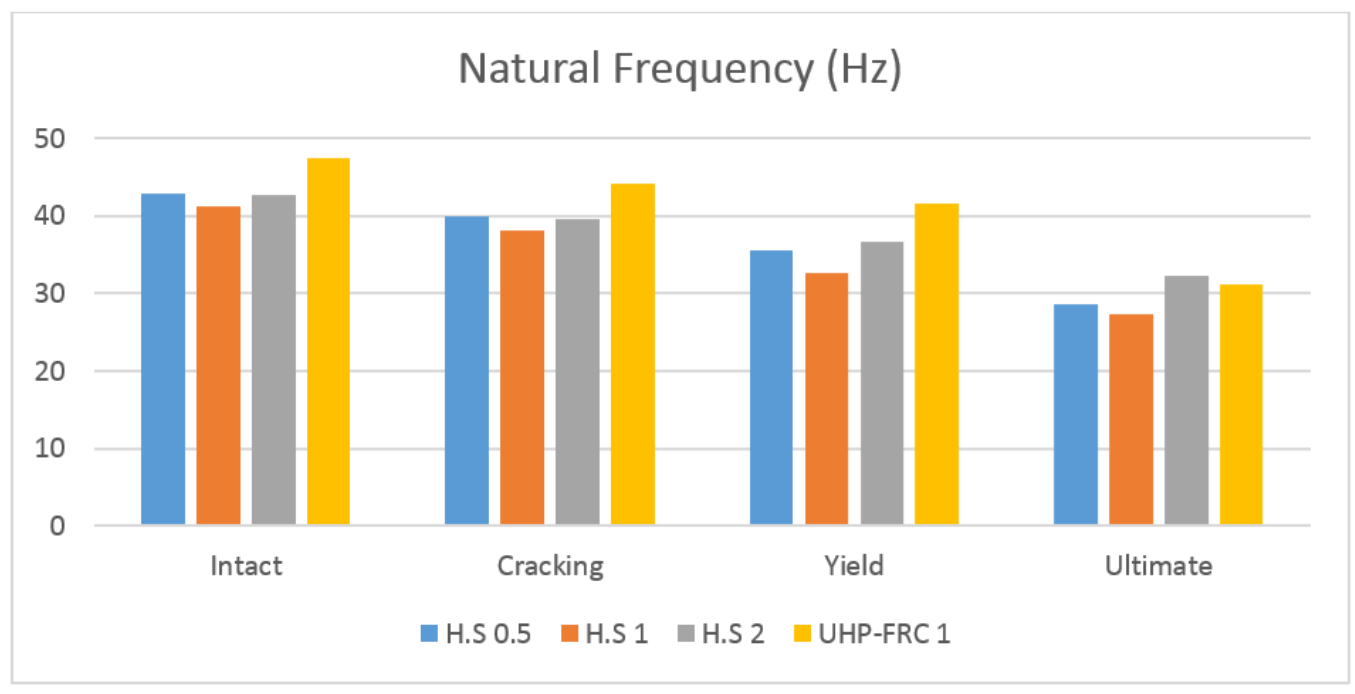

Figure 4.21 Mode 1, Natural Frequency of H.S 0.5, H.S 1, H.S 2, and UHP-FRC 1 Slabs at Intact, Cracking, Yield, and Ultimate States

Table 4.3 Mode 1, Natural Frequency of H.S 0.5, H.S 1, H.S 2, and UHP-FRC 1 Slabs at Intact, Cracking, Yield, and Ultimate States

\begin{tabular}{|l|rr|r|rr|r|}
\hline & H.S 0.5 & H.S 1 & H.S 2 & UHP-FRC 1 \\
\hline Intact & 42.9 & 41.3 & 42.6 & 47.5 \\
\hline Cracking & 40 & 38.1 & 39.6 & 44.1 \\
\hline Yield & 35.5 & 32.7 & 36.7 & 41.65 \\
\hline Ultimate & 28.5 & & 27.3 & 32.2 & 31.14 \\
\hline
\end{tabular}

\subsubsection{Damping Ratio Results}

To determine the damping ratio, the logarithmic decrement is used and the equivalent viscous damping envelope is fitted to the experimentally obtained RD signature by trial and error. Matlab programs are written for obtaining the damping ratio by the logarithmic decrement through picking peaks and plotting an equivalent viscous damping envelope on the RD signature and presented in Appendix E and F respectively. All the RD signatures with the best fitted damping 
envelopes and corresponding damping ratios are figured in Appendix $H$. The obtained damping ratio for all the specimens H.S 0.5, H.S 1, H.S 2, and UHP-FRC 1 at the intact, cracking, yield, and ultimate states are tabulated in Table 4.4 and for the better comparison they are illustrated as a bar graph in Figure 4.22.

The consistency of the intact damping ratios with the reinforcement ratios are observed in H.S 0.5, H.S 1, and H.S 2 with 4.1, 4.2, and 4.4 damping ratios. For UHP-FRC 1, the intact damping ratio is $3.1 \%$ which is much lower than the HSC specimens. Bearing in mind that the embodied energy of the UHP-FRC is much higher than the HSC due to not having large aggregates. Having larger aggregates increases sliding between the cement and aggregate in ITZ (Interfacial Transition Zone) which reduces the embodied energy and increases the damping ratio.

For all the specimens the results reveal that the damping ratio increases at each damage states cracking, yield and ultimate. The damping ratios are increased 9 to $11 \%$ from the intact to cracking for H.S 0.5, H.S 1, and H.S 2 but for the UHP-FRC 1 specimen is increased $25 \%$. The damping ratios are increased 26 to $31 \%$ from the intact to yield for H.S 0.5, H.S 1, and H.S 2 while for the UHP-FRC 1 specimen is increased $38 \%$. The damping ratios are increased 37 to $42 \%$ from the intact to ultimate for H.S 0.5, H.S 1, and H.S 2 but for the UHP-FRC 1 specimen is increased 87\%.

The damping ratio increasing rates between states for UHP-FRC 1 are about two times larger than H.S 0.5, H.S 1, and H.S 2 due to the fact that the UHP-FRC 1 specimen tolerates more load compared to the HSC specimens to reach to the cracking, yield and ultimate states. More load causes more energy dissipation which is due to the friction caused by the steel fibers.

The damping ratio in H.S 2 is increased 3.4\% from the yield to ultimate state, while this growth is more in H.S 0.5, H.S 1, and UHP-FRC 1 which are 12\%, 13\%, and 35\%, respectively. The lower increase in damping ratio of H.S 2 is attributed to its different failure mode type which is one-way shear failure at one support, while the other specimens failed in the flexure. 


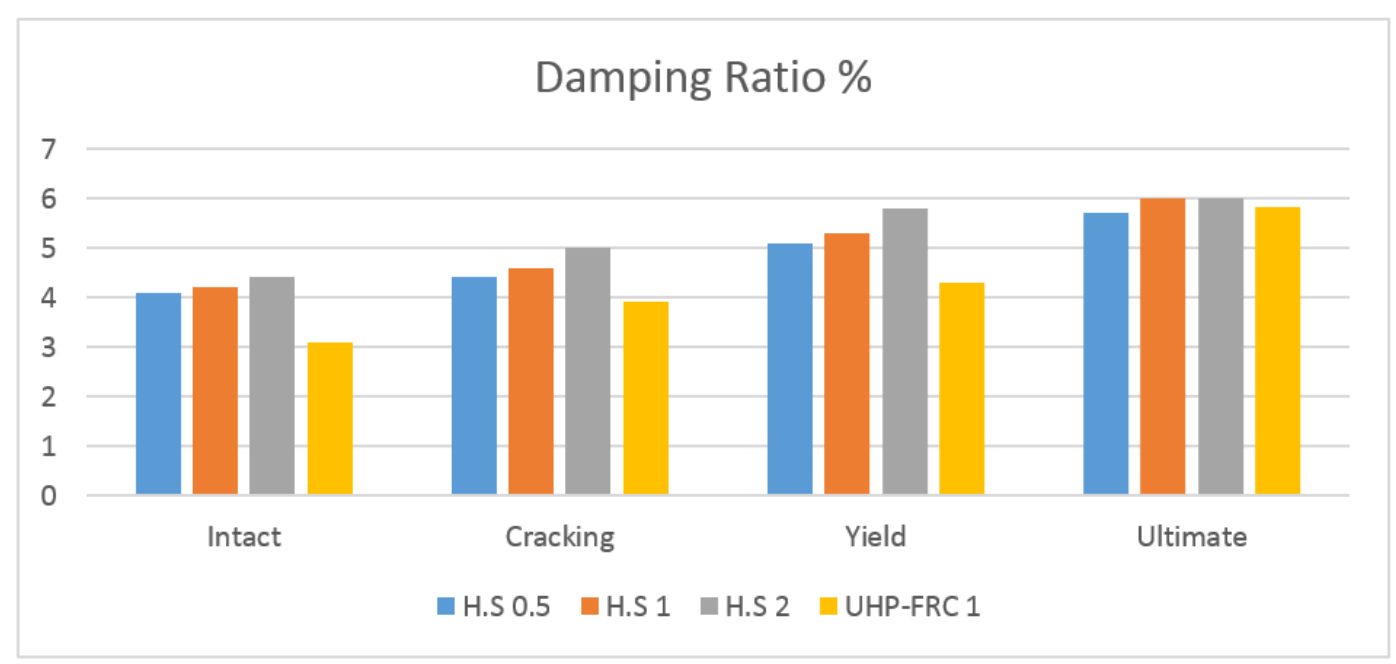

Figure 4.22 Mode 1, Damping Ratios of H.S 0.5, H.S 1, H.S 2, and UHP-FRC 1 Slabs at Intact, Cracking, Yield, and Ultimate States

Table 4.4 Mode 1, Damping Ratios of H.S 0.5, H.S 1, H.S 2, and UHP-FRC 1 Slabs at Intact, Cracking, Yield, and Ultimate States

\begin{tabular}{|l|rr|r|r|r|r|}
\hline & H.S 0.5 & H.S 1 & & H.S 2 & UHP-FRC 1 \\
\hline Intact & 4.1 & 4.2 & 4.4 & 3.1 \\
\hline Cracking & 4.4 & 4.6 & 5 & 3.9 \\
\hline Yield & 5.1 & 5.3 & 5.8 & 4.3 \\
\hline Ultimate & 5.7 & 6 & 6 & 5.82 \\
\hline
\end{tabular}




\section{CHAPTER FIVE}

\section{APPLICATIONS ON THE USE OF RD METHOD FOR DAMAGE DETECTION OF SLABS}

Two additional applications of the Random Decrement (RD) technique have been conducted and verified. First, in order to investigate the damage location in defected reinforced concrete two-way slabs, the MCRD technique is implemented to extract the mode shapes and subsequently Modified Mode Shape Difference and Mode Shape Extremum Damage Detection (EDD) techniques are utilized. Secondly, the RD technique is utilized to evaluate the extent of damage under successive equal dynamic impacts.

\section{A Applying MCRD Technique for Damage Allocation}

The Multi-Channel Random Decrement (MCRD) technique is applied to defected two-way reinforced High Strength Concrete (HSC) slabs in order to locate the damage using imbedded FBG sensors. The damage in the H.S 0.5 slab is induced in three relative level degrees of approximately $33 \%, 66 \%$, and $100 \%$. The damage location is investigated through changes in the dynamic parameter, the mode shape.

\section{A.1 Damage Induction}

For the purpose of locating damage using the MCRD technique, data are collected from four slabs with different degrees of damage as shown in Figure 5.7. Instead of casting four slabs with eight embedded FBG sensor arrays, one slab with three through holes is made only with two embedded FBG sensor arrays. At this time, the slab is defected by $100 \%$ induced damage and is ready for the non-destructive MCRD test. In order to achieve the other two degrees of induced damages of $66 \%, 33 \%$ and the intact state, the holes are filled one after another properly. The procedure detail is well designed in a way that the slab be capable of performing both the MCRD test and Chapter 3 static load test. This saves labour, money and time. In order to create the through holes, at the time of H.S 0.5 slab casting Section 3.6.4, three cylindrical sono-tubes with outer diameter of $190 \mathrm{~mm}$ and height of $100 \mathrm{~mm}$ are fabricated. The sono-tubes are bolted down to the mold floor of H.S 0.5 specimen, capped, and sealed properly for the ease of extracting out from 
the hardened concrete after casting (Figures 5.1 and 5.2). Two arrays of FBG sensors with four sensors in each array are fabricated and installed in the H.S 0.5 slab as explained in Section 3.5 and 3.6.2.1. Figures 5.2 and 5.4 show the detail involved to prepare the H.S 0.5 slab.

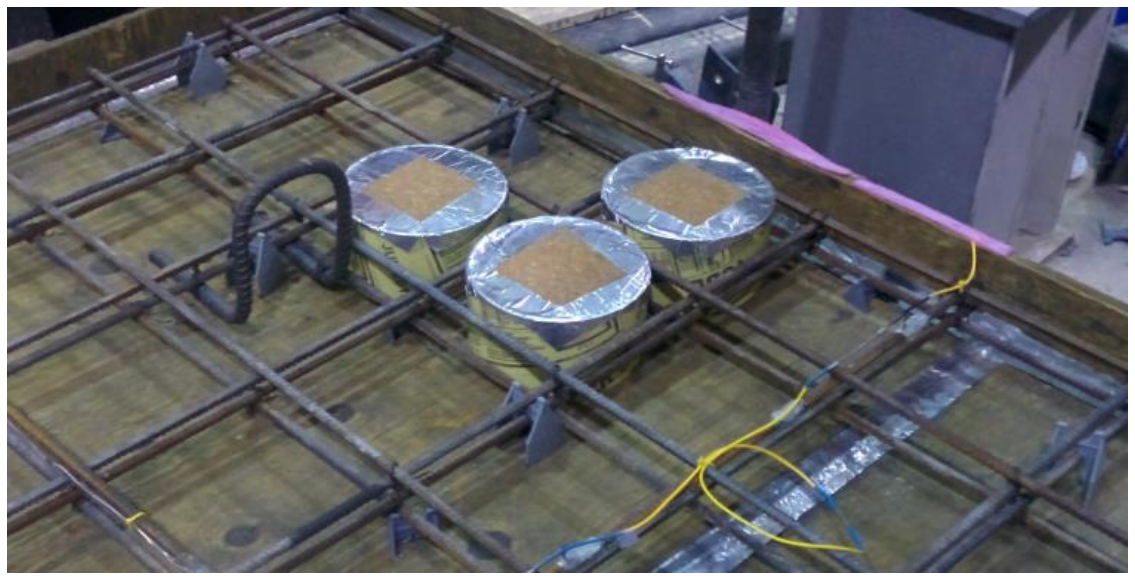

Figure 5.1 Sono-tubes Bolted Down in the H.S 0.5 Slab Mold for Damage Induction

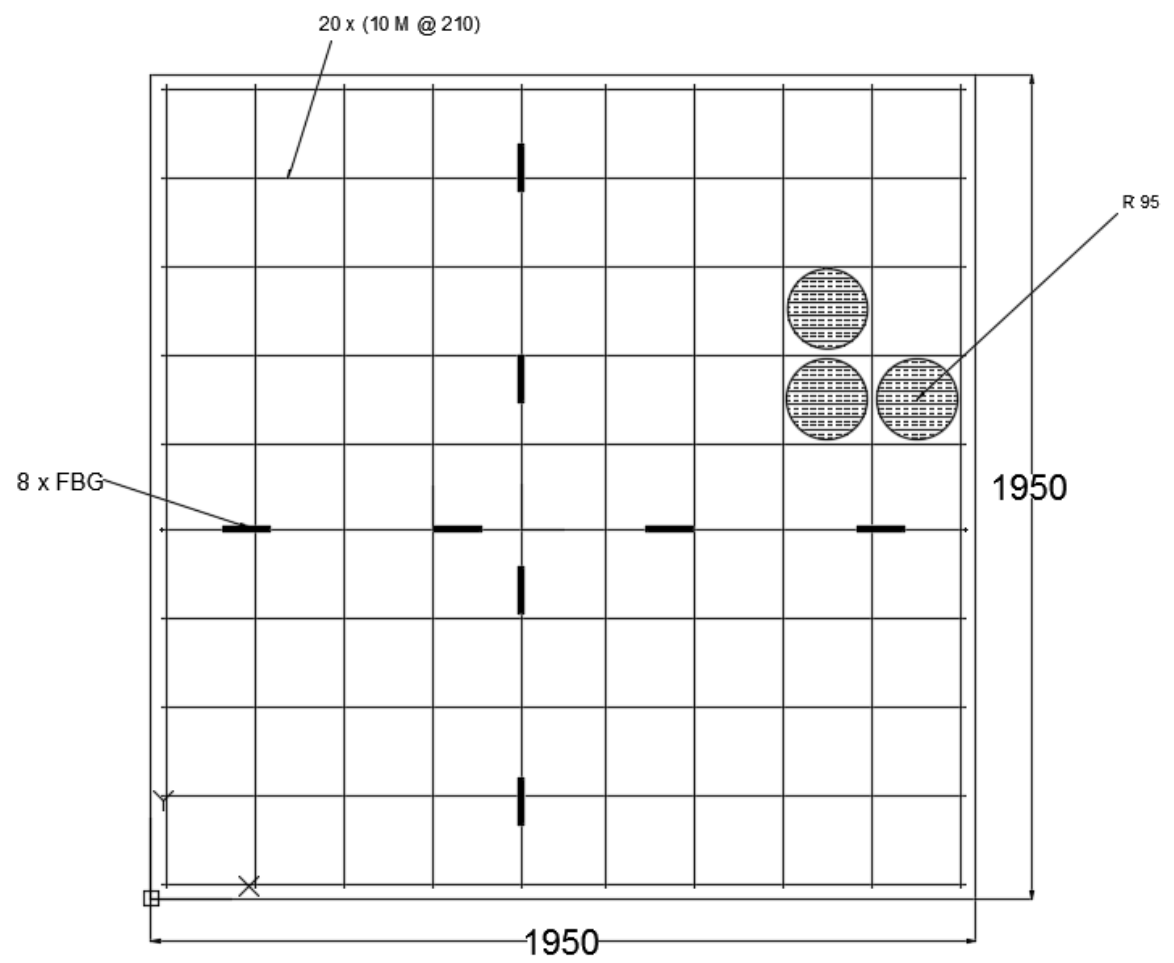

Figure 5.2 The Location of Sono-tubes and FBG Sensors 
Meanwhile, three double layer sonotubes with inner diameter of $175 \mathrm{~mm}$ which sealed at the bottom are fabricated as individual molds (Figure 5.3) in order to be casted with the same concrete material as the H.S 0.5 slab. More detail is explained in the test procedure Section 5.A.2.

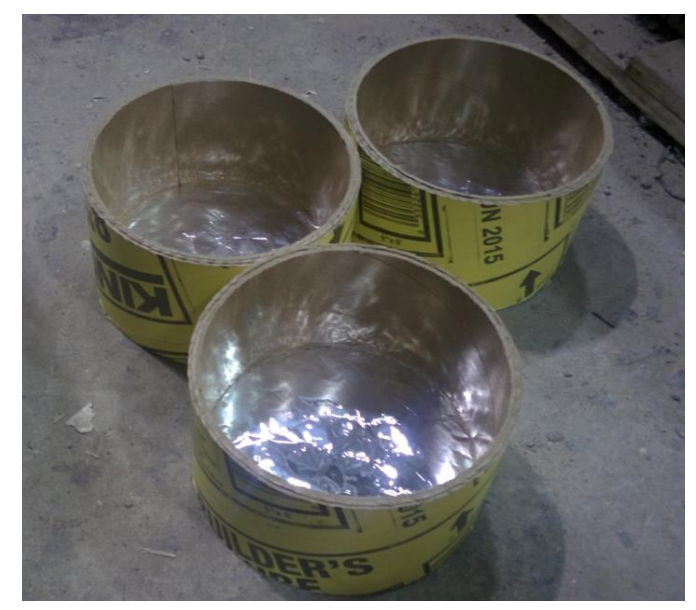

Figure 5.3 Three Double Layer Sono-tubes to be Casted with the Same Concrete Material for Repairing the Damage

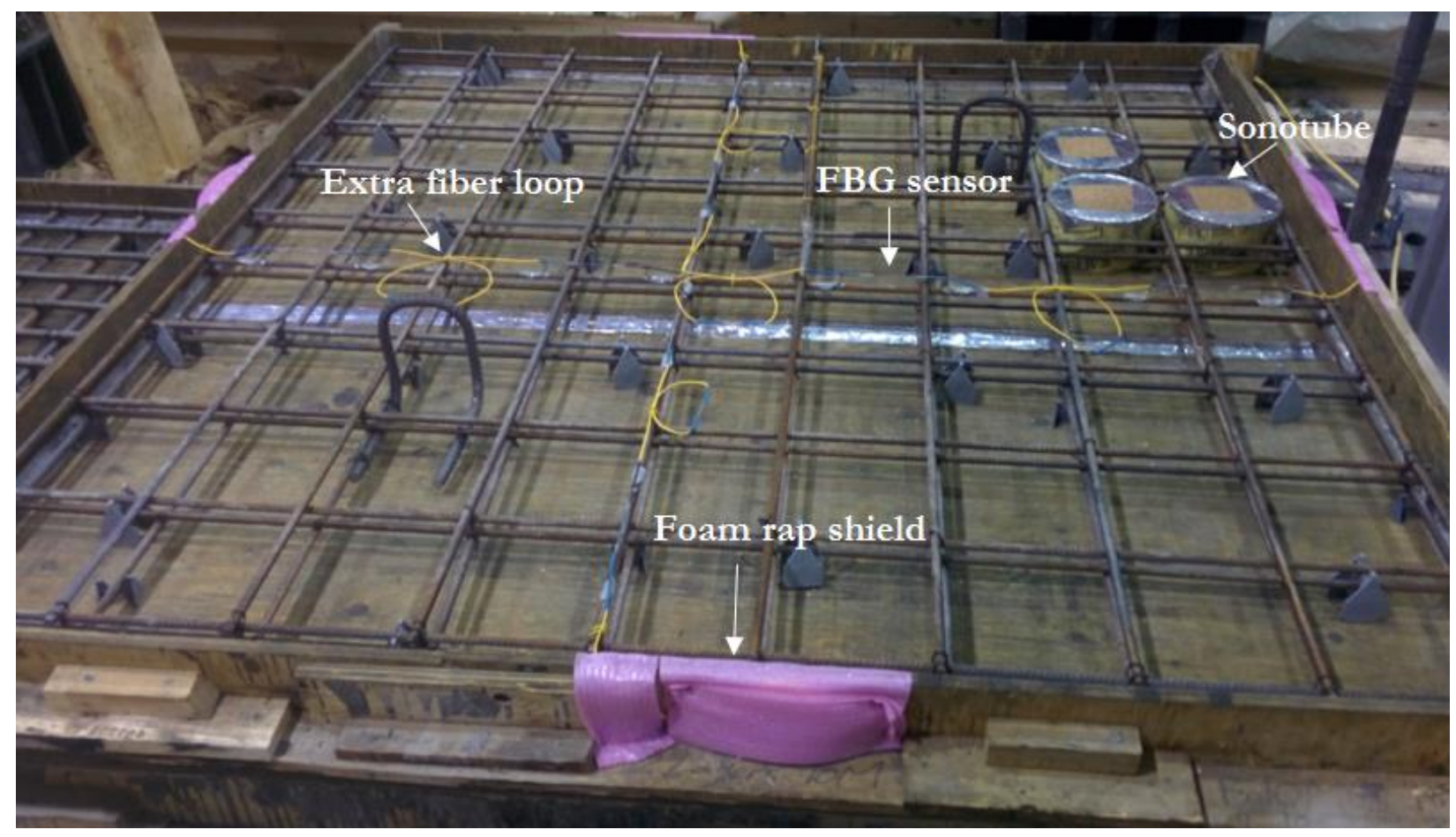

Figure 5.4 The Detail Involved to Prepare H.S 0.5 Slab 


\section{A.2 MCRD Test Procedure}

On the slab H.S 0.5 with embedded FBG sensors, the MCRD test procedure is employed. The aim of the procedure is to implement the MCRD technique for locating the induced damage. To be economical, the slab is designed in a way that performs both the MCRD test and Chapter 3 static load test. The damage in the MCRD test is induced reversely thus at the end of the test, the slab remains without damage at the intact state ready to perform the Chapter 3 static load test.

The MCRD test procedure is performed through five steps:

Step one: Slab is placed on the testing apparatus as described in Section 3.7.1 and the sensors are connected to the monitoring system as explained in Section 3.7.3.1 (Figure 5.5).

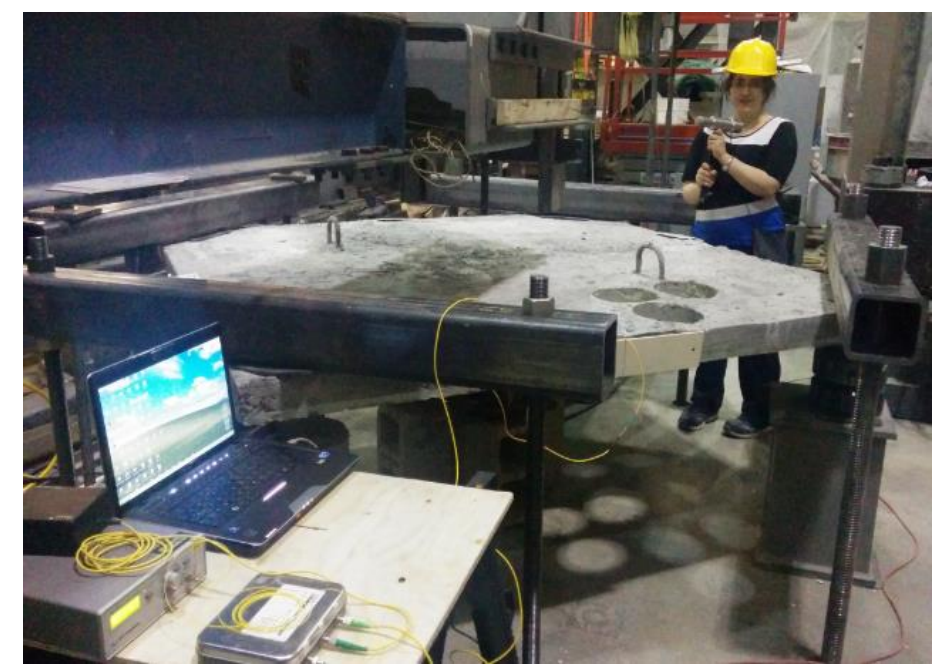

Figure 5.5 MCRD Test Apparatus

Step two: The measurements are gained for both array $\mathrm{X}$ and array $\mathrm{Y}$ three times each (two times with excitation and one time without excitation). The slab excitation is performed by hammer randomly 20 to 30 times for each measurement. These measurements are recorded for the maximum induced damage.

Step three: The approximate of $66 \%$ relative level degree of damage is created to the specimen by filling one of the holes as shown in Figure 5.7. The hole is filled with prepared concrete cylinder 
(Figure 5.6). The concrete cylinder is held in position and the Master Flow ${ }^{\circledR} 713$ High-precision non-shrink mineral-aggregate grout is used as mortar around the cylinder to eliminate the damage from the slab. After 24 hours, step two is repeated for the recent induced damage too.

Step four: The approximate of $33 \%$ relative level degree of damage is created by filling another hole with the same procedure as in step three (Figure 5.7). After 24 hours, step two is repeated for the recent induced damage one.

Step five: The intact state with no damage is created by filling the last hole with the same procedure as in step three (Figure 5.7). After 24 hours, step two is repeated in the intact state.

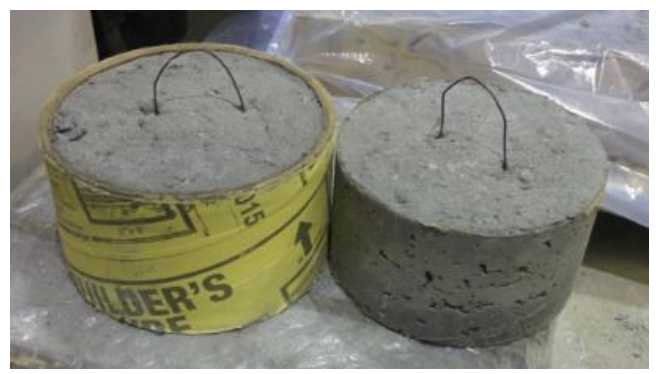

Figure 5.6 Damage Eliminating Concrete Cylinders

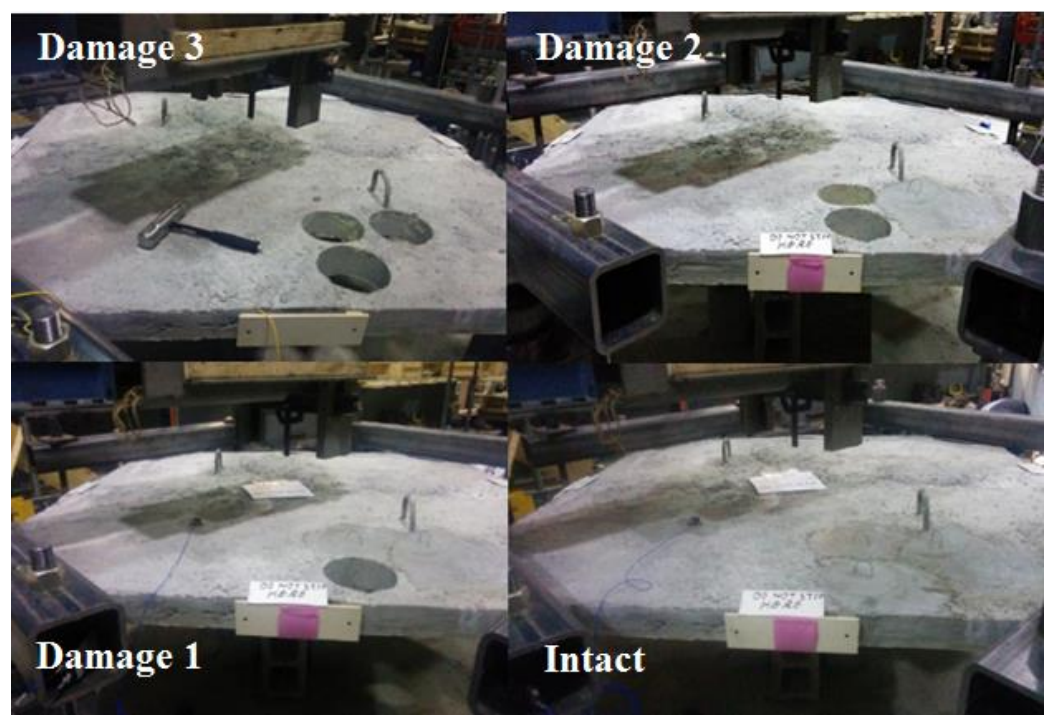

Figure 5.7 Slab Conditions for MCRD Test Procedure 


\section{A.3 Results}

In this section, the MCRD test results are investigated. These results are obtained from one reinforced High Strength concrete H.S 0.5 slab under different relative level degrees of the induced damage $0 \%, 33 \%, 66 \%$, and $100 \%$. The damage localization is examined through changes in the dynamic parameter the mode shape.

Since the slab structure is considered as two dimensional element, its harmonic mode shapes can be identified as one dimensional elements in two orthogonal directions. Thereby, two arrays of the Fiber Bragg Grating (FBG) sensors are installed in each direction of the slab as described in Section 3.6.2.1. It should be noted that prior to using the FBG sensors, electrical strain gauges were used to extract the mode shapes using the MCRD technique, however the results were all noise and could not be analyzed. Unlike the electrical strain gauges, the FBG sensors have the advantage of electromagnetic immunity and are successfully used for this experimental research. In each dimension the algorithm of MCRD mode shape extraction can be followed as a beam like structure described in Section 2.4.2. The wavelengths obtained from the FBG sensors are converted in to the strain for data analysis using Equation 2.47. The FFT analyses is used to determine the frequency spectrum of data and a bandpass Butterworth filter is used to filter the first mode data of all the channels around the first natural frequency. To extract the RD signatures for the MCRD procedure, integration is conducted using a time increment of $0.001 \mathrm{sec}$ and the number of segments used to construct the RD is equal to half of the triggered data number approximately 1500. Respectively, the total length of time series generated to extract each RD signature is approximately $1500 \mathrm{sec}$. This equals to 1.5 million sampling points. The triggering level equals to 1.4 times the standard deviation of the channel data that gives the maximum deflection which are the leading channel at node 4 for the array $\mathrm{X}$ and at node 3 for the array $\mathrm{Y}$. The same triggering time vector segments of the leading channel are used for all of the channels in the array. A Matlab program in Appendix $G$ is written to obtain the simultaneous RD signatures from four sensors for the MCRD technique. The procedure to construct the mode shape by using the MCRD technique is described in Section 2.4.2.

For two orthogonal arrays $\mathrm{X}$ and $\mathrm{Y}$, the nodes are numbered 1, 2, 3, 4, 5, and 6. The sensors in each array are at the nodes 2, 3, 4, and 5. Figure 5.9 is the rough normalized deflection mode shapes of the array $\mathrm{X}$ for the intact, damage 1 , damage 2 , and damage 3 . The discrepancy reveals 
that the damage should be around the node 5 but there is some discrepancy around the node 2 which is not the location of damage. The reason for this discrepancy will be explained later. The damage stages are shown in Figure 5.8.

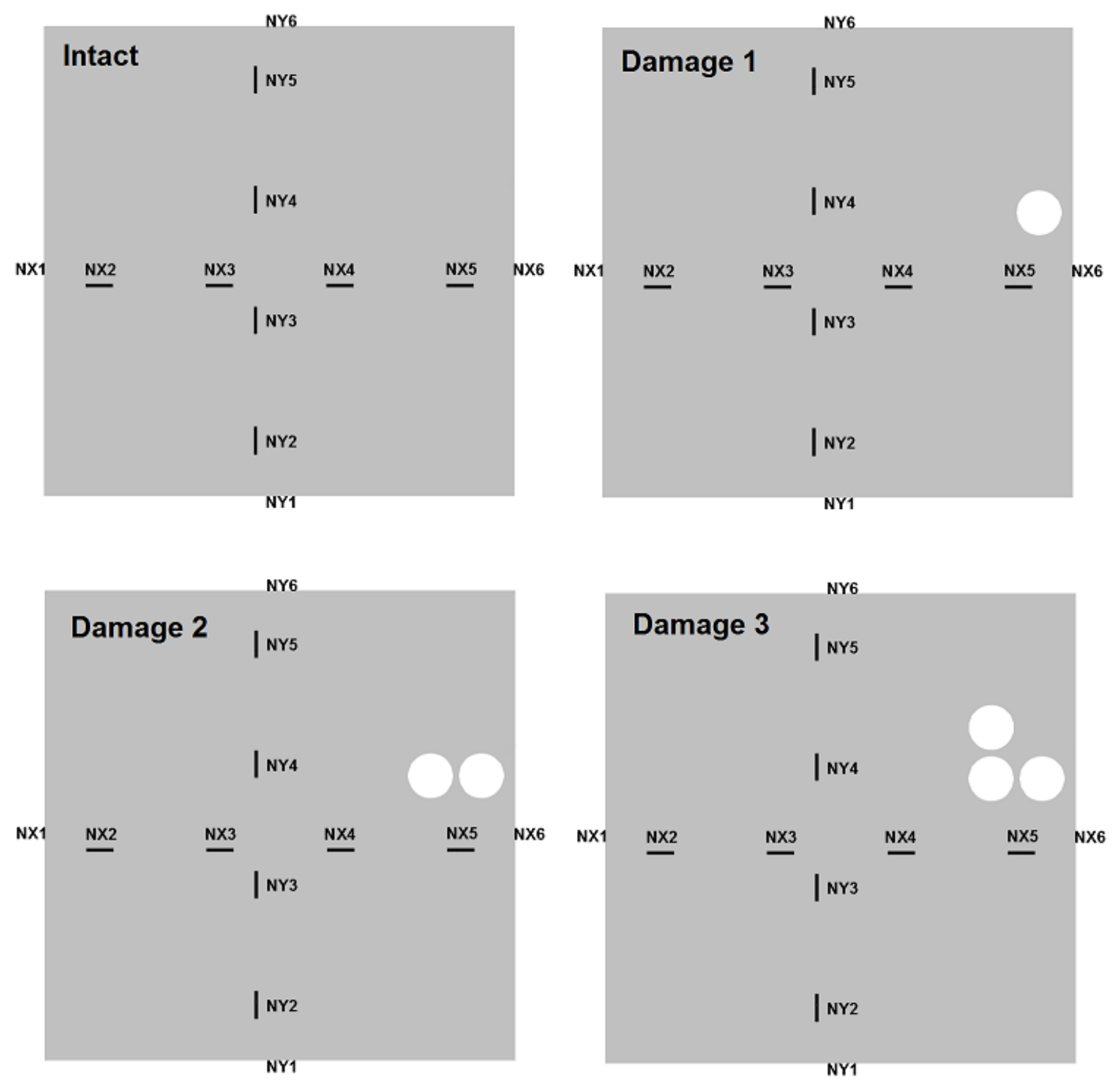

Figure 5.8 Damage Stages (N Indicates Node) 


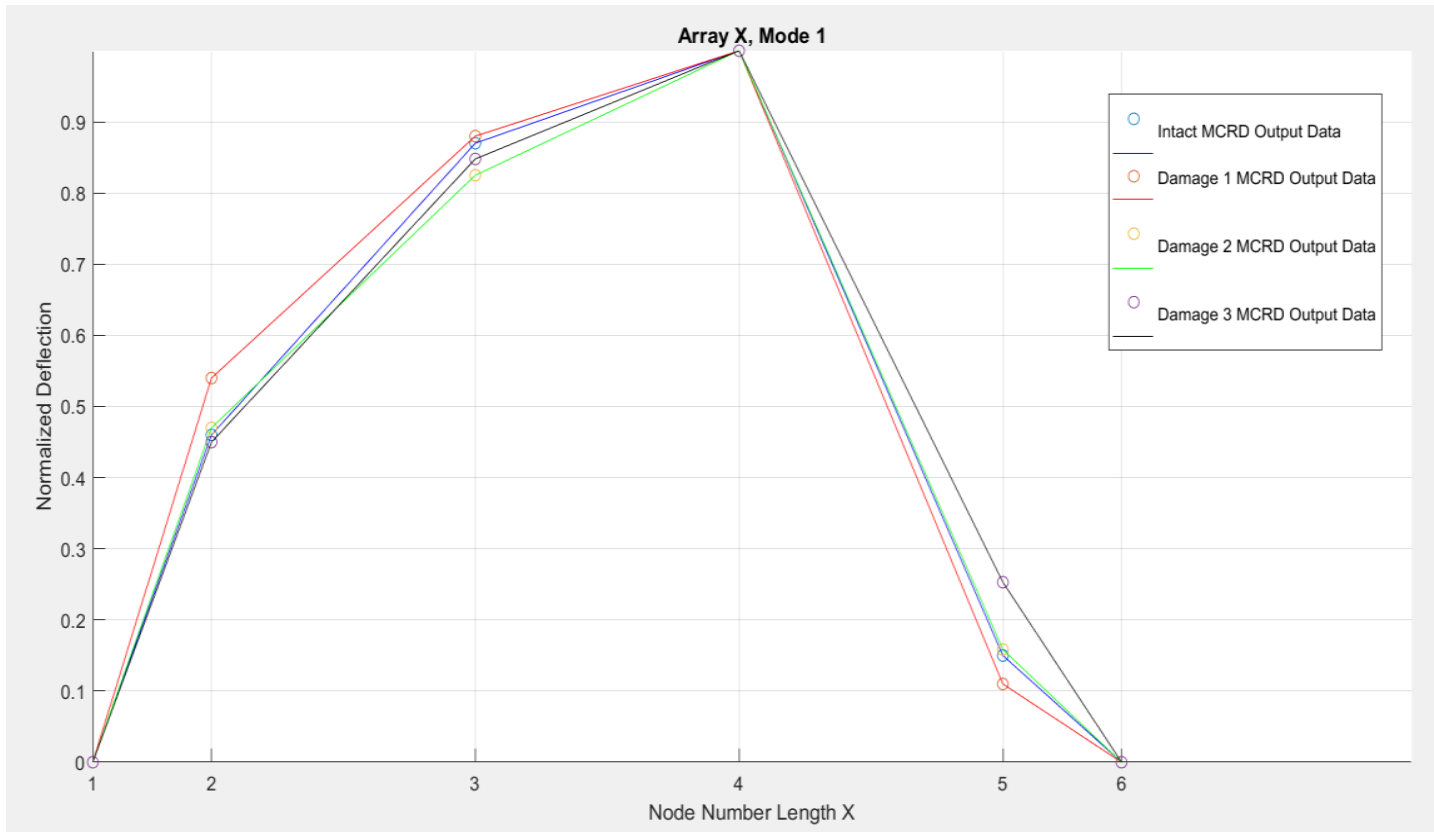

Figure 5.9 Rough Shape of Mode 1 in Array X as Extracted by MCRD

Figure 5.10 is the rough normalized deflection mode shape of array $\mathrm{Y}$ for the intact, damage 1, damage 2 , and damage 3 . The discrepancy reveals that the damage should be between the nodes 4 and 5 .

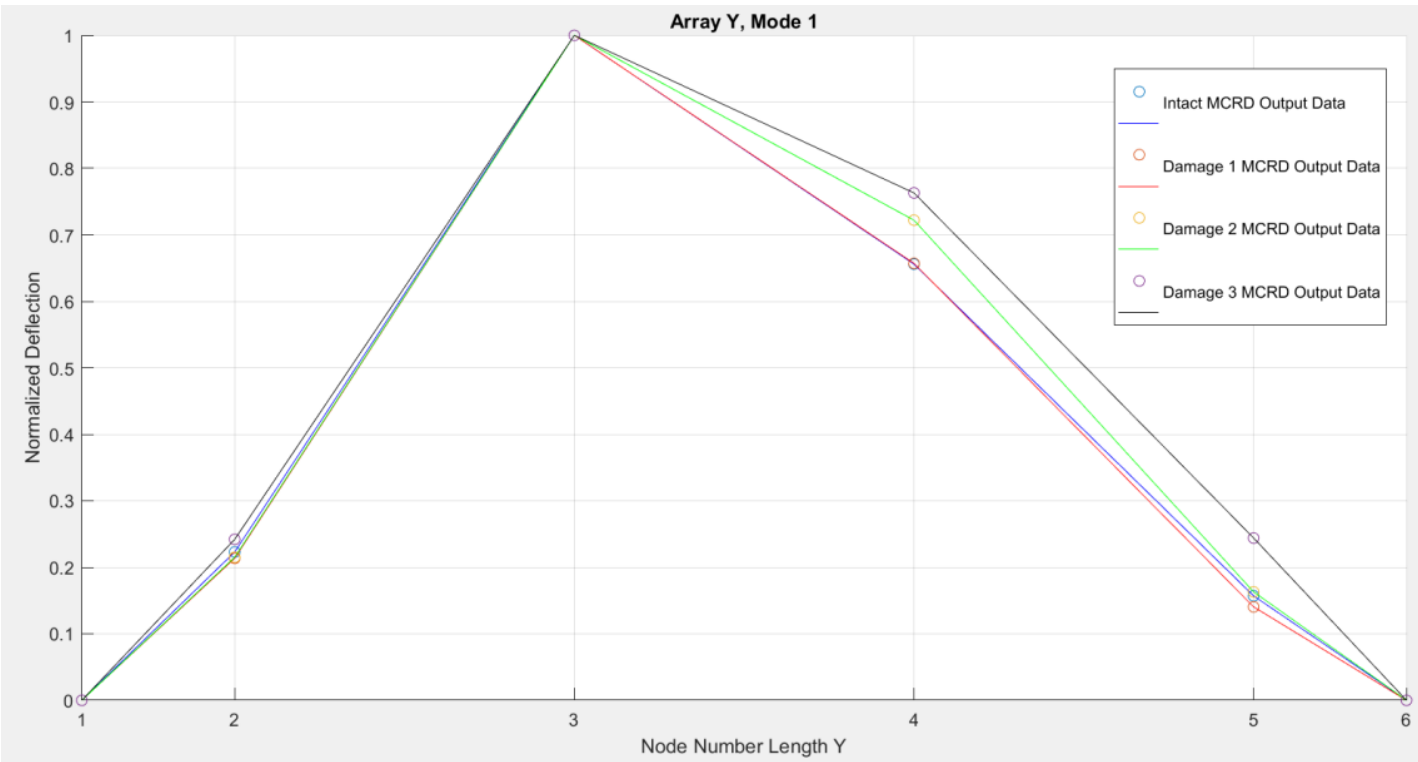

Figure 5.10 Rough Shape of Mode 1 in Array Y as Extracted by MCRD 
The Modified Mode Shape Difference Technique is described in Section 2.4.3.1 for locating the damage. Figure 5.11 shows the Normalized Mode Shape Difference in the array X. The mode shape differences are normalized with respect to the maximum damage difference. The discrepancy for the damage stage 2 and 3 reveal the damage should be at the node 5, but again Figure 5.11 also reveals discrepancy at the node 2 for the damage 1 . The intensity of discrepancy increases as the damage increases.

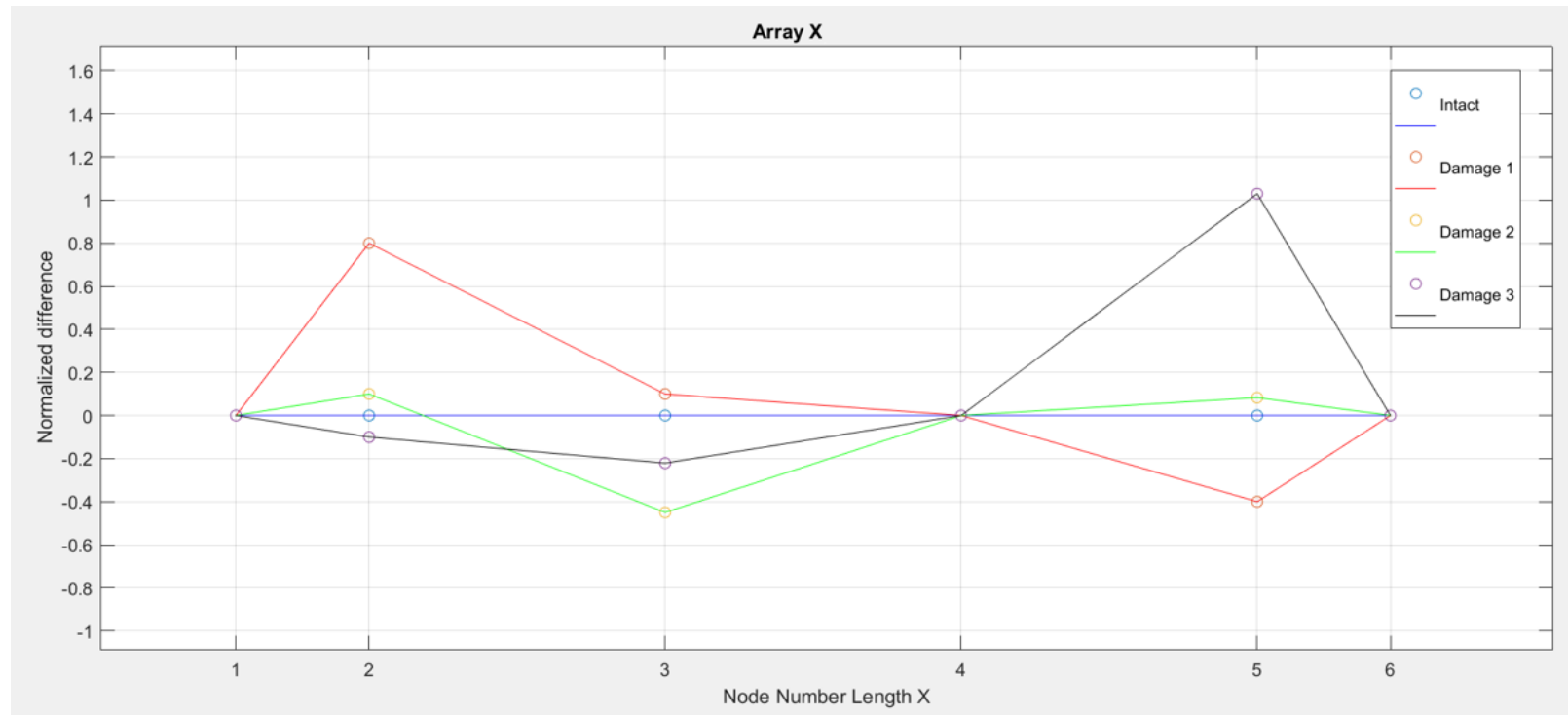

Figure 5.11 Normalized Mode Shape Difference for Mode 1 in Array X

Figure 5.12 shows the Normalized Mode Shape Difference in the array Y. The mode shape differences are normalized with respect to the maximum damage difference. The discrepancy reveals the damage should be between the nodes 4 and 5. The intensity of discrepancy increases as the damage increases. 


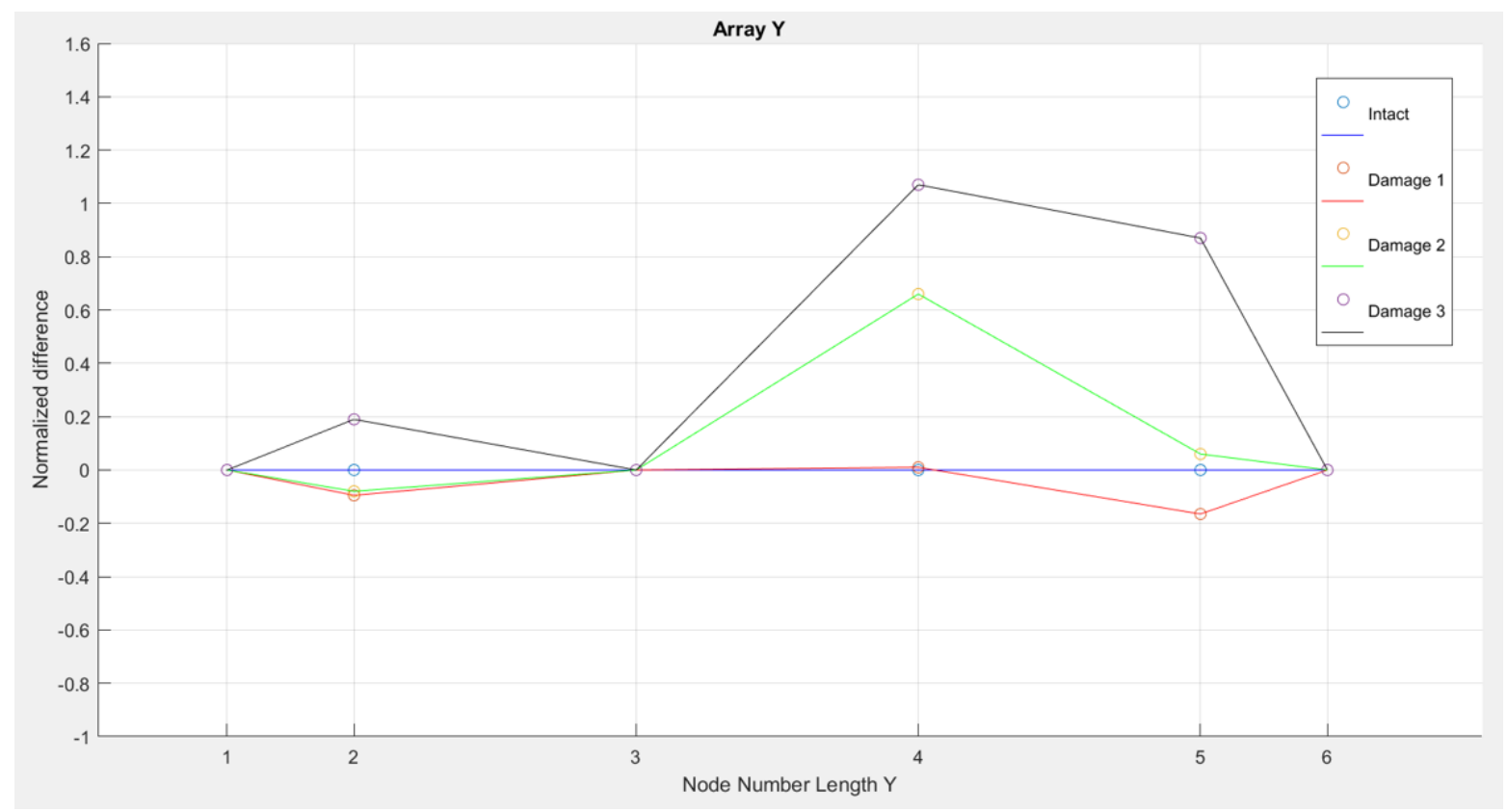

Figure 5.12 Normalized Mode Shape Difference for Mode 1 in Array Y

It should be taken into account that the mode shape of a plate has no fracture within and has to be smooth to commit the reversibility principle for the vibration to take place. In order to consider this principle, the best fit curve through the MCRD output data is drawn for the intact, damage 1, damage 2, and damage 3 (Figures 5.13 and 5.14), as described in Section 2.4.3.2.1 Mode Shape Extremum Damage Detection (EDD) technique. It can be observed that the best fit curve has exactly the same scenario as the rough mode shapes (Figures 5.9 and 5.10) but with the advantage of being smooth. There is remarkable information that is the location of maximum in the mode shape for which is better to be called "extremum location". The results reveal that the extremum location shifts toward the location where the stiffness is decreased or where the mass is increased. 


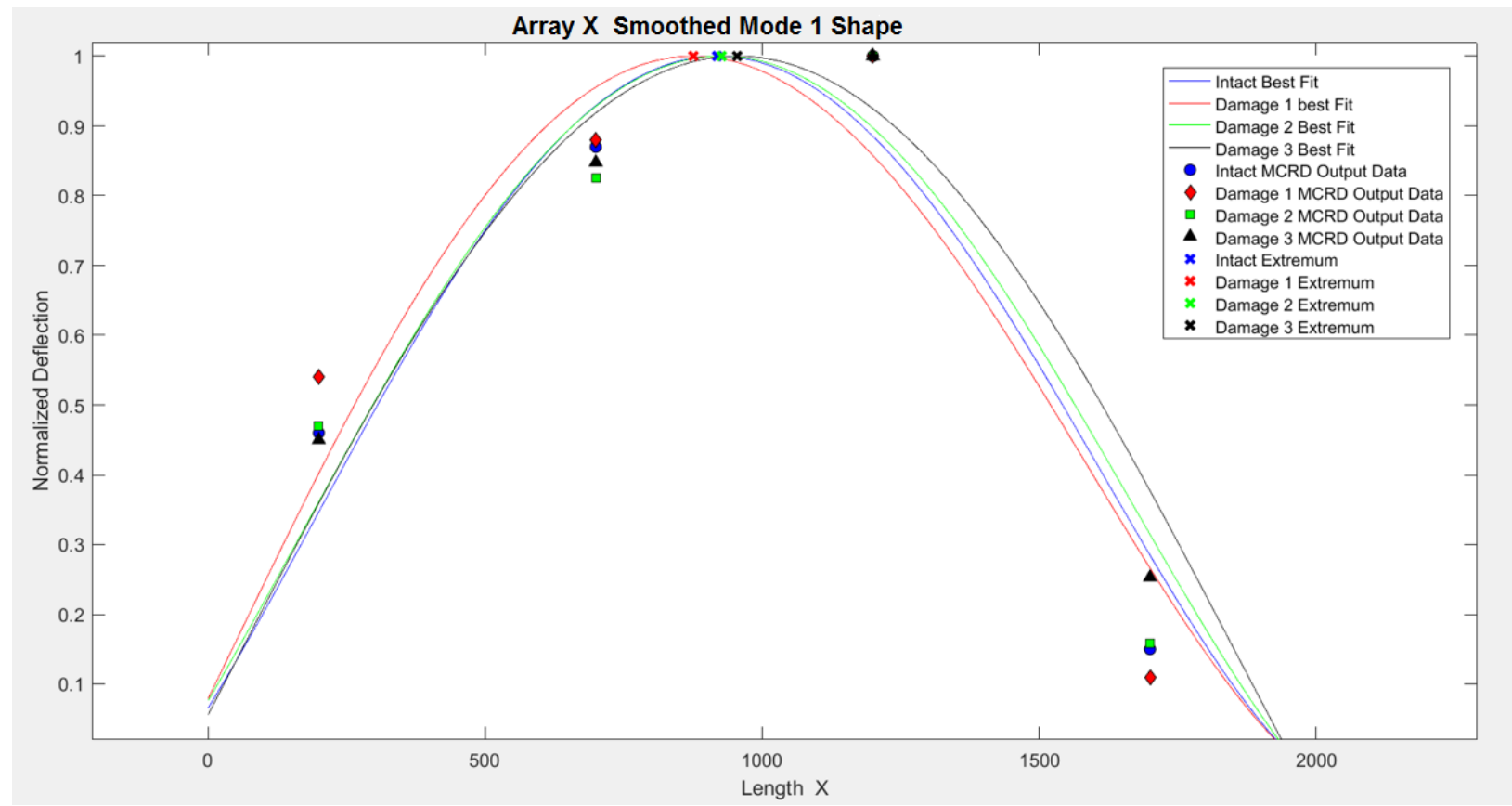

Figure 5.13 Smoothed Mode 1 Shape Constructed By Best Fit Curve through the MCRD Output Data for Array X

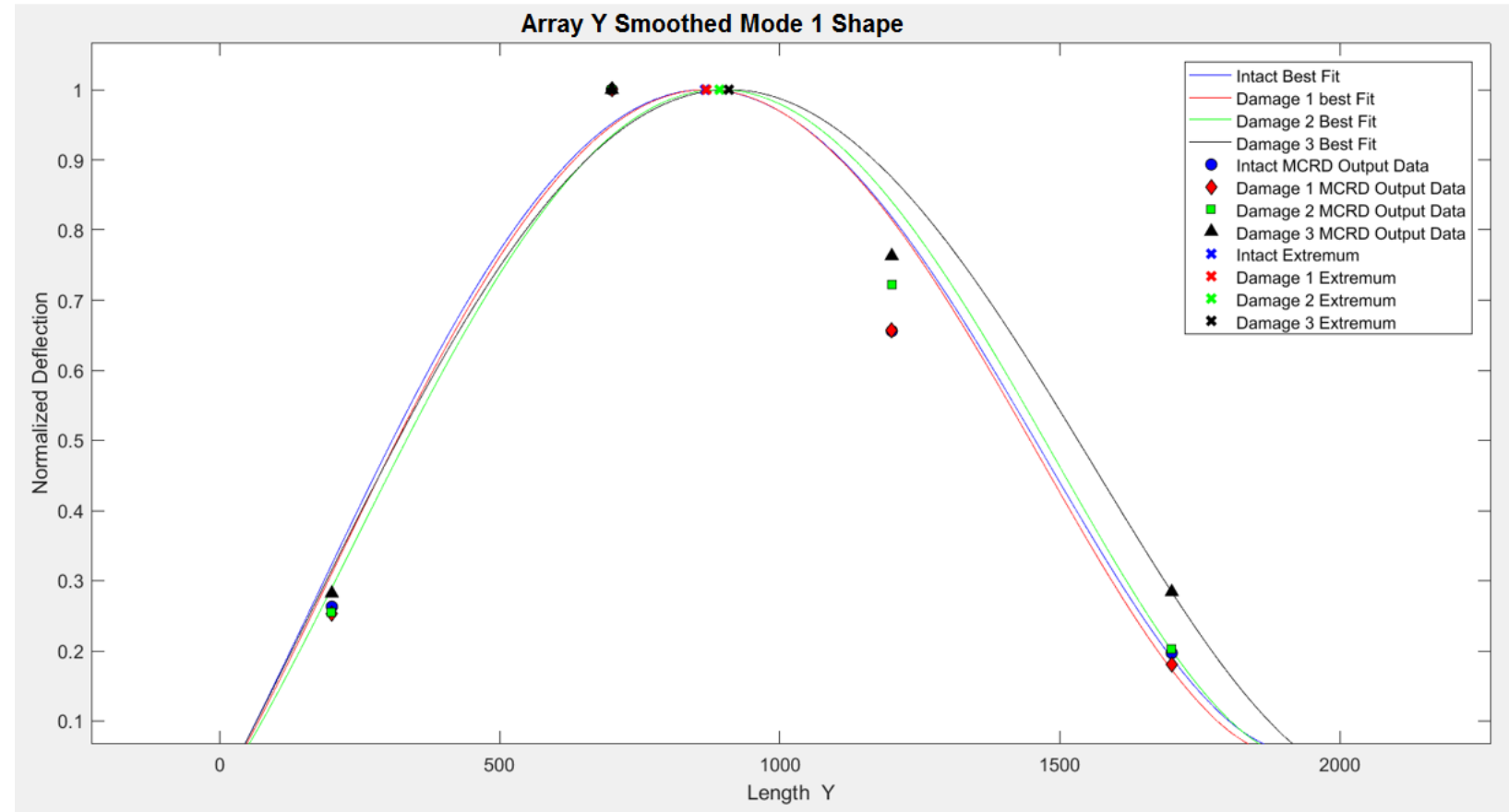

Figure 5.14 Smoothed Mode 1 Shape Constructed By Best Fit Curve through the MCRD Output Data for Array Y 
Figures 5.15 and 5.16 are the magnified normalized view of the mode shapes around the extremum location. From the intact to damage 3 in the array $X$, the mode shape extremum location is shifted $40 \mathrm{~mm}$ toward the damage location. Similarly, from the intact to damage 3 in the array $\mathrm{Y}$, the mode shape extremum location is shifted $40 \mathrm{~mm}$ toward the damage location. The extremum location in array $\mathrm{X}$ of damage 1 is shifted toward the opposite direction of damage location. In the experimental procedure, inducing the damages are accompanied by the reduction of mass as shown in Figures 5.7 and 5.8. According to the balance theory, the reduction of mass on one side is like having the excess mass on the opposite side. From the dynamic point of view, an excess mass exerts more inertia force, causing more deflection and the extremum location shifts toward it. Respectively, the effect of mass in the extremum location shift increases with the mass distance from the centroid of mode shape to a power more than one. Since the damage 1 in the array $\mathrm{X}$ has the largest distance to the centroid of the slab, its mass contribution to the shift of mode shape is more compared to its stiffness reduction. This is the reason behind the extremum location shift of damage 1 in the array $\mathrm{X}$ towards the opposite side of the damage which also explains the odd discrepancy around the node 2 of array $X$ in Figures 5.9 and 5.11. On the other hand, for the array $\mathrm{Y}$, all the damages are close to the centroid and the mass effect is not dominant. The advantage of Mode Shape EDD method is that if it is required to design an automatic control system to detect the damage, here is a measurable parameter that can be used which is the shift in the mode shape extremum. As in Figures 5.15 and 5.16, more damage causes more shift of the extremum location to the damage location.

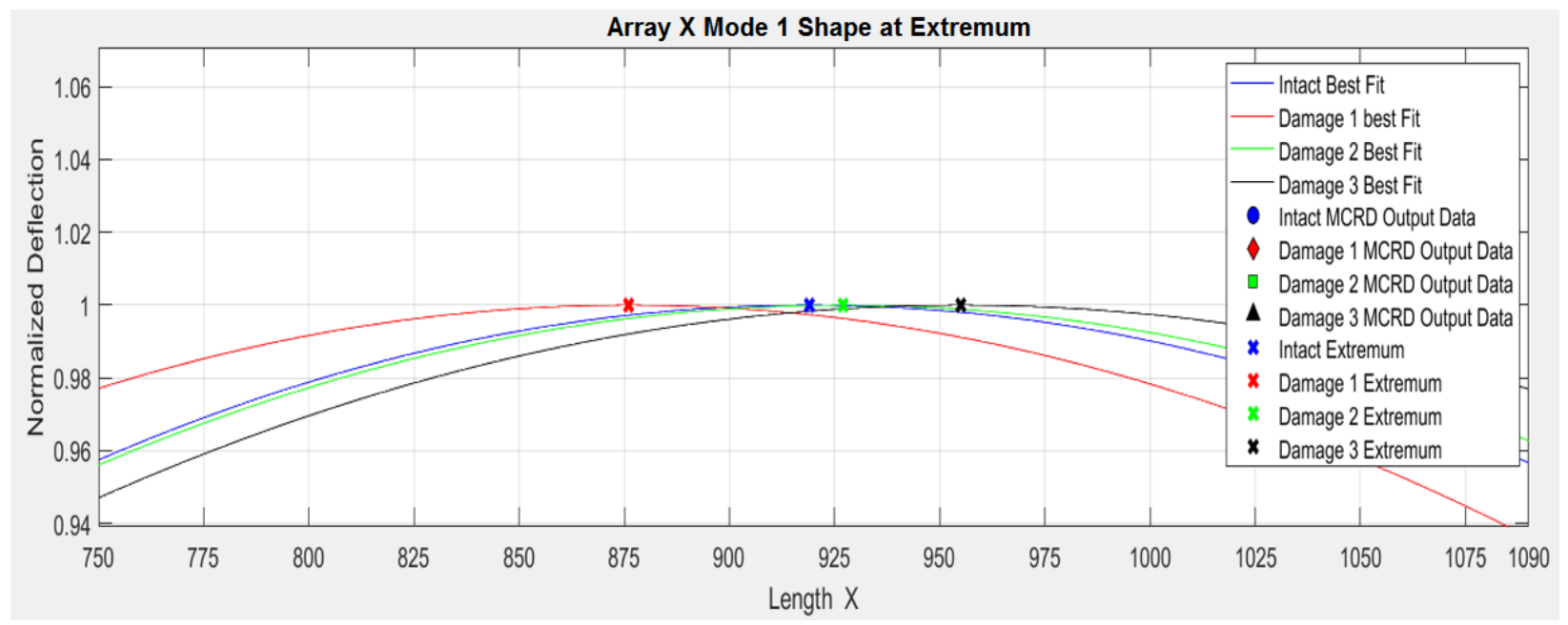

Figure 5.15 Magnified Normalized Mode 1 Shapes around Extremum Location for Array X 


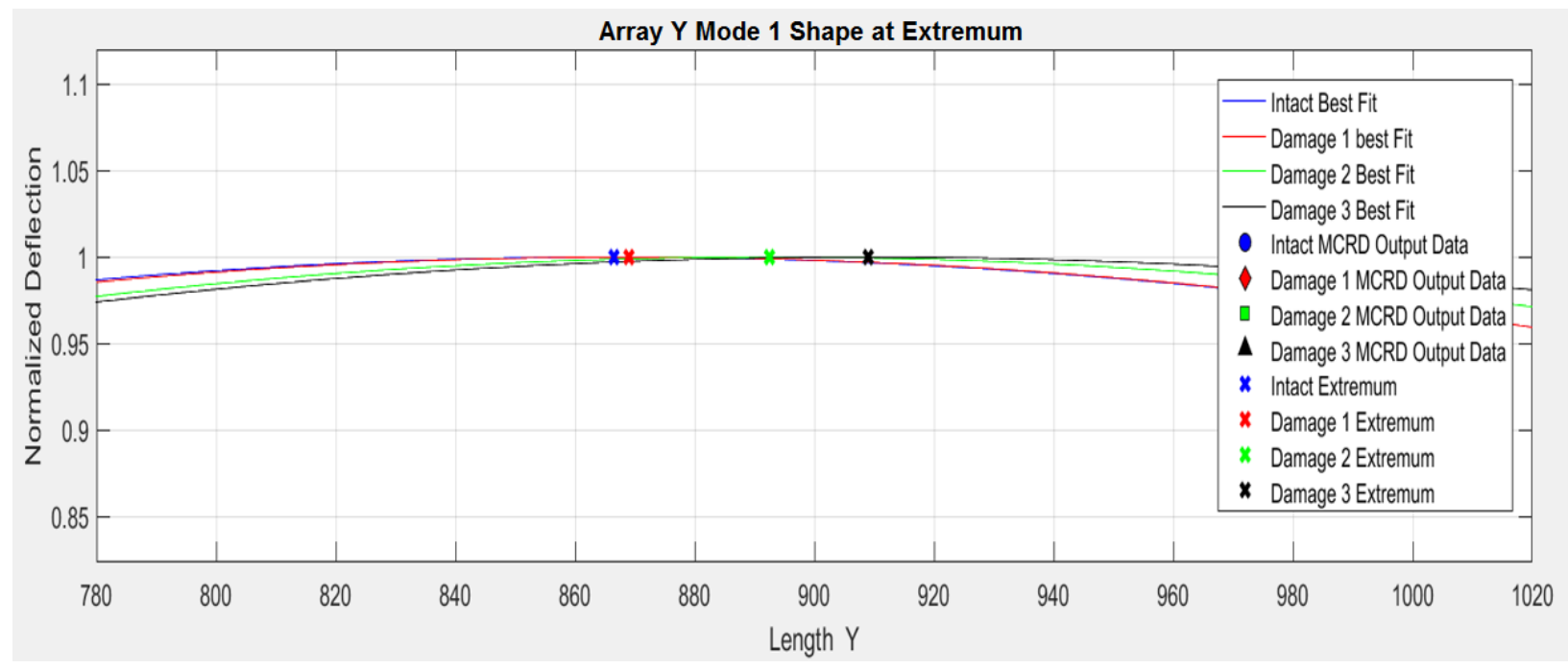

Figure 5.16 Magnified Normalized Mode 1 Shapes around Extremum Location for Array Y 


\section{B Applying RD Technique to Evaluate Damage under Dynamic Impact}

As an additional application, the RD technique is utilized to evaluate the extent of damage under the successive equal dynamic impacts. Four simply supported Ultra High Performance Fiber Reinforced Concrete (UHP-FRC) slabs having $1950 \times 1950 \times 100 \mathrm{~mm}$ dimensions using different reinforcement ratio and steel fiber volume content are prepared for the low-velocity impact test by the former PhD student Dr. Hesham Othman. The ambient vibration tests are conducted to investigate changes in the dynamic parameters natural damped frequencies and damping ratios of slabs before and after two successive impact drops.

\section{B.1 Slab Specimen Properties}

The material properties of the slab specimens are same as what is described in Section 3.2.2. The details of the UHP-FRC slabs are given in Tables 5.1 and 5.2.

Table 5.1 Details of UHP-FRC Slab Specimens

\begin{tabular}{|r|r|r|r|r|}
\hline $\begin{array}{l}\text { Series } \\
\text { No. }\end{array}$ & Specimen $^{1}$ & $\begin{array}{r}\text { Fiber Content } \\
(\%)\end{array}$ & $\begin{array}{r}\text { Reinforcement } \\
\text { Ratio }^{2}(\%)\end{array}$ & $\begin{array}{r}\text { Reinforcement } \\
\text { Spacing }\end{array}$ \\
\hline & & 1 & 1.00 & 100 \\
\hline 1 & $\mathrm{UF}_{1} \mathrm{~S} 100$ & 2 & 1.00 & 100 \\
\hline 2 & $\mathrm{UF}_{2} \mathrm{~S} 100$ & 3 & 1.00 & 100 \\
\hline 3 & $\mathrm{UF}_{3} \mathrm{~S} 100$ & 2 & 0.64 & 158 \\
\hline 4 & $\mathrm{UF}_{2} \mathrm{~S} 158$ & & & \\
\hline
\end{tabular}

${ }^{1}$ Plates' identification: fiber fibre content $\left(\mathrm{F}_{1}=1 \%, \mathrm{~F}_{2}=2 \%, \mathrm{~F}_{3}=3 \%\right)$; spacing $\left(\mathrm{S}_{100}=100, \mathrm{~S}_{158}=158\right.$, $\mathrm{S}_{210}=210 \mathrm{~mm}$ ).

${ }^{2}$ Based on total section height $=100 \mathrm{~mm}$, per layer; per direction.

*All slabs are doubly reinforced with equal top and bottom orthogonal steel reinforcement

Table 5.2 Properties of UHP-FRC Materials

\begin{tabular}{|c|c|c|c|c|c|c|}
\hline $\begin{array}{l}\text { Fiber } \\
\text { ratio } \\
(\%)\end{array}$ & $\begin{array}{l}\text { Density } \\
(\rho) \\
\qquad \mathrm{kg} / \mathrm{m}^{3}\end{array}$ & $\begin{array}{r}\text { Compressive } \\
\text { strength }\left(\mathrm{f}^{\prime}{ }_{\mathrm{c}}\right) \\
\mathrm{MPa}\end{array}$ & $\begin{array}{l}\text { Strain at } \\
\text { peak stress } \\
\left(\varepsilon_{0}\right) \\
\quad \mathrm{mm} / \mathrm{m}\end{array}$ & $\begin{array}{l}\text { Splitting } \\
\text { tensile } \\
\text { strength }\left(\mathrm{f}_{\text {tsp }}\right) \\
\mathrm{MPa}\end{array}$ & $\begin{array}{l}\text { Elastic } \\
\text { modulus }\left(\mathrm{E}_{0}\right) \\
\qquad \mathrm{GPa}\end{array}$ & $\begin{array}{l}\text { Poisson's } \\
\text { ratio (v) }\end{array}$ \\
\hline 1 & 2600 & 154.80 & 4.10 & 7.30 & 45.00 & 0.2 \\
\hline 2 & 2650 & 162.40 & 4.35 & 11.10 & 45.80 & 0.2 \\
\hline 3 & 2710 & 158.70 & 4.50 & 14.00 & 46.30 & 0.2 \\
\hline
\end{tabular}




\section{B.2 Test Procedure}

The multi-impact load is applied at the midpoint of the UHP-FRC slabs. For each impact, $475 \mathrm{~kg}$ steel weight is dropped from the constant height of $4.15 \mathrm{~m}$. The setup is shown in Figure 5.17. For the intact, after first and second drops, the random excitations are applied on the slabs using a medium impact hammer. The response is captured using $50 \mathrm{~g}$ accelerometer and the data acquisition system. The setup information of the accelerometer sensor measurement system is given in Section 3.7.3.2 (Figure 3.44). The vertical accelerations are measured at the sampling rate of $2500 \mathrm{~Hz}$ for all of four UHP-FRC slabs in four locations (points 2, 3, 6, and 7) in three stages including intact, after first and second impact drops (Figure 5.18).

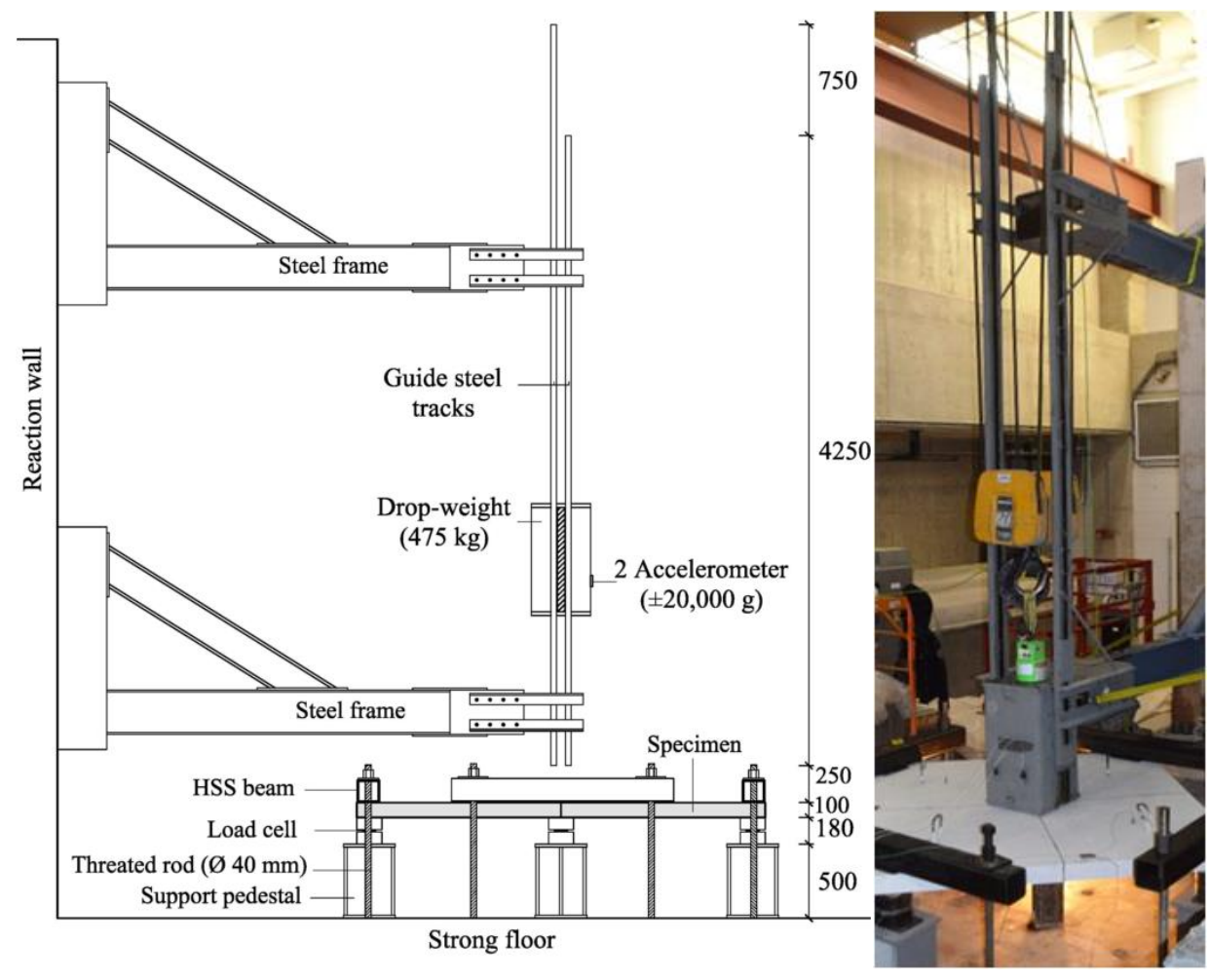

Figure 5.17 Details of Drop-Weight Impact Test Setup (Dimensions in mm) (Othman and Marzouk, 2015) 


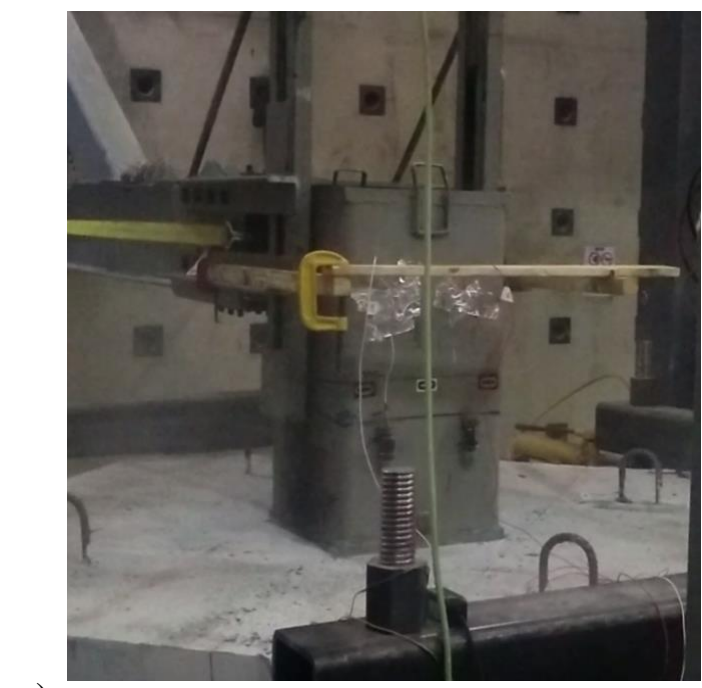

a)

Figure 5.18 Test Site a) Impact Load View b) Locations of Accelerometer

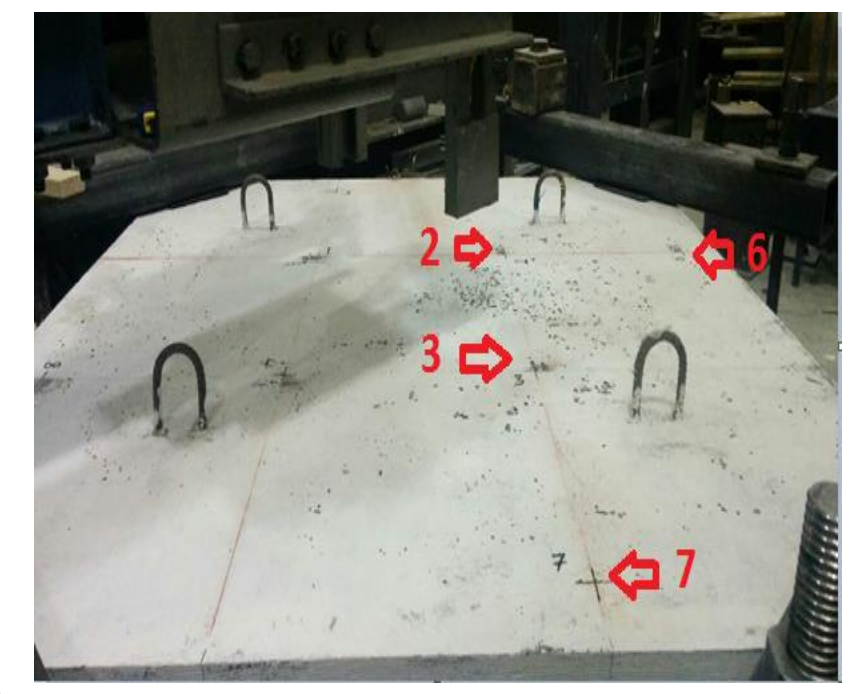

b)

\section{B.3 Results}

The dynamic parameters the natural frequency and damping ratio of the intact slabs and after applying the impact load for the first and second drop are determined. The accelerometer data are filtered using the bandpass Butterworth filter for first mode. The RD signatures are computed using the filtered accelerometer data. In order to extract the RD signature from the measured acceleration response, the triggering level of 1.4 times of the standard deviation of response is used. The integration is conducted using a time increment of $0.0004 \mathrm{sec}$ and the number of segments used to construct the RD is equal to half of the triggered data number approximately 3000 to 4000 . Respectively, the total length of time series generated to extract each RD signature is approximately 1200 to $1600 \mathrm{sec}$. This equals to 3 to 4 million sampling points. Figure 5.19 presents the extracted RD signature of point 3 for slab 3. 

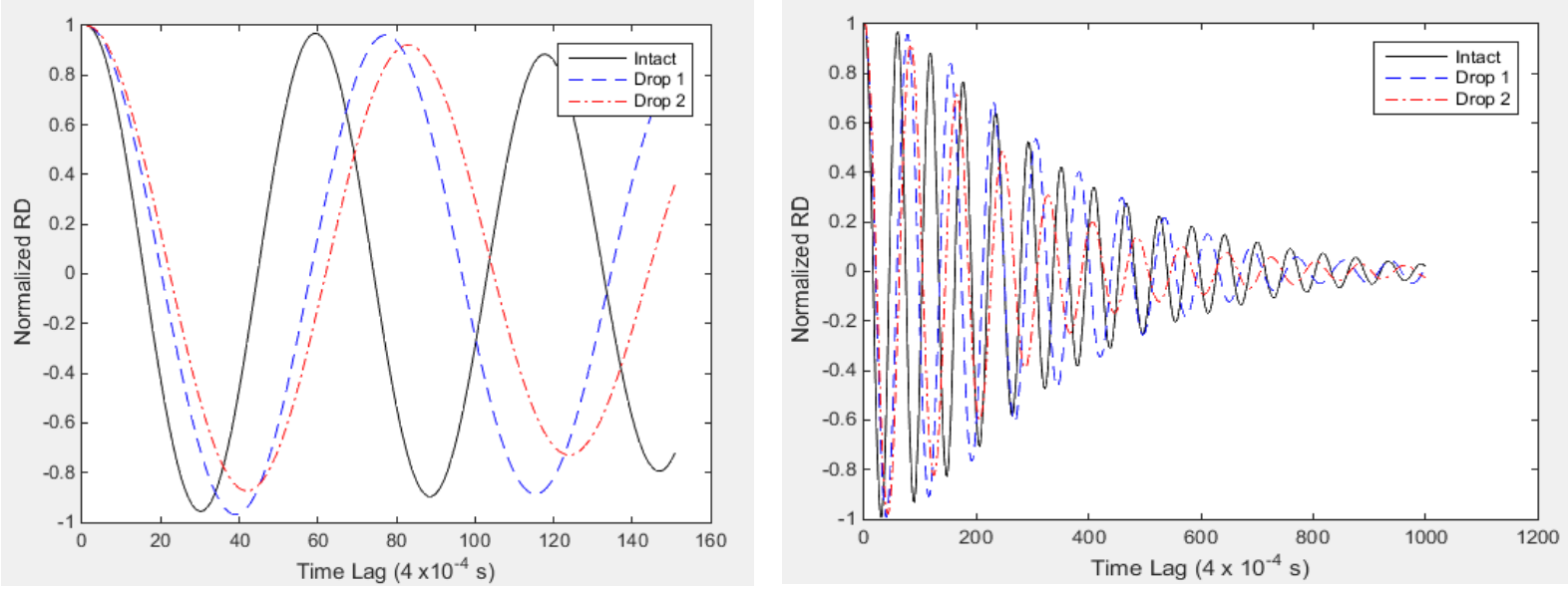

Figure 5.19 Mode 1, Normalized Random Decrement Signatures for Slab 3 Point 3 with Different Impact Loading (Intact, First and Second Drop)

The results obtained from the experimental RD signatures for the natural frequency and damping ratio found by the Logarithmic Decrement and Damping Envelope Complementary techniques are shown in Tables 5.3 and 5.4 and following bar graphs (Figures 5.20 and 5.21).

Table 5.3 Mode 1, Damping Ratio for Four Slabs at Four Points (2, 3, 6 and 7)

\begin{tabular}{|c|c|c|c|c|c|c|c|c|c|c|c|c|}
\hline $\begin{array}{r}\text { Slab } \\
\text { \# }\end{array}$ & $\begin{array}{l}\text { Point } \\
2 \\
\text { Intact }\end{array}$ & $\begin{array}{l}\text { Point } \\
2 \\
1^{\text {st }} \\
\text { Drop }\end{array}$ & $\begin{array}{l}\text { Point } \\
2 \\
2^{\text {nd }} \\
\text { Drop }\end{array}$ & $\begin{array}{l}\text { Point } \\
6 \\
\text { Intact }\end{array}$ & $\begin{array}{l}\text { Point } \\
6 \\
1^{\text {st }} \\
\text { Drop }\end{array}$ & $\begin{array}{l}\text { Point } \\
6 \\
2^{\text {nd }} \\
\text { Drop }\end{array}$ & $\begin{array}{l}\text { Point } \\
3 \\
\text { Intact }\end{array}$ & $\begin{array}{l}\text { Point } \\
3 \\
1^{\text {st }} \\
\text { Drop } \\
\end{array}$ & $\begin{array}{l}\text { Point } \\
3 \\
2^{\text {nd }} \\
\text { Drop }\end{array}$ & $\begin{array}{l}\text { Point } \\
7 \\
\text { Intact }\end{array}$ & $\begin{array}{l}\text { Point } \\
7 \\
1^{\text {st }} \\
\text { Drop }\end{array}$ & $\begin{array}{l}\text { Point } \\
7 \\
2^{\text {nd }} \\
\text { Drop }\end{array}$ \\
\hline 1 & 3.2 & 3.6 & 3.8 & 3.2 & 3.6 & 3.8 & 3.2 & 3.6 & 3.8 & 3.2 & 3.5 & 3.8 \\
\hline 2 & 3.2 & 3.5 & 3.7 & 3.1 & 3.5 & 3.8 & 3.1 & 3.5 & 3.8 & 3.0 & 3.5 & 3.8 \\
\hline 3 & 3.2 & 3.65 & 4.3 & 3.2 & 3.7 & 4.3 & 3.2 & 3.5 & 4.3 & 3.2 & 3.6 & 4.3 \\
\hline 4 & 3.3 & 4.3 & 4.5 & 3.3 & 4.5 & 4.8 & 3.3 & 4.5 & 4.9 & 3.3 & 4.6 & 4.8 \\
\hline
\end{tabular}

Table 5.4 Mode 1, Natural Frequency for Four Slabs at Four Points (2, 3, 6 and 7)

\begin{tabular}{|c|c|c|c|c|c|c|c|c|c|c|c|c|}
\hline $\begin{array}{r}\text { Slab } \\
\text { \# }\end{array}$ & $\begin{array}{l}\text { Point } \\
2 \\
\text { Intact }\end{array}$ & $\begin{array}{l}\text { Point } \\
2 \\
1^{\text {st }} \\
\text { Drop }\end{array}$ & $\begin{array}{l}\text { Point } \\
2 \\
2^{\text {nd }} \\
\text { Drop }\end{array}$ & $\begin{array}{l}\text { Point } \\
6 \\
\text { Intact }\end{array}$ & $\begin{array}{l}\text { Point } \\
6 \\
1^{\text {st }} \\
\text { Drop }\end{array}$ & $\begin{array}{l}\text { Point } \\
6 \\
2^{\text {nd }} \\
\text { Drop }\end{array}$ & $\begin{array}{l}\text { Point } \\
3 \\
\text { Intact }\end{array}$ & $\begin{array}{l}\text { Point } \\
3 \\
1^{\text {st }} \\
\text { Drop }\end{array}$ & $\begin{array}{l}\text { Point } \\
3 \\
2^{\text {nd }} \\
\text { Drop }\end{array}$ & $\begin{array}{l}\text { Point } \\
7 \\
\text { Intact }\end{array}$ & $\begin{array}{l}\text { Point } \\
7 \\
1^{\text {st }} \\
\text { Drop }\end{array}$ & $\begin{array}{l}\text { Point } \\
7 \\
2^{\text {nd }} \\
\text { Drop }\end{array}$ \\
\hline 1 & 45.0 & 31.0 & 30.0 & 45.0 & 31.0 & 30.0 & 45.0 & 31.0 & 30.0 & 45.0 & 31.0 & 29.0 \\
\hline 2 & 40.0 & 28.0 & 27.0 & 40.0 & 28.0 & 27.0 & 40.0 & 28.0 & 27.0 & 40.0 & 28.0 & 27.0 \\
\hline 3 & 42.5 & 33.0 & 32.0 & 42.5 & 33.0 & 32.0 & 42.5 & 32.0 & 30.0 & 43.0 & 33.0 & 31.0 \\
\hline 4 & 42.0 & 29.0 & 28.0 & 43.0 & 29.0 & 27.5 & 43.0 & 29.0 & 27.5 & 42.5 & 29.0 & 27.0 \\
\hline
\end{tabular}




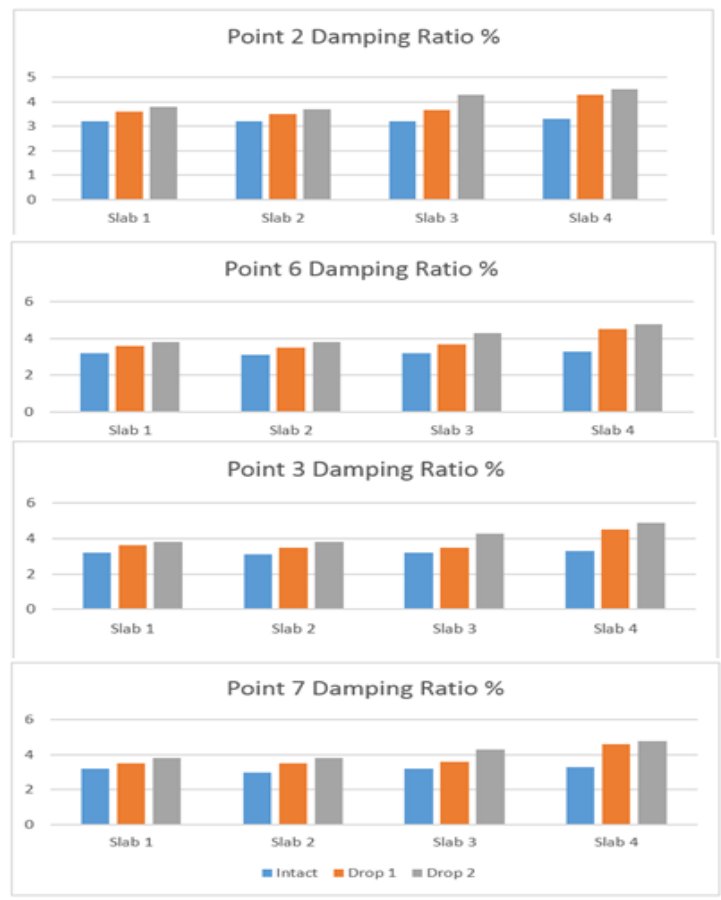

Figure 5.20 Mode 1, Damping Ratio for Four Slabs at Four Points (2, 3, 6 and 7)

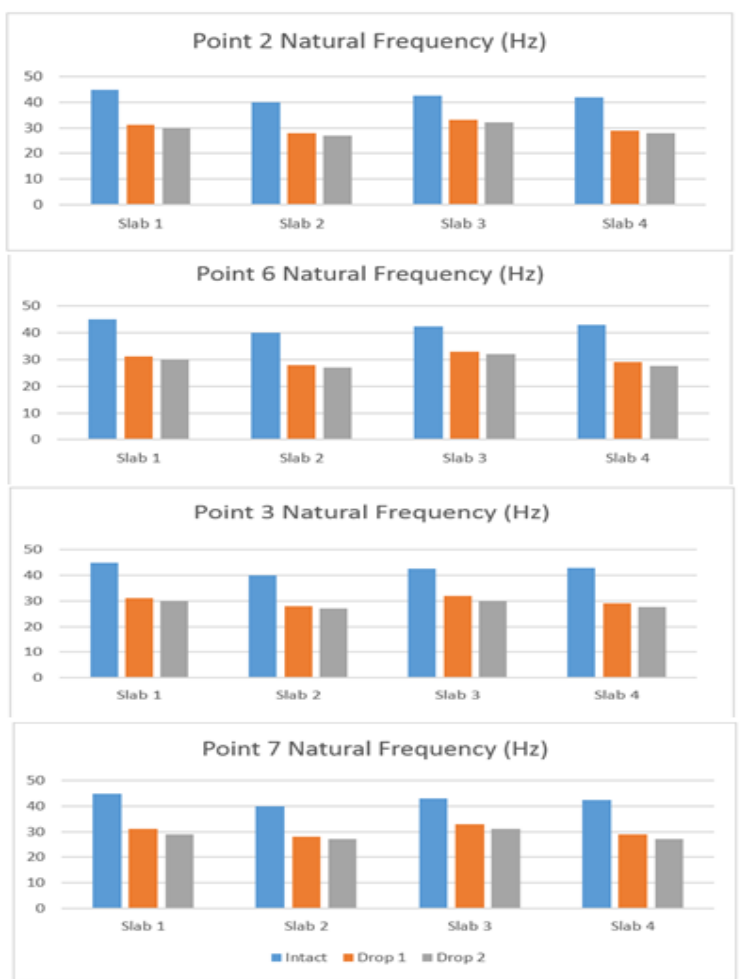

Figure 5.21 Mode 1, Natural Frequency for Four Slabs at Four Points (2, 3, 6 and 7) 
From the bar graphs, Figures 5.20 and 5.21, a decrease in the natural frequency and an increase in the damping ratio is apparent due to the damage of UHP-FRC slabs as the result of dropped steel weight. In all four slab specimens, after first impact drop, the intense decrease of natural frequency about $25 \%$ is observed. This is due to the mobilization of reinforcements and steel fibers under the initial load especially at the impact zone. After second drop, the decrease of frequency is not significant merely 3-5\%.

The slab 4 using the lowest reinforcement ratio of $0.64 \%$ has the highest damping ratio among the four UHP-FRC slabs. This truly indicates that the slab with a lower reinforcement ratio has been exposed to more damage as the result of drop impacts. The slab 3 has the intense increase in damping ratio about $18 \%$ after the second drop compared to the other slabs which have increased about $7 \%$. This is not related to more damage because there was no damage observed visually in the form of cracks. This is due to more internal friction caused by the higher fiber content. The mobilization of fibers enhances the damping ratio (Giner et al., 2011). 


\section{CHAPTER SIX \\ SUMMARY AND CONCLUSION}

\subsection{General}

In this research study, a practical and reliable SHM method for two-way reinforced concrete slabs based on the assessment of damage utilizing effective vibration based damage diagnostic technique of the Random Decrement (RD) is expressed theoretically and verified experimentally. The health monitoring challenge is almost equivalent to a pattern recognition problem where the damage detection, extent, location, and classification decisions are made by analyzing the descriptive features of RD signatures obtained from the system's response. The identification of damage is feasible simply through a comparison of different states of the structure. The RD signature is unique at each structural state and the unique global dynamic parameters natural frequency and damping ratio can be extracted from each signature in order to compare them at different states of the structural damage. Due to the fact that the behaviour of damage is tension related, the location of damage need to be properly analyzed. The RD approach is extended to the Multi-Channel Random Decrement (MCRD) technique in order to locate the damage by extracting the mode shape through applying the RD at multiple points of the structure simultaneously under certain triggering time vector segments. Implementing more points results in better analysis for locating the damage.

A study has been carried out to investigate the RD technique theoretically for the reinforced concrete slabs damage detection in terms of changes in the dynamic parameters. The RD technique is a time domain identification technique based on output measurements with no prior knowledge of the excitation which allows the method to be implemented without interrupting the normal operation of the system. Under the assumption that the system response is a realization of zeromean stationary Gaussian stochastic process, theoretically the RD signature is extracted from the single degree of freedom (SDOF) equation of motion and is equivalent to the free decay response of the system. In general, the RD technique acts as a particular case of autocorrelation function over a random process which converts it to a free decay response of the structure. The RD signature is obtained from an averaging process of time history segments of random vibration responses that 
contain certain triggering condition. The response is composed of two components: deterministic and random component. By averaging the response, the random component is eliminated and the deterministic component so called the free decay response is remaining. Here in this research, the two-way slab behaviour is successfully investigated in terms of the fundamental frequency and damping ratio obtained from the $\mathrm{RD}$ signature as a SDOF system model by filtering the data using a band pass filter for fundamental mode.

An experimental research was conducted to verify the RD method via investigating the extent of damage induced by progressive static loading at the cracking, yield, and ultimate states through the changes in the dynamic parameters frequency and damping ratio obtained via RD signatures collected from three reinforced High Strength Concrete (HSC) two-way slabs using different reinforcement ratios and one Ultra High Performance Fiber Reinforced Concrete (UHP-FRC) twoway slab. The behaviour of two-way slabs is presented in terms of the load-deflection relationship at service and ultimate load, crack pattern and failure modes. Two additional applications of the RD technique have been experimentally conducted and verified. First, the location of induced incremental damages at three levels of severity on the reinforced HSC two-way slab is identified by the MCRD technique to extract the mode shape and subsequently the Modified Mode Shape Difference and Mode Shape Extremum Damage Detection (EDD) techniques are utilized. Two Fiber Bragg Grating (FBG) arrays, including eight sensors are fabricated and tested for the MCRD data collection. Secondly, the RD technique is utilized to evaluate the extent of damage under the successive equal dynamic impacts on four UHP-FRC two-way slabs using different reinforcement ratios and fiber contents.

\subsection{Conclusion}

Based on the results of investigations, the following conclusions are drawn:

1. The result reveals that the $\mathrm{RD}$ technique is feasible and reliable to detect various kinds of damage in two-way slab caused by progressive static loading, local induction, and dynamic impact in terms of changes in the dynamic properties. Technically, the RD concept illustrates the extent of damage induced by progressive static loading via an increase in the 
damping ratio and a decrease in the natural frequency due to the damage growth. The extent of damage is more sensitive to change in the damping ratio compared to the natural frequency. The sensitivity is more vigorous for the UHP-FRC slab. The UHP-FRC slab has the intact damping ratio much lower than the reinforced HSC slabs because of the higher embodied energy due to not having large aggregates. The sliding between the cement and aggregate in ITZ (Interfacial Transition Zone) reduces the embodied energy and increases the damping ratio. The damping ratio increasing rate between states for the UHP-FRC slab is about two times larger compared to the reinforced HSC slabs since the UHP-FRC slab tolerates more load to reach to the cracking, yield and ultimate states that results more energy dissipation which is due to the friction exerted by the steel fibers.

2. The static characteristics of slabs the stiffness, ductility, and energy absorption are obtained from the load-deflection curves. For all the reinforced HSC slab specimens a trend is observed, as the reinforcement ratio is increased, the stiffness are also increased. The HSC slab using the lower reinforcement ratio deflects more and presents more ductility. It is concluded that the ductility is approximately proportional to the inverse square root of reinforcement ratios. For the slab specimens with the same failure mode, as the reinforcement ratio and compressive strength increase, the energy absorption capacity also increases.

3. The experimental results approve the implementation of MCRD for the damage location identification of the reinforced HSC slab via using the cutting edge FBG sensor technology. The plate as two dimensional element employs the in-plane coordinates. By following the algorithm of MCRD technique as two one dimensional beam elements in each in-plane orthogonal direction $\mathrm{x}$ and $\mathrm{y}$ of the slab plate, the fundamental mode shape of the plate is successfully identified for allocating the damage. An array of FBG sensors with four sensors is sufficient for collecting the MCRD data in each orthogonal direction, preferably located at the maximum deflection yield lines. The approach distinctly locates the damage by extracting and analyzing the mode shapes before and after inducing the damage through utilizing the Modified Mode Shape Difference and Mode Shape Extremum Damage Detection (EDD) techniques. 
4. The additional experimental result also reveals that the $\mathrm{RD}$ concept demonstrates the extent of damage induced by successive equal dynamic impact loading via an increase in the damping ratio and a decrease in the natural frequency. The extent of damage is more sensitive to change in the damping ratio compared to the natural frequency. To analyze the result of the RD for identifying the dynamic parameter, especially the natural frequency, the mobilization of reinforcement must be taken into consideration. As an additional conclusion, it is observed that the higher amount of steel fiber in the concrete mix after mobilization leads to more internal friction which enhances the damping ratio.

\subsection{Recommendation for Future Research}

Further experimental and numerical investigations might be conducted to understand more about the SHM of two-way slab system. The current investigation proved that the RD provides substantial information about the extent, and location of induced damage. The following recommendations are suggested for future research studies:

- According to the experimental finding of this research, the FBG sensors in two orthogonal arrays with four sensors in each array are quite sufficient and highly recommended to collect vibration data for the first mode shape of two-way slab in order to localize the damage. This arrangement of sensors also reduces the cost of required elaborate detection routines. However, for two-way slab with extremely large size, analyzing higher modes using more sensors in each array for locating the damage might be more economical.

- In this experimental research, the simply corner edge supported boundary condition is used for the two-way slab system. It is recommended to perform the same experiment for different boundary conditions and implement the FBG sensor arrays at the corresponding yield lines.

- For two-way slab vibration based analysis, it is recommended to use FBG sensor instead of an accelerometer for data collection. The FBG sensor collects data that purely contains information in its direction and reduces the extra efforts for better filtration. 
- In the UHP-FRC slab specimens after second dynamic impact drop, the mobilization of steel fibers enhanced the damping ratio. It is recommended to conduct an experiment with more impact drops to investigate the further effects of steel fiber mobilization on the damping ratio.

- Finite element (FE) modeling might be carried out based on the damage conditions provided in this research. The dynamic parameters obtained from the FE model have to be verified by the experimental results via developing required adjustments and modifications to the FE model parameters and limitations in order to optimize the numerical model.

- In the current study, the total aspects of SHM strategy are not covered. Therefore, a complementary investigation needs to be carried out as to determine the seriousness of damage, deterioration model and reliability of the estimated life cycle for two-way slab structure in order to develop a guideline for cost and maintenance plans. 


\section{APPENDICES}

\section{APPENDIX A: ULTIMATE STATIC CAPACITIES OF SLABS}

\section{A.1 Ultimate Static Capacities of HSC Slab Specimens}

According to CSA A23.3-14 the ultimate flexural and punching static capacities of HSC slab specimens are computed. There is no reduction in material properties considered for evaluating ultimate resistance by taking material safety factors equal to unity. This is because the ultimate static capacities are employed for obtaining the failure modes and not for design purposes.

\section{A.1.1 Ultimate Static Moment and Flexural Load Capacities of HSC Specimens}

The initial assumption is that the steel in tension is at yield. Figure A.1 illustrates the plane section method for ultimate flexural behaviour of RC slab.

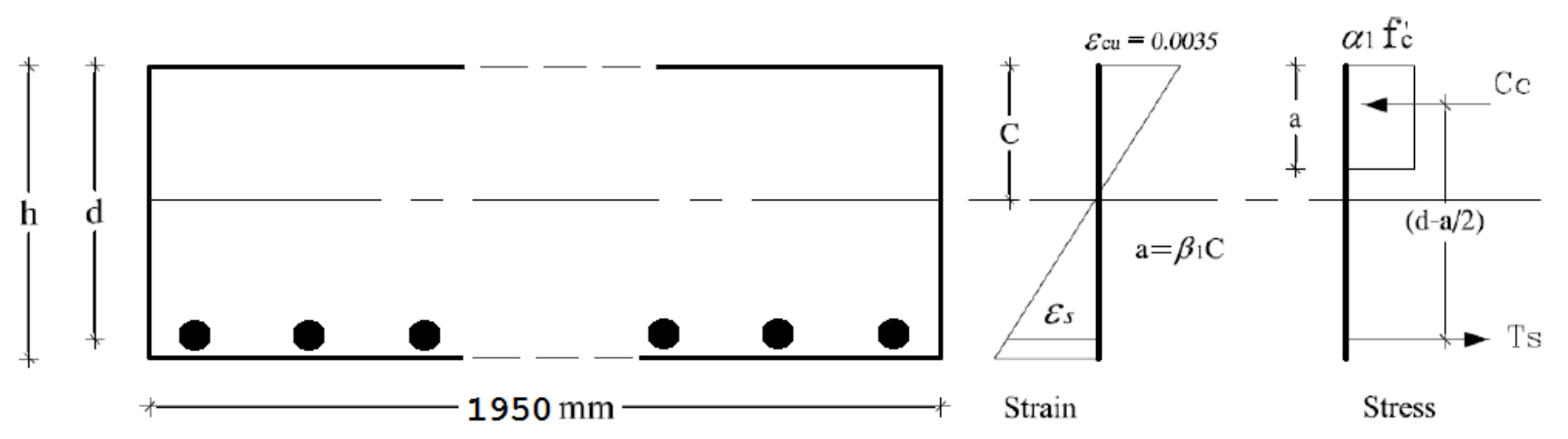

Figure A.1 Plane Section Method

\section{a) Slab specimen reinforced with $10 \mathrm{M} @ 210 \mathrm{~mm}$}

Concrete compressive strength $\left(\mathrm{f}^{\prime}{ }_{\mathrm{c}}\right)=68 \mathrm{MPa}$; clear cover $\left(\mathrm{b}_{\mathrm{c}}\right)=20 \mathrm{~mm}$; and steel yield stress $\left(\mathrm{f}_{\mathrm{y}}\right)$ $=400 \mathrm{MPa}$.

$\alpha_{1}=0.85-0.0015 \mathrm{f}^{\prime}{ }_{\mathrm{c}}=0.75$ not smaller than 0.67

$\beta_{1}=0.97-0.0025 \mathrm{f}^{\prime}{ }_{\mathrm{c}}=0.80$ not smaller than 0.67

$\mathrm{d}=\mathrm{h}-\mathrm{b}_{\mathrm{c}}-\frac{\mathrm{d}_{\mathrm{b}}}{2}=100-20-\frac{11}{2}=74.5 \mathrm{~mm}$

Calculation of tension force in steel:

$\mathrm{T}_{\mathrm{s}}=\mathrm{A}_{\mathrm{s}} \times \mathrm{f}_{\mathrm{y}}=1000 \times 400=400 \mathrm{kN}$ 
Calculation of compression stress block depth (a):

$\mathrm{a}=\frac{\mathrm{T}_{\mathrm{s}}}{\alpha_{1} \times \mathrm{f}^{\prime}{ }_{\mathrm{c}} \times \mathrm{b}}=\frac{400000}{0.75 \times 68 \times 1950}=4.03 \mathrm{~mm}$

Calculation of neutral axis depth:

$\mathrm{C}=\frac{\mathrm{a}}{\beta_{1}}=5.04 \mathrm{~mm}$

Check if steel yield:

$\frac{\mathrm{C}_{\mathrm{b}}}{\mathrm{d}}=\frac{0.0035}{0.0035+\varepsilon_{\mathrm{y}}}=0.6364 \longrightarrow \mathrm{C}_{\mathrm{b}}=0.6364 \times 74.5=47.41 \mathrm{~mm}$

$\mathrm{C}<\mathrm{C}_{\mathrm{b}} \quad$ Steel yields

Calculation of moment of resistance and ultimate flexural load:

$\mathrm{M}_{\mathrm{r}}=\mathrm{T}_{\mathrm{s}}\left(\mathrm{d}-\frac{\mathrm{a}}{2}\right)=29 \mathrm{kN} \cdot \mathrm{m}$

$\mathrm{P}_{\mathrm{u}}=4 \mathrm{M}_{\mathrm{r}}=116 \mathrm{kN}$

\section{b) Slab specimen reinforced with $10 \mathrm{M} @ 100 \mathrm{~mm}$}

Concrete compressive strength $\left(\mathrm{f}^{\prime}{ }_{\mathrm{c}}\right)=71 \mathrm{MPa}$; clear cover $\left(\mathrm{b}_{\mathrm{c}}\right)=20 \mathrm{~mm}$; and steel yield stress

$\left(\mathrm{f}_{\mathrm{y}}\right)=400 \mathrm{MPa}$.

$\alpha_{1}=0.85-0.0015 \mathrm{f}^{\prime}{ }_{\mathrm{c}}=0.74$ not smaller than 0.67

$\beta_{1}=0.97-0.0025 \mathrm{f}^{\prime}{ }_{\mathrm{c}}=0.79$ not smaller than 0.67

$\mathrm{d}=\mathrm{h}-\mathrm{b}_{\mathrm{c}}-\frac{\mathrm{d}_{\mathrm{b}}}{2}=100-20-\frac{11}{2}=74.5 \mathrm{~mm}$

Calculation of tension force in steel:

$T_{s}=A_{s} \times f_{y}=2000 \times 400=800 \mathrm{kN}$

$\underline{\text { Calculation of compression stress block depth (a): }}$

$\mathrm{a}=\frac{\mathrm{T}_{\mathrm{s}}}{\alpha_{1} \times \mathrm{f}^{\prime}{ }_{\mathrm{c}} \times \mathrm{b}}=\frac{800000}{0.74 \times 71 \times 1950}=7.77 \mathrm{~mm}$ 
Calculation of neutral axis depth:

$\mathrm{C}=\frac{\mathrm{a}}{\beta_{1}}=9.81 \mathrm{~mm}$

Check if steel yield:

$\frac{\mathrm{C}_{\mathrm{b}}}{\mathrm{d}}=\frac{0.0035}{0.0035+\varepsilon_{\mathrm{y}}}=0.6364 \longrightarrow \mathrm{C}_{\mathrm{b}}=0.6364 \times 74.5=47.41 \mathrm{~mm}$

$\mathrm{C}<\mathrm{C}_{\mathrm{b}} \quad$ Steel yields

Calculation of moment of resistance and ultimate flexural load:

$\mathrm{M}_{\mathrm{r}}=\mathrm{T}_{\mathrm{s}}\left(\mathrm{d}-\frac{\mathrm{a}}{2}\right)=56.50 \mathrm{kN} \cdot \mathrm{m}$

$\mathrm{P}_{\mathrm{u}}=4 \mathrm{M}_{\mathrm{r}}=226 \mathrm{kN}$

\section{c) Slab specimen reinforced with $15 \mathrm{M} @ 100 \mathrm{~mm}$}

Concrete compressive strength $\left(\mathrm{f}^{\prime}{ }_{\mathrm{c}}\right)=78.5 \mathrm{MPa}$; clear cover $\left(\mathrm{b}_{\mathrm{c}}\right)=20 \mathrm{~mm}$; and steel yield stress $\left(\mathrm{f}_{\mathrm{y}}\right)=400 \mathrm{MPa}$.

$\alpha_{1}=0.85-0.0015 \mathrm{f}^{\prime}{ }_{\mathrm{c}}=0.73$ not smaller than 0.67

$\beta_{1}=0.97-0.0025 \mathrm{f}^{\prime}{ }_{\mathrm{c}}=0.77$ not smaller than 0.67

$\mathrm{d}=\mathrm{h}-\mathrm{b}_{\mathrm{c}}-\frac{\mathrm{d}_{\mathrm{b}}}{2}=100-20-\frac{16}{2}=72 \mathrm{~mm}$

Calculation of tension force in steel:

$T_{s}=A_{s} \times f_{y}=4000 \times 400=1600 \mathrm{kN}$

Calculation of compression stress block depth (a):

$\mathrm{a}=\frac{\mathrm{T}_{\mathrm{s}}}{\alpha_{1} \times \mathrm{f}^{\prime}{ }_{\mathrm{c}} \times \mathrm{b}}=\frac{1600000}{0.73 \times 78.5 \times 1950}=14.27 \mathrm{~mm}$

Calculation of neutral axis depth:

$\mathrm{C}=\frac{\mathrm{a}}{\beta_{1}}=18.45 \mathrm{~mm}$ 


\section{Check if steel yield:}

$\frac{\mathrm{C}_{\mathrm{b}}}{\mathrm{d}}=\frac{0.0035}{0.0035+\varepsilon_{\mathrm{y}}}=0.6364 \longrightarrow \mathrm{C}_{\mathrm{b}}=0.6364 \times 72=45.82 \mathrm{~mm}$

$\mathrm{C}<\mathrm{C}_{\mathrm{b}} \quad$ Steel yields

Calculation of moment of resistance and ultimate flexural load:

$\mathrm{M}_{\mathrm{r}}=\mathrm{T}_{\mathrm{s}}\left(\mathrm{d}-\frac{\mathrm{a}}{2}\right)=103.78 \mathrm{kN} \cdot \mathrm{m}$

$\mathrm{P}_{\mathrm{u}}=4 \mathrm{M}_{\mathrm{r}}=415.12 \mathrm{kN}$

\section{A.1.2 Ultimate Static Punching Load Capacities of HSC Specimens}

According to CSA A23.3-14 the punching shear strength of RC plates and footings are expressed in three categories. For calculating the ultimate punching shear strength of the plate, the smallest of three shall be used. The punching perimeter of tested slab specimens loaded by a $400 \mathrm{~mm}$ square loading area is depicted in Figure A.2.

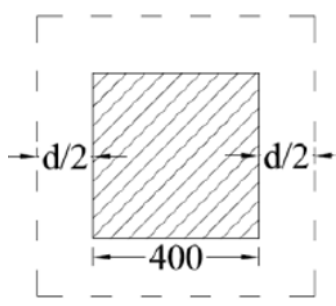

Figure A.2 Critical perimeter for punching shear as in CSA A23.3

\section{a) Slab specimens reinforced with $10 \mathrm{M} @ 210 \mathrm{~mm} \& 10 \mathrm{M} @ 100 \mathrm{~mm}$}

Depth of exterior reinforcement layer $\left(\mathrm{d}_{\max }\right)=100-20-\frac{11}{2}=74.5 \mathrm{~mm}$

Depth of interior reinforcement layer $\left(\mathrm{d}_{\min }\right)=100-20-11-\frac{11}{2}=63.5 \mathrm{~mm}$

$\mathrm{d}=\frac{74.5+63.5}{2} \cong 69 \mathrm{~mm}$

Shear perimeter $\left(b_{0}\right)=4(400+69)=1876 \mathrm{~mm}$ 
Shear resistance $\left(v_{c}\right)$ is the least of:

1) $\mathrm{v}_{\mathrm{c}}=\left(1+\frac{2}{\beta_{\mathrm{c}}}\right) \times 0.19 \times \lambda \times \varphi_{\mathrm{c}} \times \sqrt{\mathrm{f}^{\prime}{ }_{\mathrm{c}}}=\left(1+\frac{2}{1}\right) \times 0.19 \times \sqrt{64}=4.56 \mathrm{~N} / \mathrm{mm}^{2}$

Where for square column $\beta_{\mathrm{c}}=1$

2) $\mathrm{v}_{\mathrm{c}}=\left(0.19+\frac{\alpha_{\mathrm{s}} \mathrm{d}}{\mathrm{b}_{0}}\right) \times \lambda \times \varphi_{\mathrm{c}} \times \sqrt{\mathrm{f}^{\prime}{ }_{\mathrm{c}}}=\left(0.19+\frac{4 \times 69}{1876}\right) \times \sqrt{64}=2.70 \mathrm{~N} / \mathrm{mm}^{2}$

Where for interior column $\alpha_{s}=4$

3) $\mathrm{v}_{\mathrm{c}}=0.38 \times \lambda \times \varphi_{\mathrm{c}} \times \sqrt{\mathrm{f}^{\prime}{ }_{\mathrm{c}}}=0.38 \times \sqrt{64}=3.04 \mathrm{~N} / \mathrm{mm}^{2}$

The ultimate punching capacity:

$\mathrm{V}_{\mathrm{u}}=\mathrm{v}_{\mathrm{c}} \times \mathrm{b}_{0} \times \mathrm{d}=2.70 \times 1876 \times 69=348.20 \mathrm{kN}$

\section{b) Slab specimens reinforced with $15 \mathrm{M} @ 100 \mathrm{~mm}$}

Depth of exterior reinforcement layer $\left(\mathrm{d}_{\max }\right)=100-20-\frac{16}{2}=72 \mathrm{~mm}$

Depth of interior reinforcement layer $\left(d_{\min }\right)=100-20-16-\frac{16}{2}=56 \mathrm{~mm}$

$\mathrm{d}=\frac{72+56}{2} \cong 64 \mathrm{~mm}$

Shear perimeter $\left(b_{0}\right)=4(400+64)=1856 \mathrm{~mm}$

Shear resistance $\left(v_{c}\right)$ is the least of:

1) $\mathrm{v}_{\mathrm{c}}=\left(1+\frac{2}{\beta_{\mathrm{c}}}\right) \times 0.19 \times \lambda \times \varphi_{\mathrm{c}} \times \sqrt{\mathrm{f}^{\prime}{ }_{\mathrm{c}}}=\left(1+\frac{2}{1}\right) \times 0.19 \times \sqrt{64}=4.56 \mathrm{~N} / \mathrm{mm}^{2}$

Where for square column $\beta_{\mathrm{c}}=1$

2) $\mathrm{v}_{\mathrm{c}}=\left(0.19+\frac{\alpha_{\mathrm{s}} \mathrm{d}}{\mathrm{b}_{0}}\right) \times \lambda \times \varphi_{\mathrm{c}} \times \sqrt{\mathrm{f}^{\prime}{ }_{\mathrm{c}}}=\left(0.19+\frac{4 \times 64}{1856}\right) \times \sqrt{64}=2.62 \mathrm{~N} / \mathrm{mm}^{2}$

Where for interior column $\alpha_{s}=4$

3) $\mathrm{v}_{\mathrm{c}}=0.38 \times \lambda \times \varphi_{\mathrm{c}} \times \sqrt{\mathrm{f}^{\prime}{ }_{\mathrm{c}}}=0.38 \times \sqrt{64}=3.04 \mathrm{~N} / \mathrm{mm}^{2}$ 
The ultimate punching capacity:

$\mathrm{V}_{\mathrm{u}}=\mathrm{v}_{\mathrm{c}} \times \mathrm{b}_{0} \times \mathrm{d}=2.62 \times 1856 \times 64=311.62 \mathrm{kN}$

\section{A.2 Ultimate Static Capacities of UHP-FRC Slab Specimen}

For obtaining the ultimate flexural capacity of UHP-FRC specimen, the method similar to ACI ultimate strength design method is implemented by (Wasan and Tayfur, 2013), in which the tensile strength computed for the fibrous concrete is added to that contributed by the reinforcing bars. For estimating the ultimate punching capacity of UHP-FRC specimen, the model by (Moreillon et al., 2013) is implemented in which the contribution of fiber is considered. There is no reduction in material properties considered for evaluating ultimate resistance by taking material safety factors equal to unity.

\section{A.2.1 Ultimate Static Moment and Flexural Load Capacities of UHP-FRC 1 Specimen}

The initial assumption is that the steel in tension is at yield. Figure A.3 illustrates the plane section method for ultimate flexural behaviour of reinforced UHP-FRC slab.
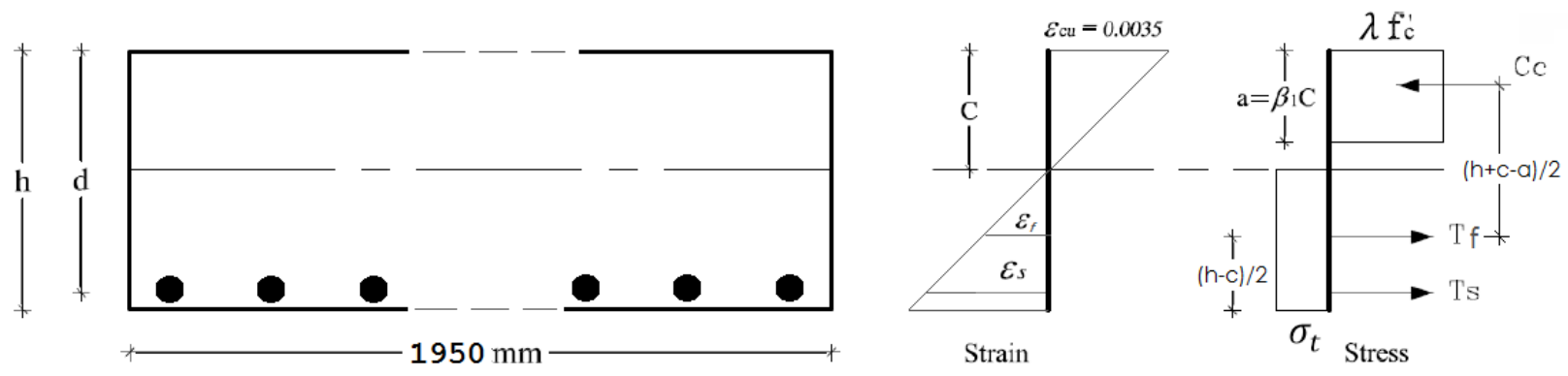

Figure A.3 Modified Plane Section Method for reinforced UHP-FRC slab

Compressive strength of fibrous concrete $\left(\mathrm{f}^{\prime}{ }_{\mathrm{cf}}\right)=162.4 \mathrm{MPa}$; clear cover $\left(\mathrm{b}_{\mathrm{c}}\right)=20 \mathrm{~mm}$; steel yield stress $\left(\mathrm{f}_{\mathrm{y}}\right)=400 \mathrm{MPa}$; concrete stress block parameter $(\lambda)=0.86$ for $\mathrm{f}^{\prime}{ }_{\mathrm{c}} \geq 55 \mathrm{MPa}$; and concrete stress block parameter $\left(\beta_{1}\right)=0.65$ for $^{\prime}{ }^{\prime}{ } \geq 55 \mathrm{MPa}$. 
Calculation of post cracking tensile strength:

Volume fraction of steel fibre $\left(\mathrm{V}_{\mathrm{f}}=2 \%\right)$; length of steel fibre $\left(\mathrm{l}_{\mathrm{f}}\right)=13 \mathrm{~mm}$; diameter of steel fibre $\left(\mathrm{d}_{\mathrm{f}}\right)=0.2 \mathrm{~mm}$; and bond efficiency factor for straight fibre $\left(\mathrm{F}_{\mathrm{b}}\right)=1$.

$\sigma_{\mathrm{t}}=2 \times \mathrm{V}_{\mathrm{f}} \times\left(\frac{\mathrm{l}_{\mathrm{f}}}{\mathrm{d}_{\mathrm{f}}}\right) \times \mathrm{F}_{\mathrm{b}}=2 \times 0.02 \times \frac{13}{0.2} \times 1=2.6 \mathrm{MPa}$

Calculation of tension force in steel:

$\mathrm{T}_{\mathrm{s}}=\mathrm{A}_{\mathrm{s}} \times \mathrm{f}_{\mathrm{y}}=2000 \times 400=800 \mathrm{kN}$

Calculation of tension force due to fibre:

$\mathrm{T}_{\mathrm{f}}=\sigma_{\mathrm{t}} \times \mathrm{b} \times \mathrm{h}=2.6 \times 1950 \times 100=507 \mathrm{kN}$

Calculation of compression stress block depth (a):

$\mathrm{a}=\frac{\left(\mathrm{T}_{\mathrm{s}}+\mathrm{T}_{\mathrm{f}}\right)}{\left(\lambda \times \mathrm{f}^{\prime}{ }_{\mathrm{cf}} \times \mathrm{b}+\sigma_{\mathrm{t}} \times \mathrm{b}\right)}=\frac{(800000+507000)}{(0.86 \times 162.4 \times 1950+2.6 \times 1950)}=4.71 \mathrm{~mm}$

Calculation of neutral axis depth:

$\mathrm{C}=\frac{\mathrm{a}}{\beta_{1}}=\frac{4.71}{0.65}=7.25 \mathrm{~mm}$

Check if steel yield:

$\frac{C_{b}}{d}=\frac{0.0035}{0.0035+\varepsilon_{y}}=0.6364 \longrightarrow C_{b}=0.6364 \times 74.5=47.41 \mathrm{~mm}$

$\mathrm{C}<\mathrm{C}_{\mathrm{b}} \quad$ Steel yields

Calculation of moment of resistance and ultimate flexural load:

$$
\begin{aligned}
& M_{r}=A_{s} \times f_{y} \times\left(d-\frac{a}{2}\right)+\sigma_{t} \times b \times(h-c) \times\left(\frac{h+c-a}{2}\right) \\
& =2000 \times 400 \times\left(74.5-\frac{4.71}{2}\right)+2.6 \times 1950 \times(100-7.25) \times\left(\frac{100+7.25-4.71}{2}\right) \\
& \quad=81.82 \quad \text { kN.m } \\
& P_{u}=4 M_{r}=327 \mathrm{kN}
\end{aligned}
$$




\section{A.2.2 Ultimate Static Punching Load Capacity of UHP-FRC 1 Specimen with 10M @ 100 mm and $2 \%$ Steel Fibres}

Depth of exterior reinforcement layer $\left(\mathrm{d}_{\max }\right)=100-20-\frac{11}{2}=74.5 \mathrm{~mm}$

Depth of interior reinforcement layer $\left(d_{\min }\right)=100-20-11-\frac{11}{2}=63.5 \mathrm{~mm}$

$\mathrm{d}=\frac{74.5+63.5}{2} \cong 69 \mathrm{~mm} ; \quad$ Shear perimeter $\left(\mathrm{b}_{0}\right)=4(400+69)=1876 \mathrm{~mm}$

Calculation of slab rotation $(\Psi)$ (Spasojević, 2008):

Displacement at maximal force $\left(\delta_{\text {Pmax }}\right)=97.5 \mathrm{~mm}$; radius of the slab $\left(\mathrm{r}_{\mathrm{b}}\right)=\frac{1950}{2}=$ $975 \mathrm{~mm}$; and loading square coloumn width $\left(\mathrm{b}_{\mathrm{c}}\right)=400 \mathrm{~mm}$.

$\Psi=\frac{\delta_{\mathrm{Pmax}}}{\left(\mathrm{r}_{\mathrm{b}}-\frac{\mathrm{b}_{\mathrm{c}}}{2}\right)}=\frac{97.5}{\left(975-\frac{400}{2}\right)}=0.125$ radians

Calculation of punching shear resistance of the matrix $\left(\mathrm{V}_{\mathrm{R}, \mathrm{c}}\right)$ :

It is assumed that punching shear strength of matrix is carried by shear friction and is function of critical crack opening which is product of effective depth $(d)$ with slab rotation $(\Psi)$. The diameter of the biggest aggregate $\left(\mathrm{d}_{\mathrm{g}}\right)=0$ for UHP-FRC.

$\mathrm{V}_{\mathrm{R}, \mathrm{c}}=\frac{3 / 4}{1+15 \times \frac{\Psi \times \mathrm{d}}{16+\mathrm{d}_{\mathrm{g}}}} \times \mathrm{b}_{0} \times \mathrm{d} \times \sqrt{\mathrm{f}_{\mathrm{c}}^{\prime}}=\frac{3 / 4}{1+15 \times \frac{0.125 \times 69}{16+0}} \times 1876 \times 69 \times \sqrt{162.4}=136.17 \mathrm{kN}$

Calculation of punching shear resistance due to fibre $\left(V_{R, f}\right)$ :

The post-cracking tensile strength determined by uniaxial test $\left(\mathrm{f}_{\mathrm{Ut}}\right)=5.5 \mathrm{MPa}$; the partial safety factor $\left(\gamma_{\mathrm{U}}\right)$ taken as 1 ; and the ultimate crack opening $\left(\mathrm{w}_{\mathrm{u}}\right)=5 \mathrm{~mm}$.

$\mathrm{V}_{\mathrm{R}, \mathrm{f}}=\frac{\mathrm{f}_{\mathrm{Ut}} / \gamma_{\mathrm{U}}}{1+\frac{\Psi \times \mathrm{d}}{\mathrm{W}_{\mathrm{u}}}} \times \mathrm{b}_{0} \times \mathrm{d}=\frac{5.5}{1+\frac{0.125 \times 69}{5}} \times 1876 \times 69=261.26 \mathrm{kN}$

Calculation of total punching shear resistance:

$\mathrm{V}_{\mathrm{R}, \text { total }}=\mathrm{V}_{\mathrm{R}, \mathrm{c}}+\mathrm{V}_{\mathrm{R}, \mathrm{f}}=136.17+261.26=397.43 \mathrm{kN}$ 


\section{APPENDIX B: FFT PROGRAM}

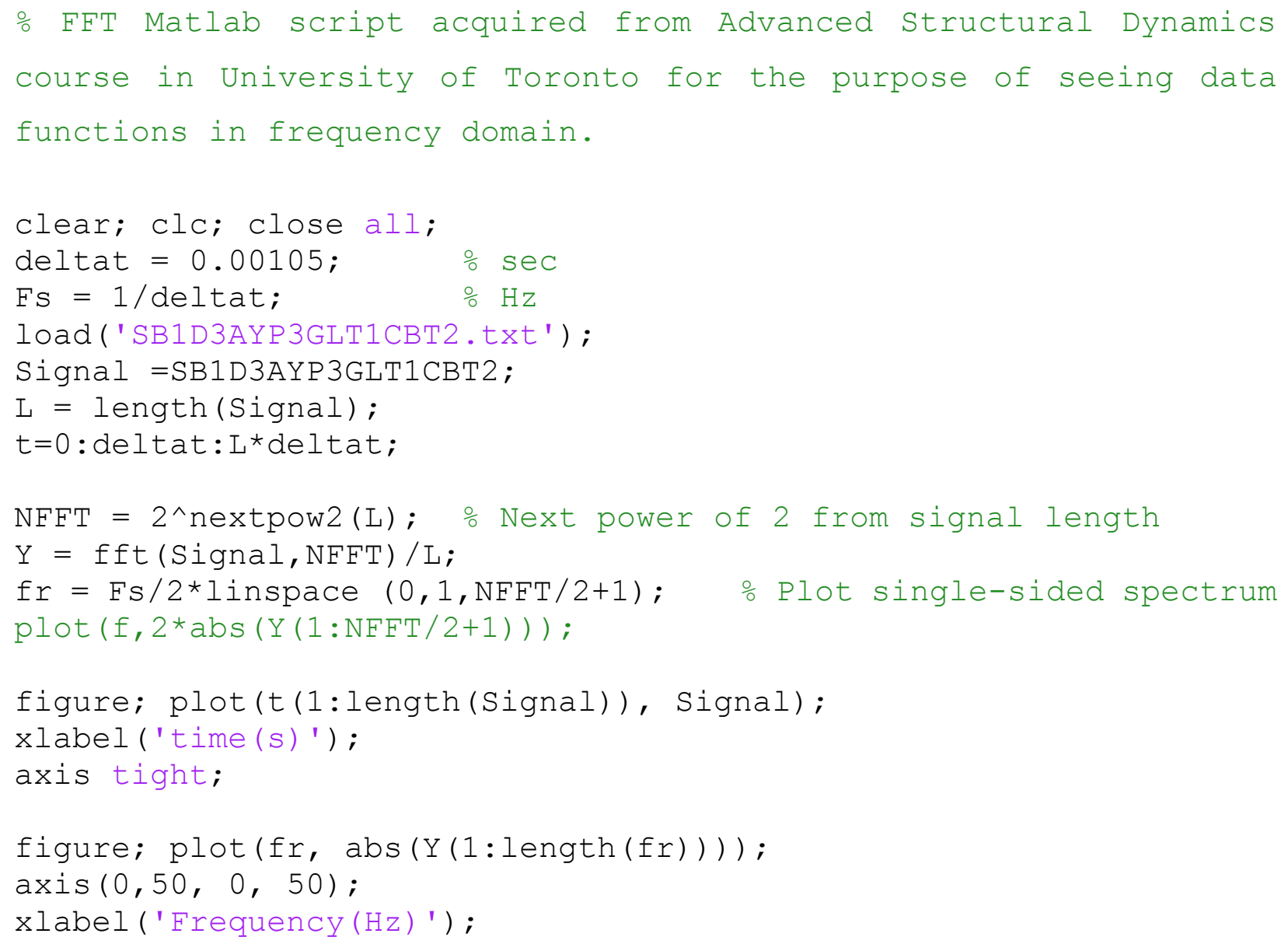




\section{APPENDIX C: BANDPASS FILTER PROGRAM}

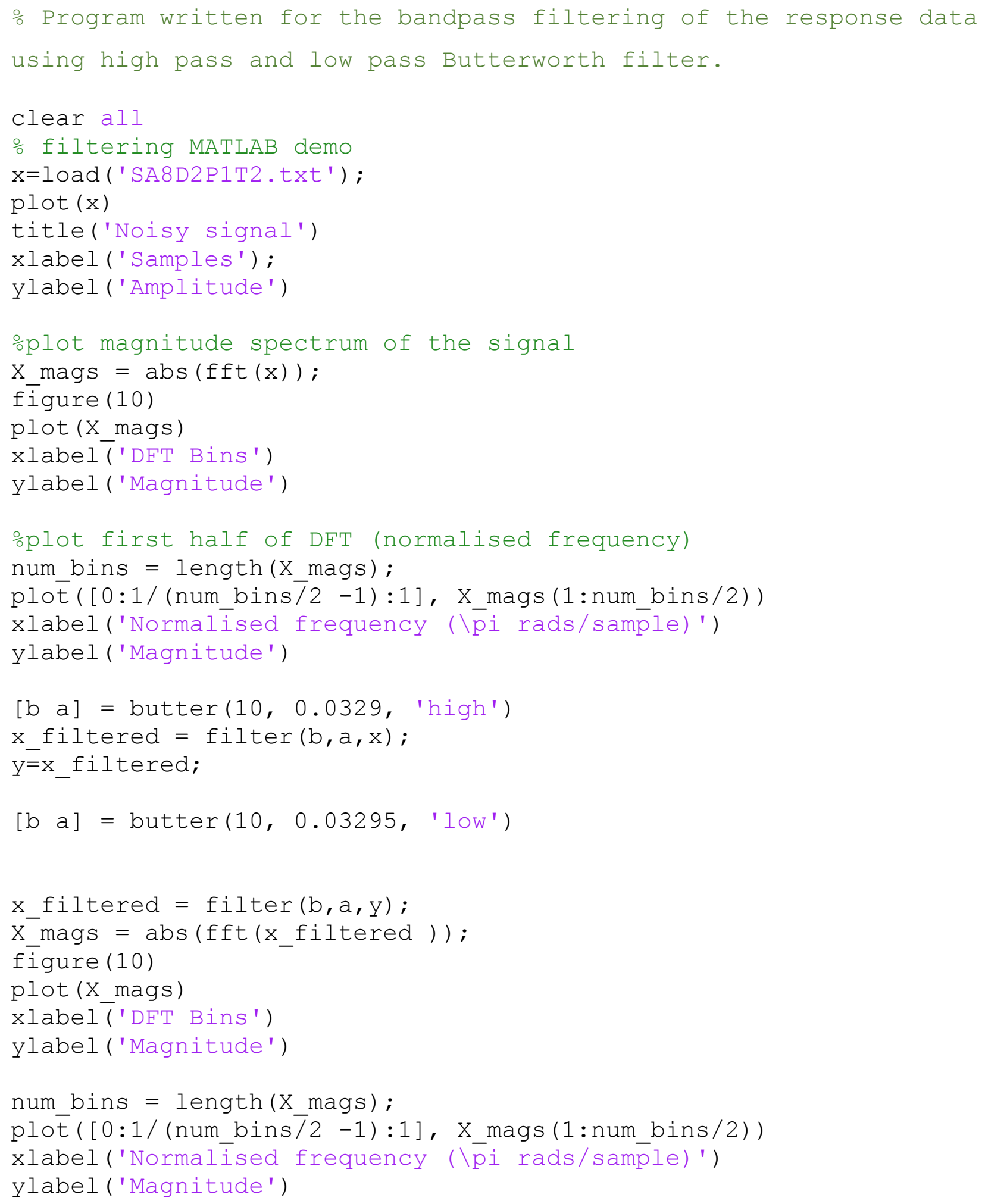




\section{APPENDIX D: RD TECHNIQUE PROGRAM}

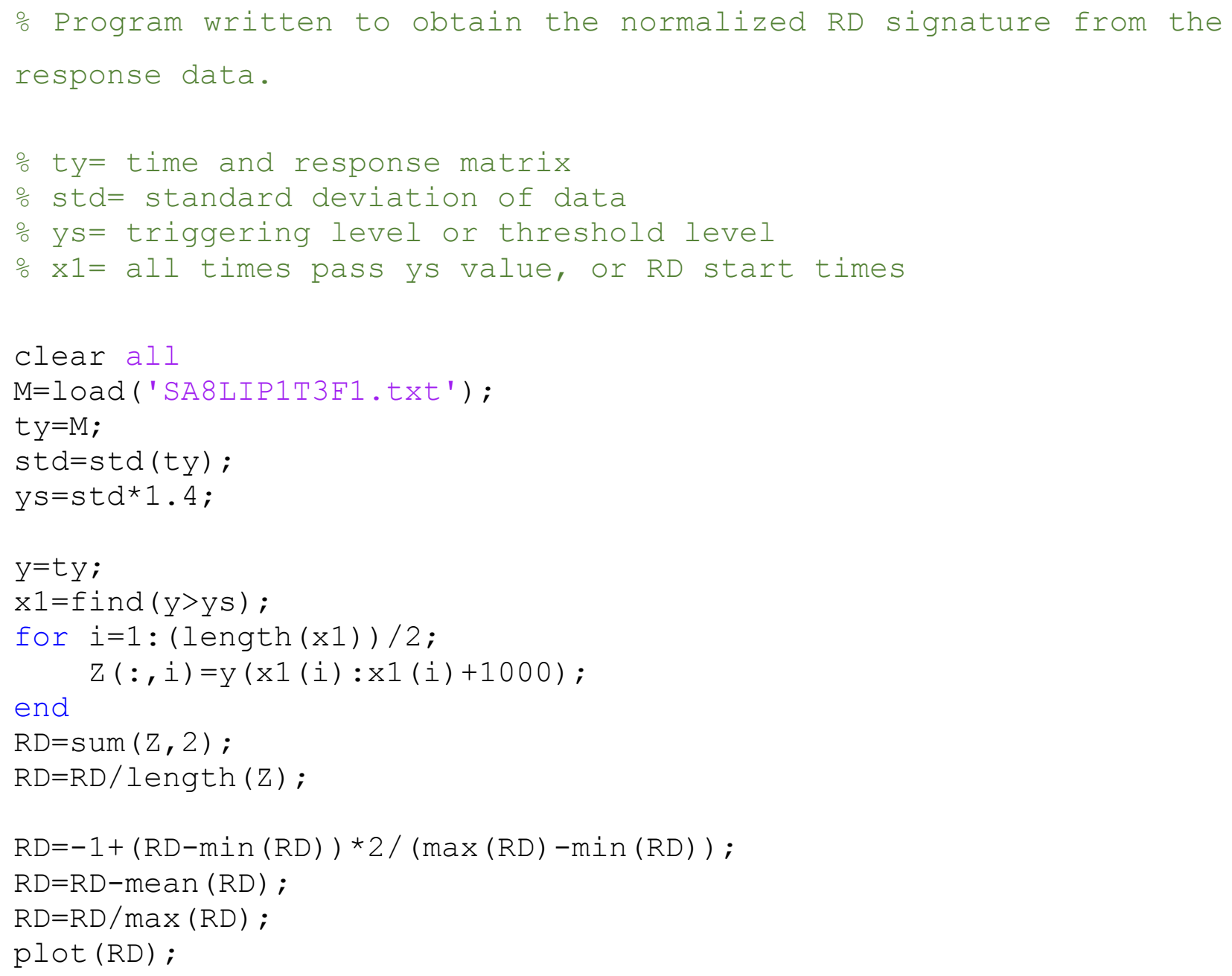




\section{APPENDIX E: LOGARITHMIC DECREMENT PROGRAM}

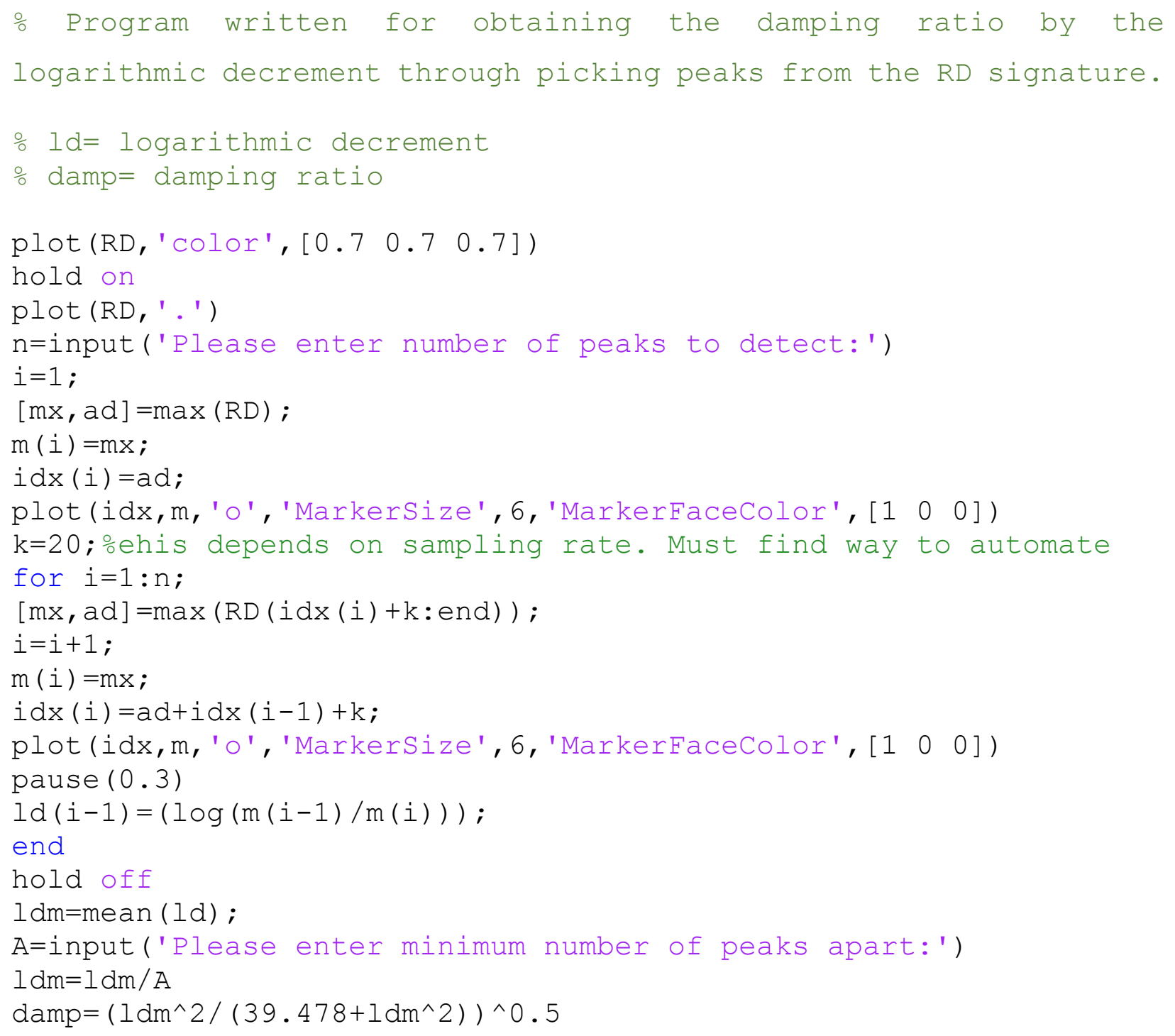




\section{APPENDIX F: DAMPING ENVELOPE PROGRAM}

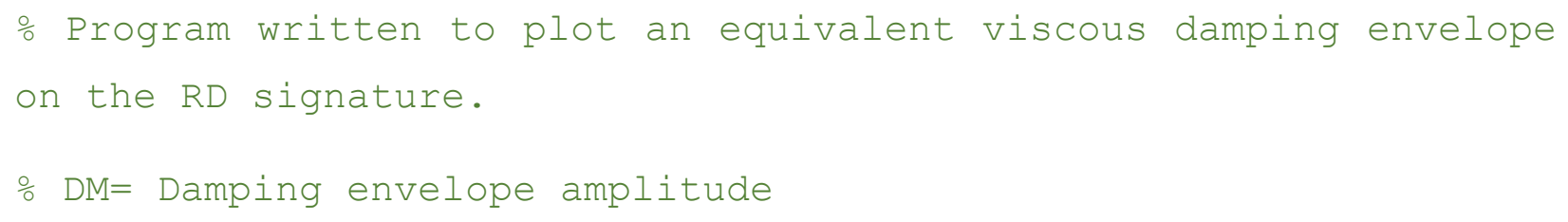




\section{APPENDIX G: MCRD PROGRAM}

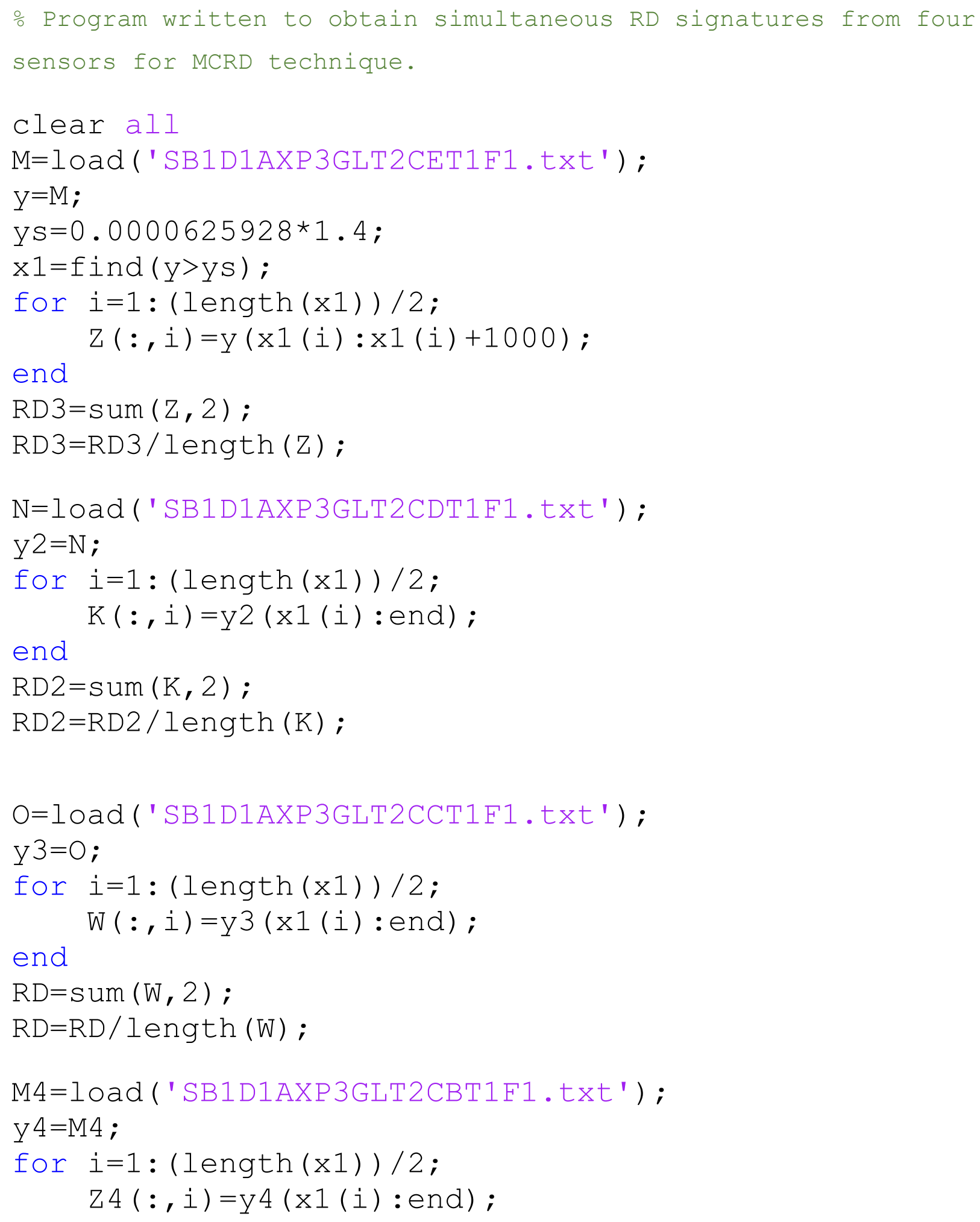




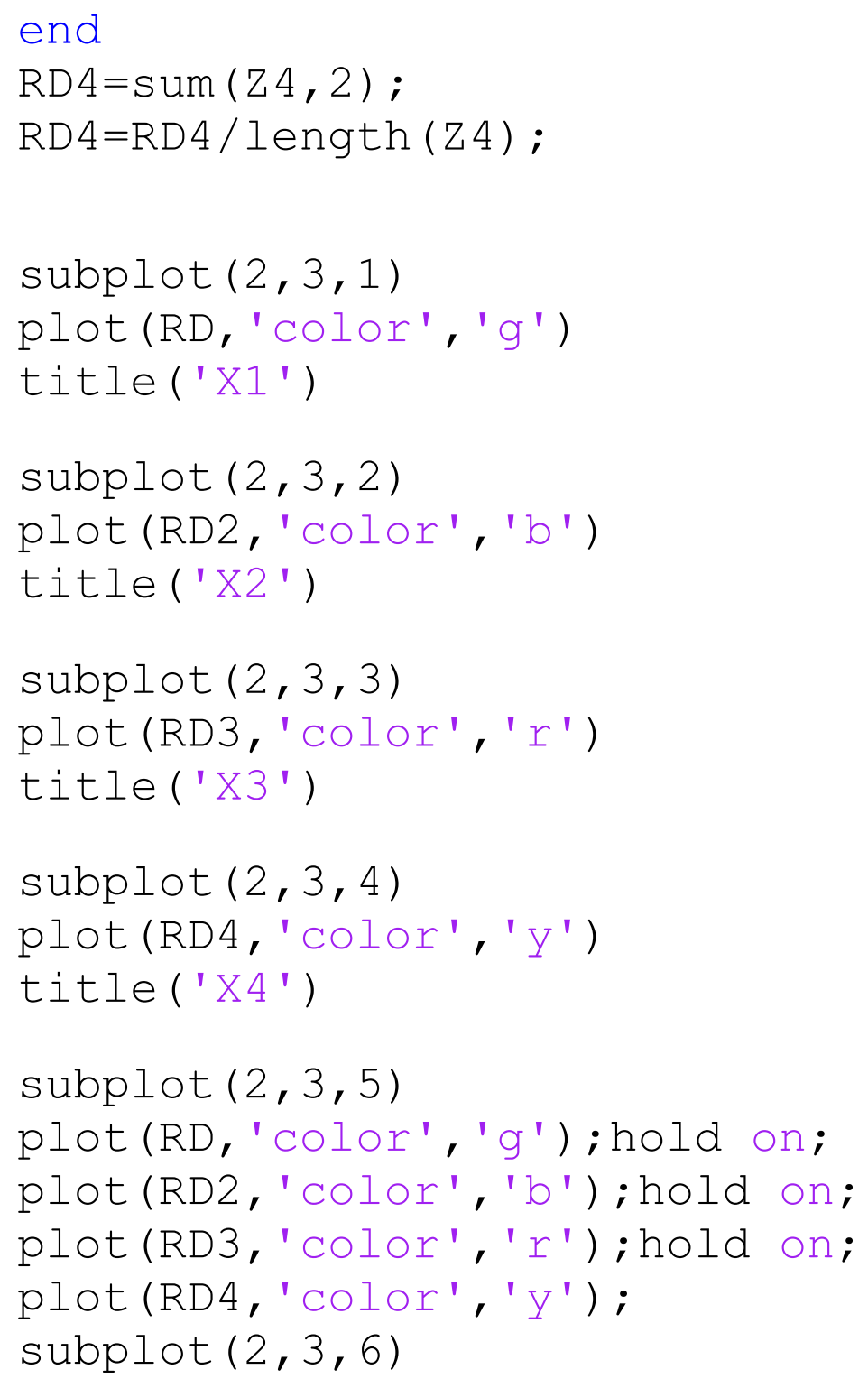




\section{APPENDIX H: RD SIGNATURES WITH BEST FITTED DAMPING ENVELOPES}

At each stage of static loading for ambient vibration excitation test, all the RD signatures for intact, cracking, yield, and ultimate states with the best fitted damping envelopes and corresponding damping ratios are depicted in the Figures below:
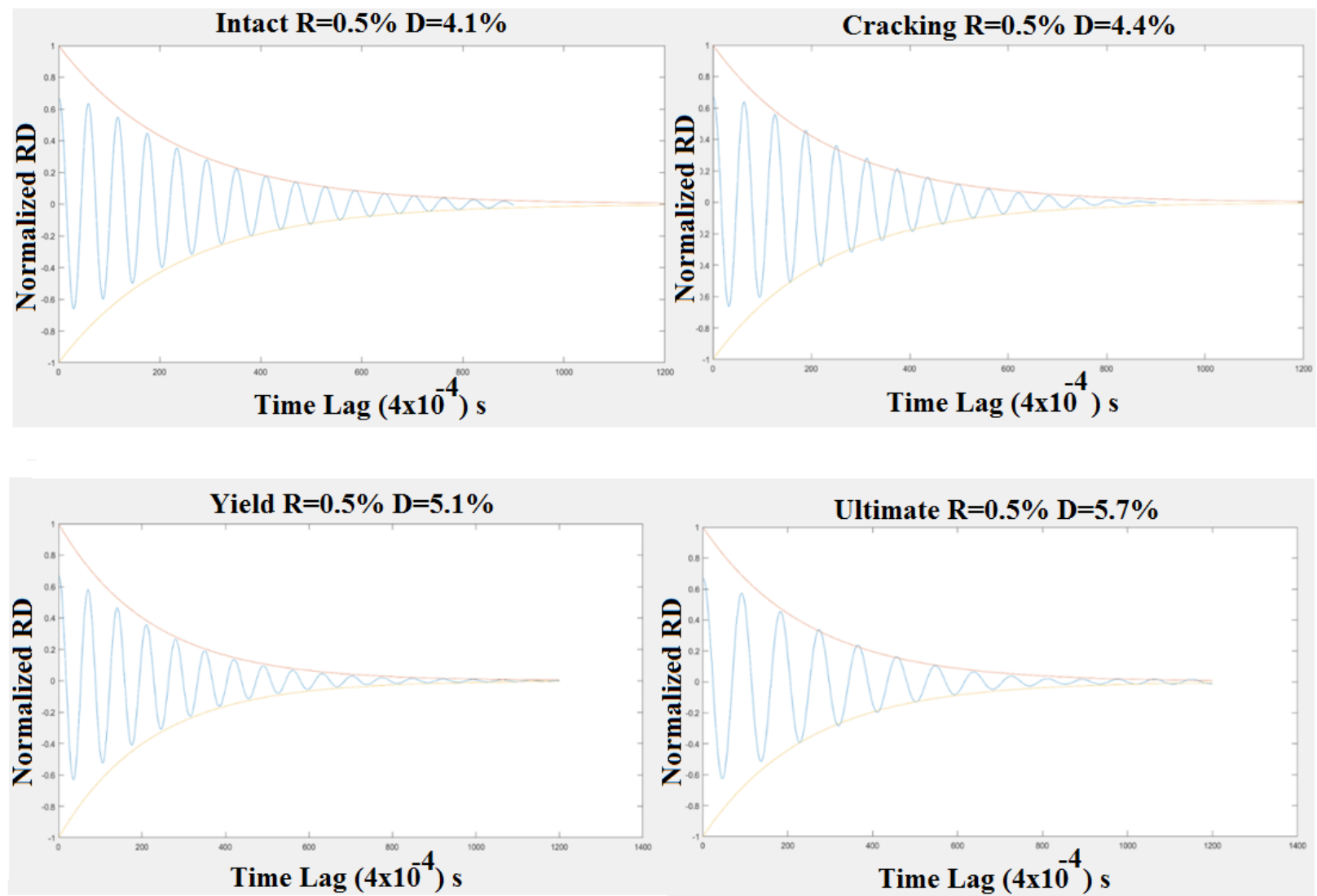

Figure H.1 H.S 0.5 Slab RD Signatures with the Best Fitted Damping Envelope Curves 

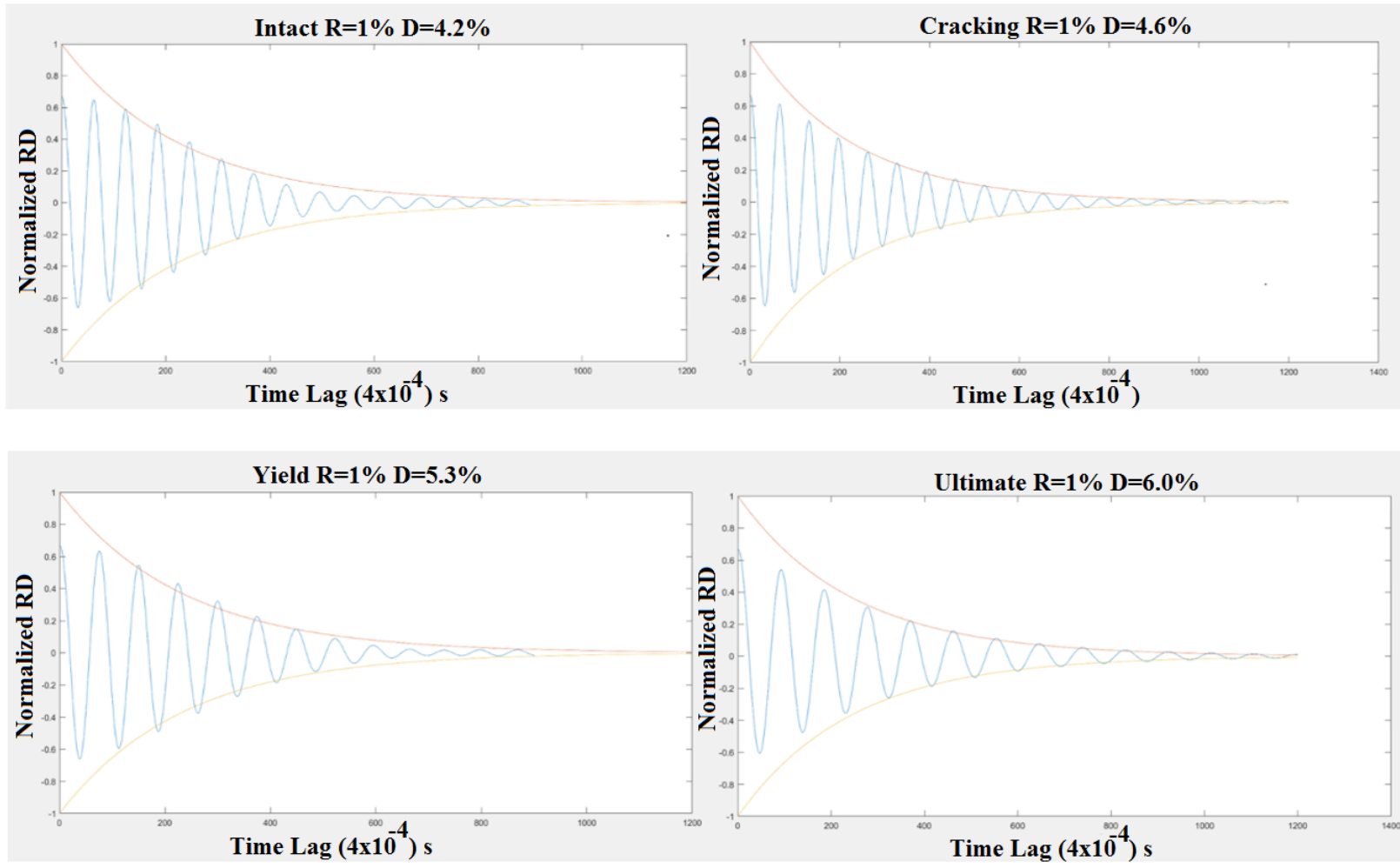

Figure H.2 H.S 1 Slab RD Signatures with the Best Fitted Damping Envelope Curves
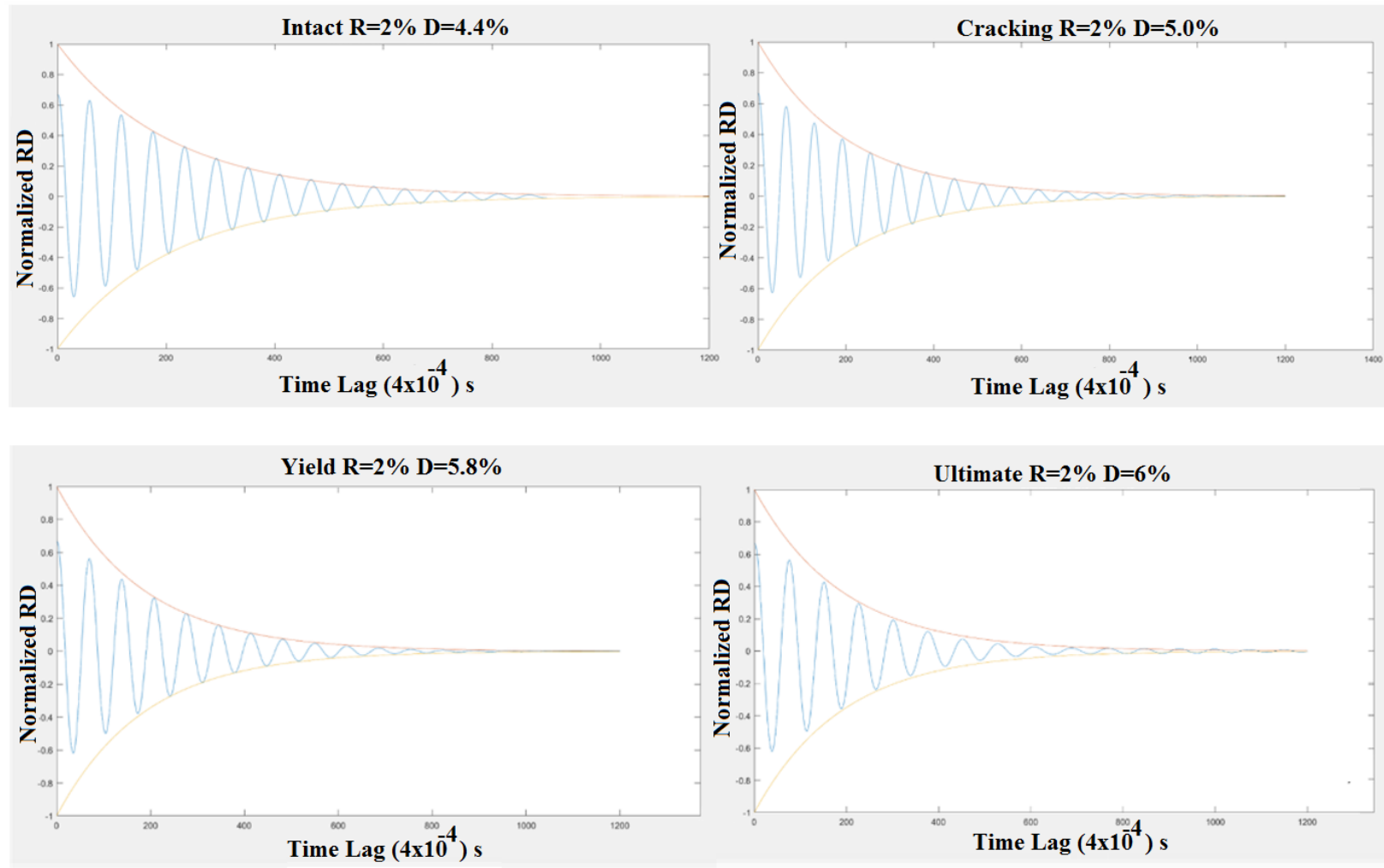

Figure H.3 H.S 2 Slab RD Signatures with the Best Fitted Damping Envelope Curves 

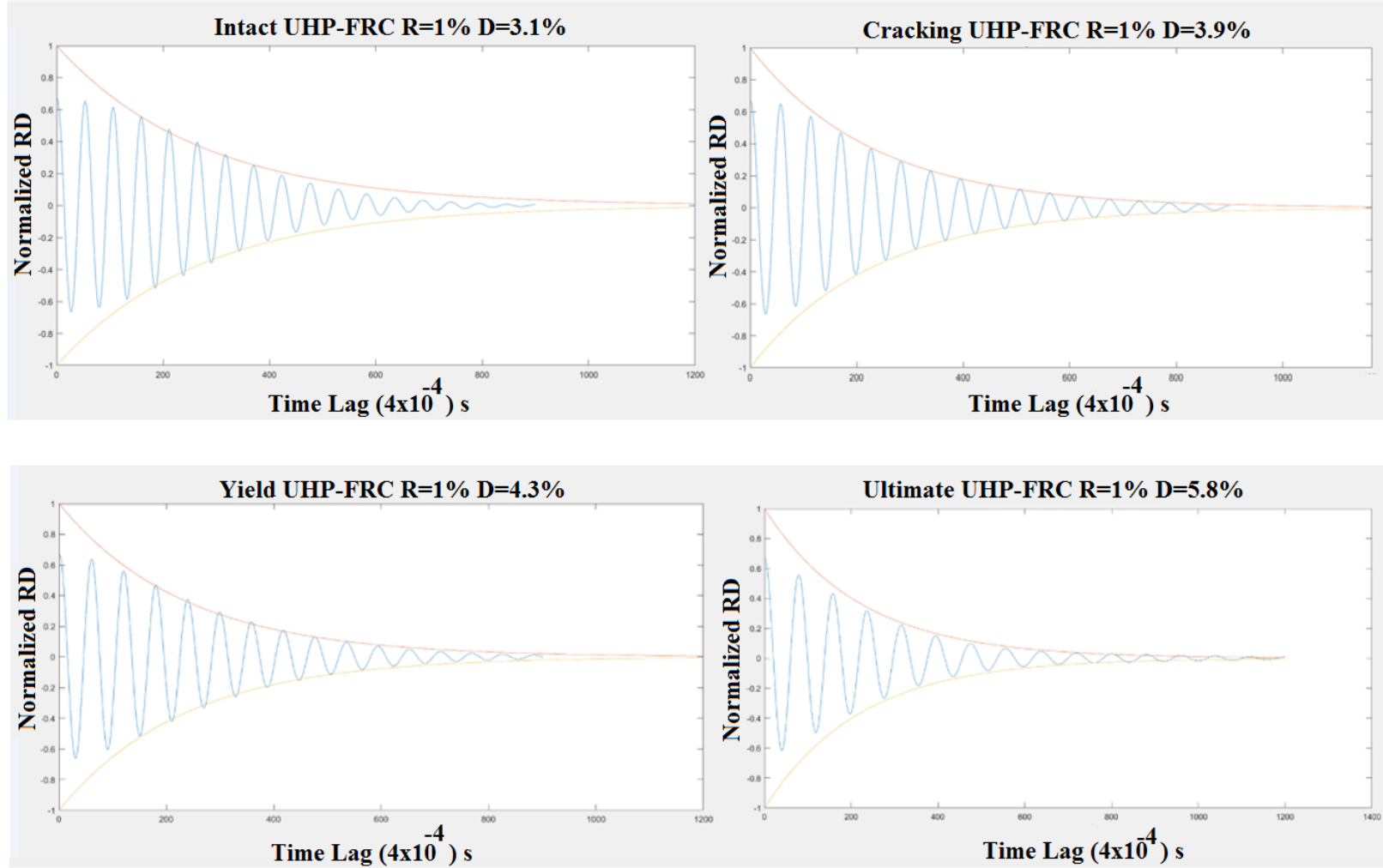

Figure H.4 UHP-FRC 1 Slab RD Signatures with the Best Fitted Damping Envelope Curves 


\section{REFERENCES}

Abdo, M. B., and Hori, M. (2001). A Numerical Study of Structural Damage Detection using Changes in the Rotation of Mode Shapes. Journal of Sound and Vibration, 227-239.

Allan C.L, W., Paul A, C., Willam, T., and Nadarajah, G. (2006). Monitoring using fiber bragg garating sensors. Advances in Structural Engineering, p. 219.

Asayesh, M., Khodabandeloo, B., and Siami, A. (2008). A random decrement technique for operational modal analysis in the presence of periodic excitations. Journal of Mechanical Engineering Science, 1525-1534.

Asmussen, J. (1997). Modal Analysis Based on the Random Decrement Technique Application to Civil Engineering Structures. Denmark: PhD Thesis, University of Aalborg.

ASTM Standard C39/C39M, (2001). "Standard Test Method for Compressive Strength of Cylindrical Concrete Specimens", ASTM International, West Conshohocken, PA, USA, www.astm.org.

ASTM C78/ C78M. (2010). Standard Test Method for Flexural Strength of Concrete (Using Simple Beam with Third-Point Loading), West Conshohocken, PA, USA.

ASTM Standard C469, (2002). "Standard Test Method for Static Modulus of Elasticity and Poisson's Ratio of Concrete in Compression”, ASTM International, West Conshohocken, PA, USA, www.astm.org.

ASTM Standard C496/C496M, (2004). "Standard Test Method for Splitting Tensile Strength of Cylindrical Concrete Specimens", ASTM International, West Conshohocken, PA, USA, WWw.astm.org.

Brincker, R., and Rodrigues, J. (2005). Application of the random decrement technique in operational modal analysis. 1st Intarnational Operational Modal Analysis Conference, (pp. 191-200).

Brincker, R., Kirkegaard, P., and Rytter, A. (1991). Identification of System Parameters by Random Decrement Technique. 16th International Seminar on Modal Analysis, (pp. 9-12). Florence. 
Brzev, S., and Pao, J. (2013). Yield Line Method. Reinforced Concrete Design A Practical Approach (pp. 689-697). Toronto: Pearson.

Caughey, T., and Stumpf, H. (1961). Transient Response of a Dynamic System under Random Excitation. Journal of Applied Mechanics, 563-566.

Chang, C. (1975). Study of Dynamic Characteristics of Aeroelastic Systems Utilizing Randomdec Signatures. NASA-CR.

Cole, H. (1973). On-line failure detection and damping measurement of aerospace structures by random decrement signatures. National Aeronautics and Space Administration, 2205.

Crandall, S., and Mark, W. (1963). Random Vibration in Mechanical Systems. Academic Press, New York and London.

EC2. (2004). Eurocode 2. Standardization, Design of Concrete Structures - Part 1-1: General rules and rules for buildings.

Elshafey, A., Haddara, M., and Marzouk, H. (2009). Identification of the excitation and reaction forces on offshore platforms. Ocean Engineering 36, 521-528.

Elshafey, A., Haddara, M., and Marzouk, H. (2009). Mode Shapes Extraction Using the MCRD Technique. Thirteenth International Conference on Structural and Geotechnical Engineering. Cairo-Egyt: ISGE.

Elshafey, A., Marzouk, H., and Haddara, M. (2011). Experimental Damage Identification Using Modified Mode Shape Difference. J. Marine Sci. Appl., 150-155.

Elshafey, A., Marzouk, H., Gu , X., and Haddara, M. (2013). Use of Fibre Bragg Grating Array and Random Decrement for Damage Detection in Steel Beam. Canadian Journal.

Elshafey, A., Marzouk, H., Gu, X., and Haddara, M. (2011). Non-destructive technique for early damage detection for bridges using dynamic response. ISSR, 190-197.

Ghrib, F., El Ragabi, A., Boufama, B., Li, L., and Sara, M. (2013). A Novel Technique for Displacement Measurements in RC Beams using Digital Image Correlation. ACI. 
Giner, V., Baeza, F., Ivorra, S., Zomoza, E., and Galao, O. (2011). Effect of steel and carbon fiber addition on dynamic properties of concrete containing silica fume. Material and Design.

Gopal, M. (2012). Yield line theory for slab design. Retrieved from Constructor: http://theconstructor.org/structural-engg/yield-line-theory/6839/

Grassino, S. B. (2000). What are optical fibers made of? Retrieved from Department of polymer science: http://www.pslc.ws/macrog/fiberopt/of.htm

Haddara, M. (2006). Complete identification of the roll equation using the stationary random roll response. Journal of Ship Research, 50(4): 388-397.

Hong-Nan, L., Dong-Sheng, L., and Gang-Bing, S. (2004). Recent applications of fiber optic sensors to health monitoring. Elsever, 11.

Houbolt, J. (1975). On Identifying Frequencies and Damping in Subcritical Flutter Testing. NASA Symposium on Flutter Testing Techniques (pp. 1-41). Caifornia: NASA SP-415.

Ibrahim, S. (1977). Random Decrement Technique for Modal Identification of Structures. J.Spacecraft, 696-700.

ICOLD. (2000). World Register of Dams 1998:Updating 2000 for China, Paris, International Commission on Large Dams.

Innocon. (2013). Agilia ${ }^{\mathrm{TM}}$ : An incredible range of self-consolidating concretes. Retrieved from Innocon: http://www.innocon.on.ca/agilia.aspx

Ismail, Z., Abdul Razak, H., and Abdul Rahman, A. (2006). Determination of damage location in RC beams using mode shape derivatives. Eng Struct 28(11), 1566-1573.

Kin-tak, L., Chi-Chiu.C, Li-min, Z., and Wei, J. (2001). Strain monitoring in composite-strengthed concrte structure using optical fiber sensors. Elsever.

Lafarge. (2015). Lafarge-North America. Retrieved from http://www.ductal-lafarge.com

Li, H., Weis, M., Herszberg, I., and Mouritz, A. (2004). Damage Detection in a Fibre Reinforced Composite Beam Using Random Decrement Signatures. Composite Structures, 159-167. 
Li, Rui, Pengcheng Wang, Yu Tian, Bo Wang, and Gang Li. "A unified analytic solution approach to static bending and free vibration problems of rectangular thin plates." Sci. Rep. , 2015: doi: 10.1038/srep17054.

Marzouk, H., and Hussein, A. (1991). Experimental Investigation on the Behavior of HighStrength Concrete Slabs. ACI Structural Journal, 701-712.

Moreillon, Lionel, Rene Suter, and Robert Le Roy. "Punching Shear Resistance of UHPFRC Slabs: Experimental Works and Design Model." Rilem-fib-AFGC, 2013: 577-586.

Morsy, R., Marzouk, H., and Gu, X. (2016). Multi-Channel Random Decrement Smart Sensing System for Concrete Bridge Damage Location Identification. Wiely Journal.

Morsy, R., Marzouk, H., Gu, X., and Elshafey, A. (2016). The Use of the Random Decrement for Non Destructive Damage Identification of Beams. Materials and Structures.

Muttoni, Aurelio. "Punching Shear Strength of Reinforced Concrete Slabs without Transverse Reinforcement.” ACI Structural Journal, 2008, V. 105, No 4, pp. 440-450.

Ndambi, J., Vantomme, J., and Harri, K. (2002). Damage assessment in reinforced concrete beams using eigenfrequencies and mode shape derivatives. Eng Struct 24(4), 501-515.

Nieuwland, R., Rylander, R., and Karlsson, P. (2016). Flexible automation in Fiber Bragg manufacturing. Noria.

Othman, H., and Marzouk, H. (2015). An experimental investigation on the effect of steel reinforcement on impact response of reinforced concrete plates. International Journal of Impact Engineering. doi:10.1016/j.ijimpeng doi:10.1016/j.ijimpeng.2015.08.015.

Othman, H. (2016). Performance of UHP-FRC plates under impact loads. PhD dissertation Ryerson University, Toronto.

Pandey, A., Biswas, M., and Samman, M. (1991). Damage Detection from Changes in Curvature Mode Shapes. J. Sound and Vibration, 145(2). 321-332.

Park, R., and Gamble, W. L. (2000). Reinforced Concrete Slabs. New York: John Wiley \& Sons. 
Petro, S., Chen., S., GangaRao, H. V., and Venkatappa, S. (1997). Damage Detection Using Vibration Measurements. Proc. 15th IMAC, (pp. 113-119). Orlando. Florida.

Pu. (2010). Fiber Bragg Grating Manual. s.l. : s.n.

Rodrigues, J., and Brincker, R. (2004). Application of the random decrement technique in operational modal.

Rubin, S., and Coppolino, R. (1983). Flexibility Monitoring of Offshore Jacket. Proc. 15th Annual Offshore Technology Conference, (pp. 201-208). Houston. Texas.

Shiryayev, O., and Slater, J. (2010). Detection of Fatigue Cracks Using Random Decrement Technique. SHM, 347-360.

Sim, S., Carbonell-Marquez, J., Spencer, B., and Jo, H. (2011). Decentralized Random Decrement Technique for Efficient Data Aggregation and System Identification in Wireless Smart Sensor Networks. Probabilistic Engineering Mechanics, 81-91.

Spasojević, Ana. Structural Implications of Ultra-High Performance Fibre-Reinforced Concrete in Bridge Design. PhD Dissertation, Suisse: Ecole Polytechnique, 2008.

Tsai, T., Yang, J., and Chen, R. (1985). Detection of Damages in Structures by the Cross Random Decrement Technique. Proceedings of the 3rd International Modal Analysis Conference, (pp. 691-700). Orlando, FL.

Vandiver, J., Dunwoody, A., Campbell, R., and Cook, M. (1982). A Mathematical Basis for the Random Decrement Vibration Signature Analysis Technique. Journal of Mechanical Design, 307-313.

Virlogeux, M., Servant, C., Cremer, J., Martin, J., and Buonomo, M. (2005). Millau Viaduc Bridge. (pp. 15(1):4-7). France: Struct. Eng.Int.

Wasan , I. Khalil, and Y. R. Tayfur . "Flexural Strength of Fibrous Ultra High Performance Reinforced Concrete Beams." Asian Research Publishing Network (ARPN), 2013: 200214. 
Yam, L., Leung, D., and Xue, L. (1996). Theoritical and experimental study of modal strain energy. Journal of Sound and Vibration 191, 251-260.

Yang, J., Chen, J., and Dagalakis, N. (1984). Damage detection in offshore structures by the random decrement technique. Journal of energy resources technology, 38-42.

Zhi, Z., and Jinping, O. (2005). Development of FBG sensors for structural health monitoring in civil infrastructure. 197-207. 